\title{
THE SOCIAL ENVIRONMENT OF PUBLIC TRANSPORT
}

\author{
By \\ Jared Austin Peter Kay Thomas \\ A thesis \\ submitted to the Victoria University of Wellington \\ in fulfilment of the requirements for the degree of \\ Doctor of Philosophy \\ in Psychology
}

Victoria University of Wellington 2009 


\section{ACKNOWLEDGEMENTS}

A special thanks to Jess, my chief editor, muse and better half.

Thanks to Marc for his insightful comments, the "you're doing great" pep talks (despite how great I was doing), his vigilant procurement of vouchers in the face of adversity, and his excellent sense of humour which kept me sane. For his "Yodaesque" wisdom, brilliant concepts and injection of enthusiasm, my thanks to Darren (my words may not be waltzing but at least they are doing a third form shuffle now). Honourable mentions go to my quasi-supervisors, Frank and Maree whose early guidance was vital in putting me on the right track. I would also thank Frank, Sam and Graham, whose very constructive feedback greatly improved the quality of my arguments.

Thanks to Marty (and sister) for the character building early mornings, braving the dark, windswept, freezing tundra of the dreaded train platforms, and even going above and beyond to rescue wayward questionnaires. Thanks to Tiff and Jerry for their sweet proofreading skills. Thanks to Matt, Jerry and Lisa for being posers. If you ever give up your day jobs to become models I will give you a reference. Big ups to the crew from the labs for all of their support, taunting and table tennis tips: Josh, Stephen, Tiffany, Steve, Kate, Nobuko, Angus, and William.

To all the great people I met while riding the bus and train, in particular the friendly staff. You are the soul of public transport, and you have the ability to produce communities out of strangers. A massive thanks to the car, train or bus goers that responded to my questionnaires, your time and feedback was truly appreciated.

I would also like to thank The Foundation for Research Science and Technology (FRST), the Tertiary Education Commission (TEC), Greater Wellington Regional Council (GWRC), Toll, and Opus International Consultants for their endorsement of the research. 


\begin{abstract}
Crowding is identified both internationally and in New Zealand as a key issue in public transport. Unfortunately, the concerns of public transport providers are focussed on economic imperative rather than a concern for the actual experiences of patrons. The social needs of public transport passengers are neglected, both in practice and in research.
\end{abstract}

This research examines the delicate balance between the need for privacy and the need for social interaction in the setting of public transport. These needs are examined through naturalistic observation of 1703 passengers' behaviours, such as seat selection, activity use, and conversation on buses and trains. This was followed by a survey-based Exploratory study examining a range of individual difference variables. Based on the findings of this Exploratory study measures were identified for use in a series of subsequent surveys of public and private transport users. Specifically, questionnaires measuring the attitudes and self-reported behaviour of train $(N=319)$, $\operatorname{car}(N=305)$ and bus commuters $(N=216)$.

Results suggest that the seating layout of public transport forces people into an intimate distance with strangers, causing social discomfort. Hall's (1966) proxemic theory suggests that these intimate distances are typically reserved for people with closer relations. People compensate by adapting to this close yet impersonal social situation. There is evidence that interactive strategies such as talking and positive body language with other passengers reduces the level of social discomfort, whereas defensive strategies do not reduce discomfort, but do form a negative relationship with social interaction which helps perpetuate a socially stagnant atmosphere. Discomfort from close interpersonal distance and less positive attitudes towards other passengers, while not as important as instrumental variables (such as longer trip durations), are still potential barriers to public transport patronage and should be given greater attention.

In conclusion, interactive behaviours are determined to be necessary to reduce social discomfort in public transport. Festinger and colleague's (1950) passive contact theory (PCT) is interrupted in the public transport setting, and it is posited that pro-social behaviours, such as smiling, and acknowledging other passengers with greetings are a precondition for successful interpersonal interaction. 


\section{PREFACE}

Take one socially and physically sterile environment, pack in more people than there are available seats, ensure most of the people are strangers, and you have public transport.

At the outset of my PhD I proposed to monitor the social environment of rail and bus public transport facilities, identify ways to improve these seemingly socially sterile environments, determine what interventions might encourage social acceptance, and whether this would lead to an increase in patronage. The social environment involves concepts such as comfort, politeness, atmosphere, enjoyment, sociability, prestige and acceptability. The central hypothesis recognises that unless the social factors associated with public transport are attended to, it is unlikely that public transport will compete successfully against the popularity of the private automobile.

Everyone has a public transport story. I learned this shortly after embarking on this research. In the course of this research I was rescued from the torrent by friendly bus drivers out at Eastbourne, where I temporarily gained shelter with the crew in the staff room, a hot cuppa and some friendly banter. I lost questionnaires to the train tracks at Johnsonville. I was serenaded by a train commuter, singing along to his radio at the top of his lungs. I was deposited in locations I had never been before, sometimes without knowing if or when another bus would pick me up. Sorry for the spoiler, but the next service did inevitably come, otherwise you wouldn't be reading this thesis. I survived bus trips around narrow roads on treacherous hills where another passenger gasped "oh my god, we're gonna die!" as the driver narrowly avoided another vehicle. It was not all narrow escapes from death and sing-a-longs. I stuffed many an envelope, stuck many a sticker, and signed many a letter.

There are many key elements to the dynamic environment of public transport, but one thing that is clear is that the conditions cause discomfort, some of which is physical, but most of which is social or psychological. Under such circumstances it is no wonder that public transport is not currently competitive with the motor vehicle. 


\section{CONTENTS}

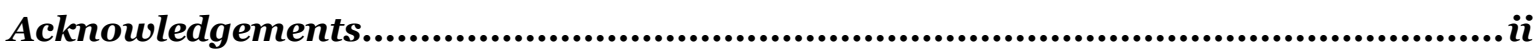

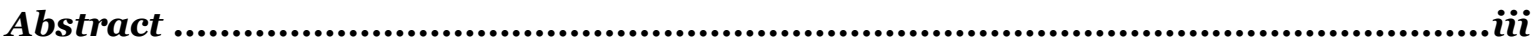

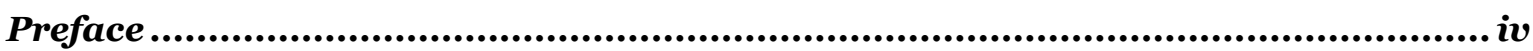

List of Tables .................................................................................................... viii

List of Figures...................................................................................................... $x$

Chapter 1: General Introduction ....................................................................... 1

Interpersonal Discomfort in Public Transport ..........................................................................2

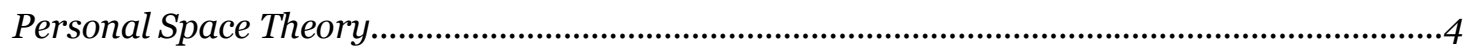

Public Transport in Context.....................................................................................................13

A Socially Stagnant Perception of Public Transport ................................................................13

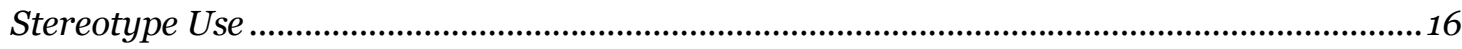

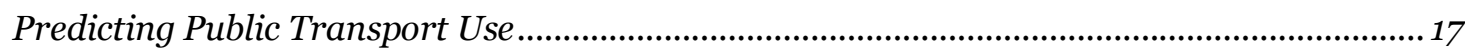

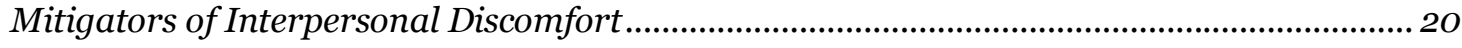

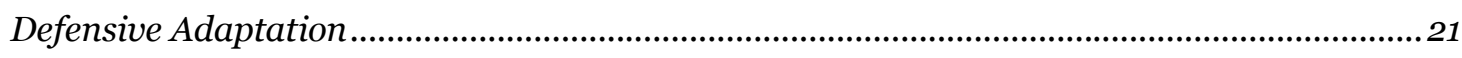

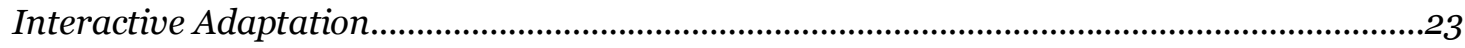

Barriers to Social Interaction in Public Transport.....................................................................25

Adaptive Measures in Practise .................................................................................................. 29

Lessons from Other Public Transport Modes.............................................................................. 31

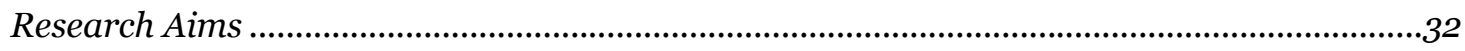

Chapter 2: Observations of Train and Bus Passenger Behaviours ......................... 34

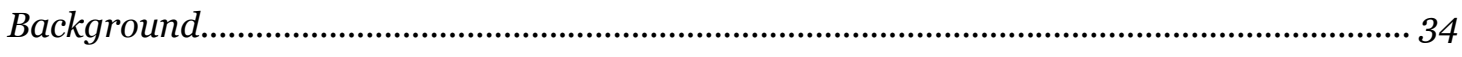

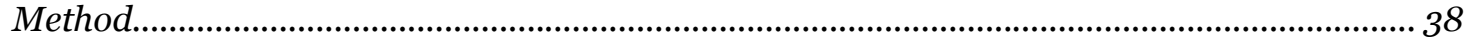

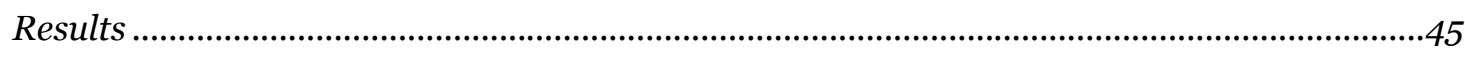

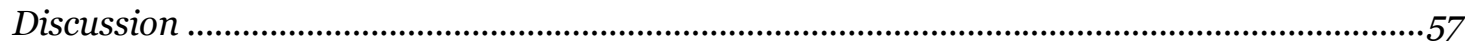

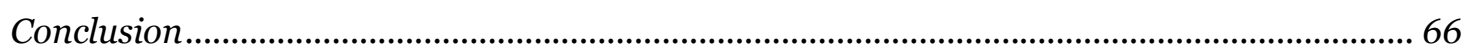

Chapter 3: Exploratory Questionnaire.............................................................. 67

Introduction ....................................................................................................................... 67

Method

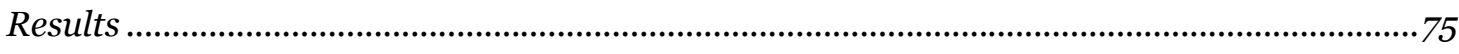

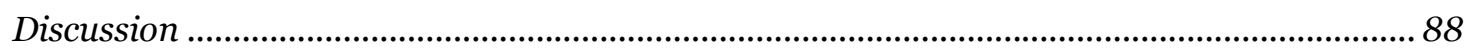


Conclusion

Chapter 4: Interpersonal Discomfort on the Train ............................................. 96

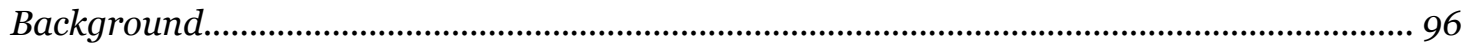

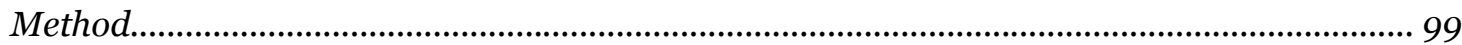

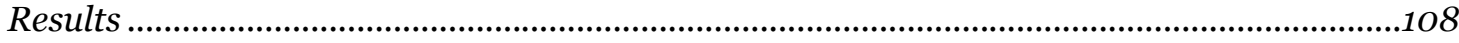

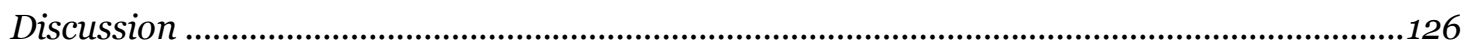

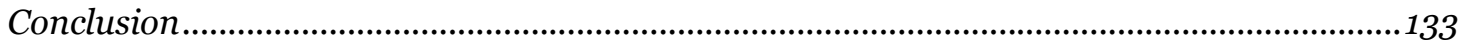

Chapter 5: Identifying Social Barriers to Train Patronage ...............................134

Background ..............................................................................................................................134

Method

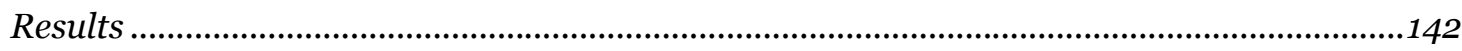

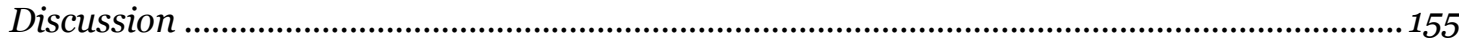

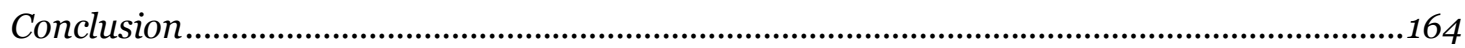

Chapter 6: Social Discomfort on The Bus .........................................................165

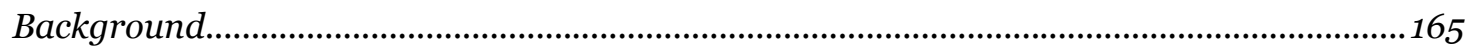

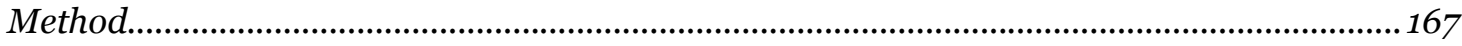

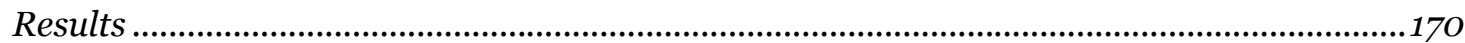

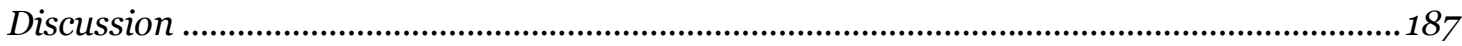

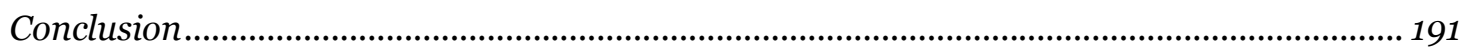

Chapter 7: General Discussion .......................................................................192

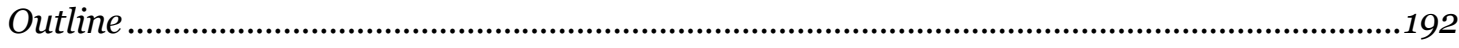

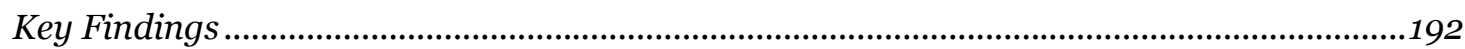

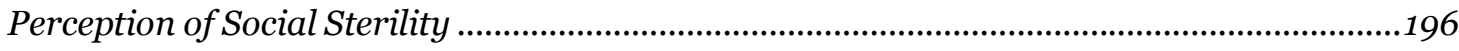

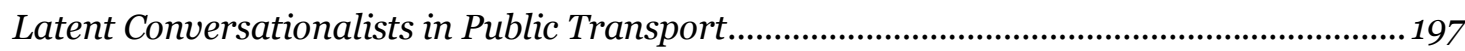

Promotion of Social Interaction as a Solution ………....................................................................199

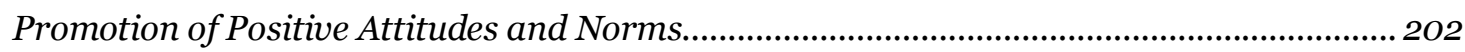

Design Solutions ..................................................................................................................... 206

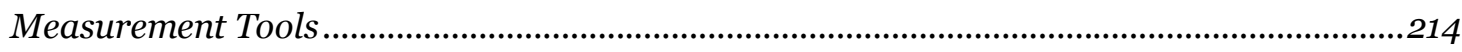

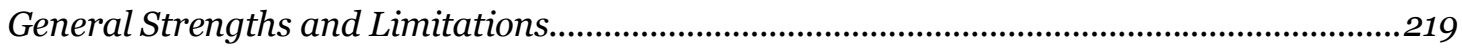

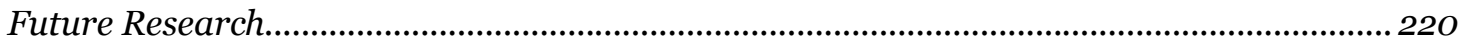

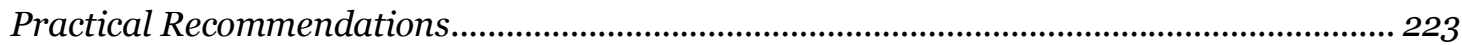




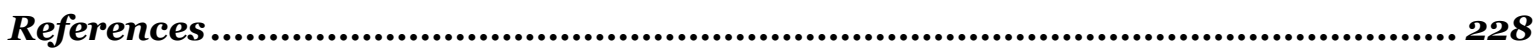

Appendix A: Exploratory Questionnaire ......................................................251

Appendix B: Train Questionnaire .............................................................. 259

Appendix C: Example Cover Letter............................................................. 267

Appendix D: General Questionnaire Transport Facts..................................... 268

Appendix E: Bus Questionnaire Transport Facts ......................................... 269 


\section{LIST OF TABLES}

Table

Page

2.1. Observational Variables and Descriptions

2.2. Inter-rater Reliabilities for Passenger Behaviours, Individual Variables and Seating Patterns

2.3. $\quad$ Means, Standard Deviations and Significant Differences between Bus and Train Travel Characteristics

2.4. Counts and Adjusted Residuals for Gender by Adjacent Gender

2.5. $\quad$ Stepwise Linear Regression of Interpersonal Passenger Distance by Key Observational Variables

2.6. Verbal Activity by Passenger Situation

2.7. $\quad$ Binary Logistic Regression of Verbal Behaviour by Key Observational Variables

2.8. Activity frequency by activity type

2.9. Binary Logistic Regression of Activity by Key Observational Variables

3.1. Verbal Descriptions and Example Photographs for the Seven Passenger Activities

3.2. Scale and Sub-Scale Reliabilities and Descriptive Statistics

3.3. Correlation Table of Primary Scales

3.4. Principal Components Factor Analysis Solutions for the Defensive Behaviour Items

3.5. Principal Components Factor Analysis Solution for Perception of Comfort in Different Social Settings

3.6. Descriptives and Significant Differences between Ratings of Bus and Train Photographs

3.7. $\quad$ Descriptives for Items that were Significantly Different between Public Transport Commuters and Other Travel Mode Commuters

3.8. Model Summary for the Binary Logistic Regression of Public Transport Use

4.1. Summary of Participant Characteristics

4.2. Trip Duration and Median Income Heterogeneity Ratings of the Train Corridor into Wellington City

4.3. $\quad$ Summary of Key Dependent Measures 104

4.4. Self-other Scale Characteristics 106

4.5. $\quad$ Scale Descriptives and Alpha Scores 109

4.6. Pearson Correlations for All 12 Scales 110

4.7. Factor Loadings, Means and Standard Deviations for the 112 Two-Factor Solution 


\section{LIST OF TABLES}

Table

Page

4.8. Stepwise Linear Regression of TSD on Key Questionnaire

116 Items

4.9. Attitudes to Conversation and Relationship Formation with Other Passengers

4.10. Mean Differences for Friendship Formation Measures in the

4.11. Stepwise Linear Regression of SI on Key Questionnaire Items

4.12. Stepwise Linear Regression of Defence on Key Questionnaire Items

4.13. Stepwise Linear Regression of IPD Discomfort on Key Questionnaire Items

122

4.14. Characteristic Differences by Location

123

4.15. Mean Differences for Friendship Formation Measures in the Train and Neighbourhood Settings for Masterton $(n=76)$.

5.1. Summary of Participant Characteristics

5.2. $\quad$ Car Commuter Scale Reliability Tables

5.3. Demographic and Household Characteristics for the Car and Train Samples

5.4. Model Summary for the Binary Logistic Regression of Train Use

146

5.5. $\quad$ Stepwise Linear Regression of IPD Discomfort on Key Questionnaire Variables for the Car Commuter Group

5.6. $\quad$ Stepwise Linear Regression of Train User Characteristics on Key Questionnaire Variables

6.1. $\quad$ Summary of Bus Sample Characteristics

6.2. Demographic, Household and Trip Characteristics for the Car, Train and Bus Commuter Groups

6.3. Scale Reliabilities by Car, Train and Bus Commuter Groups

6.4. Scale Means, Standard Deviations and Significant Differences between Car, Train and Bus Commuter Groups

6.5. Group Classification Results for Car, Train and Bus Commuters

6.6. Summary of Interpretive Measures for Discriminant Analysis $\quad 178$

6.7. IPD Discomfort Regression for Bus Commuters 


\section{LIST OF FIGURES}

Figure Page

2.1. A typical New Zealand bus layout (not drawn to scale). 40

2.2. A typical New Zealand train carriage layout (not drawn to 40 scale).

2.3. The inside of a train carriage in Wellington, New Zealand, $\quad 41$ showing perpendicular seating arrangements.

2.4. Passengers sitting apart in a train carriage. 47

3.1. $\quad$ Mean perception of comfort sitting beside or talking with the 84 person in the photograph, and whether the person in the photograph looks comfortable or would get on well with my friends.

3.2. $\quad$ Public transport use by social anxiety and income group. $\quad 87$

4.1. Above $\$ 75$, oooNZ household income locations (high income 102 meshblock areas are indicated by dark boundaries).

4.2. Below $\$ 75$, oooNZ household income locations (low income 102 meshblock areas are indicated by dark boundaries).

4.3. Mean Defence, Social Interaction, IPD Discomfort and Train 124 Relationship scale scores for Lower Hutt $(n=78)$, Johnsonville $(n=91)$, Upper Hutt $(n=103)$ and Masterton $(n=76)$.

5.1. $\quad$ Mean self, neighbour and train user characteristic assessments for car $(n=241)$ and train commuters $(n=$ 258).

6.1. Group centroids (means) for car, train and bus commuter groups. 


\section{CHAPTER 1: GENERAL INTRODUCTION}

Public transport has been described as a "socially sterile" environment (Davis \& Levine, 1967) where "second class" citizens (Guiver, 2007) are packed into "cattleclass" conditions (Close Up, 2008). This thesis attempts to examine the interpersonal discomfort of sharing inappropriately close proximities with strangers (Hall, 1966) in a setting that does not afford social interaction (Fried \& DeFazio, 1974). This general introduction will briefly outline the different facets of this problem, and then introduce the relevant personal space literature, including some of the antecedents of interpersonal distance (IPD) discomfort and the negative consequences of crowding.

This is followed by a more thorough examination of IPD discomfort applied to the public transport context, including an examination of the social sterility of the environment and any negative passenger stereotypes. There is some evidence that IPD discomfort and negative passenger affect are barriers to public transport (e.g. Stradling et al., 2007), but these social factors are given relatively little attention, and most of the important findings are qualitative in nature (e.g. Guiver, 2007).

Finally, the literature surrounding the mitigation of discomfort by defensive and interactive behaviours will be reviewed. It is posited that defensive adaptations are a symptom of discomfort, and that social interactions will be more successful in reducing IPD discomfort. The basis of this premise is Festinger, Schachter and Back's (1950) passive contact theory (PCT), which identifies how friendships form from familiarity and regular proximity in homogenous, residential environments. There are many potential barriers to successful interaction in the public transport setting, including the heterogeneity of the users, high passenger densities, low familiarity with the setting and it's users, irregular patronage, and inadequate space in which to interact. The research aims to examine whether these barriers interfere with PCT in a public transport setting. 


\section{Interpersonal Discomfort in Public Transport}

"During rush hour, subway riders lower their eyes and sometimes "freeze" or become rigid as a form of minimising unwanted social intercourse." (Sommer, 1969, p. 28).

Humans as well as other animals have a basic psychological need for space that goes beyond their immediate physical requirements, such as those limited to anthropometric design (Hediger, 1955; Sommer, 1969). People choose to sleep in large beds rather than coffin sized boxes, create rooms with ceilings that are higher than doorways, and even place a premium on features such as windows, which provide a visual escape and enhance feelings of spaciousness in crowded spaces (such as open plan workplaces).

The preference for a spacious environment is clear, with houses doubling in size and per person residential living space increasing by approximately three times since the 1950s (Wilson \& Boehland, 2005). There are also links between wealth and spaciousness, with celebrities purchasing mansions and large vehicles, which promote the concept that bigger is better. Even the word "room" indicates a sense of spaciousness. The public transport environment does not afford a sense of spaciousness. The design layout of buses and trains seem to be driven more by economic imperative than concern for the users' social requirements.

Public transport services are under increasing demand in New Zealand, to the point where crowded passengers have made complaints about the "cattle-class" conditions (Close Up, 2008). These conditions would be intolerable in a workplace, residence or other fixed location, but are simply a part of the public transport experience.

There is an insufficient literature linking the cramped conditions of these spaces to negative long-term health effects (Cox, Houdmont \& Griffiths, 2006). As such, minimum standards for passenger space are still based on physical rather than social requirements. For example, "oshiyas" (translated as "pushers") are hired in Japan to physically assist passengers to get into rail carriages when they are well over passenger capacity. Discomfort is not limited to the crowded conditions of peak commuting times. 
Public transport passengers are forced into overly close proximity even when the vehicles are far below their passenger capacity. The seat layout is such that when the vehicle is more than half full passengers are forced to sit immediately adjacent to each other at an intimate distance. Hall's (1966) proxemic theory shows how travelling on public transport forces strangers into an intimate social distance (o18 inches apart) typically reserved for people with strong personal relationships. The theory suggests that people have a set of social distances reserved for different circumstances, and that close social relationships oblige close physical distances. When there is disparity between expected interpersonal distance and actual interpersonal distance this causes psychological or social discomfort (Altman, 1975).

The invasion of personal space has been shown to lead to greater self-reported anxiety (Greenberg \& Firestone, 1977), physiological stress (Nicosia, Hyman, Karlin, Epstein \& Aiello, 1979), and under extreme exposure can lead to long-term physical or mental illness (Cox, Houdmont \& Griffiths, 2008). These findings also hold for the public transport setting, where perceptions of crowding and levels of physiological stress have been revealed to increase under conditions of higher passenger density (Lundberg, 1976) and closer interpersonal passenger distance (Evans \& Wener, 2007). In other settings, where individuals are not constrained they flee (e.g. Felipe \& Sommer, 1966) or maintain larger interpersonal distances (IPDs) to mitigate discomfort (Baxter, 1970).

In lieu of physical escape and with limited ability to increase IPD, defensive adaptations are used by passengers to diffuse the interpersonal discomfort. Hall (1966) describes how subway passengers use defence strategies to take the intimacy out of a socially awkward situation; passengers avoid eye contact, tense muscles to remain immobile and attempt to avoid touch. However, even with these adaptations it is suggested that individuals do not fully habituate to the conditions of personal space invasion (Moos \& Insel, 1974).

An alternative solution is to engage in interactive adaptations such as positive body language (e.g. smiling) and conversation, which are likely to facilitate greater positive affect (Emmons \& Dienar, 1986) and even friendship formation. 
Improving a relationship (such as from stranger to acquaintance) is likely to diminish social discomfort (Altman, 1975; Hall, 1966; Willis, 1966).

The bus and train settings both provide the close proximity to others necessary for interaction. Festinger et al.'s (1950) passive contact theory (PCT) describes how interpersonal interaction is dependent upon the spatial layout of the environment. A high frequency of passive contacts (or chance meetings) due to regular proximity to people, such as neighbours or work colleagues, increases the likelihood of friendship. Nash's (1975) observations of bus users demonstrate how friendships of convenience can develop in the public transport setting, what he calls a "community on wheels." Unfortunately this appears to be the exception to the rule.

Verbal communication appears naturally impeded in the public transport setting, with social norms that minimise superfluous conversation between strangers (Fried \& DeFazio, 1974). The other users are typically strangers or at best "familiar strangers" (Milgram, 1977), and the environment, particularly the seat layout, makes conversation awkward (Maines, 1979; Sommer, 1969). Overall, the close yet impersonal conditions caused by public transport are neither suitable for privacy nor social interaction and conditions of interpersonal discomfort are a probable deterrent of patronage (Guiver, 2007; Stradling et al., 2007).

\section{Personal Space Theory}

There is a multitude of research in the area of personal space, and there are also some very good reviews of the literature, such as those authored by Aiello (1987), Altman (1975) and Hayduk (1983). The literature examined here will by no means be exhaustive; instead it will focus only on specific examples to highlight key points. Perhaps as a function of the earlier fertility in this field, contemporary personal space research is not as prolific as it once was in the 1970s and 1980 . Consequently, the literature examined here will often be focussed on less recent research.

Sommer (1969) describes personal space from the perspective of protective behaviour, suggesting it is the personal "bubble" that surrounds a person, into which others may not intrude. As with all simple analogies, the bubble breaks 
under closer scrutiny (Aiello, 1987), but it serves a useful purpose in illustrating the concept. Hayduk (1978) defines personal space using social discomfort, suggesting that personal space is the area immediately surrounding a person that someone else may not enter without causing interpersonal discomfort.

Personal space invasion, crowding, and IPD discomfort are very similar concepts that all have their place (Bechtel, 1997). Personal space invasion is the most colloquial and easiest to grasp, while crowding has ties to the density of people in a specified space, and IPD discomfort describes the anxiety caused by the close proximity of the nearest person. All three concepts will be used throughout this research to discuss the broader concept, but IPD discomfort is more technically accurate when examining the method and measurement of anxiety.

The distance between people, while related to social density (the person to physical space ratio), has been shown to be a better predictor of social anxiety. Worchel and Tedley (1976) found that people in a controlled lab setting reported feeling more crowded, uncomfortable, ill at ease and confined as a function of close IPD, as compared with social density. Evans and Wener (2007) replicated this finding in the train setting, where IPD is a better predictor of physiological stress than the density of passengers in a carriage. As such, IPD discomfort is the preferred term for the purposes of this research.

IPD discomfort is complex and difficult to measure as it is confounded by individual (gender, ethnicity, status and culture), interpersonal (level of relationship, attraction, affect) and situational factors (seat layout, temperature, formality of setting; Altman, 1975; Altman \& Vinsel, 1977). This means that attempted replications in laboratory conditions have difficulty simulating situational conditions, while in the real setting it is difficult to experimentally isolate any one variable.

Hayduk (1983) and Aiello (1987) review the research on interpersonal distance and suggest that much of the research that attempts to cue participants via photographs or moving dolls in models fails to translate to IPD findings in real settings. Controlled laboratory studies and, where possible, naturalistic observation studies are preferable (Aiello, 1987; Hayduk, 1983). The use of 
multiple measures of behavioural discomfort taken in concert is also preferred (Evans \& Howard, 1973). Early examples of field research concentrated on observing participant responses when a confederate invaded their space (e.g. Felipe \& Sommer, 1966). The strongest indicator of discomfort was when the participant fled from the area.

\section{Flight Behaviour and Territorial Markers}

The concept of flight or fight distance originated in animal studies and is the basis of personal space theory. In the zoo setting Hediger (1955) found that a keeper would reach a certain distance when approaching an animal that would cause the animal to give its full attention to the keeper, then at a closer distance the animal would flee or charge.

Basic flight behaviour is also evidenced in humans (e.g. Sommer, 1969; Patterson, Mullens \& Romano, 1971), as is the use of more sophisticated territorial markers. Humans have not developed the use of scent or urination to mark their territories, but they do place mobile objects such as bags or jackets to lay temporary claim on an area (Sommer \& Becker, 1969).

The basic tenet of flight behaviour is self-protection. Typically those people that one allows to be physically close are good friends or family, hence the term "close friend". One of the key factors relating to close relationships is trust, which would include trusting another person to do no physical harm. External sources of threat have been linked to higher IPDs (e.g. Evans \& Howard, 1973), with the implication that sources of trust (i.e. friends) are linked to closer IPDs.

Hall's (1966) theory of proxemics is based on four categories of relationships derived from sensory information, much of which was borrowed from animal studies. From these categories Hall (1966) generalises four distances with which intimate (o-18inches), personal (18inches to $4 \mathrm{ft}$ ), social (4-12ft) and public (12$25 \mathrm{ft}$ ) interpersonal interaction typically occurs. The intimate zone is the one in which this research is focussed, as bus and train seats are joined such that there is no real buffer of space between the immediately adjacent passengers and lateral physical contact is almost unavoidable (e.g. see Fried and DeFazio, 1974). Altman 
and Vinsel (1977) observe that flight behaviour is faster if the intrusion occurs in the intimate zone.

\section{IPD Invasion Studies}

Invasion studies demonstrate how a disparity between appropriate distance and actual distance can cause a range of observable reactions. Behavioural reactions to intrusion have been measured by moving away (such as latency to "flight" behaviour), non-verbal behaviour (such as posture and eye glance) and affective reactions (such as self-report measures of liking for the intruder; Altman \& Vinsel, 1977).

In a classic study, Garfinkel (1964) instructed his sociology students to converse with acquaintances or close friends, and at some stage during the course of the conversation to move their face very close to the other conversationalist, to the point where their noses were almost touching, and give no immediate explanation for this behaviour. This demonstration of inappropriate closeness caused avoidance behaviour and feelings of acute embarrassment, bewilderment and even anger in the invaded subjects.

Discomfort seems particularly apparent when interpersonal distances are closer. Felipe and Sommer (1966) varied the degree of invasion when positioning confederates beside students while they were sitting alone at a table in a library study hall. They measured latency to flight behaviour under conditions where the confederate sat either: 1) about three inches away 2) about 15 inches away, 3) about 42 inches away (a whole seat's gap away), 4) about 48 inches away, but sitting across the table from the student (rather than in an adjacent seat), or 5) a non-invasion control group. Within 30 minutes approximately $70 \%$ of participants had fled in the closely invaded condition (about 3 inches apart). This closely invaded condition is very similar to the seating situation in public transport. Only $27 \%$ of participants had fled within this duration in the other invasion conditions (conditions 2, 3 and 4 were combined as they were not significantly different), and $10 \%$ had fled in the non-invaded control group. 


\section{Factors That Influence IPD Discomfort}

Having established that closer IPDs are associated with greater discomfort, the factors that influence IPD discomfort will now be examined. These can be broadly categorised as individual, interpersonal and situational factors (Altman \& Vinsel, 1977).

\section{Individual factors}

Individual personality differences may cause avoidance of public transport. For example, socially anxious or introverted individuals may be more sensitive to close IPDs than socially comfortable or extroverted individuals. Katsikitis and Brebner (1980) found that people with extroverted personalities had reduced performance on a complex task (a letter elimination task) under conditions of crowding (where participants were so close they made physical contact). This indicates that an extroverted public transport commuter may find it difficult to perform tasks such as reading a complicated book or finishing a difficult crossword due to the close proximity of the immediately adjacent passenger.

Subway passengers have been found to look for commonality when selecting a seat beside another passenger. Maines (1979) found that passengers were significantly more likely to select seats beside other passengers of the same ethnicity and gender. Similarly, Barash (1973) found that students seated in a library had lower tolerance of intruders who wore different attire from them. Students wearing casual attire fled more quickly when their space was invaded by someone wearing a suit, when compared with someone who was similarly attired (although latency to escape may have been hastened by the fact that wearing a suit was also nonnormative).

Passengers are likely to make visual discriminations when selecting a seat to find passengers that they determine will be similar to them. Selecting similar passengers is a beneficial strategy because they will be more likely to have similar expectations regarding social rules, what behaviours are appropriate, and use similar space regulation mechanisms (such as gaze avoidance or body orientation; see Baxter, 1970). Disparity between appropriate distances will cause anxiety (Baxter, 1970), for example, think of someone who is a "close talker". Cultural 
differences are a classic example of this incongruence. Hall (1966) demonstrates how different cultures have different expectations of appropriate distance when conversing, for example South Americans accept closer distances than Germans, most likely because they use touch more often when communicating.

\section{Interpersonal factors}

As has already been stated, Hall's (1966) proxemic theory is grounded in the fact that people expect closer distances from people with closer relationships. Naturalistic observations of students meeting on college grounds found that friends engaged in conversation stood at closer distances than people identified subsequently as acquaintances (Willis, 1966). Crane, Russell and Griffin (1983) examined married couples and found that chair placement is partially predicted by divorce potential. Couples that were rated as more likely to divorce placed their chairs further apart.

"The preponderance of data suggests that persons who are friendly with each other or wish to communicate a positive affect will tend to interact at smaller interpersonal distances than those who are not friendly." (Evans \& Howard, 1973, p.337)

Altman (1975) suggests that the association between close social relationship level and close interpersonal distance is perhaps the most robust finding in the personal space literature. The strength of this association suggests that interpersonal interaction strategies may be the most effective in reducing interpersonal discomfort or stress. Interactive strategies engage other passengers in positive non-verbal (e.g. smiling) and verbal interaction. If the conditions are correct, such as common interests or individual similarities, and there is an appropriate environment to interact within, friendships may form (Sommer, 1969).

\section{Situational factors}

Physical situational factors that influence the parameters of social distance include noise, illumination and vocal levels, such that loud noise, low illumination and low vocal levels encourage intimate IPDs (Hall, 1966). Certainly the loud music and dim lighting of nightclubs are used to increase intimacy. 
The motivation behind the use of available space also influences IPD, even within the same setting. For example, patrons waiting in the lobby of a movie theatre were revealed to stand apart from one another and avoid interpersonal touch when a family picture was showing (Ellison, 1967). Whereas when an adult comedy was shown almost three times as many patrons crowded into the same lobby and subsequently were observed to accept far closer IPDs. Even within public transport, people commuting for work are likely to be less tolerant of close IPDs and less likely to converse than people who are all going to the same social event, such as a concert or a football game.

According to Miller (1981), perception of crowding in an elevator was reduced when passengers were previously instructed that being close to people is good, because the world is so impersonal. This paradigm shift to examine the crowded conditions as positive is a similar concept to a shift in the perceived formality of the setting. People ordinarily stand further apart in a business meeting compared with a cocktail party (Freedman, 1975). Crowded conditions are typically viewed negatively, particularly in formal situations, but there are certain circumstances where a high density of people with close interpersonal distances are viewed as positive, such as a "good" crowd of people at a party, concert or sports event, where the large social mass improves the atmosphere.

\section{Crowding, Personal Space Invasion and Physiological Stress}

In the worst-case scenario, high exposure to crowded or over-stimulated social environments is likely to cause mental and physical illness (e.g. Cox, Paulus \& McCain, 1984; Kirmeyer, 1978). While there is some evidence that the short-term effects of crowding in public transport may manifest in long-term effects (Evans \& Wener, 2007), such as illness, the evidence for a direct causal link is limited and contentious (e.g. Freedman, 1975; Cox, Houdmont \& Griffiths, 2006).

Most of the crowding literature is based on situations, such as prisons or crowded homes, where people are forced to be close to others for a majority of their personal time (Freedman, 1975). It has been suggested that the problem with these situations is a lack of privacy and the negative outcomes of these crowded 
situations may result from a reduction in self-reflection and "alone" time (Freedman, 1975).

Public transport has far shorter exposure times, but there is evidence that passenger stress does influence other aspects of the commuters' daily life. Cox, Houdmont and Griffiths (2006) review the effects of rail crowding on passenger stress and reveal that interpersonal stress is likely to have spill-over effects. In particular, the review identifies the economic consequences of stressful transport services, as stressed workers have lower levels of productivity (an estimated £230 million per annum in London alone; Cox, Houdmont \& Griffiths, 2006).

Very few studies actually use task performance and even fewer use physiological stress to examine the negative repercussions of close interpersonal distances on public transport. Lundberg (1976) examined the physiological and reported stress of long and short trip train commuters travelling to the central business district under different levels of passenger density (before and after the 1974 oil crisis, which led to an increase in rail passengers). Physiological (as measured by catecholamine excretion in urine) and perceived stress increased with passenger density as the train approached the city, and was found to be significantly higher under the high passenger density condition.

Long trip commuters had significantly lower perceived and physiological stress levels than short trip commuters (Lundberg, 1976). This finding was explained in relation to the additional level of control the long trip commuters had over their environment. Long trip commuters could select their seating arrangement, had more opportunity to spread out any belongings (at least in the initial stages of the trip) and sit with whom they chose. These findings raise the importance of the seat selection process in mitigating discomfort on public transport.

More recently, Evans and Wener (2007) examined the effects of carriage density and row density on 139 regular train commuters. They found that physiological stress (as measured by salivary cortisol), task performance (persistence on a proofreading task) and mood (feeling burdened or frustrated) were all adversely affected under higher row densities, but not under higher carriage densities. The passenger density in the row represents a better indicator of proximity to the 
nearest passenger than passenger density in the carriage (although all other things being equal, row and carriage density would be equivalent under conditions of full passenger capacity). This means that the effects of stress are evident even when the carriage is less than full.

Car commuting may be a less stressful alternative to public transport. The stress caused by inappropriate interpersonal distances could be one reason why some groups who drive have better health than those that take public transport (Ellayway, Macintyre, Hiscock \& Kearns, 2003). For example, elderly drivers have been shown to have better health than elderly public transport users, although these health findings may simply be due to better transport access and a subsequent increase in participation in social activities (Ellayway et al., 2003).

Fried and DeFazio (1974) suggest that the need to defend territory and a reduced sense of privacy are definite barriers to public transport. Other potential barriers in the context of public transport include negative passenger affect (e.g. Stradling, 2007) and poor attitudes towards the socially and physically sterile environment (Davis \& Levine, 1967). This review has addressed the theory surrounding personal space invasion, some of the key factors that mitigate or exacerbate IPD discomfort, as well as some of the negative physiological consequences of exposure to short and long term crowding. The next section of the review closely examines negative elements of public transport to see how these may exacerbate IPD discomfort.

\section{PUBLIC TRANSPORT IN CONTEXT}

\section{A Socially Stagnant Perception of Public Transport}

"The city's rapid transit system was defined at different periods in its history as a realm of technological novelty, as a setting of such urban problems as noise, pollution, crowding, and sexual harassment, as a netherworld occupied by the poor, and as a prison that teemed with criminals." (Hood, 1996, p. 309). 
Hood's (1996) historical review of the New York public transport system suggests that early negative stereotypes of public transport influenced peoples' decision to adopt private motor vehicles. Those who did risk the "netherworld" of public transport (Hood, 1996) faced a socially stagnant, morbid environment, a theme that resonates through negative attitudes towards public transport.

Perhaps the earliest example of the entrenchment of morbid associations in public transport comes from Greek mythology. In this ancient folklore the newly dead souls were required to pay the ferryman, Charon, to cross the river Acheron into the underworld (Brewster, 1977). Stretching this example further, there are even parallels to public transport and Hades, the underworld. Hades is described as a place where "Greeks continue their existence without life's joys" (Merry, 2004, p. 99). In a popular song, the underworld was a place where:

"Daughter does not speak to mother, nor mother to daughter, Nor children to their parents, nor parents to children, The king is equal to all the rest, Houses there are dark, the walls are covered with spider webs, Great people and simple mix.” (Merry, 2004, p. 99)

This song emphasises two key facets of public transport, those of non-exclusivity (or the heterogeneity of the individuals) and social stagnancy. Public transport is non-exclusive, the only barrier to use is the cost of a ticket, but this is typically a cheap form of transport. ${ }^{1}$ Any interpersonal differences, such as differences in class, are temporarily suspended, as passengers have equal opportunity to get a seat of the same quality. ${ }^{2}$ Davis and Levine (1967, p. 90) make the observation that "...individuals on transit vehicles appear to be in a state of suspension from the larger social system.”

The socially stagnant atmosphere of public transport draws interesting parallels to the underworld. This is particularly the case with underground subways, where

\footnotetext{
${ }^{1}$ Public transport is subsidised by the government in New Zealand to encourage patronage and reduce social exclusion.

${ }^{2}$ There is no separation of seating by ticket cost on commuter buses and trains in New Zealand (i.e. there are no first-class seats that provide greater comfort and space at a higher cost).
} 
this norm is so strong that verbal behaviour is viewed as odd and to be avoided where possible (Fried \& DeFazio, 1974).

"People learn how not to come into conflict with one another by avoiding provocation, providing appropriate respect for others in public by not staring or attempting to strike up conversations, and knowing how to be discouraging yet not impolite if someone else violates such norms" (Birenbaum, 1976, p. 67).

The morbidity theme is reinforced in popular culture, with the movie Shaun of the Dead (2004) creating a parody of the soulless atmosphere of modern day public transport, drawing comparisons between bus riders and the living dead in the form of zombies (for more information on zombies see Brooks, 2003). In this film bususer behaviour was shown to differ very little after a zombie epidemic, with passengers displaying the same vacant expressions, lack of social interaction or even any sign of sentience, and the only apparent passenger movement is to the rhythmic, mesmerising sway of the bus (Shaun of the Dead, 2004).

The apparent lack of sentience observed on public transport is thought to be a defence mechanism used by people in overloaded environments (Ittelson, Proshansky, Rivlin \& Winkel, 1974). In a high-density environment, the incoming stimulus-information received from other people and the physical environment may exceed the processing speeds of an individual. Adaptation is required to reduce the incoming stimuli to which an individual attends or responds. Consequently, the individual appears more withdrawn, engaging only in simplified or routine behaviours, and avoiding all but superficial interactions with strangers (Ittelson et al., 1974).

There are similar parallels to a psychiatric ward and this morbid view of public transport. Edwards and Johnston (1977) associated a low rate of social interaction with people with behavioural issues or mental illness. In a psychiatric ward, successful social interaction was the best sign that a patient could cope with the outside world, whereas extremely withdrawn behaviours were a sign of maladjustment (Holahan \& Saegert, 1973). Emmons and Diener (1986) support 
this finding in a student population, as passenger affect is negatively influenced by a perceived lack of sociability.

Friendship formation definitely seems impeded in public transport. Milgram (1977) suggested that commuters regarded other travellers more as scenery than as people to engage with in pleasantries. Milgram (1977) labelled the regular users of shared spaces "familiar strangers," as they visually recognised each other, expected to see each other in a location, and so were not complete strangers, but they did not verbally interact with each other, and so were not quite acquaintances either.

The extent of interpersonal interaction avoidance means that it often requires extraordinary or at least atypical events to create conversation when travelling on public transport (Paulos \& Goodman, 2004; Sommer, 1969). Familiar strangers interact under such atypical circumstances as meeting the person in an unusual location (e.g. a chance meeting with them while travelling in a foreign city), or because of a salient event, such as a traffic accident or an earthquake (Paulos \& Goodman, 2004; Sommer, 1969). Sommer (1969, p. 37) describes these situations as ones in which "people become real" again.

This morbidity theme highlights a sombre view of public transport that does not necessarily depict an accurate representation of contemporary buses and trains, but that these examples exist is enough to reinforce negative stereotypes.

\section{Stereotype Use}

People use impression formation techniques on strangers because of the need to rapidly categorise people in a public setting with limited knowledge of those people, and this process is generally very stereotypical (Burgoon, 1994). It is important for people to categorise others, as different social rules are applied to different interpersonal interactions, dependent on factors such as status, ethnicity, gender, age and perceived attractiveness. However, stereotyping is often associated with negative associations and discrimination against groups based on these differences (Burgoon, 1994). 
Popular culture reinforces the stereotype that public transport is used by people of lower status. For example, the movie Crash (2005) suggests that buses have big windows on them to humiliate the people who are reduced to riding on them.

"You actually expect me to get on a bus? You have no idea do you?

You have no idea why they put them great big windows on the side of buses do you? One reason only. To humiliate the people...who are reduced to riding on them." Crash (2005)

There has been very little research into the area, but anecdotally people have negative stereotypes of public transport, aligning it with lower status. There is a perception that public transport users are "second class citizens" (Guiver, 2007), where buses are referred to as "loser cruisers" with suggestions that "suits don't ride buses" (McIlheran, 2008). Public transport, in particular buses, are often described in a negative light as a "down market" form of transportation (Witten, McCreanor \& Rose, 2006) where the users are not even perceived as part of "middle-class lifestyle," rather they service those that cannot access private motor vehicles (Department for Transport, 2003, p.18).

Research has long supported the importance of perceived similarity as an important factor in interpersonal liking (e.g., Byrne, 1961). Siegfried, Tedeschi and Cann (1982) found that perceived passenger dissimilarity reduced reported liking of other passengers and reduced willingness to use public transport. More recently, prejudiced attitudes have been linked to public transport avoidance in New Zealand (Walton, Murray \& Thomas, under review). Individuals may form irrational assumptions or stereotypes about the type of people that use public transport. For example, "I have nothing in common with the person sitting next to me”, even though both parties are leaving from and going to a similar location using the same transport mode. Highlighting similarities between train users to break down stereotypes may be a successful strategy to encourage a socially comfortable setting and improve patronage (Siegfried et al., 1982).

The theory of planned behaviour demonstrates how social influences can predict behaviour (Ajzen, 1985). The theory posits that positive attitudes and social norms surrounding public transport as well as a high perceived level of behavioural 
control (or the ease with which public transport can be used) determine the level of intention or willingness to use public transport, which should relate strongly to actual public transport use (Ajzen, 1985). Bamberg (2000) examined several metaanalytic review articles which concluded that intentions account for approximately $20-30 \%$ of the variance in actual or revealed behaviours.

Gardner and Abraham (2008) used a meta-analysis to examine social predictors of car use and found that the elements of the Ajzen's (1985) theory of planned behaviour were all supported in the context of car use. Habit was also found to have a strong social influence over car driving behaviour (Gardner \& Abraham, 2008). The authors suggest that if habit is the primary psychological factor determining car use, then advertising campaigns to shift attitudes to promote public transport use are unlikely to succeed, as the decision to travel is automated and better interrupted by instrumental interventions (e.g. price or trip duration changes).

\section{Predicting Public Transport Use}

A broader focus of this research is to examine interpersonal discomfort as a deterrent to public transport patronage. There is a strong focus in the literature on instrumental predictors of public transport patronage. While there is strong evidence that non-social factors require attention, it is important that social factors are not neglected or even overridden simply because there is a paucity of empirical evidence (e.g. Richards, 1978; Stradling et al., 2007). Until passengers are all physically separated from each other in personalised cubicles, public transport providers must consider the interpersonal social needs of passengers. Factors relating to public transport use can be broadly categorised into social and nonsocial factors.

\section{Non-Social Factors}

Instrumental (or utility based) factors that have been previously studied in the context of public transport and found to influence patronage include: regularity (i.e. trip frequency and potential wait times), trip duration, cost (ticket cost versus petrol cost), egress time and information provision, (Balcombe et al., 2004; Currie \& Wallis, 2008; Eriksson, Friman \& Gärling, 2008; Holmgren, 2007). 
Currie and Wallis (2008) reviewed the influence of different factors and interventions focussed on increasing bus patronage, and found that among the "soft" variables relating to the on-board passenger experience, air conditioning, closed-circuit television (CCTV) surveillance and a smoother ride were most likely to increase patronage (with possible gains of about $3-4 \%$ when implemented in unison).

Key demographic variables that have also been linked to increased public transport patronage include lower income, lower access to private motor vehicles (e.g. lower number of vehicle in household), higher residential density (Balcombe et al., 2004), and higher employment in the central business district (CBD; Hendrickson, 1986). There are also external variables such as weather conditions.

\section{Social Factors}

One of the underlying hypotheses of this research is that even if all of the instrumental factors associated with public transport were equal, people would still use cars, as the social influences on patronage have been neglected in public transport. Complaints about the instrumental factors associated with public transport such as trip duration, frequency of service and cost may just be symptomatic of a poor social acceptability of public transport as well as the strength of our acceptance of the private automobile.

From a passenger perspective it is certainly easier to point to well-known, alterable factors such as cost than complain about less tangible factors such as privacy, or even appear prejudiced because the socially heterogeneous group of public transport patrons make you uncomfortable. Richards et al. (1978) indicate that there is a need that goes beyond the typical instrumental measures associated with public transport. The Department for Transport (2003, p.5) in London suggests that it is not enough to simply attend to reliability and pricing strategies, but that the image of public transport needs to be "radically improved".

Contemporary research is beginning to address the lack of studies examining the social influences on public transport (Stradling et al., 2007). Semi-structured 
interviews and focus groups are the most common methods to examine social factors, where all facets relating to transport are more likely to arise. There is a subsequent lack of quantitative measurement and analysis of social influences on public transport use. This is because factors relating to the trip experience are difficult to quantify (Guiver, 2007) and are not typically consistent (Gardner \& Abraham, 2008).

Buses are perceived as vulnerable spaces, where the intrusion of other passengers and a perceived lack of control over anti-social behaviours are identified as key problems (Guiver, 2007). Discourse analysis of ten focus groups of car and bus users discovered that discussions of buses frequently used "worst-case" scenarios that highlighted feelings of powerlessness when travelling, whereas car travel was not stereotyped by its worst elements in this way (Guiver, 2007). The issues surrounding car travel, such as congestion, are perhaps less emotive than the feelings associated with personal space invasion and a lack of control.

Some of the worst anti-social behaviours identified by Guiver's (2007) research included the frequent use of swearing, being spat on, and intoxicated passengers being abusive and being sick, most of which was perceived to occur at night. Bus drivers were viewed as exerting little authority, often saying they would not get involved, and passengers felt that if they said anything they would become the target, with the comment that there is "nobody there to back you up" (Guiver, 2007). Participants made the suggestion of bringing back bus conductors to exert control, or be seen to exert control, over anti-social behaviour.

Gardner and Abraham (2007) used structured interviews with 19 regular car commuters and found that in addition to instrumental variables (trip duration, convenience and cost), journey-based affect and concerns for personal space influenced car use. Among other reasons, car drivers stated that they avoid public transport because they do not want to have to deal with "undesirable" passengers. They also enjoy the freedom from the social surveillance of others when using the car, for example, the freedom to sing loudly which would be inhibited by the presence of other passengers in the public transport setting. 
Stradling et al. (2007) used quantitative and qualitative analysis to examine the attitudes of just under 1000 residents living along a bus corridor, and revealed eight factors that discouraged bus use, including unwanted physiological arousal from close conditions with other passengers, and feelings of safety around other passengers. The other factors were preference for walking and cycling, preference for car, problems with service provision, cost, disability and physical discomfort, and self-image. Despite some participants exuding discomfort from exposure to other passengers, Stradling et al. (2007) describes the situation as a continuum, with other passengers taking the opportunity to observe and participate in positive social interaction, with a consequential feeling of community.

This review has highlighted the problem of interpersonal discomfort in the context of public transport. The next section will examine how people adapt within a public transport setting to mitigate discomfort and identify aspects of other successful environments that may help reduce discomfort.

\section{MITIGATORS OF INTERPERSONAL DISCOMFORT}

Humans are very good at adapting to different habitats, by altering the physical parameters to fit their needs, where possible, but also by behavioural adaptation (Freedman, 1975). Crowding is a subjective and context-specific concept in which expectation and adaptation are key components (Insel \& Lindgren, 1978). The context specific nature of IPD discomfort also means that different settings afford different types of behavioural adaptation dependent on the features in the environment, the nature of the activities that take place there, the other users of the space, and the expected formality of the setting. For the purposes of this research, behavioural adaptations are being placed into two broad categories, defensive adaptation and interactive adaptation.

\section{Defensive Adaptation}

Unlike other public domains such as parks or beaches, public transport users do not have the luxury of flight behaviour, as they have a fixed destination. Individuals also have a limited ability to manipulate IPD in a public transport 
setting as they are in fixed seating. Fried and DeFazio (1974) observe that seat selection choices attempt to maximise IPD and minimise the chance of personal space intrusion, but as the subway carriage fills passengers rely on more subtle behavioural adaptation, such as gaze aversion.

Behaviours that are intentionally or unintentionally used to protect an individual from interaction with other passengers are categorised as defensive adaptations for the purposes of this research. Within their arsenal of defensive tools passengers can use defensive body language, such as averted glance or turning their body away (Fried \& DeFazio, 1974). Passengers can also physically defend their space, by placing an object such as a bag on the adjacent seat or physically spreading out to take up more than their half of a paired seat (Nash, 1975; Zurcher, 1979).

Another defensive adaptation is what Zurcher (1979) describes as the use of "situational withdrawal," where passengers distract themselves from the discomfort of the situation through the use of an activity, such as reading or listening to music. While this may not be intentionally defensive in nature (the person may simply want to read their book) it reduces the likelihood that other passengers will interact and so it is labelled as defensive. The ultimate in defensive behaviour is arguably the intentional avoidance of public transport because of interpersonal passenger proximity.

\section{Symptom or Solution}

A key question regarding defensive behaviour is whether it is a symptom of discomfort or a solution to discomfort. Argyle and Dean (1965) suggest that defensive behaviours can be used to maintain equilibrium. For example, when IPD is closer than desirable individuals can reduce the unwanted intimacy of the situation by reducing the frequency and duration of their gaze.

There is some evidence that attempting cognitive withdrawal will not reduce discomfort from crowding. When individuals imagined that other elevator passengers were just part of a movie they were watching their perception of elevator crowding did not reduce (Miller, 1981). While cognitive situational withdrawal is not the same as activity-based situational withdrawal it does follow 
the same process by mentally withdrawing from the setting. Activity withdrawal may be more effective in reducing discomfort, particularly in a task like reading as it visually distracts from the presence of others.

Proshansky, Ittelson and Rivlin (1976) suggest that the acceptance of, or adaptation to, crowded situations does not equate with the absence of discomfort. In a crowded elevator passengers are likely to attempt to preserve equilibrium through gaze avoidance and the maintenance of larger IPDs (such as by moving into the corners first). But if they rated the crowded elevator against other social situations, this would still be rated as an uncomfortable setting. Moos and Insel (1974, pp. 186) describe defensive behaviours as "surface adaptations" that may be partially successful in desensitising passengers to their surroundings but never fully successful in habituating passengers to the interpersonal intrusion such that they are truly comfortable.

Edney (1972b) examined the use of barriers, such as fences, walls and hedges to defend the home, and found that occupants of homes with a higher level of barriers answered the door more quickly, indicating greater sensitivity to territorial infringement. This finding provides evidence for the use of defensive behaviour as a proxy of sensitivity to personal space invasion. There is also evidence that the same people who make more effort to repel invaders are also those who will be most negatively affected by an intrusion into their space (Hayduk, 1981).

Real solutions to privacy issues may have to rely primarily on physical solutions, simply because the degree of intrusion on public transport is so high. Physical solutions would ideally include larger spaces between passengers, and especially benefit from physical barriers between seats (such as armrests) to better demarcate allotted passenger space. Evans and Wener (2007) come to similar conclusions.

\section{Interactive Adaptation}

In contrast to defensive behaviours, interactive adaptations include positive body language (such as smiling and making eye contact), verbal communication, and friendship formation. Positive body language is not as clear as negative body 
language, as the use of glance and smiling to signal positive intent can be misinterpreted if it does not fit with the expectation of the other person.

Eye contact is associated with positive affect, such that those who use greater levels of eye contact are seen as more likeable, pleasant and interesting (Scherer, 1974). However, gaze duration must be appropriate, as gaze durations that are equated with staring form negative impressions (Ellsworth, Carlsmith \& Henson, 1972). Similarly, a smile must be genuine and not forced, as non-genuine smiles can be identified and consequently may not have the intended effect (Miles \& Johnston, 2007). Lill and Willkinson (2005) found that smiling increased positive affect, and further to this, people who had genuine, enjoyment smiles are seen as even more positive (Frank, Ekman \& Friesen, 1993).

Success in residential design has been shown to be achieved in designs that facilitate close social interaction (Abu-Ghazzeh, 1999; Freedman, 1975; Yancey, 1971). At least on the surface of it, the frequency of passive contacts with train regulars is higher than with neighbours. The amount of coincidental time spent in the presence of other commuters is probably longer than that spent with neighbours. Public transport has the requisite qualities to form relationships of convenience, just like in workplaces and neighbourhoods. However, this may not hold as a function of passenger density and the dilution of the "familiar strangers" amongst complete strangers.

The idyllic passenger experience is often related to situations where there is a community, or as Nash (1975) describes it, a "community on wheels." This is supported by people talking about their positive public transport experiences. Discourse analysis from focus groups asking bus and car users about their travel experiences revealed that some of the best experiences associated with buses came from the more rural areas where social interactions were part of the experience (Guiver, 2007).

“...it's a wonderful way of meeting people I can have some really good laughs with some of the people on that bus and some of the drivers have got a wonderful sense of humour and you might be feeling wet, miserable, down but you get on that bus and somebody says 'hello' to 
you it makes you feel a lot better I mean there's a good community out there that use the bus routes and, I mean, I think that is lovely" (Guiver, 2007, p. 238).

A key psychosocial benefit of public transport is the opportunity to observe or engage in social interaction with other passengers (Stradling et al., 2007). In Auckland, New Zealand, there is evidence that regular passive contacts with strangers on the train can form long-term friendships (Witten et al., 2006).

"The trains are very social, too...I caught it for two years every day and I actually got to know the people in my carriage. A group of us still actually get together every now and then and have lunch." (Witten et al., 2006, p. 24)

In addition to reducing discomfort with the other passengers, there are many concomitant benefits to social interaction or the creation of informal social networks (e.g. Abu-Ghazzeh, 1999; Freedman, 1975; Yancey, 1971). A sense of pride, respect and belonging to the public transport community can improve social surveillance and the enforcing of informal social rules (Greenberg \& Firestone, 1977). A consequence of this is that anti-social behaviours, such as swearing, graffiti and littering are likely to be reduced and altruistic behaviours, such as greetings, farewells, giving up seats for vulnerable users and thanking of the driver are likely to be increased.

With all these benefits it seems logical to chose interactive adaptations, but there are several barriers inherent in the public transport setting that make interaction less attractive. For example, interactive behaviour requires greater effort, especially engaging in conversation with strangers where there is no mutual history, and the social norm is likely to be against conversation (e.g. Fried \& DeFazio, 1974). There may be less trust, fear of rejection could be higher, there might be greater discomfort if there is an awkward silence, and difficulty finding a mutually interesting topic.

Fried and DeFazio (1974) observed that social norms on subways precluded the use of superfluous conversation. However, there is also evidence that functional 
conversation is prohibited in crowded, transient settings. While examining a crowded elevator setting Rodin et al. (1978) found that $46 \%$ of passengers leaned past another person to press the button rather than asking someone else to do it for them. That people are relatively equally spread between more intensely invading someone's space and asking someone else for some minor assistance does not bode well for the use of altruistic behaviour or even verbal behaviour in crowded public transport settings.

\section{Barriers to Social Interaction in Public Transport}

As suggested previously, public transport is commonly depicted as a socially stagnant setting. There are several factors that have been identified as necessary for a successful social setting. Flemming et al. (1985) suggest that social interaction is enhanced by opportunity for contact, proximity to others and appropriate space to interact. Public transport certainly allows proximity to others, though opportunity for contact may be more limited, and the appropriateness of the space for interaction definitely seems wanting.

Hall (1983) provides a good review of some of the factors that influence relationship formation, including examples of how homogeneity of regular users and proximity promote friendship. In the specific context of public transport, Nash (1975) identified three interrelated factors that encouraged social interactions on buses; the experience or competency of passengers and drivers, the density of people or crowdedness, and the duration of the ride. Social interaction is impeded in public transport if passive contacts fail to translate into friendships.

\section{Perceived Heterogeneity and Commonality}

"Social groups and friendships do form on the basis of common occupation, common sex, residence in the same expensive suburb, or the fact that two people went to the same college or came from the same point of the country" (Festinger et al., 1950, p.4).

Festinger et al.'s (1950) passive contact theory (PCT) relies not only on proximity but also on homogenous populations. Subjects placed together in a fall-out shelter 
for ten days were less likely to form friendships with people that had dissimilar attitudes (Griffitt \& Veitch, 1974). There is also demographic evidence (Mitchelson, 1982; Parolin, 1992) and social commentary that suggests that public transport users belong to a "variegated" social group (Hood, 1996). The heterogeneity of public transport users may impede passive contacts from inducing any relationship with other users.

\section{Regular Patronage}

Regular patrons have a larger number of passive contacts with each other, which indicates greater opportunity for social interaction and friendship according to Festinger et al.'s (1950) PCT. In less transient settings the relationship between regular proximity and friendship formation is substantiated.

Segal (1974) was able to isolate the influence of regular proximity on friendship formation in a natural experiment. Police trainees at a facility in Maryland were allocated sleeping quarters and classroom seating alphabetically, based on their surname. After a six week period the trainees were sent questionnaires asking about demographic and social variables relating to friendship as well as soliciting the names of their three closest friends on the police force.

When these friendships were examined $45 \%$ of relationships at the training facility occurred with trainees that were immediately adjacent in the alphabetic order, and the correlation between an individual's place in the alphabetic order and the mean place of people that person chose as friends was 0.91 (Segal, 1974). Segal (1974) concluded that this natural measure of regular proximity was a better indicator of friendship formation than any of the other demographic and social predictors.

\section{Exposure and Familiarity}

A meta-analysis examining the relationship between affect and exposure (using 134 different studies) revealed that exposure does promote positive attitudes towards a stimulus (Bornstein, 1989), supporting the concept that "familiarity breeds liking”. Claypool (2007) found that when shown photographs of familiar 
faces participants rate them more positively than novel faces. Claypool's (2007) findings suggest that all other things being equal, familiar regulars on public transport will be viewed with greater affect than non-familiar passengers. Passengers that travel regularly on longer trips will have greater exposure to each other, and consequently are likely to have greater affect than short trip passengers.

Further, even under adverse environmental conditions, such as a crowded train carriage, the familiar regulars are still likely to be viewed positively.

Saegert, Swap and Zajonc (1973) had participants taste either pleasant or noxious liquids when they met people, and found that even with aversive stimuli there was still a positive exposure effect, with higher attractiveness ratings after a greater number of contacts.

\section{Social Density}

Sommer (1969) suggests that the public transport context removes privacy, dignity and individuality to the point where it is difficult to interact with others. Crowdedness leads to greater deindividuation and a lessened sense of social responsibility. The responsibility to either acknowledge the presence or intentionally avoid eye contact with the intimately close adjacent passenger is reduced under crowded situations. McCarthy and Saegert (1978) found that higher density living situations led to a reduction in social activity, which they put down to social overload.

Milgram's (1970) theory of social overload posits that social interaction is necessarily minimised, such that reciprocity, helping behaviour, and basic social courtesies (such as greetings or apologies) are reduced as social density increases. DeBeer-Keston, Mellon and Solomon (1986) established that helping behaviour diminishes as a function of personal space intrusion. Applied to the social situation of public transport, this explains why other passengers do not ask if the seat is taken before sitting next to someone, or do not apologise when they accidentally touch another passenger. Under crowded circumstances people do not have the resources to meet, greet and maintain social politeness with all of the strangers that share their temporary space. These greetings are a precondition for the 
opportunity for "familiar strangers" to develop into friends. The lack of social courtesy caused by crowded conditions impedes this development.

\section{Appropriate Space (Design)}

"Environments can bring different kinds of people together in ways that create stress and bring together people who might be compatible without providing the necessary props for successful interaction" (Prohansky, Ittelson \& Rivlin, 1976, p. 221; cf Altman \& Lett, 1970).

Patterson and Sechrest (1970) had participants interview confederates seated at distances of two, four, six and eight feet and found that when confederates seated themselves four feet away they were rated most positively (i.e. friendly and extraverted). The conditions at two and six feet were rated next in terms of affect and the eight feet condition was rated as least positive (with a particularly large drop in extraversion). At smaller distances, one to three feet apart, opposite seating (facing across) is preferred to adjacent seating (sitting beside) when engaging in conversation (Sommer, 1969). Similarly, Maines (1979) found that subway users were more likely to interact when using L-shaped rather than adjacent seating.

Maines' (1979) research provides sufficient evidence to suggest that the immediately adjacent, paired seating on public transport is inappropriate for conversation. The distance is simply too close, and the angle of orientation means that passengers have to attempt to turn sideways in very cramped conditions if they wished to fully engage in conversation (i.e. getting non-verbal feedback from the other person's facial expressions and level of eye contact).

Holahan and Saegert (1973) show how social interaction can be built into the design of spaces in their examination of an upgraded psychiatric ward. They found that upgrades increased social interaction, decreased passivity and produced more positive ratings towards the physical and social environment (when compared with a control ward). Interventions to upgrade the ward included making the facilities more attractive by repainting and refurnishing, private areas were created with the 
use of partitions and small social areas through the arrangement of tables and chairs.

Increased architectural depth, with the use of partitions, is successful at reducing social withdrawal in the residential setting (Evans, Lepore \& Schroeder, 1996). Moos and Insel (1974) also examined the use of partitions in barracks, and found that this intervention reduced overall knowledge of names, but increased pockets of friendships.

Davis and Levine (1967) proposed that part of the reason for the socially stagnant atmosphere in public transport is due to the lack of physical stimuli. The use of stimuli in the form of three prints and three posters placed on the walls and two wind chimes attached to the lights of a lab environment mitigated perceptions of crowding (Worchel \& Teddlie, 1976). Bleak settings are likely to reduce passenger affect. Maslow and Mintz (1956) found that judgements of people depicted in photographs were more positive when the person was located in attractive surroundings. Given the correct circumstances, appropriate environmental stimuli could also act as conversation pieces.

\section{Adaptive Measures in Practise}

The previous section highlighted key defensive and interactive behaviours, and barriers to successful interaction in the public transport setting. A key part of this research is to examine whether adaptive behaviours are likely to be successful in reducing discomfort. There is speculation that people use "surface adaptations" but do not fully habituate to their situation such that they are truly comfortable (Moos \& Insel, 1974, p. 186). It has also been posited that other people are one stimulus to which habituation fails (Saegart, 1976).

Epstein, Teitelbaum, Karlin, Katz and Aiello (1981) examined the success of both defensive and interactive strategies in reducing stress in lab conditions designed to simulate crowded public transport. Participants were given two non-intervention conditions (crowded and uncrowded) and two intervention conditions (reading and talking) that were both in crowded conditions. Four subjects were seated in two rows of two, and this was repeated three times for each condition, so that there 
were 12 participants in each of the four conditions (all participants were male). A small room $(1.17 \mathrm{~m}$ by $0.85 \mathrm{~m})$ was used for the crowded condition, where participants were so close to the immediately adjacent and opposite participants that they experienced bodily contact. A larger room (3.66m by $6.10 \mathrm{~m}$ ) was used for the non-crowded condition, with a spacing of $0.91 \mathrm{~m}$ to the adjacent chair and $1.83 \mathrm{~m}$ to the opposite chair. Subjects were exposed to these conditions for 30 minutes, and measures of skin conductance were taken every 2 minutes.

Epstein et al.'s (1981) study revealed that neither the defensive strategy of reading a newspaper, nor the interactive strategy of talking to others, reduced physiological stress (as measured by tonic skin conductance level). In all three crowded conditions (regardless of intervention) stress increased significantly over time, whereas in the non-crowded condition stress levels remained stable over time. Subjective measures found that the non-intervention crowded condition was perceived as more crowded, small and uncomfortable than the non-crowded condition and that participants in the talking condition had a significantly higher perception of control.

The authors recognised the limitations of the lab conditions and the fact that the participants were strangers (Epstein et al., 1981). The reading material may not have been engaging for those in the reading condition, as they would not have picked it themselves. Forced conversation with complete strangers for 30 minutes may not be stress-reducing when compared with conversation with friends or acquaintances. The stimulus-free lab environment, although not too different from the vacant environment of public transport, is missing the stimulus from other passengers as well as the views out the window, both of which could be used as conversational fodder. Similarly, males may be less likely to naturally favour interactive solutions (e.g. Smith, 1997).

Despite these limitations this research provides evidence that adaptation does not reduce actual physiological stress, it merely improves subjective assessments of crowding, and for interactive passengers it improves perception of control. That conversation is not physiologically stress-reducing with strangers alludes to why passengers may have trouble beginning to acquaint themselves with each other. The seating layout of buses and trains is more akin to the crowded than the non- 
crowded situation, suggesting that buses and trains are likely to induce stress, particularly during longer trips (however most public transport seating in New Zealand does not face each other in this way).

\section{Lessons from Other Public Transport Modes}

\section{Failure of Subways and Elevators}

Personal space research often cites crowded elevators and crowded subway carriages as worst-case examples of interpersonal stress, with the greatest need for behavioural adaptation (e.g. Birenbaum, 1976). Some of the elements of these settings will be briefly examined to elucidate specific factors that lead to interpersonal discomfort.

First, the density of passengers in these examples is typically high. Subways and elevators are more typically located in high density cities as the cost-benefit of having them requires a reasonable level of patronage. Second, elevators have no windows and subways windows predominantly view the tunnel, so the lack of view is likely to increase feelings of crowding. Windows extend the space beyond the limited confines of the vehicle and provide a visual escape. Windows have been found to reduce the perception of crowding in student living quarters if they are perceived to be a part of an individual's territory (Baron, Mandel, Adams \& Griffen, 1976).

\section{Success of Aeroplanes}

Aeroplanes are a good example of a socially successful environment, with some particular points of difference that place them above other modes in terms of meeting user needs. Most of the elements of success relate back to perception of control, but also include greater social surveillance and the enforcement of social rules.

Arguably the most important point of difference is the presence of an air steward who is focussed on delivering not only passenger comfort but passenger control. In addition to this there is a set of individualised controls that help each passenger 
control the immediate environment around them. Features can include call buttons (to get the attention of the crew), reading lights, folding tray tables, access to music, personal or shared televisions, foot rests, and adjustable seats (features may vary slightly between planes with longer distance flights providing more features).

Among the individualised physical controls is a temperature control. High temperature conditions, when compared with room temperature conditions, are found to reduce ratings of the positive affect of strangers (Griffitt \& Veitch, 1971). The heightened perception of control is likely to mitigate the effects of crowding. For example, standing in front of the control panel of a crowded elevator significantly reduced a person's perception of crowding and increased the perceived size of the space (Rodin, Solomon \& Metcalf, 1978).

Additionally, there is a greater impression of exclusivity in the aeroplane setting, as it is more exclusive in terms of cost, and there are status based differences (such as first class or business class). There is also clear demarcation of seats with folding armrests that not only mark where the seat ends, but also provides a physical barrier between seats.

\section{Research Aims}

The first part of this research aimed to establish whether there was evidence of interpersonal discomfort on buses and trains in the local context of Wellington, New Zealand, and to find a good method or suite of methods to measure any interpersonal discomfort variation. Because people are adept at adapting to different situations, behavioural adaptation was also examined, particularly interactive and defensive behaviours. This part of the research established whether passengers favour interactive or defensive strategies and determined which was likely to be more successful in reducing discomfort. It was postulated that interactive adaptations would be a more sustainable solution to reducing interpersonal discomfort when compared with defensive adaptations. A further aim of this research was to examine whether Festinger et al.'s (1950) passive contact theory worked in the transient setting of public transport. 
The second part of the research aimed to determine whether passenger proximity was a potential barrier to public transport patronage, and identify which factors were likely to mitigate or exacerbate interpersonal discomfort. The design implications for public transport were considered in light of the findings. There was a particular focus on identifying which elements induce privacy and which facilitate social interaction. The issue of how both elements could be designed into a space when these passenger preferences seemed mutually exclusive was examined. 


\title{
CHAPTER 2: OBSERVATIONS OF TRAIN AND BUS PASSENGER BEHAVIOURS
}

\begin{abstract}
BACKGROUND
"The affordances of the environment are what it offers the animal, what it provides or furnishes, either for good or ill...It implies the complementarity of the animal and the environment..." (Gibson, 1979, p. 127).
\end{abstract}

Many of the lessons learnt from the ecological studies of interpersonal distance, territoriality and the invasion of personal space in the 1960 s and 1970 s (e.g. Hall, 1966; Sommer, 1969; Altman, 1975) remain absent from the design of contemporary social spaces. In the public transport setting at least, considerations of economic concern (passenger capacity) and even physical comfort (anthropometrics of seat design) seem to be given higher priority (e.g. Jung, Han, Jung et al., 1998) than interpersonal discomfort. Perhaps this is because the permeability of interpersonal discomfort makes it difficult to measure (see Hayduk, 1983), and even more difficult to quantify economically (for example, the difficulty of measuring the consequent cost of health effects from short-term crowding).

Ecological studies in the public transport context demonstrate that the environment affords intimate sitting and standing distances with other passengers. These intimate interpersonal distances require complex behavioural adaptation (e.g. Maines, 1977) that indicates a lack of "complementarity" between passengers and their environment (see Gibson, 1979).

To better understand the broad range of behaviours adopted by public transport users, an important first step is to identify those behaviours using an unobtrusive approach. This research examines the behavioural adaptations and seat selection patterns used on buses and trains in Wellington, New Zealand using naturalistic observation. There is a particular focus on defensive behaviour and interactive behaviour. 
Public transport is a commonly used setting, as it has several unique features that compel passengers to adapt to the interpersonal discomfort of the setting. First, public transport vehicles (any further reference to vehicle in this chapter means a bus or a train carriage) provide a seating situation with a design that forces passengers into an intimate distance that causes physiological stress, even when the vehicle is not at capacity (Evans \& Wener, 2007). Second, public transport limits a passenger's ability to flee from the situation, as they must stay until they arrive at their destination.

Flight behaviour is a common reaction to a threatening situation (Hall, 1966), and the time to onset of flight behaviour is a commonly used proxy of discomfort in personal space invasion studies. For example, Felipe and Sommer (1966) invaded the space of students sitting alone at a table in a library study hall, and measured onset time to flight behaviour when positioning a confederate at a table seat. In Felipe and Sommer's (1966) closely invaded condition (3 inches apart) 70\% of participants left within 3omins, compared with $27 \%$ in the far invasion conditions (where conditions ranged between $15-48$ inches) and $10 \%$ in the non-invaded control group. This field experiment demonstrates not only how the degree of invasion increases stress, but that a typical public transport setting would equate to the most closely invaded condition of a few inches apart, indicating the greatest desire to flee. In the public transport setting, Fried and DeFazio (1974) observed that passengers shifted seats to maximise IPD.

Zurcher (1979) observed several defensive behaviours during the airplane boarding process that discourage the intrusion of other passengers into the immediately adjacent seats. These behaviours are likened to defending territory, where passengers physically occupy the space so that it becomes an inconvenience to the defender of the space if another passenger intrudes. Sommer (1967) coined the term "offensive ownership" to describe this behaviour. Spatial defence strategies typically include placing a bag or other object on the immediately adjacent vacant seat or sitting in the aisle seat so that another passenger would have to squeeze past to get to the vacant window seat (Nash, 1975; Zurcher, 1979).

During a trip another common interaction defence strategy is "situational withdrawal”, where passengers discourage interaction by occupying themselves 
with an activity such as reading, listening to music, working or feigning sleep (Zurcher, 1979). Other techniques used to reduce social interaction are gaze avoidance with other passengers (often achieved by looking out a window) and curt responses to any verbal enquiries (Nash, 1975; Zurcher, 1979).

Social interaction is not commonly examined as an adaptive behaviour to interpersonal discomfort. Verbal interaction is typically only referred to in studies that attempt to holistically describe the environment and all of the behaviours that occur there (e.g. Nash, 1975; Zurcher, 1979). The benefit of the commentary is that it encompasses behaviours that are difficult to observe, and provides a more holistic picture of events. Unfortunately these types of study do not provide any specific frequency data on verbal behaviour, so the findings may place too much weight on salient events or simply omit non-salient events.

Nash's (1975) observations of buses suggests that there are a set of social rules that accompany seat selection and that seat selection can represent the level of openness for social interaction with other passengers. Riders that were hesitant to interact with other passengers typically sat in the middle of the bus where they used defensive strategies to mark the double seat as theirs (Nash, 1975). Nash (1975) also observed that verbal interaction was usually more successful where the passengers were regulars, the duration of the trip was high and the vehicle was not too crowded.

Zurcher (1979) observed several conversation initiation techniques used in the airplane setting, such as helping other passengers getting settled, offering objects (such as chewing gum), or querying or providing another passenger with relevant travel information. Reciprocity is a common technique used to engage with others, whereby a positive action is taken with the expectation of a positive response. In this way conversation initiators are less likely to be given a curt response or other negative reaction when they attempt to interact with another passenger.

Fried and DeFazo (1974) observed passengers travelling by subway and found that there was very little verbal interaction between passengers that were strangers. The conversation vacuum brought about in the context of public transport may be 
caused by social rules or norms that "prohibit" superfluous conversation between strangers (Fried \& DeFazo, 1974).

Reciprocity, helping behaviour, and basic social courtesies (such as greetings or apologies) have been posited to reduce in crowded conditions, such as those of cities (Milgram, 1970). It was suggested that this was because of social overload, where an individual faced excessive exposure to social information, and social interaction was necessarily self-restricted as a coping mechanism (Milgram, 1970; McCarthy \& Saegart, 1978). Tenants living in high-rise, high-density buildings, when compared with low-rise, low-density buildings, reported a higher perception of crowding, anonymity and detachment from the residence, a reduced level of social interaction, and a lower perception of privacy, control, and safety in shared building spaces (McCarthy \& Saegart, 1978).

Guiver (2007) performed discourse analysis of ten focus groups made up of car and bus users, and found that many of the worst-case scenarios of using the bus related to the intrusion of other people in terms of smells, litter, intimidation, fear of safety and close proximity. Alternatively, positive scenarios talked about the bus as a "...place of social interaction, of pleasant chance meetings and greetings from friendly staff" (Guiver, 2007, p.237).

The purpose of this study was to naturalistically observe how passengers adapt to interpersonal discomfort on the bus and train settings, both in terms of defensive and social adaptations. The benefit of naturalistic observation was that it was not contrived, so it had none of the restrictions that lab settings and simulation studies place on participant behaviour (see Altman, 1975). The corollary to this was that it also had none of the controls.

An observer sat on buses and trains in the Wellington, New Zealand area over a period of eight weekdays to examine passenger behaviours, notating their spatial location and the presence of key behaviours, such as the physical defence of the seat location (e.g. placing a bag on the adjacent seat), situational withdrawal into an activity (e.g. listening to music), and verbal communication. It was expected that defensive behaviours would be common and verbal interaction would be infrequent, particularly in more crowded conditions. 
Due to the focus on interpersonal distance a new measure of proximity measurement was developed specifically for the bus and train setting. Evans and Wener (2007) called for a more finely tuned measure to capture the actual experience of interpersonal proximity. This new measure examined the seat distance to the nearest passenger, so it was more sensitive than the row level data examined by Evans and Wener (2007), and it was also directionally sensitive (see the Method section for more details). This measure ensured a closer examination of the successfulness of different adaptive behaviours in increasing interpersonal distances, and subsequently provided evidence of interpersonal discomfort on the train and bus. It was expected that in the initial seat selection process passengers would attempt to maximise IPD and then defence behaviours would be used minimise unwanted social interaction.

\section{METHOD}

\section{Participants}

Observations were made of 1703 passengers using bus $(n=1142)$ and train $(n=$ 561) services in Wellington, New Zealand. Travel was examined over eight weekdays, between 6:30am and 6:0opm, with observations of 38 bus trips and 23 train trips. All trips were taken in the New Zealand Winter, with air temperatures ranging from 3.0-12.1 degrees $\mathrm{C} ; M=7.91$ degrees $\mathrm{C}, S D=2.34$ degrees $\mathrm{C}$. The sample of passengers was $47.5 \%$ female.

\section{Procedure}

Bus services were randomly selected using the bus numbers, and all four train services into Wellington city were observed. For observational purposes each train carriage was split in half, as piloting found that it was too large to adequately observe passengers. The observer was placed in a randomly selected carriage half. Both peak and off-peak travel times were selected, although it is important to note that previous observational research has avoided peak times, suggesting that observations are difficult to make under crowded situations (Maines, 1977). Peak times for the services were 7:00am-9:00am and 3:00pm-6:0opm. 
An observer was placed on a bus or train carriage (also referred to as vehicle for the purposes of this chapter) in a position where they could best view passengers boarding for transit. Typically near the rear of the bus or on the side seating in the middle of the train carriage so that they were either facing or side on (respectively) to most passengers and had a good view of the entry points and any activity in the aisle. The observer sequentially recorded each passenger movement (boarding, swapping seat, departing), their gender, and seat location. Figure 2.1 shows the typical seating layout of a public bus.

A second observer was used for a sample of the data collected to ensure the interobserver agreement of the measures was reliable. Permission was given to conduct this observational study, but a full ethical committee was not deemed necessary. This is because there was no direct interaction with other passengers, no permanent record of the observations (such as photographs or video footage), and the observations were in a "non-threatening" public setting (an example of a more "threatening" public setting would be public toilets, e.g. see Middlemist, Knowles \& Matter, 1976). Statistical Package for the Social Sciences (SPSS) version 15 was used for all data analysis in this observational research, and for all of the statistical analyses in the chapters that follow.

\section{Train and bus settings}

Bus and train services in New Zealand typically have paired seats that are designed to hold two passengers immediately adjacent to each other. Buses mostly have forward facing seats (see Figure 2.1). Train carriages have a relatively even mix of forward and backward facing seats (as the carriages travel in both directions on the rail track without being turned around), and typically have more sideways facing seats than buses (see Figures 2.2 and 2.3). Paired train seats had dimensions of approximately $98.00 \mathrm{~cm}$ wide (so allowing $49.00 \mathrm{~cm}$ width per seat) by $36.00 \mathrm{~cm}$ deep, with about $30.00 \mathrm{~cm}$ leg room. Paired bus seats had smaller dimensions, with a seat width of approximately $87.00 \mathrm{~cm}(43.50 \mathrm{~cm}$ width per seat) by $37.00 \mathrm{~cm}$ deep, with 28 .oocm leg room. These dimensions did vary between different vehicles. 


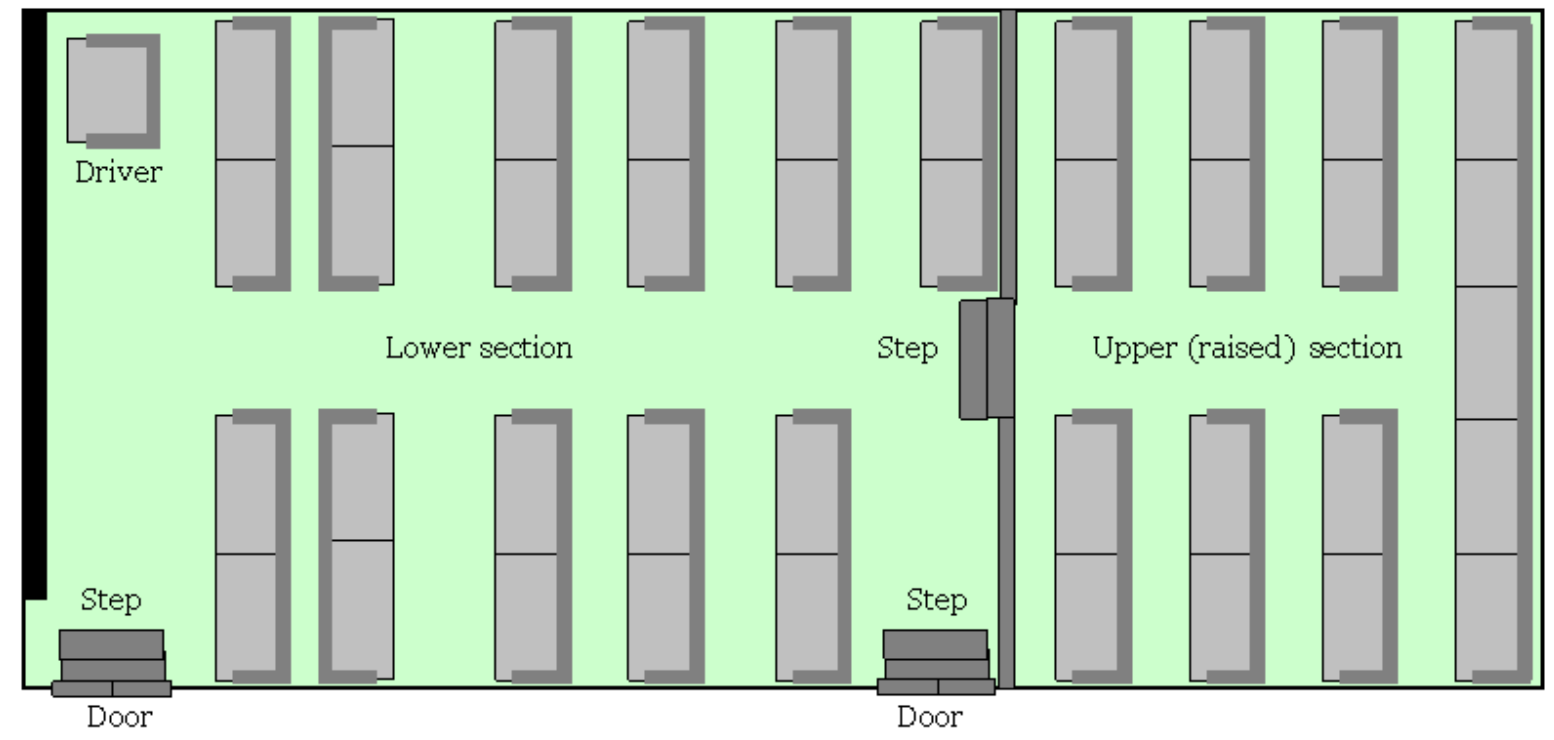

Figure 2.1. A typical New Zealand bus layout (not drawn to scale).

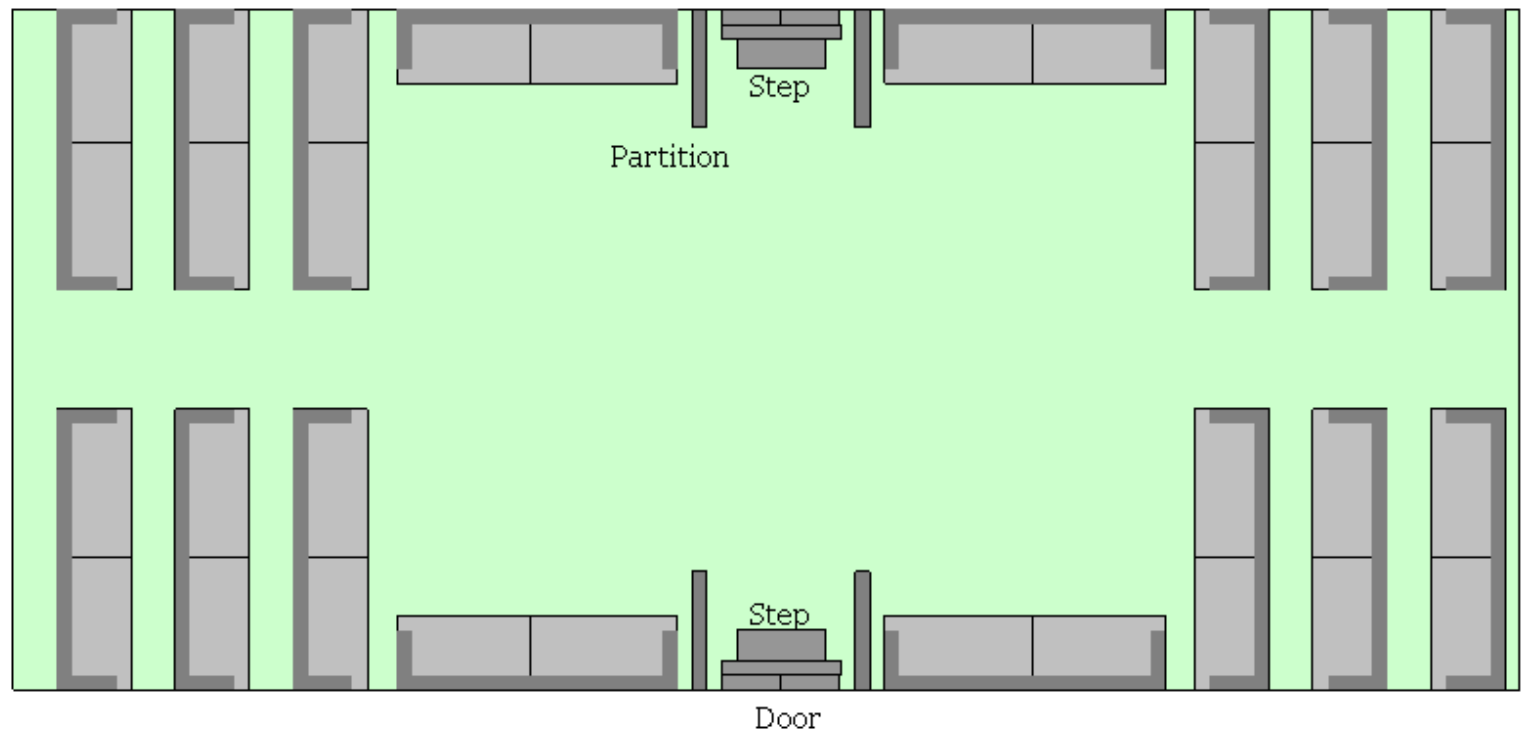

Figure 2.2. A typical New Zealand train carriage layout depicting half a train carriage (not drawn to scale). 


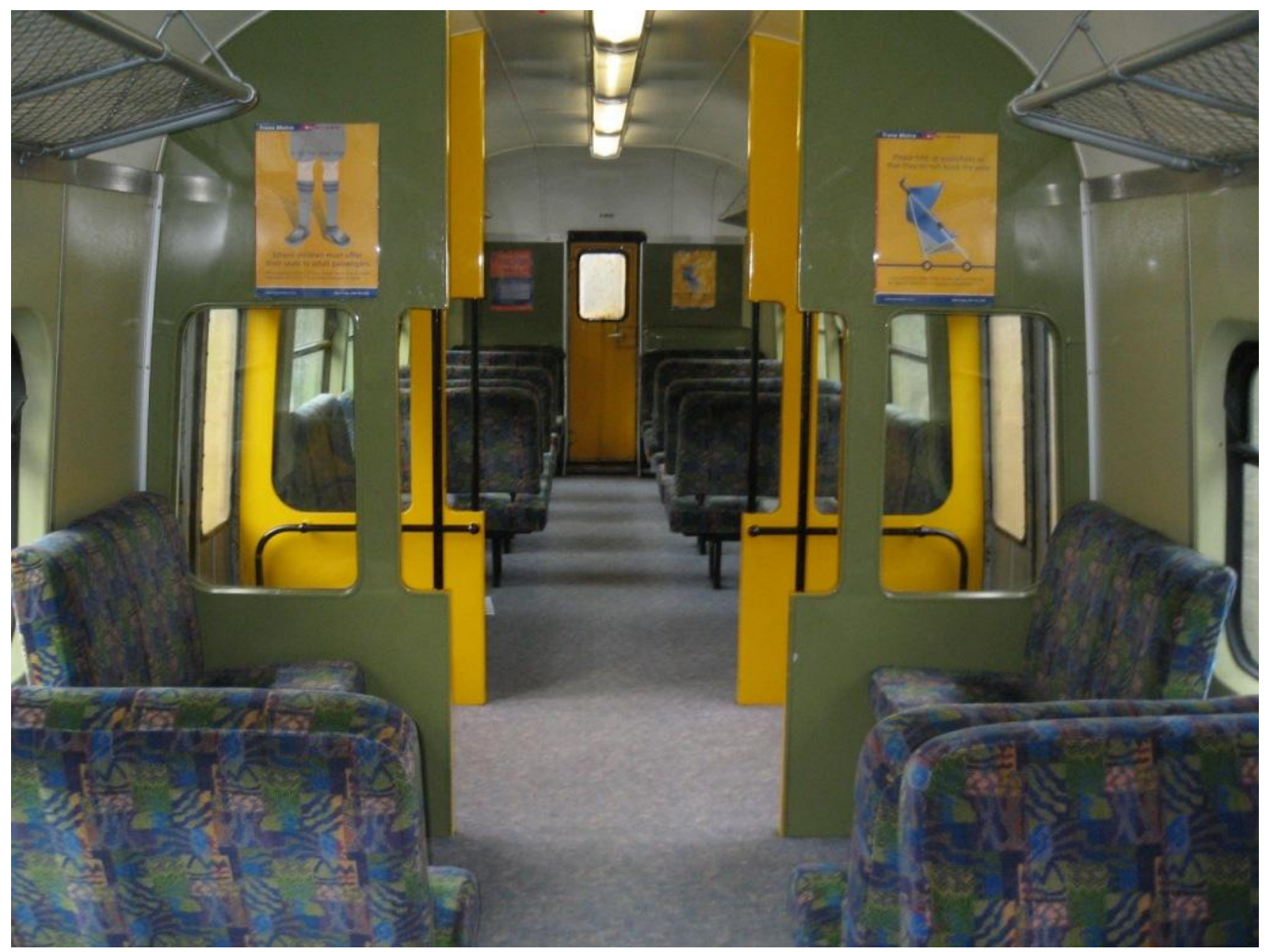

Figure 2.3. The inside of a train carriage in Wellington, New Zealand, showing perpendicular seating arrangements.

\section{Measures}

Previous research identified two key defensive behaviour types, the initial defence of territory by physically occupying the space, and the use of situational withdrawal, where passengers occupy themselves with an activity (Nash, 1975; Zurcher, 1979). Both behaviour types were expected to reduce social interaction. For the purposes of this study defensive passenger behaviour is defined as that which discourages interaction with other passengers. Even though activities such as reading or listening to music may not have the direct intention of being defensive, as passengers may simply want to perform these activities, these actions still have the result of discouraging verbal interaction and are therefore labelled defensive. Table 2.1 outlines the key observational measures, including the defensive measures. 
Table 2.1.

Observational Variables and Descriptions

\begin{tabular}{|c|c|}
\hline Variable & Description \\
\hline Seat location & $\begin{array}{l}\text { Row number, window seat, side of vehicle, and seat } \\
\text { direction. }\end{array}$ \\
\hline Gender & Male or female \\
\hline Age group & $\begin{array}{l}\text { A very basic age measurement was created, but this only } \\
\text { measured the extreme age groups of elderly, baby, child, } \\
\text { and school (identified by school uniform). }\end{array}$ \\
\hline Stand & Whether a passenger was standing. \\
\hline
\end{tabular}

Visible weather

Measured weather

Percent full

Adjacent defence

Adjacent same gender

Shift seat

Couple

Interpersonal distance

Verbal interaction

Defensive behaviours

Physical occupation of space

Bag on seat

Situational withdrawal into an activity
A visible weather rating was given by the observer at the beginning of each trip: sunny, cloudy/fine, light rain/drizzle, heavy rain.

Temperature (in degrees Celcius) and relative humidity (collected post-hoc using data from a local NIWA [National Institute of Water \& Atmospheric Research] weather station).

The number of passengers divided by the capacity of seats, expressed as a percentage.

Whether the passenger sat beside someone using any form of defensive activity or behaviour.

Whether the passenger sat beside someone of the same gender (indicating evidence of homogeneity within passengers).

Shifting position after initially choosing a space to sit or stand.

Couples were identified as those passengers that entered together, and sat immediately adjacent to each other (see the section on Couples below for more detail).

Seat distance to next passenger (see the section on Interpersonal distance below for more detail below on this method).

Conversation with another passenger (this did not include very short conversation, such as greetings or farewells)

Aisle sitting: blocking the window seat by sitting in the aisle seat.

Device/artefact placement (e.g. bag or coat) or enlarging posture (e.g. spreading out arms, legs, or sitting in the middle of two seats) to take up space on the immediately adjacent seat.

Listening to music, reading, cell phone texting, cell phone talking, head down likely to be reading, sleeping, knitting, and laptop use. 


\section{Interpersonal distance to nearest passenger}

A new measure of interpersonal distance was developed specifically for train and bus settings. A similar method had already been applied to residential settings, where the functional distance between a participant's room and a friend's room was measured by room units, taking into account the shortest path to the friend's room using the closest stairwell (Festinger, Schachter \& Back, 1950; see the Introductory Chapter for a more detailed description of this study). The essential components were 1) using already existing units of space and 2) not focussing on precise measurements.

The unit distance was designed to be a functional relative distance based on the decision-making process of the passenger. As the passenger's decision was based on seat selection, the primary distance unit was measured by the number of seats of separation. So distance to the nearest passenger was increased by one for: each seat across (horizontal direction on the template); going across the aisle (horizontal direction); each row of separation (vertical direction); each row gap across a door (vertical direction).

The exception to this was that one was not added for the immediately adjacent seat, so a score of zero was given if a passenger sat beside someone else (i.e. touching distance to the nearest passenger). Similarly, a distance score of zero was given to other seat combinations that placed passengers in touch distance included facing seats, or seats that met at 90 degree angles (where the legs of passengers would have to be manoeuvred to avoid touching).

Even though interpersonal distance was dynamic, based on the changing pattern of passengers as the trip progressed, this distance measure was static. This is because the focus of the distance measure was related to seat selection decision-making. After initial seat selection the only choice left to the passenger was to make that space less appealing to potential intruders or shift to another seat, and these choices were also measured. Consequently, the distance measure did not represent the overall trip and the proportion of passengers at a distance of zero (immediately adjacent or at touch distance) was likely an underestimate, and the average interpersonal distance was an overestimate of the circumstances of the overall trip. 


\section{Couples}

Couples were identified as those passengers that entered together (i.e. they were labelled with consecutive sequential numbers), and sat immediately adjacent to each other. This meant that people that arrived together and sat across the aisle from each other were not counted as couples, even if they talked to each other. Similarly, passengers that boarded the bus at different stops but sat together and talked together were not included as couples either. The couple measure was intentionally conservative to ensure that there was likely to be a greater level of relationship between these passengers. The couple group size was selected to keep the measure simple, as most seats were bench seats designed for two passengers.

\section{Subtle measures}

The frequency of more subtle behaviours were not measured in this study, such as body contact (accidental or intended), eye contact (acknowledgment of another passenger or gaze avoidance), and curt verbal responses or greetings. Attempts to record frequencies of some of the more subtle behaviours were discarded, as they were difficult to accurately measure. For example, frequency of passengers thanking the staff or waving goodbye to the staff as they departed were discarded as behavioural measures. These measures would have required closer observer proximity for accurate measurement, and even then accuracy would not be assured. Previous research where the sole focus was recording data on greeting and farewell frequencies on buses reported variable (between $67 \%$ and $100 \%$ agreement) inter-rater reliability (Edwards \& Johnston, 1977).

Intentional defensive manoeuvres to save a seat for someone were not differentiated from defensive manoeuvres to discourage anyone from sitting in the immediately adjacent seat. In fact, objects placed on the immediately adjacent seat were often removed as the carriage or bus became more crowded and it was apparent that there would be more passengers than seats. These removals were not measured due to the difficulty of knowing at what time they were removed. 


\section{RESULTS}

\section{Missing data and inter-rater reliability}

The variables had very low levels of missing data (ranging from $0-2 \%$ missing cases) with the exception of trip duration, which had the highest level of missing data with 386 missing cases (13\% missing cases). This was because time was not collected for the data collection on the first day.

Two buses and two trains were examined using two observers to test inter-rater reliability $(N=31)$. Cohen's Kappa and percent agreement findings show that the observational measures were at acceptable levels of agreement, except for the Bag on seat variable, which was just below the acceptable threshold (Kappa values above 0.80 are acceptable in most situations; Lombard, Snyder-Duch \& Bracken, 2008). This was most likely because the backs of seats interfere with the view of observers.

Table 2.2.

Inter-rater Reliabilities for Passenger Behaviours, Individual Variables and Seating Patterns

\begin{tabular}{lllcc}
\hline Variable & & Kappa & \% agreement & Sig \\
\hline Passenger behaviour & Activity & 0.77 & 85 & $* * *$ \\
& Bag on seat & 0.39 & 77 & $*$ \\
& Verbal & 1.00 & 100 & $* * *$ \\
Individual variables & Gender & 1.00 & 100 & $* * *$ \\
& Age & 1.00 & 100 & $* * *$ \\
& Sequential passenger & 1.00 & 100 & $* * *$ \\
& number & & & $* *^{*}$ \\
& $\begin{array}{l}\text { Row } \\
\text { Side of vehicle (left or }\end{array}$ & 1.00 & 100 & $* * *$ \\
& right) & & &
\end{tabular}

\section{Bus and train differences}

There were significant differences between bus and train travel modes, such that the train was less full, had lower passenger totals, lower capacity for passengers, longer trip durations and larger interpersonal distances between passengers (see Table 2.3 for more detailed descriptives). It is important to note that mean percent 
fullness and mean passenger totals do not reflect the maximum fullness of each trip, merely an average.

Table 2.3.

Means, Standard Deviations and Significant Differences between Bus and Train Travel Characteristics

Bus Train

\begin{tabular}{llllllc} 
Characteristic & $\mathrm{N}$ & \multicolumn{2}{c}{$\mathrm{M}$} & \multicolumn{2}{c}{$\mathrm{M}$} & Sig \\
\hline Percent full (\%) & 1703 & 36.52 & $(26.27)$ & 33.64 & $(23.03)$ & $*$ \\
Passenger total & 1703 & 14.28 & $(10.13)$ & 12.18 & $(8.97)$ & $* * *$ \\
$\begin{array}{l}\text { Number of seats } \\
\text { (capacity) }\end{array}$ & 1703 & 39.65 & $(5.36)$ & 35.79 & $(4.52)$ & $* * *$ \\
$\begin{array}{l}\text { Trip duration (mins) } \\
\text { Trip time of day }\end{array}$ & 1317 & 15.79 & $(10.27)$ & 20.85 & $(13.88)$ & $* * *$ \\
(hours:mins) & 1703 & $10: 47$ & $(2: 54)$ & $11: 41$ & $(3: 34)$ & $* * *$ \\
Interpersonal distance & 1639 & 1.56 & $(1.89)$ & 1.77 & $(1.80)$ & $*$ \\
\hline
\end{tabular}

Note: Standard deviation is in parentheses $*=\mathrm{p}<.05 ; * * \mathrm{p}<.01 ; * * * \mathrm{p}<.001$

\section{Seating patterns}

Passengers would typically select empty bench seats when possible. There was a positive relationship between the sequential order someone boarded the bus or train and whether that person sat in an aisle seat $(r(1677)=0.23, p<.001)$. Passengers typically chose window seats away from other passengers.

There was a low positive relationship between duration and distance amongst the train passengers $(r(460)=0.20, p<.01)$, suggesting that passengers that entered the vehicle first had a better chance to sit by themselves, and chose to do so. Figure 2.4 shows an actual example of how passengers chose to maximise the distance between themselves and other passengers when the choice was available.

Passengers also tended to favour the left side of the vehicle earlier in the sequential order, when they had greater opportunity to select their seat $(r(1684)=0.10, p<$ .001). In New Zealand the traffic travels on the left side of the road, so all exits, upcoming stops, and arguably the least obstructed views (by other traffic), were on the left side of the vehicle. 


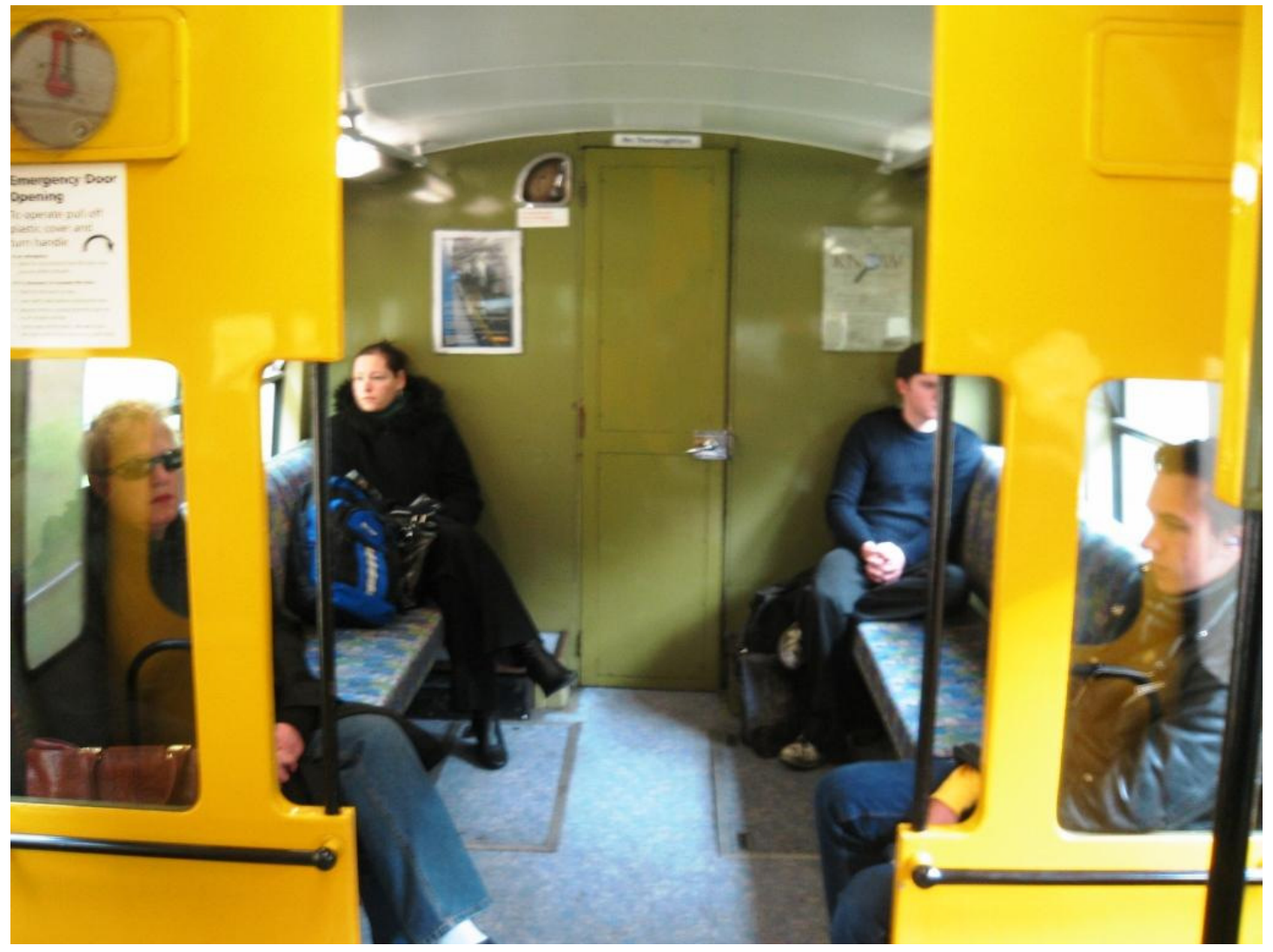

Figure 2.4. Passengers sitting apart in a train carriage.

As expected, the chance that no one sat adjacent reduced as sequential order increased. All passenger adaptations also reduced as sequential order increased. Physical defence of the space, as measured by aisle defence and placing a bag or other object or body part on the adjacent seat reduced as sequential order increased. Similarly, the likelihood of engaging in an activity reduced, as did the likelihood of verbal behaviour with the immediately adjacent passenger.

If these behaviours were performed primarily to reduce social discomfort from other close passengers, then you would expect the opposite, with an increase in adaptation. It may be that observations of adaptations were under-reported under more crowded conditions, where the observer had less time to observe each passenger.

When participants sat beside another passenger, about two thirds of participants sat beside someone of the same gender, indicating a preference for similarity. Males were 2.4 times more likely to sit beside other males than other females $\left(\chi^{2}\right.$ $(1, N=382)=16.46, p<.001$; see Table 2.4). This finding holds when controlling 
for couples. Most participants (78\%) sat beside passengers that were not engaged in defensive behaviour (i.e. activities, aisle defence and object placement).

Table 2.4.

Counts and Adjusted Residuals for Gender by Adjacent Gender.

\begin{tabular}{llrr}
\hline & & \multicolumn{2}{c}{ Gender } \\
Adjacent passenger gender & & Male & Female \\
\hline Same gender & Count & 79 & 162 \\
& Expected Count & 97.8 & 143.2 \\
Opposite gender & Adjusted Residual & -4.1 & 4.1 \\
& Count & 76 & 65 \\
& Expected Count & 57.2 & 83.8 \\
& Adjusted Residual & 4.1 & -4.1 \\
\hline
\end{tabular}

\section{Standing passengers}

The motivation to stand was typically based on a lack of seats, but there were exceptions to this. For example, two separate passengers chose to stand to talk to their bus drivers. Two other passengers that were wearing school uniforms chose to stand as the bus became more crowded (there are signs in place on many buses in New Zealand asking students that are getting discounted travel to stand for full fare passengers).

Standing passengers were typically beside exits (particularly when they had the option, that is, when the aisle was not crowded), so you could assume that standing passengers were exit-oriented. The average time spent standing was 8.82 mins ( $S D$ $=3.97$ ), which was significantly lower than the average time spent sitting of 17.85 mins $(S D=12.06 ; t(20)=8.85, p<.01)$.

Train carriages that had more sideways facing long bench seats (that had space for up to seven passengers on each bench seat - as opposed to the typical allocated space for two passengers) were less likely to fill all of their seats, and consequently often had standing passengers. 


\section{Shifting seats}

Fifty eight passengers shifted either from standing to sitting or moved to a different seat during the trip. It was difficult to understand the motivation for shifting seat based purely on observation, as there could be multiple reasons, many of which were within the scope of this study.

Overall, shifting seat did increase interpersonal distance, $t(57)=-2.34, p<.05$ (distance before, $M=0.98, S D=1.47$; distance after, $M=1.55, S D=1.86$ ). This was evidence that one motivation was to avoid close interpersonal distance with other passengers.

\section{Interpersonal passenger distance}

The average interpersonal passenger distance when passengers initially selected a seat using the seat separation technique was 1.63 seat units $(S D=1.86)$. Just over a quarter (28\%) of passengers selected a seat or stood immediately beside another passenger. Fifty-five percent of passengers sat with no other passenger immediately adjacent to them, a further $21 \%$ had another passenger sit beside them during the course of the trip, and $24 \%$ sat beside another passenger when they initially took a seat.

A stepwise linear regression was used to examine which factors influenced Interpersonal Distance (IPD) between passengers. The following 20 variables were included in the regression (entered in the following order): standing, gender, public transport type (bus or train), weather conditions (sunny, fine/cloudy, drizzle, rain), time of day, distance to nearest exit, sitting directly adjacent to another passenger, vehicle fullness, passenger activity, aisle defence, bag (or other object on seat), age group (baby, child, school uniform, other, elderly), second activity, window seat, shift seat, verbal behaviour, couple, air temperature (degrees Celsius), relative humidity, seat direction. Duration was removed from the model, as it was not a significant contributing factor and it reduced sample size. The stepwise criterion for entry into the model was a $p$ value of .05 and the criterion for exclusion from the model was a $p$ value of .10 . 
The independent variables in the model explained significant variation in the Interpersonal Distance of passengers $(F(8,1595)=119.61, p<.001)$. The final model has a Multiple-R of 0.61 and an adjusted $\mathrm{R}^{2}$ of 0.37 indicating that $37 \%$ of the variance in Interpersonal Passenger Distance was explained by the model (see Table 2.5).

Intuitively, a passenger's initial interpersonal distance reduced as more passengers boarded the vehicle. In terms of adaptive behaviour, higher interpersonal distance scores are likely to be maintained when passengers have made an effort to move away from the nearest exit, have physically defended their space (aisle sitting and bag/other device placement), or chosen a window seat. Whereas verbal behaviour is more closely associated with low interpersonal distance scores.

Table 2.5.

Stepwise Linear Regression of Interpersonal Passenger Distance by Key Observational Variables

\begin{tabular}{lccccccc}
\hline & & & & & & \multicolumn{2}{c}{ Correlation } \\
\cline { 7 - 8 } & B & SE & Beta & $t$ & Sig. & Partial & Part \\
\hline Window seat & 0.87 & 0.12 & 0.21 & 7.47 & 0.001 & 0.18 & 0.15 \\
Aisle defence & 0.85 & 0.17 & 0.13 & 5.11 & 0.001 & 0.13 & 0.10 \\
Bag on seat & 0.47 & 0.10 & 0.10 & 4.72 & 0.001 & 0.12 & 0.09 \\
$\begin{array}{l}\text { Stand } \\
\text { Distance to }\end{array}$ & 1.09 & 0.26 & 0.10 & 4.11 & 0.001 & 0.10 & 0.08 \\
$\begin{array}{l}\text { exit } \\
\text { Adjacent }\end{array}$ & 0.06 & 0.02 & 0.05 & 2.61 & 0.009 & 0.07 & 0.05 \\
passenger & -0.23 & 0.10 & -0.06 & -2.28 & 0.023 & -0.06 & -0.05 \\
$\begin{array}{l}\text { Verbal } \\
\text { Vehicle }\end{array}$ & -0.43 & 0.10 & -0.10 & -4.21 & 0.001 & -0.10 & -0.08 \\
fullness & -3.41 & 0.19 & -0.46 & -18.21 & 0.001 & -0.41 & -0.36 \\
(Constant) & 2.06 & 0.16 & & 12.65 & 0.001 & & \\
\hline
\end{tabular}

\section{Overall adaptation}

Approximately 60\% $(n=1031)$ of passengers made some effort to adapt to the public transport setting by interacting with other passengers, withdrawing into an activity, sitting in the aisle seat, or placing an object or body part on the immediately adjacent seat. Of the passengers that adapted, 22\% $(n=227)$ engaged 
in two adaptations, $3 \%(n=34)$ engaged in three adaptations, and one passenger engaged in all four adaptations.

\section{Verbal behaviour}

About a quarter of passengers were observed with verbal behaviour while on the bus or train. None of the verbal behaviours observed showed any indication of negative connotations in terms of the volume, tone, or content.

The proportion of passengers participating in verbal behaviour reduces to $15 \%$ when you control for couples, as $82 \%$ of couples engaged in verbal behaviour (couples were described as those passengers that entered the vehicle consecutively and sat adjacent to each other). Many passengers sat across the aisle from each other and engaged in verbal behaviour, so the passenger count of couples $(n=230)$ is likely to be a conservative figure.

Just over half ( $55 \% ; n=932)$ of the passengers sat with no one directly adjacent to them, and of these only $5 \%(n=43)$ were verbal with others. Arguably passengers that were seated alone had reduced opportunity to verbally interact with other passengers. Just examining the passengers that were seated with someone else and were not in couples, 33\% ( $n=176)$ of these engaged in verbal behaviour (see Table 2.6).

When modelled in a forward conditional stepwise logistic regression (using the same key variables as in the stepwise linear regression for IPD above), observational data accounts for significant variation in the verbal behaviour of passengers $\left(X^{2}(12, N=1590)=782.11, p<.001\right)$. The Hosmer and Lemeshow test shows that the model adequately fits the data $\left(X^{2}(8, N=1590)=4.55, p=.80\right.$, $n s)$. The final model had a Nagelkirke $\mathrm{R}^{2}$ of 0.58 indicating that $58 \%$ of the variance in verbal behaviour was explained by the model (see Table 2.7).

Verbal behaviour intuitively relates to passenger proximity, which was confirmed by positive relationships between verbal behaviour and the presence of an adjacent passenger (and whether there was a bag on the adjacent seat), the passenger entering the vehicle as part of a couple, the fullness of the vehicle, and the distance 
to the nearest passenger when they selected their seat. Weather conditions also appeared to influence verbal behaviour, with wet weather increasing conversation and high relative humidity reducing conversation (relative humidity ranged from $39-100 \% ; M=79.33 \%, S D=15 \cdot 94 \%)$.

Table 2.6.

Verbal Behaviour by Passenger Situation

\begin{tabular}{cccccccc}
\hline & & \multicolumn{2}{c}{ Not verbal } & \multicolumn{2}{c}{ Verbal } & \multicolumn{2}{c}{ Total } \\
& & $n$ & $\%$ & $n$ & $\%$ & $n$ & $\%$ \\
\hline Passenger adjacent & Not couple & 360 & 67 & 176 & 33 & 536 & 31.5 \\
& Couple & 42 & 18 & 188 & 82 & 230 & 13.5 \\
Passenger alone (no one adjacent) & 889 & $95 \%$ & 43 & $5 \%$ & 932 & 55.0 \\
& Total & 1291 & 76 & 407 & $24 \%$ & 1698 & 100 \\
\hline
\end{tabular}

Table 2.7.

Binary Logistic Regression of Verbal Behaviour by Key Observational Variables

\begin{tabular}{lrrrrrrr}
\hline & & & & & & \multicolumn{3}{c}{ Correlation } \\
\cline { 6 - 8 } & B & SE & Wald & Sig. & Exp (B) & Partial & \multicolumn{1}{c}{ Part } \\
\hline Standing & 3.01 & 0.68 & 19.51 & 0.001 & 20.31 & -0.03 & -0.02 \\
$\begin{array}{l}\text { Weather } \\
\text { conditions }\end{array}$ & 0.34 & 0.10 & 10.97 & 0.001 & 1.41 & 0.23 & 0.17 \\
$\begin{array}{l}\text { Adjacent to } \\
\text { another passenger }\end{array}$ & 3.16 & 0.24 & 176.75 & 0.001 & 23.50 & 0.47 & 0.39 \\
Vehicle fullness & -3.26 & 0.47 & 47.89 & 0.001 & 0.04 & -0.19 & -0.14 \\
Activity & -1.12 & 0.23 & 24.21 & 0.001 & 0.33 & -0.15 & -0.11 \\
Aisle defence & 0.83 & 0.32 & 6.76 & 0.009 & 2.30 & 0.03 & 0.02 \\
Bag & 0.57 & 0.26 & 4.70 & 0.030 & 1.76 & 0.15 & 0.11 \\
$\begin{array}{l}\text { Age group } \\
\text { Couple }\end{array}$ & -0.56 & 0.16 & 11.79 & 0.001 & 0.57 & 0.04 & 0.03 \\
$\begin{array}{l}\text { Relative humidity } \\
\text { Seat direction }\end{array}$ & -0.04 & 0.01 & 34.63 & 0.001 & 0.96 & -0.11 & -0.08 \\
(forward) & -0.42 & 0.20 & 4.69 & 0.030 & 0.65 & -0.05 & -0.04 \\
$\begin{array}{l}\text { Distance } \\
\text { (Constant) }\end{array}$ & -0.20 & 0.06 & 10.43 & 0.001 & 0.81 & -0.14 & -0.10 \\
\hline L & 2.60 & 0.86 & 9.18 & 0.002 & 13.43 & & \\
\hline
\end{tabular}

Log Likelihood $=968.95$ 
Passengers engaged in activities, such as reading or listening to music, were 3.4 times less likely to engage in verbal behaviours $\left(\chi^{2}(1, N=1703)=56.65, p<.001\right)$. Other passengers would have had to interrupt an activity to converse with these passengers, which could have been deemed rude. Standing increased verbal behaviour, perhaps because of the close proximity to other passengers when standing.

Older age group reduced conversation (but the age categories were not evenly spread, so any age findings should be examined with caution). Closer examination revealed that children and passengers wearing school uniforms and the elderly were more likely to engage in conversation, and other adults were less likely to engage in conversation $\left(\chi^{2}(4, N=1703)=84.32, p<.001\right)$. This was evidence of homogeneity, where children, school goers and the elderly have similarities in their lifestyle that encourage the verbal behaviour necessary for relationship formation.

Tourists were another example that showed evidence that people with common interests were more likely to engage in verbal behaviour. People travelling on the inner city circular bus which travelled past common tourist destinations (e.g. museums) were 13.1 times more likely to use verbal behaviour when compared with the other public transport services examined $\left(\chi^{2}(1, N=1703)=58.78, p<\right.$ .001). These passengers were less likely to be rushed by deadlines, such as being late for work, they would view the trip as a social occasion, and they had some commonality of purpose (i.e. exploring the city with limited knowledge of the layout).

The only counter-intuitive finding was that aisle defence increased verbal behaviour, but this could be explained by passengers sitting in the aisle seats and talking across the aisle. Passengers engaged in aisle defence were no more likely to stretch out their bodies than any other passengers $\left(\chi^{2}(1, N=1703)=0.39, p=.53\right.$, $n s$ ), demonstrating they did not chose the aisle seat simply to increase physical comfort. Similarly, there was no relationship between aisle defence and distance to the nearest exit $(r(N=1674)=-0.05, p=.07, n s)$, so it was unlikely that passengers chose the aisle seat to exit the vehicle more quickly. 


\section{Activities}

A quarter of passengers engaged in activities (see Table 2.8). The most popular activities were reading or writing (44\%; with a further $6 \%$ with their head down likely to be reading) and listening to music (35\%). The third most popular activity was writing text messages on cell phones, and less popular activities included cell phone calls, sleeping, knitting and using a laptop.

Table 2.8.

Activity Frequency by Activity Type

\begin{tabular}{lrr}
\hline Activity & \multicolumn{2}{c}{$\%$} \\
\hline Reading/Writing & 190 & 43.8 \\
Music & 151 & 34.8 \\
Phone texting & 41 & 9.4 \\
Head down (likely to be & 25 & 5.8 \\
reading) & & \\
Phone call & 12 & 2.8 \\
Sleeping & 12 & 2.8 \\
Laptop & 2 & 0.5 \\
Knitting & 1 & 0.2 \\
Total & 434 & 100 \\
\hline
\end{tabular}

A forward conditional stepwise logistic regression (using the same key variables as in the stepwise linear regression for IPD above, except for second activity) was used to model which observed variables accounted for significant variation in whether passengers engage in activities $\left(X^{2}(9, N=1590)=296.81, p<.001\right)$. The Hosmer and Lemeshow test shows that the model adequately fits the data ( $X^{2}(8$, $N=1590)=6.97, p=.54, n s)$. The final model had a Nagelkirke $\mathrm{R}^{2}$ of 0.25 indicating that $25 \%$ of the variance in activity engagement was explained by the model (see Table 2.9).

Situational withdrawal into activities was more likely to occur on the train, in lower temperatures, when there was an adjacent passenger, when passengers were able to sit in a window seat, place a bag beside them, and sit closer to the rear of the vehicle. Couples were less likely to use activities (odds ratio $=3.4, \mathrm{CI}=0.17$ $0.48, p<.001$ ) when compared with other paired passengers that did not arrive and sit together. 
Table 2.9.

Binary Logistic Regression of Activity by Key Observational Variables

\begin{tabular}{lccccccc}
\hline & & & & & \multicolumn{3}{c}{ Correlation } \\
\cline { 6 - 8 } & B & SE & Beta & Sig. & Exp (B) & Partial & Part \\
\hline Gender & -0.55 & 0.13 & 18.38 & 0.001 & 0.58 & -0.11 & -0.10 \\
$\begin{array}{l}\text { Public transport } \\
\text { type (1 = Bus, 2 }=\end{array}$ & 1.46 & 0.13 & 122.06 & 0.001 & 4.32 & 0.29 & 0.28 \\
$\begin{array}{l}\text { Train) } \\
\text { Exit distance }\end{array}$ & & & & & & & \\
Passenger adjacent & 0.11 & 0.04 & 7.81 & 0.005 & 1.12 & 0.07 & 0.07 \\
Verbal & 0.16 & 4.33 & 0.037 & 1.39 & 0.04 & 0.04 \\
Bag & -1.17 & 0.22 & 29.05 & 0.001 & 0.31 & -0.13 & -0.12 \\
Window & 0.45 & 0.15 & 8.60 & 0.003 & 1.57 & 0.09 & 0.08 \\
Couple & 0.64 & 0.16 & 15.73 & 0.001 & 1.91 & -0.09 & -0.09 \\
Temperature & -0.73 & 0.28 & 6.79 & 0.009 & 0.48 & -0.04 & -0.04 \\
(Constant) & -0.07 & 0.03 & 6.82 & 0.009 & 0.93 & -0.06 & -0.06 \\
\hline L & -2.47 & 0.38 & 42.13 & 0.001 & 0.08 & & \\
\hline
\end{tabular}

Log Likelihood $=1539.18$

\section{Physical defence of space}

About a quarter of passengers physically defended their space, with about 3\% of these passengers engaging in both aisle defence (sitting in the aisle seat when the immediately adjacent seat was empty) and placing an object on the immediately adjacent seat. The object was typically a bag or item of clothing being placed on the adjacent seat $(n=277$ ), but this also included people simply spreading out by sitting in the middle of the two seats $(n=8)$, placing a leg or arm on the adjacent seat $(n=38)$, or even partially blocking the aisle with a body part (such as a fully extended leg, $n=4)$. Overall, the use of an object or part of a body was about twice as common (19\%, $\mathrm{n}=327)$ as aisle defence $(10 \%, \mathrm{n}=161)$. Couples were less likely to use physical defence (odds ratio $=3.2, \mathrm{CI}=0.14-0.70, p<.01$ ) when compared with other paired passengers that did not arrive and sit together.

\section{Bus driver interaction}

Bus driver friendliness or politeness varied as well, one driver whistled the entire journey. Some drivers had short conversations with their regular passengers as they entered the bus, or notified non-regular passengers when it was their stop. Negative interactions were observed as well, including chastising passengers about 
not having the correct change, or not apologising when they accidently closed the door on a passenger as they entered (partially trapping the person in the door).

Passenger interaction with the driver also included positive interactions, such as "you have a good day", as well as negative interactions (typically relating to timeliness), such as "why are you so late". The proportion of passengers that thanked the driver on buses as they departed seemed higher when the bus was less crowded. Also, if the passenger thanked the driver the next departing passenger was more likely to thank the driver as well.

\section{Additional observations}

The additional findings that follow may only be singular occurrences of salient events, but they highlight some of the many factors that may negatively impact on the public transport trip, including road safety, personal safety, "odd" passenger behaviour, and a bland environment.

Some driving routes were more difficult to drive, with curvy roads around hills, where passenger feelings of road safety may have differed. For example, in one incidence where a driver had to brake on a narrow road a passenger could be heard to exclaim "oh my god, we're gonna die".

The amount of graffiti varied across buses and carriages, such that graffiti was particularly prevalent down the rear end of buses. Presumably this was because there was less monitoring of this location, as the driver is further away and occupied by driving or passengers entering or departing.

Some "odd" passenger behaviour was observed during the course of the study. For example, one passenger was playing a transistor radio loudly, bobbing his head, clapping and singing.

The public transport vehicle environment was typically vacuous, with little visual or audio stimulus to engage the passengers. The typical visual stimulus was a sparse selection of posters which contained information about public transport announcements, safety warnings (such as "Please stand away from doors"), and 
public transport rules (such as "School children must give up their seats to adult passengers" or "Please fold up pushchairs so they do not block up the aisle"). There was also some limited advertising for local events.

In terms of auditory stimuli, two of the observed buses played music from a local radio station using speakers in the front and rear of the vehicle. The use of music on these services reduced the relative frequency of verbal behaviour $\left(\chi^{2}(1, N=\right.$ $1703)=3.84, p=.05)$. Passengers on public transport services without music were 1.8 times more likely converse, although the number of passengers exposed to music was small $(\mathrm{n}=86)$. Other noises were typically caused by the vehicle, which in some of the older vehicles was quite loud due to rattling doors and windows.

\section{DISCUSSION}

People do adapt to the public transport environment by spreading out and taking up space, withdrawing into an activity or conversing with other passengers. Only $40 \%$ of passengers simply sit there engaging in none of these adaptations, and most of these only on very short trips. Some of these adaptations indicate effort to avoid social discomfort due to close interpersonal distances.

Proxy evidence of social discomfort due to close interpersonal distances is provided by the extra effort of some passengers to travel further from the exit to select their seat, to shift to a seat with greater distance to the nearest passenger, and to defend the immediately adjacent seat by aisle sitting or spreading out either body parts or objects. All of these techniques succeed in increasing interpersonal distance.

Participants that shifted seats typically increased their distance to the nearest passenger. This was arguably the strongest evidence of discomfort due to close proximity with other passengers, as it not only required a physical shift, but moving in front of the other passengers. The shifting passenger typically moves away from a paired seat with another passenger, which could be viewed as a social rejection of that passenger. 
Passengers also travelled further from the door to increase their interpersonal distance. The additional IPD provided by the increased effort supports Sommer and Becker's (1969) findings regarding the avoidance of the other users of the space. Sommer and Becker (1969) examined seat selection decision-making processes in a library setting under retreat and active defence conditions. Under the retreat condition, where participants were asked where they would sit if they wanted to be as far away as possible from other people, participants typically chose the end chair closest to the wall away from the exit (Sommer \& Becker, 1969). The authors suggested that a greater distance from the door reduces the chance of people walking or intruding into their space, as people are typically "lazy intruders", and all things being equal, are more likely to sit in the first available chair.

About a fifth of passengers used aisle defence to physically protect their space. There is no relationship between aisle defence and row distance to the closest exit, indicating that aisle defence is not commonly used as part of a quick exit strategy. Similarly, sitting in the aisle seat is unlikely to provide any more physical comfort, as these passengers did not chose to spread out any more than those in the window seats. Therefore, it seems clear that passengers do sit in the aisle seat to defend the immediately adjacent seat, which is supported by fact that passengers with this behaviour also have higher interpersonal distance scores.

An additional motivation to select the aisle seat is to maintain a more comfortable distance while conversing. That people choose to select aisle seats and talk across the aisle implies that the typical vehicle seating layout of paired, forward-facing seats forces passengers into an intimate distance with the adjacent passenger that is not ideal for conversation. Sideways facing seats and grouped seats where there is a perpendicular seating arrangement or a forward facing and reverse facing group of paired seats (where passengers are opposite and directly facing each other) are more conducive to conversation compared with the typical forward facing seats. This supports previous findings that L-shaped seating induces greater frequency of verbal behaviour (Maines, 1979).

These alternative seating arrangements are more prevalent in the train settings, but there is no consequent increase in verbal behaviour on the train, which is 
contrary to Maines (1979) findings. Additionally, any change to seating patterns must be balanced against considerations of physical comfort, as there is evidence that alternative seating arrangements such as reverse seating can cause nausea (Han, Jung, Jung et al., 1998). Han et al. (1998) found that the preference value for forward facing seats was about nine times greater than that of reverse facing seats.

While the motivation behind the physical defence of space through aisle sitting is clear, placing an object, such as a bag, on the adjacent seat could arguably have mixed motivations. Placing a bag on the adjacent seat may be more physically comfortable than placing it on your lap or by your feet, where there is limited leg room. Alternatively, the primary motivation may be to prevent another passenger from sitting in that seat. There is evidence of the later in other settings, for example, library intrusion studies show that participants use books and other objects to form physical barriers between themselves and intruders (Felipe \& Sommer, 1966; Ajdukovic, 1988).

Regardless of motivation, the outcome is to increase interpersonal distance. The placement of artefacts on the adjacent seat clearly acts as a signal not to invade the space, with only $22 \%$ of passengers sitting beside someone engaged in defensive behaviour. Both aisle sitting and artefact placement have the consequent increase in interpersonal distance that holds even when controlling for the fullness of the vehicle. So passengers still engage in these physical occupations of space successfully even when the vehicle becomes more crowded. Even if this offensive ownership of space may be viewed as rude, as the passenger is taking up more space than they have paid for, it is a successful adaptation that does increase interpersonal distance. More subtle behavioural adaptations, where motivation is less clear, may not be as successful at increasing interpersonal distance.

Withdrawal into an activity such as reading or listening to music does not relate to IPD. Perhaps this is because passengers may simply participate in activities to fill time or because they enjoy the activity (e.g. Han et al., 1998). However, activities did reduce verbal behaviour (3.4 times less likely), so perhaps passengers performed activities so they could ignore the presence of the immediately adjacent passenger. It is unclear whether this tactic would successfully reduce social 
discomfort, though there is evidence that reading and verbal behaviour do not reduce discomfort in lab settings (Epstein, Teitelbaum, Karlin et al., 1981).

Sitting in the window seat can be viewed as another form of situational withdrawal, by distracting the crowded passenger with an eye-catching view. Passengers predominantly chose a window seat, which is likely to be related to convenience (as they do not want to have to shift from the aisle to the window seat when another passenger needs a seat), but may also relate to reducing social discomfort.

Baron et al. (1976) found that crowded living conditions were perceived as less cramped if part of their perceived territory incorporated a window. Therefore, there may be a reduction in the level of stress due to crowding if the passenger's space includes the window. Alternatively, temporary ownership of the window seat also means that the passenger does have a barrier to a hasty exit if another passenger sits in the aisle seat beside them.

Overall, the greatest level of adaptation opportunity occurs when the public transport vehicle is relatively empty, which provides the passenger with the space to spread out and engage in activities and clearly mark the double-seat as theirs. Singer et al. (1978) described the empty train (at the first stop) as somewhere that offered passengers their choice of seat and sitting partner, where they could arrange their belongings as they pleased to ensure greater control over their immediate environment. Their description of the environment for the group boarding mid-trip was quite different, where passengers were more constrained in these behaviours, and had a limited ability to comfort themselves (Singer et al., 1978). The greater level of adaptation in the initial riders is likely to relate to greater feelings of control.

Singer, Lundberg and Frankenhaeuser (1978) found that physiological stress levels were lower for passengers that were seated first, even though the duration of their trip was longer and the train became more crowded as they progressed to their destination. They explained this finding in relation to the additional control early riders had over their environment. Perception of control mediates the negative 
effects of crowding, for example, people feel less crowded in an elevator if they are in front of the control panel (Rodin, Solomon \& Metacif, 1978).

The only adaptive behaviour to have a negative relationship with interpersonal distance was verbal passenger behaviour. A quarter of passengers participated in verbal behaviour with fellow passengers, and this increased to $33 \%$ when examining the passengers that were seated with someone else and were not in couples. The assumption is made that all verbal interactions are viewed positively. While there will be exceptions to this, the volume, tone and content of observed conversations lend support to this assumption.

Talking about poor weather conditions is a perfect example of a conversation initiation technique. Similar techniques were observed by Zurcher (1979) in the context of aeroplane travel, particularly when the topic was relevant, such as querying or providing another passenger with travel information. Weather is not only a common conversation starter, it also relates to the implicit needs of public transport users to adapt to poor weather conditions, where other groups, such as car drivers may not have the same level of interest. Common interests are also used as social topics by other groups, for example, smokers have been found to talk about cigarette brands to fill in awkward conversation gaps (Fry et al., 2008).

Against expectation, the presence of music on the bus reduces conversation when compared with all other trips. In shopping contexts music has been successful in improving attitudes of customers, creating a better atmosphere and a more positive shopping experience (Ng, 2003). Even in high-density environments slowtempo music has a positive effect (Eroglu, Machleit \& Chebat, 2005). Under conditions where there is music there may be less pressure to fill awkward silences or lulls in conversation that can occur during small-talk. The perception that others are eavesdropping is reduced under conditions where there is music. Also, music can provide a conversation cue, as it is another environmental stimulus to which everyone is immersed. So in this way it differs from personal music devices in that it is not exclusive.

One explanation for why music had an apparent negative influence on verbal activity is that there is less need to fill the awkward silence by conversing when 
music is present. Davis and Levine (1967) offer the suggestion that people feel the need to converse to reduce the awkward silence inherent on public transport. The presence of music may reduce this awkwardness, and therefore create a more relaxed environment. Whatever the case, the sample exposed to music was only small, and when placed into the regression analysis the presence of music does not appear as a factor.

Social relationships form on the basis of commonality in lifestyle, occupation, gender and residence (Festinger et al., 1950), which suggests that people look for overt similarities in the people with which they interact. There were commonalities in lifestyle groups, such that the elderly, children, school goers and tourists were more likely to engage in conversation. It could be argued that selecting a passenger to sit beside that had common elements was likely to reduce social discomfort.

Different cultures, genders and age groups have different spatial arrangement expectations which can lead to greater anxiety when these are not met (Baxter, 1970). Searching for homogeneity in a seating partner is one way to manage this problem, as your expectations will be similar, and although there is only limited space on public transport, any available adaptations (such as placing your arms in front of you to avoid touch) are likely to be mirrored by your seating partner. American subway studies found that there was a preference to sit beside someone of the same gender and ethnicity (Fried \& DeFazio, 1974; Maines, 1977).

The findings here show that females prefer to sit beside other females; however, males also prefer to sit with other females. The research generally suggests that the male-with-male pairing would be least comfortable, as they are typically less tolerant of close interpersonal distances (e.g. Aiello, 1987). In a review of personal space literature, Hayduk (1983) did not make any conclusive findings regarding gender differences and personal space preference, although males do appear to take up more space than females, there are a number of confounding variables (e.g. age, body size or level of acquaintance).

Ickes and Barnes (1977) found that gender findings are indicative of larger body types rather than a preference for larger interpersonal distances. Placed back into a public transport context, the larger body size of males is likely to increase the 
likelihood of physical touch, so one would expect that passengers would choose smaller body types to sit beside, which does explain why females are the preferred seating partner.

The types of people that were more likely to engage in conversation did display similarities in terms of age group. Likewise, tourist groups participate in more verbal behaviour, at least in part due to similarities. Davis and Levine (1967) made the observation that when passengers are not "exit" oriented, but instead focus on the enjoyment of the journey (such as tourists do), more passenger interaction occurs.

Other influences on passenger interaction and trip enjoyment may have stemmed from the general ambience of the vehicle. Descriptive observations of the bus and train suggested that bus driver interactions, the presence of graffiti, and the lack of stimulus in the environment may impact on the latent environmental atmosphere. While these findings should be treated with caution, they still present relevant issues and potential barriers to an enjoyable public transport experience.

Members of staff have the ability to influence the mood of the vehicle. In focus groups discussions participants talked about a much more positive feel to the environment when they were greeted by friendly staff (Guiver, 2007). Edwards and Johnston (1977) also demonstrated how positive greetings and farewells from the driver had reciprocating effects on passenger greetings and farewells, which had concomitant benefits in the form of improved ratings of driver friendliness, ride experience, and ride quality (but this did not extend to the improved rating of other passengers).

The presence of graffiti exists on public transport facilities can be used as an indicator of anti-social behaviour on public transport, which has consequent impacts on the feelings of personal safety of passengers. Miles (2008) used graffiti, litter and lack of greenery as proxy measures for the perceived safety of the neighbourhood environment, and found that the presence of graffiti and litter and a lack of greenery reduced the likelihood that parents would encourage their children to use the local playground. Graffiti was particularly prevalent at the rear of the bus where there was a lower level of surveillance by the driver and other 
passengers. Ley and Cybriwsky (1974) also found that settings with low surveillance and low territorial control were more conducive to deviant behaviour in the form of the abandonment, stripping and vandalism of cars.

Davis and Levine (1967) point out that there is a paucity of diversions on public transport, which is supported by the vacuous environments observed in the train and bus settings in Wellington, New Zealand. Contemporary design is charged with the challenge of delivering an "enlivening experience" (Alben, 1997). While design considerations have progressed to account for the activities of users (such as reading and listening to music), public transport vehicles do not typically go beyond anthropometric needs (Jung et al., 1998).

\section{IPD Method}

Evans and Wener (2007, p.93) call for "more fine tuned indices of density that more fully capture the actual experience of physical proximity to other people may prove more potent in predicting health and behavioral outcomes of crowding." The simple observational measure of interpersonal distance developed and used in this study allows a more accurate measure of passenger proximity without requiring actual measurement.

The concept of functional distance units has already been utilised in previous experiments (e.g. Festinger et al., 1950), but does not appear to have found a foothold in contemporary research methodology. It allows for the easy measurement by observers without sophisticated surveillance equipment. Such equipment allows for more precise measurement, but usually comes with issues such as privacy, a reduction in unobtrusive measurement (which can interfere with naturalistic behaviour), and an increase in the time and resources required. Easier observational methods mean that even if the primary interest of the research isn't proxemics, IPD can be used as an additional indicator of the successfulness of the space.

Many studies focussed on infrastructural ergonomics would benefit from utilising interpersonal distance data, especially where the goal of the design is to encourage or discourage interpersonal interaction, such as inner city outdoor spaces, offices, 
residential apartments or even buses or train carriages. With an increasing trend towards dense cities people are over-stimulated and adapt by reducing their interpersonal interactions (Milgram, 1970). To improve the design of urban spaces and transport systems requires knowledge of how people actually interact in different environments under different social contexts.

The method could be further refined by taking into account the direction of the nearest passenger. This is likely to relate to the ability to assess someone as a threat if you can see them. Consequently, it is possible that the observational measure of IPD could be further improved by weighting passengers seated immediately behind more closely. A simple alteration to the method could include a zero distance score if there was a passenger sitting directly behind them. This would break the rule of thumb that a score of zero was given only if passengers were in touch distance. The seat back acts as a naturally occurring barrier between passengers and so removes them from touch distance. A physiological study could examine the variation in stress levels dependent on where the passenger sat, but this was outside the scope of this research.

\section{Limitations}

Establishing a clear link to causality when examining spatial behaviour decisionmaking is difficult, particularly from observational information alone, as there is no control over confounding variables such as the history of intimacy shared by individuals (e.g. see Kenner \& Katsimaglis, 1993).

A further limitation is that the observational measures were taken over a large catchment area to encompass the most behavioural interaction across the group of passengers. This meant that the more subtle behavioural indicators such as smiling, eye contact, or body turn were not measured. Due to the limited attentional resources of an observer, other measures were simply not taken, including body size and ethnicity.

More subtle measures could be taken through the use of video footage analysis over a more limited catchment area. Similarly, verbal behaviour could be measured through the use of audio equipment, where the audio frequency of the 
human voice could be separated from other noise, providing a pure measure of volume to indicate level of social interaction (D. Walton, personal communication, March 20, 2006).

Physiological measures of stress, such as galvanic skin response (Epstein et al., 1981), adrenaline excretion (Singer et al., 1978), or salivary cortisol (Evans \& Wener, 2007) were not taken, as the study was designed to be unobtrusive. These measures would have quantified the success of any adaptations in reducing stress.

\section{CONCLUSION}

People do adapt to their environments. In the public transport setting $60 \%$ of participants used a variety of behavioural responses. While the motivation behind some of the behaviours is difficult to reveal with simple observations, other responses do act as proxy measures of interpersonal discomfort, as they indicate avoidance of close proximity with other passengers. Avoiding close proximity to other passengers is achieved by initially selecting or shifting to a more isolated seat, further away from the nearest door, and protecting the immediately adjacent seat by sitting in the aisle seat or using artefacts (such as bags).

The bus and train settings are far from socially stagnant. Despite a stimulus-free environment, with a seating layout that seemingly affords defensive behaviours and raises barriers to positive social interaction, a quarter of passengers still participate in conversation. The current design is contestable under these circumstances, as at least a quarter of the passengers are not afforded with an environment that is conducive to their requirements. 


\section{CHAPTER 3: EXPLORATORY QUESTIONNAIRE}

The previous chapter examined observed behaviour on buses and trains, specifically focused on chronological seat selection strategies and easily observed defensive behaviours and social interactions, finding that at least $60 \%$ of passengers adapt to the conditions. The underlying motivation for the adaptation and the effect the adaptation has on other passengers is largely unknown. This exploratory study examines the influence of individual personality characteristics on public transport use and interpersonal behavioural adaptations. Photographic analysis of different adaptations also allows for inspection of any consequent effects these behaviours are likely to have on other passengers.

\section{Introduction}

Public transport users form an "encapsulated group” where individuals share physical but not necessarily social closeness (Zurcher, 1979). Hall's (1966) proxemic theory shows how travelling on public transport routinely forces strangers into an intimate social distance (o-6 inches apart), a distance typically reserved for people with strong personal relationships. Subway passengers use defence mechanisms to take the intimacy out of their socially awkward situation; averting their eyes, tensing their muscles to remain immobile, and avoiding touch (Hall, 1966; Maines, 1977). The need for a typical passenger to avoid bodily contact suggests that people with a particular predilection for touch avoidance would likely suffer greater anxiety in this situation, and have a cause to avoid public transport.

Little is known about which individual characteristics are likely to influence the use of defensive behaviour or how these behaviours affect other passengers. In the airplane setting, Hai, Khairullah and Coulmas (1982) observed that the arm rest is a shared resource that can act either as an extension of territory or an intrusion into territory, and as such is a potential cause of conflict. Hai et al. (1982) found that males were more likely to monopolise the armrest on airplanes (even when controlling for body size), and that inability to use the armrest when there was an expectation of use resulted in anger. This study illustrates how individual differences (in this case gender) influence the use of territorial behaviour, and also 
how the use of defensive behaviour has a subsequent negative effect on the adjacent "invaded" passenger.

This research aims to examine whether individual personality characteristics are likely to influence defensive and interactive behaviours, and to examine how these compensatory behaviours are perceived by other passengers. A further goal is to explore the usefulness of different measures of discomfort, and to examine discomfort on the bus and train relative to other settings.

Crowded subways and elevators are often raised as extreme examples of interpersonal distance (IPD) discomfort, but there is little empirical evidence showing where crowded public transport ranks in terms of perceived discomfort and anxiety relative to other settings. McCleland and Auslander (1978) examined the antecedents of perceived crowding by asking participants to rate their perception of the level of crowding and pleasantness for 137 slides examining 20 settings under different conditions (such as different densities of people, IPDs, and levels of lighting). In addition to finding that IPD influenced perception of crowding, social (as opposed to work) environments were seen to have a reduced perception of crowding and were the best predictor of pleasantness. Social environments (e.g. watching a live sports event) were rated as more pleasant and less crowded than neutral environments (e.g. bus stops) which were more pleasant and less crowded than work environments (e.g. studying at the library or grocery shopping). It is difficult to say from McCleland and Auslander's (1978) categories whether riding a bus or train fits into a neutral environment or a work environment.

There is a preference for the maintenance of higher IPDs in high anxiety settings (Long, 1984). A selection of 18 settings was rated for anxiety by a group of 50 students to determine the top four high and the top four low anxiety settings. A sample of five female and five male subjects were then approached in the four highest anxiety settings (such as a dentist's waiting room) and the four lowest anxiety settings (such as a shared television lounge area). Long (1984) measured self-reported anxiety and preferred IPD (using a stop-distance technique where the subject indicated the distance at which they would prefer an approaching person to 
stop) and found that the level of situational setting anxiety was a better predictor of IPD than the self-reported anxiety level.

Long, Calhoun and Selby (1977) also used high and low anxiety settings to examine the consistency of personality characteristic influences on seating distance preferences at tables. They found that neuroticism consistently predicted a preference for higher IPDs across the settings. Touch-avoidant individuals may also be more sensitive to close proximities or even avoid public transport. In his proxemic theory Hall (1966) posits that touch-based cultures (i.e. cultures that use touch more often as a communication tool) are more comfortable with close IPDs.

Katsikitis and Brebner (1980) found evidence that personality characteristics influence task performance under differing IPD conditions. People with extroverted personalities were better at simple tasks (single letter elimination task, search and delete the letter ' $a$ ') but worse at complex tasks (a four letter elimination task, deleting the letters ' $w$ ' 'm' ' $n$ ' and 'c'; Katsikitis \& Brebner, 1980). They also found an interaction effect for level of crowding which meant that the complex task error rate for extroverts was exacerbated under crowded conditions, where participants were so close they made physical contact with other participants (Katsikitis \& Brebner, 1980). When applied to a public transport setting, the level of physiological arousal caused by close interpersonal distance is likely to interfere with different tasks, and may increase stress and reduce patronage for certain personality types. For example, an extroverted train commuter attempting to read a complicated book or finish a difficult crossword is likely to be impaired under train conditions where they are within touch distance to the nearest passenger.

In addition to the examination of personality differences under close IPDs, this research aims to explore different measures of IPD discomfort. This involves both the use of direct self-reported measures of anxiety or discomfort with different social situations, and the use of indirect measures, with defensive or even altruistic behaviour acting as proxies of IPD discomfort. DeBeer-Keston, Mellon and Solomon (1986) found a negative relationship between IPD discomfort and altruistic behaviour frequency. They left a "lost" letter (enveloped, addressed and stamped) on a counter beside some phone booths and had a confederate invade a 
phone user's space (by using the immediately adjacent phone booth) or not (invasion and control conditions). Subjects were included in the experiment if they were observed to notice the letter. Pro-social behaviour was determined as taking the letter. Under the intrusion condition only $19 \%$ of users took the letter (indicating pro-social behaviour) compared with $69 \%$ in the non-intrusion condition. In the public transport setting altruistic behaviours such as thanking the driver/ticket collector or offering a seat to a vulnerable user could be used as a proxy measure of IPD discomfort.

Traditionally, more direct measures of self-report regarding social anxiety and social comfort have been used in clinical environments to examine the patient's ability to deal with common social activities, such as entering a room when others are already seated or going to a party (Liebowitz, 1987). These types of measures have been used to measure the social discomfort of vulnerable groups that are concerned by social interaction, such as groups that deal with perceived stigma (Lawrence, Fauerbach, Heinberg, Doctor \& Thombs, 2006), or groups that are still developing their relationship skills (Zubeidat, Salinas \& Sierra, 2008). Disparity in levels of social anxiety has been shown to interfere with the formation of friendship by causing awkwardness in initial encounters (Kashdan \& Wenzel, 2005).

This exploratory study examined 1) relative setting discomfort, 2) perceptions of compensatory behaviour in other passengers, and 3) the influence of individual personality characteristics on public transport attitudes and behaviour, in a sample of psychology students at Victoria University of Wellington. The measures included seat selection motivations, defensive behaviours, perception of politeness, and personal characteristic assessments. Perceptions of compensatory behaviour were examined using photographs depicting passengers using positive (e.g. smiling) and negative (e.g. sitting with a bag on the adjacent seat) behaviours. It was expected that ratings of passenger affect are likely to reduce if the passenger is using defensive behaviours, as there is evidence that a perception of sociability is linked to positive affect (Emmons \& Diener, 1986). 


\section{METHOD}

\section{Participants}

A sample of 105 first year psychology students at Victoria University of Wellington completed a questionnaire. Participants were $67 \%$ female, and ranged in age from 17 to 34 years (with $96 \%$ of participants between 17-24 years). The students typically had an annual household income of less than $\$ 15,000 \mathrm{NZ}(87 \%)$ and a completed secondary school education level (87\%). The primary ethnicity of the participants were New Zealand European (73\%), with a further 6\% Maori, 6\% Pacific Islanders, and 14\% other ethnicities.

\section{Materials}

A questionnaire was developed with 15 versions, with either 172 or 176 items depending on the version (Appendix A shows an example version of the exploratory questionnaire). The versions examined different configurations of photographs of passenger behaviour (see Table 3.1). Questionnaire items examined typical travel habits to the participants' main weekly activity. The main weekly activity was defined as the activity that took up the greatest amount of their time away from home each week.

Thirteen items were created to examine comfort in different settings, such as a busy airport and sitting next to a stranger on a train (following McClelland \& Auslander, 1978). This was intended to help place the discomfort in relation to other settings commonly associated with comfort (e.g. at home in your lounge) or discomfort (e.g. a dentist's waiting room). Seven Likert scale items were developed to examine effort to avoid crowded public places, such as, "I would rather take a crowded elevator than use the stairs".

Scales were also developed to examine the reported likelihood of polite behaviour and defensive behaviour on public transport. Five Likert scale items examined the perceived frequency of polite behaviour on public transport, such as a passenger offering their seat to an elderly person or someone that may have trouble standing. Seventeen Likert scale items examine reported defensive behaviour and seat selection on public transport, such as, "I select a seat as far away from other 
passengers as possible" or, "I sit next to people that are already busy with an activity, such as reading or listening to music".

Lawrence et al.'s (2006) eight-item Social Comfort Questionnaire was used to examine social comfort (with items such as "I feel comfortable in crowds" and "I feel like I fit in with most groups"). Social anxiety was also assessed, with 24 items adapted from Liebowitz's (1987) Social Anxiety Scale to examine performancebased (e.g. "I do not like to present a report or give a speech") and situation-based (e.g. "I do not like to throw a party") anxiety. Eighteen items adapted from Andersen and Liebowitz (1978) examined same sex touch avoidance (e.g. "I find it difficult to be touched by a member of my own sex") and opposite sex touch avoidance (e.g. "When a member of the opposite sex touches me, I find it unpleasant”).

Individual personality differences were measured using the 50-item Big Five Personality Scale (Goldberg, 1999) to measure Intellect (e.g. "Have a rich vocabulary"), Extraversion (e.g. "Am the life of the party"), Neuroticism (e.g. "Get stressed out easily"), Agreeableness (e.g. "Feel concern for others"), and Conscientiousness (e.g. "Am always prepared"). The Big Five scale was used as it is a well-established method to conceptualise and measure the dimensions of personality and has been tested as reliable and valid (Goldberg, 1999).

The 15 versions of the questionnaires each contained four different photographs of passengers seated either on a bus or train involved with different activities. Two female and two male Caucasian young adults (ranging in age between 23 and 30 years) acted as passengers in the photographs. These confederates posed in each of the seven activities outlined in Table 3.1, in both train and bus settings. A photo of an empty seat on a bus and a train were used as the baseline condition photographs. A total of 58 different photographs were used, with both baseline photographs used twice within the different versions. Participants were asked whether they would feel comfortable sitting in the seat shown in the baseline photograph.

For the photographs that contained people, participants were also asked to respond to the following four Likert scale items $(1=$ Strongly Disagree to $5=$ 
Strongly Agree): "Does the person in Figure X look comfortable", "I would feel comfortable sitting in the seat beside the person in Figure X", "I would feel comfortable talking to the person in Figure X" and "Just from first appearances, I believe the person in Figure X would get on well with my friends”. Participants were also asked whether they knew the person in the photograph, as it was important to establish that the person was a stranger to them.

Table 3.1.

Verbal Descriptions and Example Photographs for the Seven Passenger Activities

\begin{tabular}{ll}
\hline Activity & Description \\
1. Look ahead & $\begin{array}{l}\text { Looking straight ahead } \\
\text { performing no activity }\end{array}$ \\
2. Look towards & $\begin{array}{l}\text { Looking towards where a } \\
\text { they entered the public } \\
\text { transport to find their } \\
\text { seat }\end{array}$ \\
& $\begin{array}{l}\text { Looking towards and } \\
\text { smiling at where a } \\
\text { passenger would be as } \\
\text { they entered the public } \\
\text { transport to find their } \\
\text { seat }\end{array}$ \\
& \\
sook towarding & \\
&
\end{tabular}




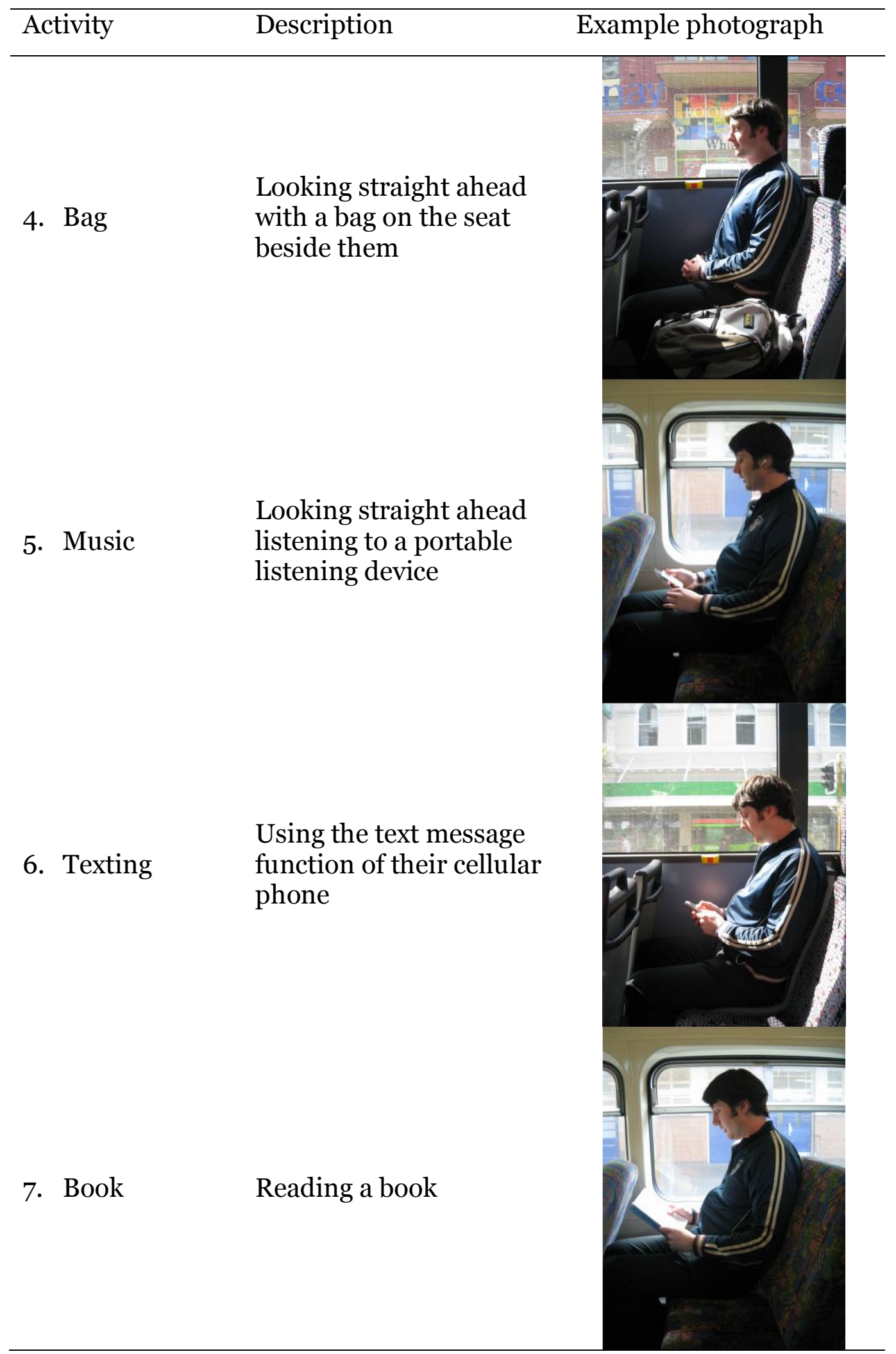




\section{Procedure}

A sample of 105 students volunteered to do the research as part of a psychology course requirement. Students were given a brief oral description of the general purpose of the research. They were then given questionnaires to fill out (taking them approximately 20-30 mins to finish). On completion of the questionnaire participants were given a precise written brief explaining the nature of the research. Ethical approval was given for the research.

\section{RESULTS}

\section{Travel Behaviour}

The main weekly activity (defined as that which took up the greatest amount of time away from home) was education (79.6\%), followed by social and recreational (11.7\%), work (5.8\%) and lastly shopping (2.9\%). The primary travel mode used to get to the main weekly activity (defined as the mode that covers the largest part of the distance travelled) was walking (40.4\%), followed by bus (23.1\%), train (19.2\%), motor vehicle (15.4\%), cycling (1\%) and other (1\%).

\section{Reliability of Scales}

The internal reliability (Cronbach's Alpha), number of items, range, mean and standard deviation for each of the 11 scales can be seen in Table 3.2. The Crowd Avoidance Scale (Cronbach's Alpha = 0.55) and the Politeness Scale (Cronbach's Alpha $=0.44$ ) both had low internal consistency, and the Cronbach's Alpha scores did not attain acceptable levels through the removal of items, so they were not examined as scales. Instead the crowd avoidance and politeness items were examined as individual items in the subsequent analyses. The remaining scales all had Cronbach's Alpha scores of 0.70 or above and so were adequate for scale formation (Christmann \& Van Aelst, 2006). The high scores for Intellect and Agreeableness may be a function of a student sample that is better educated and still focussed on forming social networks. 
Table 3.2.

Scale and Sub-Scale Reliabilities and Descriptive Statistics

\begin{tabular}{lccccc}
\hline Scale & $\begin{array}{c}\text { Cronbach's } \\
\text { Alpha }\end{array}$ & $\begin{array}{c}\text { Number of } \\
\text { items }\end{array}$ & Range & \multicolumn{2}{c}{$M$} \\
\hline Extraversion & 0.90 & 10 & $1-5$ & 3.39 & $(1.04)$ \\
Agreeableness & 0.84 & 10 & $1-5$ & 4.28 & $(0.76)$ \\
Conscientiousness & 0.71 & 10 & $1-5$ & 3.10 & $(0.71)$ \\
Neuroticism & 0.88 & 10 & $1-5$ & 3.03 & $(1.04)$ \\
Intellect & 0.82 & 10 & $1-5$ & 3.84 & $(0.80)$ \\
Social comfort & 0.84 & 8 & $1-5$ & 3.58 & $(0.55)$ \\
Defensive behaviour & 0.79 & 13 & $1-5$ & 3.04 & $(0.48)$ \\
Opposite gender touch & 0.82 & 8 & $1-5$ & 2.07 & $(0.51)$ \\
avoidance & 0.76 & 10 & $1-5$ & 2.72 & $(0.52)$ \\
Same gender touch avoidance & 0.85 & 13 & $1-4$ & 2.08 & $(0.55)$ \\
Performance social anxiety & 0.85 & 11 & $1-4$ & 2.10 & $(0.56)$ \\
Situation social anxiety & 0.81 & 4 & $0-10$ & 8.82 & $(1.22)$ \\
Relaxed setting comfort & 0.73 & 4 & $0-10$ & 6.54 & $(1.60)$ \\
Neutral setting comfort & 0.84 & 5 & $0-10$ & 6.03 & $(1.56)$ \\
Tense setting comfort & 0.55 & 7 & $1-5$ & 2.85 & $(0.54)$ \\
Crowd avoidance & 0.44 & 5 & $0-10$ & 5.76 & $(1.08)$ \\
Perceived politeness & & & & &
\end{tabular}

Note: Standard deviations are in parentheses.

Correlations between all scales are shown in Table 3.3. Extraversion and Social Comfort have the strongest positive relationship and Social Anxiety has strong negative relationships with both Extraversion and Social Comfort. Socially anxious participants were more likely to use defensive behaviours, as were participants that were less agreeable (less concerned with other people and their feelings). Touchavoidant subjects were more likely to use defensive behaviours, be introverted and socially uncomfortable. 
Table 3.3.

Correlation Table of Primary Scales

\begin{tabular}{|c|c|c|c|c|c|c|c|c|}
\hline & 1 & 2 & 3 & 4 & 5 & 6 & 7 & 8 \\
\hline 1. Touch avoidance & - & & & & & & & \\
\hline $\begin{array}{l}\text { 2. Defensive } \\
\text { behaviour }\end{array}$ & $0.22^{*}$ & - & & & & & & \\
\hline 3. Extraversion & $-0.21^{*}$ & -0.15 & - & & & & & \\
\hline 4. Agreeableness & -0.19 & $-0.27^{\star *}$ & $0.20^{*}$ & - & & & & \\
\hline 5. Conscientiousness & 0.10 & 0.11 & -0.10 & 0.01 & - & & & \\
\hline 6. Neuroticism & -0.17 & -0.02 & $0.20^{*}$ & 0.03 & 0.16 & - & & \\
\hline 7. Intellect & -0.17 & -0.15 & $0.21^{*}$ & $0.33^{\star *}$ & 0.01 & 0.18 & - & \\
\hline 8. Social comfort & $-0.28^{* *}$ & -0.18 & $0.74^{* *}$ & $0.34^{\star *}$ & -0.01 & $0.28^{* *}$ & 0.14 & - \\
\hline 9. Social anxiety & 0.11 & $0.29^{\star *}$ & $-0.66^{* *}$ & -0.08 & 0.06 & -0.07 & $-0.23^{*}$ & $-0.56^{* *}$ \\
\hline
\end{tabular}

\section{Perceived Politeness}

Five items examined the likelihood of polite or impolite behaviours occurring on public transport (from $\mathrm{o}=$ Very unlikely to $10=$ Very likely). In terms of polite behaviours (with means above 5), participants believed that public transport users were most likely to thank bus drivers $(M=7.89, S D=1.84)$, followed by offering their seat to an elderly person or someone who might need it $(M=6.88, S D=$ 1.76), and apologising when they accidentally touched another passenger $(M=$ $6.40, S D=2.09$ ).

In terms of impolite behaviours, passengers were not perceived as likely to acknowledge the person they sat beside by making eye contact with them or saying hello $(M=4.14, S D=2.22)$, and passengers were perceived as likely to take up more space than they needed $(M=6.51, S D=1.95)$. Both impolite behaviours relate to the selection of a seat beside another passenger.

\section{Crowd Avoidance}

Seven Likert scale items ( 1 = Strongly disagree; $5=$ Strongly agree) examined effort to avoid crowding. In terms of crowd avoidance, participants would rather walk an extra five minutes to find a spot away from other people in the context of a 
beach $(M=3.60, S D=1.00)$, but would tolerate a crowded bus shelter over standing out in the cold wind $(M=3.59, S D=0.97)$. In terms of avoiding close interpersonal distance, participants would rather sit on the grass than share a small park bench with a stranger $(M=3 \cdot 32, S D=1.13)$, and rather stand when taking the bus or train than sit pushed up next to another passenger $(M=3.66, S D$ =1.01). The remaining three items had means that were close to neutral.

\section{Defensive Behaviour}

The 17-item defensive seating behaviour scale was made up of Likert scale items (1 = Strongly disagree; 5 = Strongly agree) relating to the selection of a seat away from other passengers and the physical defence of the passenger's immediate seat location to make it less attractive to boarding passengers. Seven of the 17 items were reverse-coded as they examined attitudes that were positive to sitting next to other passengers, for example "I like to sit beside other passengers".

Eighty percent of participants did not like to select seats that would face other passengers, and 75\% did not like to sit beside other passengers (see Table 3.4). There was no evidence here that participants preferred to sit beside passengers with similarities to themselves, with fairly neutral responses to sitting next to someone of a similar age or same gender.

Participants typically disagreed that they would engage in defensive behaviours to physically defend territory, with $85 \%$ reporting disagreement that they would defend their space by sitting in the aisle seat (and leaving the window seat open), and $58 \%$ disagreed that they would spread out so no one would sit beside them. ${ }^{1}$ Similarly, 70\% agreed that they would always leave room for other passengers. In terms of situational withdrawal into activities as a defence from other passengers, there was some agreement that this does occur. Fifty-two percent of participants agreed that they performed activities such as reading and listening to music as a tactic to avoid conversation with other passengers. A further $55 \%$ agreed that they chose to sit next to people that were already busy with an activity.

\footnotetext{
${ }^{1}$ Disagreement percentages were calculated by collapsing the "Disagree" and "Strongly Disagree" categories. Similarly, agreement percentages were calculated by collapsing the "Agree" and "Strongly Agree" categories.
} 
To examine latent defensive factors a principal components factor analysis was carried out which revealed six factors with eigenvalues over 1.oo. Using the "scree criterion" (Cattell, 1966) to examine where the gradient of the scree plot decreased substantially, either a two-factor or one-factor solution was appropriate. The Kaiser-Meyer-Olkin measure of sampling adequacy was 0.74 (exceeding the 0.50 typically required for factor analysis; Hair et al., 1995), indicating that there was a reasonable proportion of common variance that may be caused by underlying factors. Bartlett's test of sphericity revealed that there were significant relationships between the variables $\left(X^{2}(136)=371.49, p<.001\right)$, suggesting that the level of correlation in the data was appropriate for factor analysis.

For the two-factor solution an oblimin rotation was used, as the factors extracted were likely to be highly correlated. The items "I like sitting next to someone I've never met before on public transport" and "I prefer to sit next to someone about the same age as me" were discarded as they had factor loading scores below 0.30. In the two-factor solution the first factor showed reasonable internal reliability (Cronbach's Alpha = 0.76), but the second factor showed poor internal reliability with relatively low inter-item correlations (Cronbach's Alpha = 0.63). Cronbach's Alpha scores of 0.70 or above provide adequate internal reliability for scale formation, scores below this level may indicate that the scale items are not necessarily measuring the same underlying factor (Christmann \& Van Aelst, 2006).

The one-factor solution was preferred as it had adequate internal reliability (Cronbach's Alpha = 0.79). A further two items ("I dislike sitting next to school kids and teenagers" and "I like seats that face other passengers") were removed in the one-factor solution due to factor loadings below 0.30, leaving a 13-item defensive behaviour scale (see Table 3.4). 
Table 3.4.

Principal Components Factor Analysis Solutions for the Defensive Behaviour Items

\begin{tabular}{|c|c|c|c|c|c|}
\hline \multirow{3}{*}{$\begin{array}{l}\text { Defensive behaviour item } \\
\text { I like to sit beside other passengers (R) }\end{array}$} & & & \multicolumn{2}{|c|}{$\begin{array}{l}\text { Two-factor } \\
\text { solution }\end{array}$} & \multirow{3}{*}{$\begin{array}{c}\begin{array}{c}\text { One- } \\
\text { factor } \\
\text { solution }\end{array} \\
0.49\end{array}$} \\
\hline & \multicolumn{2}{|c|}{$M$} & 1 & 2 & \\
\hline & 3.91 & $(0.83)$ & 0.67 & & \\
\hline I really don't care where I sit (R) & 3.29 & $(0.89)$ & 0.60 & & 0.47 \\
\hline $\begin{array}{l}\text { I dislike sitting next to school kids and } \\
\text { teenagers }\end{array}$ & $3 \cdot 34$ & $(0.97)$ & 0.57 & & \\
\hline $\begin{array}{l}\text { I sit next to people that are already busy with } \\
\text { an activity, such as reading or listening to } \\
\text { music }\end{array}$ & $3 \cdot 52$ & $(0.74)$ & 0.54 & & 0.51 \\
\hline $\begin{array}{l}\text { I like to perform activities such as read and } \\
\text { listen to music so other passengers wont talk to } \\
\text { me }\end{array}$ & $3 \cdot 34$ & $(0.98)$ & 0.49 & & 0.60 \\
\hline I like seats that face other passengers (R) & 4.03 & $(0.75)$ & 0.47 & & \\
\hline $\begin{array}{l}\text { I like it when another passenger chooses to sit } \\
\text { beside me (R) }\end{array}$ & 3.13 & $(0.71)$ & 0.34 & & 0.37 \\
\hline $\begin{array}{l}\text { The person I sit next to has no influence on my } \\
\text { decision to sit there }(\mathrm{R})\end{array}$ & 3.23 & $(1.09)$ & 0.30 & & 0.34 \\
\hline $\begin{array}{l}\text { I prefer to sit next to someone about the same } \\
\text { age as me }\end{array}$ & 3.17 & $(0.90)$ & & & \\
\hline $\begin{array}{l}\text { I like sitting next to someone I've never met } \\
\text { before on public transport }(\mathrm{R})\end{array}$ & 3.25 & $(0.79)$ & & & \\
\hline $\begin{array}{l}\text { I always leave room for other passengers to sit } \\
\text { next to me (R) }\end{array}$ & 2.24 & $(0.86)$ & & -0.80 & 0.63 \\
\hline $\begin{array}{l}\text { I leave the window seat open and sit in the } \\
\text { aisle seat to avoid sitting beside other } \\
\text { passengers }\end{array}$ & 1.87 & $(0.81)$ & -0.32 & -0.78 & 0.39 \\
\hline I like to spread out so no one will sit next to me & 2.66 & $(1.02)$ & & -0.74 & 0.68 \\
\hline $\begin{array}{l}\text { I avoid the eye contact of boarding passengers } \\
\text { in the hope that they wont sit next to me }\end{array}$ & 2.97 & $(0.97)$ & 0.45 & -0.52 & 0.78 \\
\hline $\begin{array}{l}\text { I choose the seat that will give me the most } \\
\text { space to spread out my gear and give me } \\
\text { enough leg space }\end{array}$ & 3.73 & $(0.92)$ & & -0.45 & 0.48 \\
\hline $\begin{array}{l}\text { I select a seat as far away from other } \\
\text { passengers as possible }\end{array}$ & 2.73 & $(0.97)$ & 0.37 & -0.43 & 0.64 \\
\hline $\begin{array}{l}\text { If I have to sit next to another passenger, I sit } \\
\text { next to someone of the same gender }\end{array}$ & 2.96 & $(0.90)$ & & -0.38 & 0.36 \\
\hline Eigenvalue & & & 3.05 & 3.23 & 3.93 \\
\hline Explained variance & & & $23.14 \%$ & $\begin{array}{c}10.27 \\
\%\end{array}$ & $23.14 \%$ \\
\hline Cronbach's Alpha & & & 0.76 & 0.63 & 0.79 \\
\hline
\end{tabular}

Note: $\mathrm{N}=103$. Explained variance (cumulative): 33.40; (R) = Reverse item; Factor loadings below 0.3 are not shown; standard deviations are in parentheses. 


\section{Relative Comfort in Different Social Settings}

As can be seen in Table 3.5, a person's lounge at home was perceived as the most comfortable setting, and a crowded elevator was seen as the most uncomfortable setting ( $\mathrm{o}=$ Very uncomfortable $; 10=$ Very comfortable) . A within-subjects analysis of variance (ANOVA) revealed significant differences between the social settings $(F(8,791)=73.72, p<.001) .{ }^{2}$ Paired samples t-tests reveal that sitting next to a friend in a movie theatre was more comfortable than sitting next to a stranger in a movie theatre $(t(100)=16.03, p<.001)$, and an uncrowded beach was rated as more comfortable than a crowded beach $(t(99)=6.35, p<.001)$.

When considering transport decisions, being a passenger in a car (driven by a friend or family member) was a significantly more comfortable setting than car pooling with a neighbour $(t(97)=5.01, p<.001)$. Being a passenger in a car was a significantly more comfortable setting than sitting next to a stranger on a plane ( $t$ $(101)=6.09, p<.001$ ), which in turn was a more comfortable setting than sitting next to a stranger on a bus $(t(101)=2.453, p<.05)$, which was more comfortable than sitting next to a stranger on a train $(t(99)=2.91, p<.01)$.

A principal components factor analysis with an oblimin rotation was used to examine any underlying subscales of comfort within different social setting items. The Kaiser-Meyer-Olkin measure of sampling adequacy was high (o.80) indicating that a factor analysis would be useful, and the Bartlett's test of sphericity was significant $\left(X^{2}(78)=559.23, p<.001\right)$, suggesting significant relationships between the variables.

Analysis revealed three factors with eigenvalues over 1.oo. Factor one (Tense Settings) was formed from settings which involved sitting close to unfamiliar people (sitting next to a stranger on the bus or train or at the movie theatre), and being placed in crowded conditions (at the beach on in an elevator). Factor two (Relaxed Settings) was made up of either familiar settings (the lounge at home) familiar people (friend at a movie theatre) or uncrowded conditions. Factor three (Neutral Settings) included a more neutral relationship with a neighbour, but the

${ }^{2}$ A Greenhouse-Geisser test was used here as sphericity was not assumed. 
other items may have been typically associated with more stressful situation. Sitting next to a stranger was not as problematic in the plane setting; similarly a busy airport was rated as more comfortable than other situations of crowding. Finally, a dentist's waiting room was grouped with these items even though this was typically a setting associated with stress, and was ranked as the second most uncomfortable setting.

A within-subjects ANOVA revealed significant differences between the social setting factors $(F(2,204)=199.09, p<.001)$, such that Relaxed Settings $(M=$ $8.82, S D=1.22)$ were rated as significantly more comfortable than Neutral Settings $(M=6.54, S D=1.60 ; t(102)=15.56, p<.001)$, which in turn were significantly more comfortable than Tense Settings $(M=6.03, S D=1.56 ; t(102)=$ $3.54, p<.01)$.

Table 3.5.

Principal Components Factor Analysis Solution for Perception of Comfort in Different Social Settings

\begin{tabular}{lccccc}
\hline & & & \multicolumn{3}{c}{ Factor } \\
\cline { 4 - 6 } Location & \multicolumn{2}{c}{$M$} & 1 & 2 & 3 \\
\hline Crowded elevator & 5.05 & $(2.06)$ & 0.89 & & \\
Stranger on a train & 5.97 & $(1.81)$ & 0.85 & & \\
Stranger at movie theatre & 6.08 & $(2.01)$ & 0.78 & & \\
Crowded beach & 6.54 & $(2.17)$ & 0.63 & & \\
Stranger on a bus & 6.39 & $(2.01)$ & 0.59 & & \\
Lounge at home & 9.50 & $(1.19)$ & & 0.90 & \\
Friend at a movie theatre & 9.36 & $(1.22)$ & & 0.89 & \\
Uncrowded beach & 8.20 & $(1.93)$ & & 0.69 & \\
Passenger in a car & 8.15 & $(1.93)$ & & 0.56 & \\
Stranger on a plane & 6.85 & $(2.03)$ & & & -0.85 \\
Busy airport & 6.56 & $(2.31)$ & & & -0.83 \\
Car-pooling with neighbour & 7.10 & $(1.82)$ & & & -0.48 \\
Dentist's waiting room & 5.59 & $(2.42)$ & 0.33 & & -0.44 \\
\hline Eigenvalue & & & 5.15 & 1.86 & 1.09 \\
Explained variance & & & $39.63 \%$ & $14.32 \%$ & $8.40 \%$ \\
Cronbach's Alpha & & & 0.84 & 0.81 & 0.73 \\
\hline
\end{tabular}

Note: $\mathrm{N}=99$. Explained variance (cumulative): 62.35; Factor loadings below 0.3 are not shown; standard deviations are in parentheses. 


\section{Photograph Analysis}

The four measures relating to perceptions of comfort did not vary significantly between train and bus settings (see Table 3.6). Participants reported greater comfort sitting next to someone of the same gender $(M=3.88, S D=0.68)$ compared with someone of the opposite gender $(M=3.68, S D=0.76 ; t(303)=$ $2.45, p<.05)$. There were no significant differences based on ethnicity.

Four different confederates were photographed, two females and two males. There were no differences between perceptions of the confederates when it came to perceptions of comfort when sitting next to them $(F(3,301)=2.00, p=.12, n s)$ or talking to them $(F(3,299)=0.86, p=.46, n s)$. One of the female confederates appeared less comfortable than one of the male confederates $(F(3,301)=3.27, p<$ $.05)$. Two of the confederates were less likely to get along with participants' friends, the most comfortable male and the most uncomfortable female $(F(3,300)$ $=5.80, p<.01$ ).

Table 3.6.

Descriptives and Significant Differences between Ratings of Bus and Train Photographs

\begin{tabular}{lllllll}
\hline & \multicolumn{2}{c}{ Bus } & \multicolumn{2}{c}{ Train } & \\
\cline { 2 - 5 } Item & \multicolumn{2}{c}{$M$} & & $M$ & $p$ \\
\hline $\begin{array}{l}\text { The person in Figure X looks } \\
\text { comfortable }\end{array}$ & 3.82 & $(0.90)$ & 3.81 & $(0.82)$ & .91 \\
$\begin{array}{l}\text { I would feel comfortable sitting in the } \\
\text { seat beside the person in Figure X }\end{array}$ & 3.80 & $(0.77)$ & 3.84 & $(0.72)$ & .63 \\
$\begin{array}{l}\text { I would feel comfortable talking to the } \\
\text { person in Figure X }\end{array}$ & 3.08 & $(0.91)$ & 3.06 & $(0.92)$ & .87 \\
$\begin{array}{l}\text { Just from first appearances, I believe } \\
\text { the person in Figure X would get on } \\
\text { well with my friends }\end{array}$ & 2.91 & $(0.77)$ & 3.00 & $(0.77)$ & .31
\end{tabular}

Note: Standard deviations are in parentheses. 
One-way analysis of variance (ANOVA) revealed that there were significant differences between the seven different behaviours displayed in the photos in terms of: the perceived comfort of the person $(F(6,298)=6.47, p<.001)$; comfort sitting beside the person $(F(7,324)=, p<.001)$; comfort talking to the person $(F$ $(6,296)=, p<.01)$; and the perception that the person would get on with their friends $(F(6,297)=, p<.01)$.

Post-hoc tests revealed that participants felt more comfortable sitting in an empty seat compared with sitting next to another passenger with a bag in the immediately adjacent seat or another passenger reading a book (see Figure 3.1). ${ }^{3}$ Participants were least likely to respond to being comfortable sitting next to a passenger that had their bag in the immediately adjacent seat than any other behaviour.

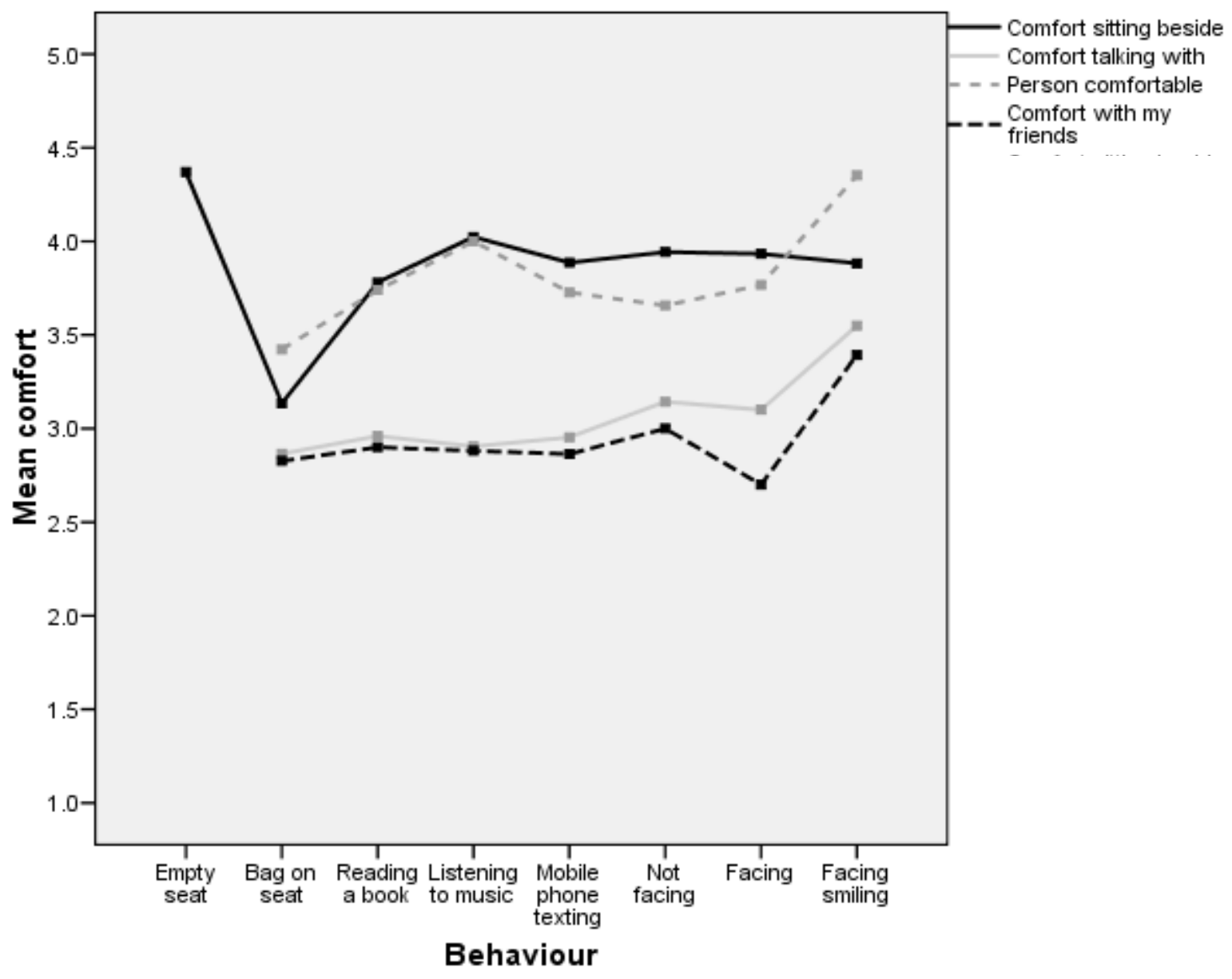

Figure 3.1._Mean perception of comfort sitting beside or talking with the person in the photograph, and whether the person in the photograph looks comfortable or would get on well with my friends.

3 Bonferroni adjustments were used to adjust for the family-wise error, with an adjusted Alpha level of 0.03 . 
Further post-hoc analysis revealed that photographs of passengers that were facing the aisle and smiling were typically perceived as more comfortable, easier to talk to and be more likely to get on with participants' friends compared with the other behaviours (see Figure 3.1). There were a few exceptions where ratings of passengers facing the aisle and smiling were not significantly higher. Passengers listening to music were not perceived as significantly less comfortable than smiling passengers.

Participants rated passengers engaged in activities or with a bag on the adjacent seat as significantly more uncomfortable to talk with compared with smiling passengers, but passengers that were looking ahead or facing the aisle (e.g. towards the camera) were not significantly less comfortable to engage in communication compared with smiling passengers (see Figure 3.1). Passengers that were looking towards participants were rated as least likely to get on with their friends. Passengers that were looking ahead were not perceived as significantly less likely to get on well with a participant's friends compared with smiling passengers.

\section{Differences by Travel Mode}

Walking, cycling and driving travel modes were grouped into one category to simplify the examination of differences between public transport commuters ( $n=$ $44)$ and all other commuting modes $(n=60)$. The rationale behind this was that walking, cycling or driving a motor vehicle are all typically solitary travel modes, and do not require strangers to share a close proximity.

Table 3.7 shows the individual items that were significantly different between public transport commuters and other transport mode commuters (using $t$-tests with Bonferroni adjustments to account for the family-wise error). These findings indicate that public transport users are more uncomfortable meeting strangers, touching a friend of the same sex and sitting next to school kids and teenagers on public transport. While it was expected that public transport users would be more comfortable with strangers (as they are in frequent close contact with strangers when using public transport), they were reported being more likely to make an extra effort to walk further to find a secluded beach location. 
Table $3 \cdot 7$.

Descriptives for Items that were Significantly Different between Public Transport Commuters and Other Travel Mode Commuters

\begin{tabular}{|c|c|c|c|c|c|}
\hline \multirow{3}{*}{$\begin{array}{l}\text { Item } \\
\text { When I visit the beach I would prefer to walk an } \\
\text { extra } 5 \text { minutes to find a spot away from other } \\
\text { people (scale range 1-5) }\end{array}$} & \multirow{2}{*}{\multicolumn{2}{|c|}{$\begin{array}{c}\text { Public } \\
\text { transport }\end{array}$}} & \multirow{2}{*}{\multicolumn{2}{|c|}{$\begin{array}{l}\text { Other } \\
\text { travel } \\
\text { modes } \\
M\end{array}$}} & \multirow{3}{*}{$\begin{array}{c}p \\
.018\end{array}$} \\
\hline & & & & & \\
\hline & 3.86 & $(0.85)$ & 3.40 & $(1.04)$ & \\
\hline $\begin{array}{l}\text { Just from first appearances, I believe the person in } \\
\text { Figure X would get on well with my friends }(1-5)\end{array}$ & 3.16 & (0.60) & 2.85 & $(0.62)$ & .028 \\
\hline $\begin{array}{l}\text { Expected likelihood of passengers thanking the bus } \\
\text { driver as they leave the bus (o-10) }\end{array}$ & 8.38 & $(1.81)$ & $7 \cdot 53$ & $(1.80)$ & .019 \\
\hline $\begin{array}{l}\text { Expected likelihood of passengers acknowledging } \\
\text { the person they sit next to by making eye contact or } \\
\text { saying hello (o-10) }\end{array}$ & 3.50 & $(2.30)$ & 4.61 & $(2.07)$ & .011 \\
\hline $\begin{array}{l}\text { I dislike sitting next to school kids and teenagers (1- } \\
\text { 5) }\end{array}$ & 3.70 & $(0.88)$ & 3.08 & $(0.94)$ & .001 \\
\hline Comfort when car-pooling with a neighbour (0-10) & 6.60 & $(1.93)$ & 7.44 & $(1.67)$ & .023 \\
\hline I am uncomfortable meeting strangers (1-4) & 2.32 & $(0.93)$ & 1.90 & $(0.82)$ & .017 \\
\hline $\begin{array}{l}\text { Touching a friend of the same sex does not make me } \\
\text { uncomfortable (1-5) }\end{array}$ & 3.24 & $(1.07)$ & 3.69 & $(0.85)$ & .033 \\
\hline
\end{tabular}

Note: Standard deviations are in parentheses.

A forward conditional stepwise logistic regression was used to determine the influence of the main predictor variables on Public Transport use. The independent variables included in the logistic regression were: Age, Gender, Income, Touch Avoidance, Social Anxiety, Social Comfort, Intellect, Extraversion, Openness, Agreeableness, Conscientiousness, and Defensive Behaviour. 4 The Hosmer and Lemeshow test shows that the model adequately fits the data $\left(X^{2}(N=\right.$ 103 ) $=3.75, p=.88, n s$ ), but the explanatory value of the model is low (NagelKerke

\footnotetext{
4 Variables that showed some relationship to Public Transport use (significance values at about 0.3 or less) were also investigated for interaction effects. Ethnicity, Education and Same gender touch avoidance were not significant variables when included in the initial model, and as they had substantial missing data that would reduce the sample by $20 \%$, they were not included in the final model.
} 
$R^{2}=0.15$ ), so it explains $15 \%$ of the variance between public transport users and other travel modes.

Table 3.8.

Model Summary for the Binary Logistic Regression of Public Transport Use

\begin{tabular}{lccccccc}
\hline & & & & & \multicolumn{3}{c}{ 95.0\% C.I. for } \\
\cline { 6 - 8 } & B & S.E. & Wald & Sig. & Exp(B) & Lower & Upper \\
\hline Defence & -1.05 & 0.48 & 4.71 & 0.030 & 0.35 & 0.14 & 0.90 \\
Social Anxiety by Income & 0.50 & 0.22 & 5.19 & 0.023 & 1.65 & 1.07 & 2.53 \\
$\begin{array}{l}\text { Opposite gender touch } \\
\text { avoidance }\end{array}$ & 0.88 & 0.44 & 3.91 & 0.048 & 2.41 & 1.01 & 5.75 \\
Constant & -0.14 & 1.57 & 0.01 & 0.928 & 0.87 & & \\
\hline
\end{tabular}

Regular public transport users were less likely to engage in defensive behaviour, suggesting a higher level of comfort when taking the train or bus (see Table 3.8). Public transport users were more likely to be touch-avoidant of the opposite gender and there was also an interaction effect; such that regular public transport users were more likely to feel social anxiety when they have a higher level of income (see Figure 3.2).

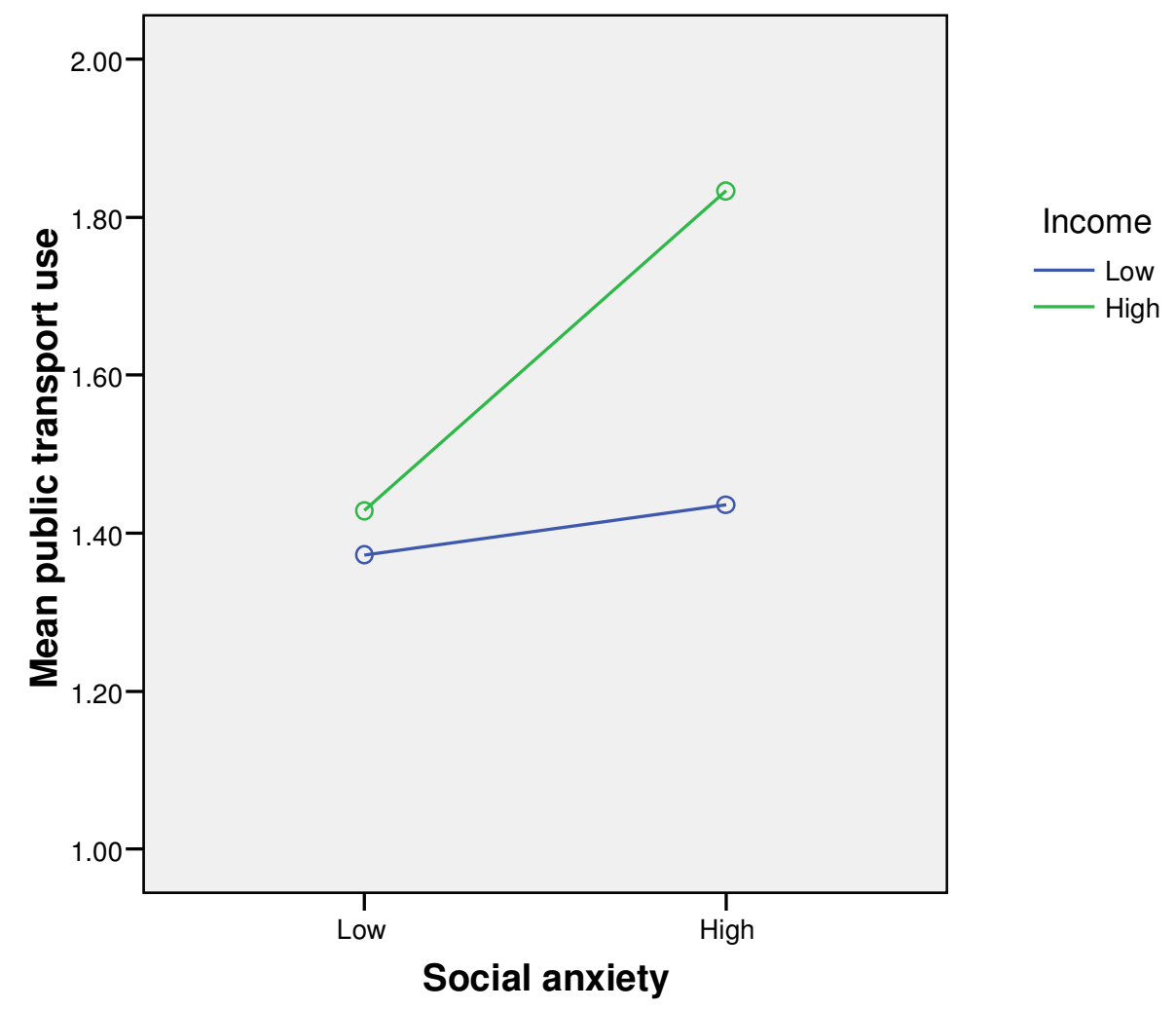

Figure 3.2. Public transport use by social anxiety and income group. 


\section{Discussion}

The three key components of this exploratory research provide evidence that: public transport is rated as among the most uncomfortable of social settings; that positive body language adaptations are viewed very positively; and that users of public transport are more likely to be touch-avoidant.

\section{Relative Setting Discomfort}

Relative to other settings, sitting next to a stranger on the bus and train are among the most uncomfortable settings. References to close interpersonal distances and non-familiar relationships reveal why public transport is ranked among the most uncomfortable of social settings. The ratings of comfort for different settings appear to vary based on the relationship the participant has to other users of these settings (i.e. friend, neighbour or stranger), which supports Hall's (1966) theory that people are more comfortable in close proximity to people with which they have formed a close relationship. This finding is also supported in proximity research, where participants are more tolerant of close interpersonal distances (such as sitting directly beside someone) when they have a more intimate level of friendship with the person in question (e.g. Burgess, 1983). The only context where this finding was broken was when sitting next to a stranger on the plane. The plane was not grouped with "tense settings," instead it was placed with "neutral settings," such as car-pooling with a neighbour.

A plane is viewed as different from a train or bus, perhaps this is because the passengers on this transport mode have a greater level of control over their environment (Rodin, Solomon \& Metacif, 1978). The presence of air stewards mean that there is at very least a perception that social and safety rules can be enforced. The driver of a bus is occupied by driving, and the ticket collector by ensuring everyone is a paying passenger, whereas the primary concern of the air steward is to ensure the safety and comfort of the passengers. On a plane, there is also a call button to get the attention of a steward, giving the passenger more physical control than on a bus or train. 
A perception of physical control and cognitive control when in a crowded environment reduces discomfort. Participants placed next to the control panel of a crowded elevator are in a place of physical control, and consequently feel less crowded (Rodin et al., 1978). Similarly, interventions aimed at increasing cognitive control to reduce the effects of crowding have been shown to increase positive assessments of setting environments and improve mood, although they did not reduce physiological stress (Karlin et al., 1979).

Another explanation for the more positive assessment of sitting next to a stranger on a plane is that airplane travel is more expensive, indicating a certain level of exclusivity that is not present on the bus or train. There is also a class-based seating system (i.e. first class, business class or standard class) that further ensures the passengers immediately nearby are more homogenous than bus or train users that can sit anywhere they like. Seat selection preferences indicate that people look for similarity in gender and ethnicity when choosing a seat on public transport (Maines, 1977). Similarly, willingness to travel by public transport increases if people perceive that the "typical" user is similar to them (Siegfried et al., 1982). Therefore, acceptance of sitting immediately next to a stranger may be higher in the plane setting because of a perception that the nearby passengers have a minimal level of similarity.

Unsurprisingly, crowded setting conditions, such as that of a crowded elevator, reduce the perceived comfort of a setting. This supports a body of research that shows that stress and discomfort are caused under crowded conditions, or conditions of close interpersonal distance (Hayduk, 1983). While the setting descriptions of bus and train user were not labelled with "crowded" in this study, the description "sitting next to" does imply an intimate interpersonal distance. Evans and Wener (2007) found that close interpersonal distance on the train increased the physiological stress levels, increased self-reported frustration and reduced the motivation of participants engaged in a proofreading task. These findings of stress occurred even when the train wasn't full, indicating that the close proximity of other passengers has a large impact on discomfort level (Evans \& Wener, 2007). 
All of the settings were rated positively, except the crowded elevator, which was rated as neutral. This highlights the problem associated with measuring perceived comfort in commonplace settings, as a minimal level of comfort is required to tolerate the social setting, so comfort ratings are likely to be skewed towards positive. One way to avoid this problem is to measure adaptivity to achieve comfort (for example, see Walton, Dravitzki \& Donn, 2007). A scale of defensive behaviours was examined in this exploratory study that revealed that public transport regulars used less defensive behaviour than other commuting modes, which may be indicative of less social discomfort in the public transport setting.

\section{Interactive and Defensive Behaviours}

Perceptions of other passengers displaying different "defensive" behaviours in photographs found that situational withdrawal into activities such as reading, using a mobile phone or listening to music does not deter passengers from sitting beside them. Previous research indicates that adaptive behaviour, in the form of talking or reading a newspaper, did not reduce physiological stress due to crowded conditions, but talking did improve feelings of control (Epstein, Teitelbaum, Karlin et al., 1981). Talking was not measured here, but about half of the participants did report engaging in activities such as reading and listening to music as a conversation avoidance technique.

Comfort in sitting beside someone listening to music was ranked as second only to sitting in an empty seat. Listening to music may be more acceptable simply because it is not visually engrossing, and consequently allows the passenger to engage in non-verbal social niceties, such as eye contact and smiling, but still avoids unwanted verbal interaction. Reading a book does not allow for this visual politeness, and could lead passengers to interpret the reading behaviour (subconsciously or consciously) as discourteous. It is important to note that the inactive nature of the photograph means that other factors, such as auditory annoyance from the immediately adjacent passenger listening to music is not taken into account. Withdrawal into activities will reduce the likelihood that the adjacent passenger will attempt to engage in conversation. 
Physically defending territory by placing a bag on the immediately adjacent seat is the most obvious signal that a passenger does not want someone intruding their space, and induces the greatest discomfort with taking the seat beside them. However, a large majority of participants reported that they did not attempt to spread out to defend their space, with even more reporting that they would not sit in the aisle seat to prevent someone from sitting beside them. Findings from the Observational study show that this behaviour typically only occurs when the bus or train is less full and people alter their behaviour to accommodate others as it gets more crowded. People do report that they like to choose a seat where they can spread out their belongings and get the most leg room, suggesting that this behaviour is primarily motivated by physical comfort, but this behaviour does have the added advantage that other passengers will have to select empty bench seats first.

Individual items examining polite behaviour on public transport revealed an underlying perception of "rudeness" associated with the seating process. There was a perception that the other passengers were likely to take up more space than they need implying a selfish lack of concern for other passenger needs. Only a quarter of passengers overtly spread out to physically occupy space in the Observational study. This display of territory defence does not appear to create emotions as strong as anger or strong discomfort towards the person, as the airplane armrest encroachment research would have suggested (Hai et al., 1982), possibly because there was still a choice over seat selection. Similarly, it was perceived that the person invading the space would not acknowledge the person whose space they were about to invade. This failure to communicate (verbally or non-verbally) violates a social rule present in other settings, such as restaurants, where there is an expectation to acknowledge the other person and even ask permission to sit.

Photographic ratings revealed that passengers looking toward the aisle were perceived as least likely to get on with a participant's friends. This does not support literature that relates gaze to positive assessments and gaze avoidance to negative assessments. For example, Scherer (1974) found that greater eye contact increased ratings of individuals to make them appear more likeable, pleasant and interesting. Length of gaze is not measured in a static photograph, so there is nothing to differentiate a brief eye contact, which may be viewed as positive, from staring, 
which is likely to form negative impressions (Ellsworth, Carlsmith \& Henson, 1972). When the gaze is accompanied by the obvious positive body language afforded by smiling, passenger photograph ratings are significantly higher.

Smiling induces the greatest level of overall comfort with another passenger. Lill and Willkinson (2005) also found that smiling increased the positive assessment of photographs of doctors in their research examining patient comfort with doctors' appearance. It is important to recognise that putting on a smile with non-genuine motivation may not have the intended effect. People are able to detect smile authenticity (Miles \& Johnston, 2007), and people with genuine, enjoyment smiles are seen as more positive (Frank, Ekman \& Friesen, 1993).

Johnson (1989) examined the predictors of friendship formation and found that being perceived as friendly was a strong predictor, so smiling or showing any signs of positive body language is likely to encourage an increased level of friendship and following Hall's (1966) proxemic theory will lower levels of interpersonal discomfort. In terms of body language, leaning towards someone, smiling and looking all represent positive attitudes towards that person (Argyle, 1978). These positive body language cues are an effective means of communicating friendliness to boarding passengers.

\section{Influences on Public Transport Patronage}

Analysis of differences between regular public transport commuters and other, more solitary travel modes (cycling, walking, and private motor vehicle) revealed that public transport users are more touch-avoidant with the opposite gender, they use less defensive behaviour, and that those with higher household incomes are more socially anxious. These findings are relatively contradictory. Regular public transport patrons display less defensive behaviour, indicating that they are more comfortable with the setting, however, they are also more touch-avoidant and anxious.

Social anxiety and touch avoidance are not barriers to public transport patronage within this student sample. Instead it may be that being anxious when around others, with a particular dislike of touching others is a reinforced outcome caused 
by regularly maintaining close distances with strangers. Saegart (1976) does suggest that the presence of other people is one of the stimuli to which we do not easily habituate.

People living in higher density apartments are more likely to experience social overload, with a greater anxiety regarding their social relations, greater alienation, lower perceived control, and less privacy (McCarthy \& Saegert, 1978). Even though the public transport setting is more temporary than a housing situation, public transport users appear to be sensitised to social anxiety and touch avoidance, and this can be at least partially explained by their continued exposure to high passenger densities. Those travelling by more solitary modes (car, cycling, walking) are not exposed to these conditions and have more tolerance of complex social situations and touch with others.

The relationship between high income and social anxiety may exist because students in higher income households are more sheltered from socially testing environments, and are consequently less familiar and comfortable with stressful social situations. Sears (1986) suggests that students may not have fostered the same level of social connections and built the same level of confidence when interacting with strangers. The income finding may not be applicable to a wider sample of public transport and motor vehicle users. Students were the main focus of this sample, and had relatively low annual household incomes $(M=\$ 10,050)$ compared with the average annual household income in New Zealand $(M=$ \$73,952; Statistics New Zealand, 2008).

Other differences between travel mode groups indicate that regular public transport commuters expect there will be less social politeness towards and acknowledgement of other passengers, but higher social politeness in the form of thanking the driver. Ajdukovic (1988) found that discomfort from close proximity was related to expectation. In a library setting, where crowding was not a common occurrence, participants were less tolerant of crowded conditions than in a dentist's waiting room, and adjusted by adopting more defensive behaviours (Ajdukovic, 1988). Similarly, non-regular public transport users may have expectations of greater levels of social interaction and social politeness from other 
passengers, and when they do not receive this may perceive the other passengers less favourably and adjust by adopting defensive behaviours.

There is evidence enough here to suggest that individual differences influence transport mode choices, and that further examination of social anxiety, touch avoidance, income and defensive behaviour would be appropriate in a general sample of New Zealand commuters.

\section{Limitations}

This is an exploratory study, with a limited student sample that may not be representative of the wider public transport using community. For example, the lower income of students may mean the proportion of "captive" passengers, as opposed to "choice" users were higher than normal. Krizek and El-Geneidy (2007) show how captive and choice users differ in their public transport service preferences.

The personality characteristic findings regarding differences between public transport commuters and other commuting modes are only tentative, and should be treated with caution. Students had high scores on agreeableness, suggesting that these students are still looking at extending their social networks. This lends some support to Sears (1986) theory that narrow samples have less stable peer groups. Sears (1986) examined systemic biases in narrow student samples and conclude that there are several characteristics of these samples that may be weaken their ability to replicate findings in more general samples, including less crystallised attitudes.

\section{Conclusion}

Sitting immediately adjacent to strangers on trains and buses is reported among the most uncomfortable of social settings. Interpersonal distance and level of relationship with the immediately adjacent passenger are influential on perception of setting discomfort. The aeroplane setting has similar parameters regarding IPD but is viewed as more comfortable. It is speculated that this is because of a higher 
perception of passenger control and greater exclusivity and consequently greater homogeneity of passengers.

The behaviours examined on public transport indicate that smiling will encourage positive passenger affect, but will not necessarily influence seat selection. Engaging in an activity will reduce the likelihood of communication between passengers. Reading will discourage people selecting the adjacent seat, whereas passengers are more likely to sit next to someone listening to music. Placing a bag on the adjacent seat is the only clear cue to send to other passengers that will prevent them from sitting there.

The findings regarding individual differences are somewhat contradictory. Regular public transport users find less need for defensive, indicating a greater level of comfort on public transport. However, these passengers are also more touchavoidant and socially anxious, indicating that exposure to public transport has enhanced their level of interpersonal anxiousness. These factors require further examination in a more representative sample of public transport users. 


\section{CHAPTER 4: INTERPERSONAL DISCOMFORT ON THE TRAIN}

The Exploratory study established that train and bus travel are amongst the most uncomfortable social settings, and developed a self-report measure of defensive behaviours used to mitigate social discomfort that was based on the behaviours identified in the Observational study. This study engages a more representative sample of public transport commuters to examine the effectiveness of both social and defensive strategies in mitigating social discomfort.

\section{Background}

Many regular public transport users avoid the opportunity to form positive social interactions with other patrons that live in the same location, are nonetheless travelling to the same location and may have very similar lifestyles. If patrons met regularly in another context it is possible, based on these commonalities as well as their familiarity, that they would become friends. Instead they attempt to maintain their “stranger" status (Zurcher, 1979).

This study aims to examine whether perceived heterogeneity increases social discomfort when travelling in close proximity to other passengers on public transport. It is expected that passenger awareness of interpersonal commonality is low, passengers focus on salient "weird" passengers to form stereotypes of the "typical" passenger, and that discomfort is enhanced under crowded conditions.

Festinger, Schacter and Back's (1950) Passive Contact Theory (PCT), also known as the propinquity effect, suggests that relationships form when people are regularly at the same physical location. Festinger et al. (1950) showed that PCT applied in the context of residence, however it is unclear whether this will hold for the more transitory setting of public transport.

Previous evidence for PCT relies on two important premises. First, consistency of distance; most PCT studies used residential settings, where distance to the nearest neighbour is constant. Second, that the group studied is essentially homogenous; 
the housing project studied by Festinger et al. (1950) examined relationships among a group of students that had inherent similarities, such as age and lifestyle.

Previous research has found that public transport users are socially heterogeneous (Mitchelson, 1982; Parolin, 1992), and social commentaries describe using public transport as a "variegated social experience" (Hood, 1996, p. 309). The heterogeneity of public transport users may impede passive contacts from inducing any relationship with other users. Griffitt and Veitch (1974) found that people with dissimilar attitudes were less likely to form friendships when placed in a fall-out shelter together for ten days. Siegfried, Tedeschi and Cann (1982) found that perceived passenger heterogeneity reduced willingness to ride the bus.

Findings regarding actual transport behaviour vary, with Mitchelson (1982) finding that social heterogeneity did relate to bus patronage in the U.S., but no support for this was found in a replication of Mitchelson's (1982) study in an Australian context (Parolin, 1992). The difference implies greater tolerance of the social mix of people in the Australian setting. Both studies examined travel survey data-sets and used measures of employment status, income, housing type, education, ethnicity, car ownership and residential density as indicators of social heterogeneity. These studies do not benefit from attitudinal data, and so do not account for more complex interactions, such as personality characteristic differences.

Another problem with the formation of relationships with other public transport passengers through passive contacts is that consistency of distance is not assured. Seats are not assigned on buses and trains in New Zealand, and while there is some evidence for a pattern in seating arrangements (Maines, 1977), it is unlikely that the same passengers sit consistently close to each other unless that is their intention. Nash (1975) found that regular bus users did sit together; suggesting that over time passive contact does lead to friendship.

Nash (1975) identified three interrelated factors that encouraged social interactions on buses; the experience or competency of passengers and drivers, the density of people or crowdedness, and the duration of the ride. Competency implies familiarity or comfort with the social schema, which can lead to a relaxed 
atmosphere more conducive to social interaction. It also relates to recognition of the other regular patrons that utilise the same service on their daily commute and have commonality of travel destination. Regular patrons have a larger number of passive contacts with each other, which relates to social interaction and friendship according to Festinger et al.'s (1950) passive contact theory.

Crowdedness leads to greater deindividuation and a reduced sense of social responsibility (Geen, 1991). The responsibility to either acknowledge the presence or intentionally ignore and avoid eye contact with the intimately close adjacent passenger is reduced under crowded situations. Sommer (1969) suggests that the public transport context removes privacy, dignity and individuality to the point where it is difficult to interact with others.

In terms of the duration of the ride, it may be less stressful to maintain a social defence for a short period of time. Previous research in the context of psychiatric institutions, park benches and university libraries has used the duration spent in an intimate distance to a stranger as a measure of social discomfort (Felipe \& Sommer, 1966; Patterson, Mullens \& Romano, 1971). Similarly, Epstein et al. (1981) found that discomfort (measured by skin conductance levels to indicate physiological stress) was higher, and increased at a faster rate on crowded conditions compared with non-crowded (designed to simulate a seated public transport setting).

In this research, train users waiting at train platforms are given questionnaires to examine the influences of social discomfort on public transport. There is a particular focus on perceived social heterogeneity, the interpersonal distance of other passengers, and strategies to reduce discomfort. A further aim is to examine the latent factors underlying positive social interaction and friendship formation on public transport, and test whether the assumptions of PCT hold for a transient, heterogeneous group. It is expected that PCT is more likely to hold if passengers prefer to sit in the same section of the same carriage, such that they are likely to be surrounded by the same "familiar strangers" (Milgram, 1977). Evidence of PCT will be that regular public transport users and passengers with longer duration trips will have more train friendships and be more open to social interaction than less regular passengers. 


\section{Method}

\section{Participants}

A sample of participants was taken from members of the public who were waiting at four train platforms within the Greater Wellington region of New Zealand. Questionnaires were handed to people at Melling station ( $n=140$; completed returns $=78)$, Johnsonville station ( $n=168$; completed returns $=91)$, Upper Hutt station ( $n=157$; completed returns $=103)$ and Masterton station $(n=135$; completed returns $=76$ ). Of the 600 questionnaires handed out, 387 were returned by mail (response rate $=65 \%$ ), and of these, 366 were complete.

Participants were primarily train users, with 317 (87\%) responding that they primarily travelled by train to their main weekly activity, with the remaining 49 (13\%) indicating that they had travelled by train at some point. Closer examination of the remaining 49 participants' weekly train use revealed that 31 of them travelled by train at least three days a week. These were recoded as train users for the purpose of all following analyses, increasing the regular train users in the sample up to 348 (95\%). The remaining $5 \%$ of participants (14 motor vehicle drivers, two cyclists, one walker and one bus user) were not included as they were not regular train users.

The average household income for participants was $\$ 85,000$ ( $S D=\$ 34,270$; New Zealand dollars), with an average participant age of 39.87 years ( $\mathrm{SD}=12.12$ years). Table 4.1 shows a summary of other participant characteristics. 
The sample was primarily of New Zealand European ethnicity, as was expected. The 2006 New Zealand Census found that the majority (78.7\%) of the population identifies itself as either New Zealand European or New Zealand (Statistics New Zealand, 2008c). ${ }^{1}$ The Ethnicity variable was collapsed into New Zealand European and other for the purposes of all further analyses due to low cell sizes in the other ethnicity categories.

Table 4.1.

Summary of Participant Characteristics

\begin{tabular}{llrc}
\hline Characteristic & & $n$ & $\%$ \\
\hline Gender & Male & 162 & $48.4 \%$ \\
& Female & 173 & $51.6 \%$ \\
& High school qualification & 78 & $23.6 \%$ \\
& Other post-school qualification & 91 & $27.6 \%$ \\
Ethnicity & Bachelor degree & 104 & $31.5 \%$ \\
& Higher degree & 57 & $17.3 \%$ \\
& New Zealand European & 254 & $76.3 \%$ \\
& Maori & 15 & $4.5 \%$ \\
& Asian & 22 & $6.6 \%$ \\
& Indian & 5 & $1.5 \%$ \\
& Pacific Islander & 2 & $0.6 \%$ \\
& Other & 35 & $10.5 \%$ \\
\hline
\end{tabular}

\section{Train Station Sample Selection}

Train stations from the Wellington region were initially identified as samples of geographic convenience. To ensure that train routes from the Wellington region would encompass a range of socially homogenous and heterogeneous locations a preliminary visual analysis of the region was performed using Quickmap software.

\footnotetext{
${ }^{1}$ The New Zealand Census is taken every five years, and collects an official population and dwelling count including key demographic information such as ethnicity, gender, age and income. Participation is legally required by all New Zealanders so the data collected provides the most comprehensive representation of New Zealanders and their households.
} 
The Quickmap software was loaded with data from the 2006 New Zealand Census, which contains many key sociodemographic variables, including median household income.

According to the Household Income Survey (Statistics New Zealand, 2008a) the median household income for New Zealand was approximately \$70,000 in 2007. The data was split between small geographic units called meshblocks with above and below $\$ 70,000$ median household income to determine high and low income regions. ${ }^{2}$ The sections of Figure 4.1 surrounded by black highlight the high income meshblocks (with more than \$70,000 median household incomes) and the sections highlighted in black in Figure 4.2 indicate the low income meshblocks (with less than $\$ 70,000$ median household incomes). The meshblocks along the different rail corridors give both heterogeneous (e.g. Melling or Johnsonville) and homogenous (e.g. Masterton or Upper Hutt) groups of train users (see Figures 4.1 and 4.2 and Table 4.2). While this method was not refined, it did give an indication that the Wellington region had a reasonable social mix from which to sample.

Table 4.2.

Trip Duration and Median Income Heterogeneity Ratings of the Train Corridor into Wellington City

\begin{tabular}{|c|c|c|c|c|}
\hline \multirow[b]{2}{*}{ Train line } & \multirow{2}{*}{$\begin{array}{l}\text { Trip } \\
\text { duration } \\
\text { (mins) }\end{array}$} & \multicolumn{3}{|c|}{ Visual heterogeneity rating of train line segment } \\
\hline & & Start & Middle & End (Wellington CBD) \\
\hline Melling & 20 & Mixed & Mixed & Mixed \\
\hline Johnsonville & 22 & Low & High & High \\
\hline Upper Hutt & 45 & Low & Low & Mixed \\
\hline Masterton & 100 & Low & Low & Mixed \\
\hline
\end{tabular}

\footnotetext{
2 Definition of meshblock: "The meshblock is the smallest geographic unit for which statistical data is collected and processed by Statistics New Zealand. A meshblock is a defined geographic area, varying in size from part of a city block to large areas of rural land. Each meshblock abuts against another to form a network covering all of New Zealand including coasts and inlets, and extending out to the two hundred mile economic zone. Meshblocks are added together to 'build up' larger geographic areas such as area units and urban areas. They are also the principal unit used to drawup and define electoral district and local authority boundaries" (Statistics New Zealand, 2008b).
} 


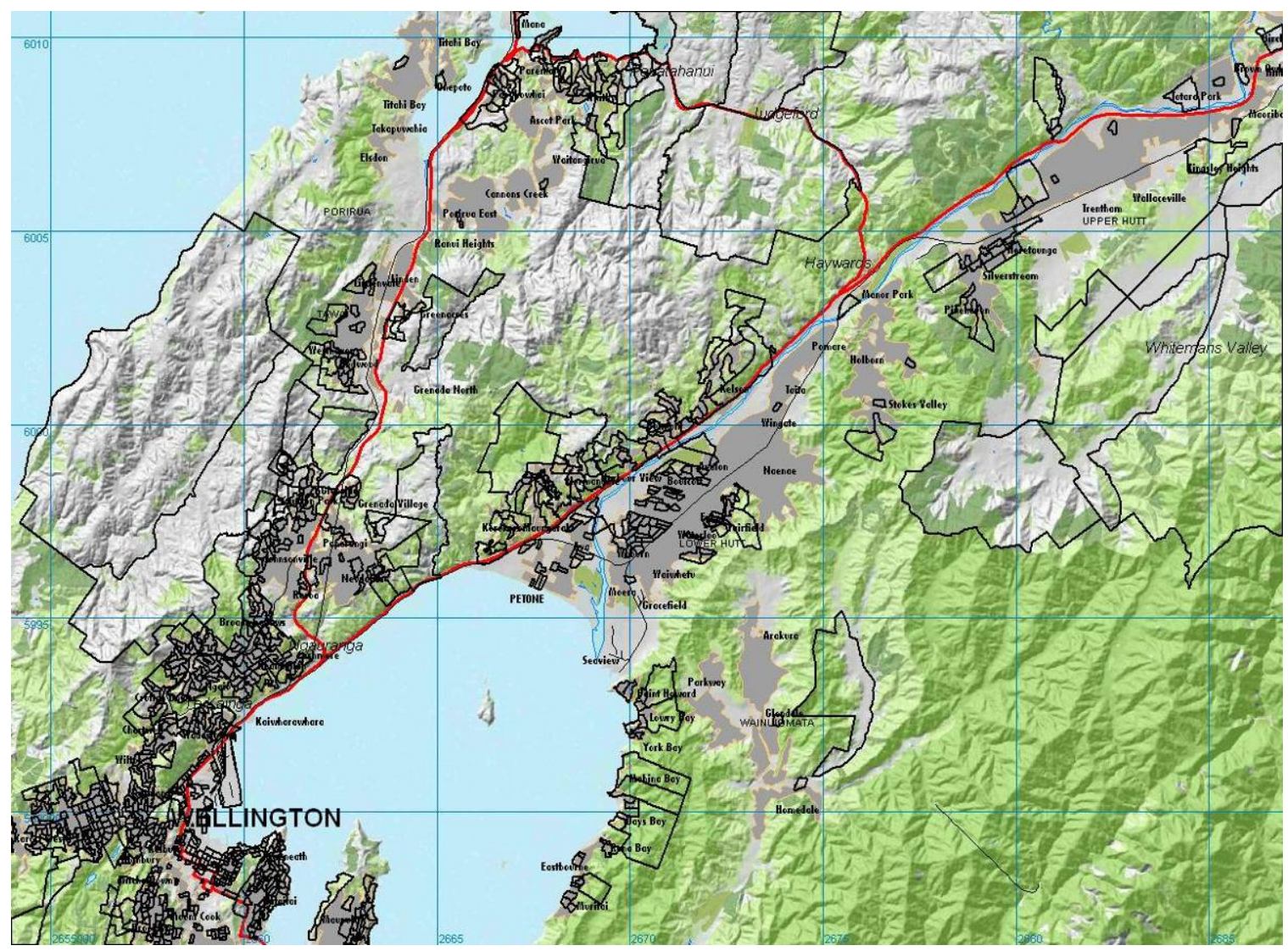

Figure 4.1. Above \$70,oooNZ household income locations (high income meshblock areas are indicated by dark boundaries).

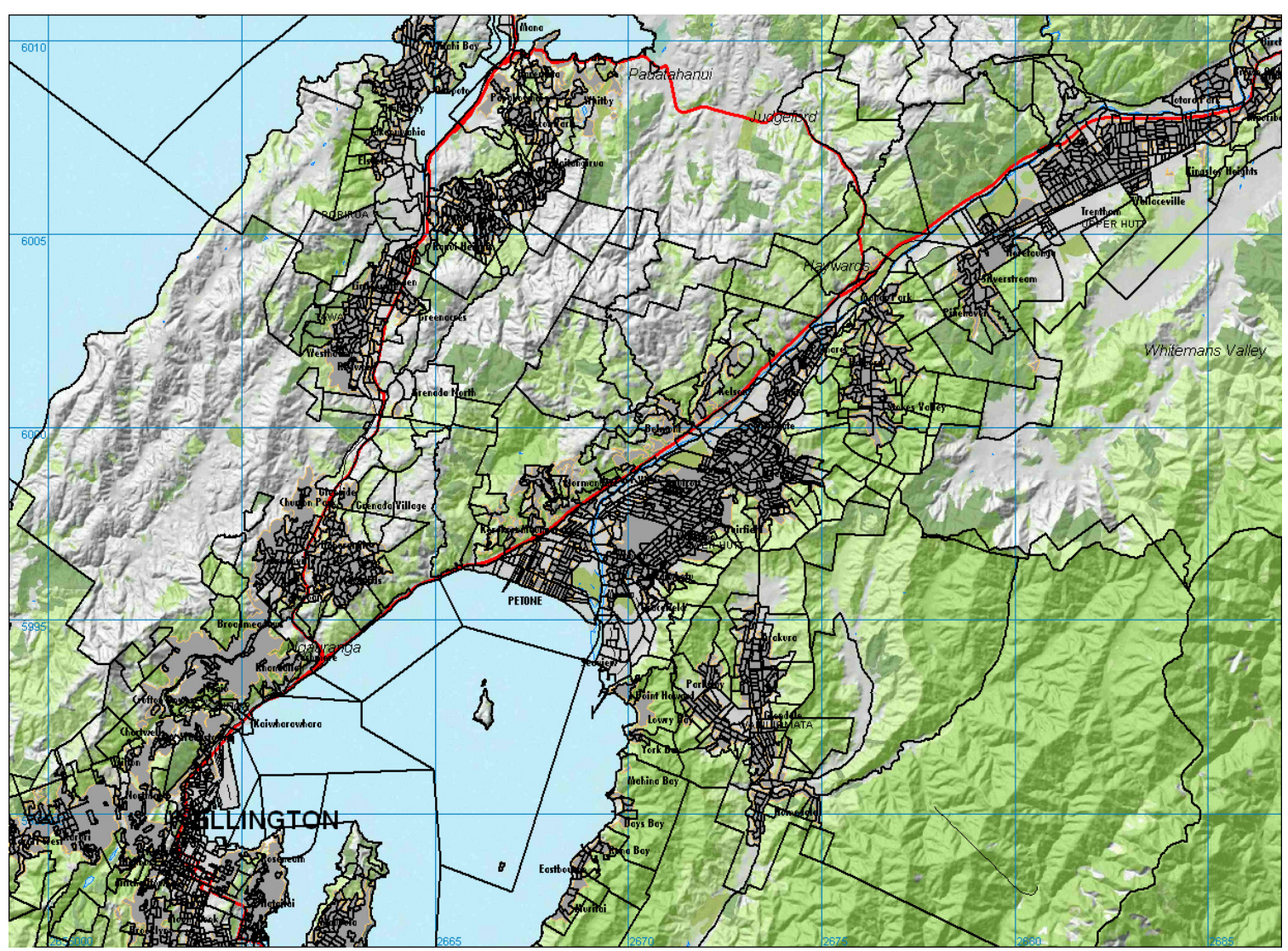

Figure 4.2. Below \$70,oooNZ household income locations (low income meshblock areas are indicated by dark boundaries). 


\section{Materials}

\section{Questionnaire pack}

The questionnaire pack included a questionnaire, a freepost return envelope and a prize draw card to go into the draw to win $\$ 500$ worth of vouchers (e.g. book, petrol or public transport vouchers). The questionnaire was printed on colour paper, had a VUW logo, and the introduction, which described the purpose of the questionnaire, was personally signed to encourage higher response rates. Examinations of previous research via meta-analyses have identified that university sponsorship, monetary incentive, inclusion of a freepost return envelope, and questionnaire colour all increase response rates (Fox, Crask \& Kim, 1988; Yammarino, Skinner \& Childers, 1991).

Participants were clearly informed on the front page of the questionnaire that their answers were entirely confidential to encourage open, honest answers, and reduce biases such as Socially Desirable Responding (see Paulhus, 1991 for more information on perceived anonymity and response biases). Questionnaires were not numbered or otherwise distinguished with any identifying marks. Only the prize draw card required contact information and participants were clearly informed that their contact details would never be matched with their survey responses. They were also informed that their details would only be used to notify them if they won the prize draw and would be destroyed after the prize draw.

\section{Variables examined}

The questionnaire was made up of 137 items targeting social comfort and the perceived heterogeneity of the sample. Appendix B shows the train questionnaire. Table 4.3 gives a summary of the key dependent measures, with a more detailed description of the scales to follow in the text. Parolin (1992) and Mitchelson (1982) identified key demographic measures relating to mode choice. 
Table 4.3.

Summary of Key Dependent Measures

Key variables

Social Interaction,

Politeness and IPD

Discomfort

Applied social

discomfort

Self-other

characteristic

assessments

Touch avoidance

Defensive behaviour

Relationship

likelihood
Description

Items to measure the latent social atmosphere, for example, "the passenger next to me will talk to me" and elements of IPD discomfort, for example, "I am a comfortable distance to the next passenger."

This scale was adapted from Lawrence's (2006) Social Comfort scale, and is applied to public transport, a public transport platform and a neighbourhood setting (e.g. "I feel like I don't fit in with the other people on my train").

This scale was adapted from Olmstead and Durham's (1976) characteristic assessment scale, applied to self, train users and people from their neighbourhood. It taps into personality characteristics such as sincerity, wisdom and warmth.

An adapted version of Andersen and Liebowitz's (1978) touch avoidance scale (e.g. "I don't like to touch my friends")

A scale of reported defensive behaviours designed specifically for the public transport setting, developed from behaviours in the Observation study and tested on a sample of students in the Exploratory study (e.g. "I like to spread out so no one will sit next to me").

Items to measure the latent ability to make acquaintance in the train and neighbourhood settings (adapted from Festinger \& Kelley, 1951). For example, "how likely are you to make a good friend on the train?"

Several of these demographics were measured, including employment status, income, housing type, education, ethnicity, car ownership and residential density. At the end of the questionnaire participants were given the opportunity to provide written comment on any aspect of the research. These comments were used, where appropriate, to highlight and expand upon results.

\section{Social interaction, politeness and IPD discomfort}

Fifteen, five-point Likert-scale items were developed to examine likelihood $(1=$ Very unlikely" through to 5 = "Very likely") of politeness, social interaction, and 
interpersonal distance (IPD) discomfort. These items were placed together as it was expected that passenger density and social interaction interrelate (see Nash, 1975). An exploratory factor analysis was used to reduce these measures into their latent constructs statistically (see Social Interaction, Politeness and IPD Discomfort in the Results section).

IPD discomfort measures were made up of items such as "I was too close to another passenger" or "the train feels stuffy because there are so many people". The Social Interaction measures focussed on the presence of interactions with passengers (e.g. "passengers acknowledged the person they sat next to by making eye contact or saying hello"), as well as indications of the latent social atmosphere (e.g. "other passengers smile at me if we make eye contact"). Politeness items were also examined (e.g. "passengers apologise if they accidentally touch me").

\section{Applied social discomfort}

Lawrence et al.'s (2006) eight-item Social Comfort scale was adapted and altered specifically to three different social settings; train, train platform and neighbourhood. 3 For example, "I like meeting new people" was adapted to "I like meeting new people on my regular train", "I like meeting people when waiting on the local train platform" and "I like meeting people from my neighbourhood". The item "No one can understand me" was removed as it was deemed too general. Discomfort items were measured using five-point Likert scales ( $1=$ "Strongly disagree" through to $5=$ "Strongly agree").

\section{Self-other assessment differences}

An adapted version of Olmstead and Durham's (1976) scale was applied to self, other train passengers and neighbours. The scale was shortened from Olmstead and Durham's (1976) original 12-item scale down to a five-item scale due to the

3 Liebowitz's (1987) Social Anxiety was a better predictor of public transport use than Lawrence et al.'s (2006) Social Comfort in the Exploratory study. However, Social Comfort was selected over Social Anxiety as it was shorter, more adaptable to different social settings and tapped into similar concepts. For example, "I like meeting new people" compared with "I am comfortable approaching someone I don't know to make new friends". Many of the examples used in the Social Anxiety scale relate directly to specific social situations that do not include public transport, and so this scale is difficult to adapt. For these reasons it was deemed appropriate to use a more tailored version of the Social Comfort scale for the studies that follow. 
need for brevity in the questionnaire. Items were identified for removal by using data from another study (Wilson \& Bryson, 2004) that recently used Olmstead and Durham's (1976) scale to examine the same general population, that is, people living in the greater Wellington region. Only data for the following target groups was used for this analysis: Me, Average Man, Average Woman, Most People. These four groups (of the possible 12 groups) were selected as examining attitudes towards specific groups, such as people with mental illnesses, was not the focus of this study.

Items that showed the lowest inter-item scale correlations in Wilson and Bryson's (2004) data were removed until the scale was reduced from 12 items (with a Cronbach's alpha of 0.73), down to five items (with a Cronbach's alpha of 0.81). Three items were added to the scale, including two items relating to perceived status that examined attitudes towards poverty and education, and a further item that examined perceived attractiveness. Table 4.4 shows the final eight characteristics being measured.

Table 4.4.

Self-other Scale Characteristics

Characteristics

Insincere-Sincere

Wise-Foolish (R)

Cold-Warm

Safe-Dangerous (R)

Dirty-Clean

Attractive-Unattractive (R)

Poor-Rich

Educated-Uneducated (R)

$(\mathrm{R})=$ Reverse item

Participants were asked to place a mark on an 11-point, numbered, continuous line (from 0-10) using these polar opposite semantic anchors shown (see Table 4.4). Low scores represented negative assessments of the individual or group under consideration and high scores represented positive assessments. 


\section{Touch avoidance}

Eighteen items adapted from Anderson and Leibowitz (1978) examined same-sex touch avoidance (e.g. "I find it difficult to be touched by a member of my own sex") and opposite sex touch avoidance (e.g. "When a member of the opposite sex touches me, I find it unpleasant"). A shortened version of the Touch Avoidance scale was developed. Data from the Exploratory study were used to identify items for removal (following the same process as used for the self-other assessment scale above). The four items with the highest inter-item scale correlation scores from the Exploratory study were kept for the shortened scale. The shortened scale had a high internal reliability (Cronbach's Alpha $=0.76$ ) and a high level of correlation with Anderson and Leibowitz's (1978) original 18-item Touch Avoidance scale $($ correlation $=0.77)$.

All four items in the shortened scale related to the same gender, so wording such as "same sex" was removed to make the scale more general. The four items were all worded positively towards touch, so to reduce participant response bias (such as acquiescence bias, see Paulhus, 1991) items were reversed.

\section{Defensive behaviour}

A 13-item scale was developed from actual behaviours in the Observational Chapter and tested in the Explanatory Chapter to examine defensive behaviour. This scale examines reported seat selection preferences, activities and behaviours that reduce social interaction and defend territory in the public transport setting.

\section{Friendship formation}

A four-item scale examined progressive stages of friendship formation, from likelihood of making an acquaintance on public transport through to inviting someone to a social event or becoming good friends. These items have been adapted from Festinger and Kelley's (1951) investigation of friendship formation in different neighbourhoods. 


\section{Procedure}

The sample of participants was made up of members of the public who were waiting to board at selected train platforms. Participants were approached by two experimenters on train platforms, given a brief description of the research and asked if they wished to volunteer. Participants either filled in the questionnaire during their train ride or at a later stage, and returned it in the prepaid envelope provided.

Ethical approval was gained for this study, with the questionnaire and the procedure being deemed appropriate. Consent was also gained from the agencies in charge of the train stations where the questionnaire was to be handed out. The agencies were informed of which stations, and when the experimenters would be distributing the questionnaire, so that station staff could be informed.

\section{Results}

\section{Scale Reliability}

Table 4.5 shows a summary of the scale scores, including the sample size, number of items in the scale, the internal reliability of the scale (Cronbach's alpha), the scale range, mean and standard deviation. All scale scores were formed by taking the mean score of its component items. The mean was selected instead of aggregating the item scores to increase the number of respondents. A mean score was calculated for any participant that filled in at least $50 \%$ of the items.

The scales were normally distributed, with no signs of skew (skew values were all under 1), and only minor indications of central clustering (with some positive kurtosis values, but all of these were under 2, which is acceptable given the sample is over 300, see Fife-Schaw, 2008). All scales had acceptable levels of internal reliability, with Cronbach's alpha scores of 0.7 or above (Christmann \& Van Aelst, 2006). Correlation analysis for the scales is shown in Table 4.6. Defensive Behaviour forms a negative relationship with Social Interaction and Train Relationships and a positive relationship with Social Discomfort on the Train. 
Table 4.5.

Scale Descriptives and Alpha Scores

\begin{tabular}{lcccccc}
\hline & \multicolumn{5}{c}{$\begin{array}{c}\text { Number } \\
\text { of items }\end{array}$} & \multicolumn{3}{c}{ Scale } \\
Scale & $N$ & in scale & Alpha & range & $M$ \\
\hline Social Interaction & 348 & 6 & 0.71 & $1-5$ & 2.95 & $(0.67)$ \\
Interpersonal Discomfort & 348 & 6 & 0.70 & $1-5$ & 3.11 & $(0.71)$ \\
Self Assessment & 337 & 8 & 0.71 & $0-10$ & 7.48 & $(1.01)$ \\
Train User Assessment & 302 & 8 & 0.78 & $0-10$ & 6.35 & $(0.97)$ \\
Neighbour Assessment & 317 & 8 & 0.86 & $0-10$ & 6.66 & $(1.21)$ \\
Social Discomfort (Train) & 348 & 7 & 0.72 & $1-5$ & 2.58 & $(0.50)$ \\
Social Discomfort (Train platform) & 348 & 7 & 0.80 & $1-5$ & 2.62 & $(0.51)$ \\
Social Discomfort (Neighbourhood) & 348 & 7 & 0.87 & $1-5$ & 2.43 & $(0.57)$ \\
Defensive Behaviour & 348 & 13 & 0.75 & $1-5$ & 2.74 & $(0.48)$ \\
Touch Avoidance & 348 & 4 & 0.70 & $1-5$ & 2.53 & $(0.66)$ \\
Train Relationship & 348 & 4 & 0.88 & $1-5$ & 2.45 & $(0.97)$ \\
Neighbourhood Relationship & 348 & 4 & 0.84 & $1-5$ & 3.45 & $(0.80)$ \\
\hline
\end{tabular}

Note: Standard Deviations are in parentheses.

\section{Social Interaction, Politeness and IPD Discomfort}

The 15 items that examined passenger interaction, politeness, and discomfort caused by close IPDs were placed into a factor analysis. Initial testing revealed that this data was suitable for factor analysis. The Kaiser-Meyer-Olkin measure of sampling adequacy was satisfactory (0.73) indicating that a factor analysis would be useful, and the Bartlett's test of sphericity was significant $\left(X^{2}(105)=957.98, p\right.$ $<$.05), suggesting significant relationships between the variables.

A principal components factor analysis revealed four factors with eigenvalues above 1.0o. The "scree criterion" (Cattell, 1966) was used to examine where the gradient of the scree plot decreased substantially. According to this criterion either a two-factor or three-factor solution was appropriate. The three-factor solution was not used as it had several items that loaded on more than one factor (even after oblimin and orthogonal rotations), and it was more difficult to clearly identify the underlying construct (both logically and statistically, as the factors had lower Cronbach's alpha scores in the three-factor solution). 


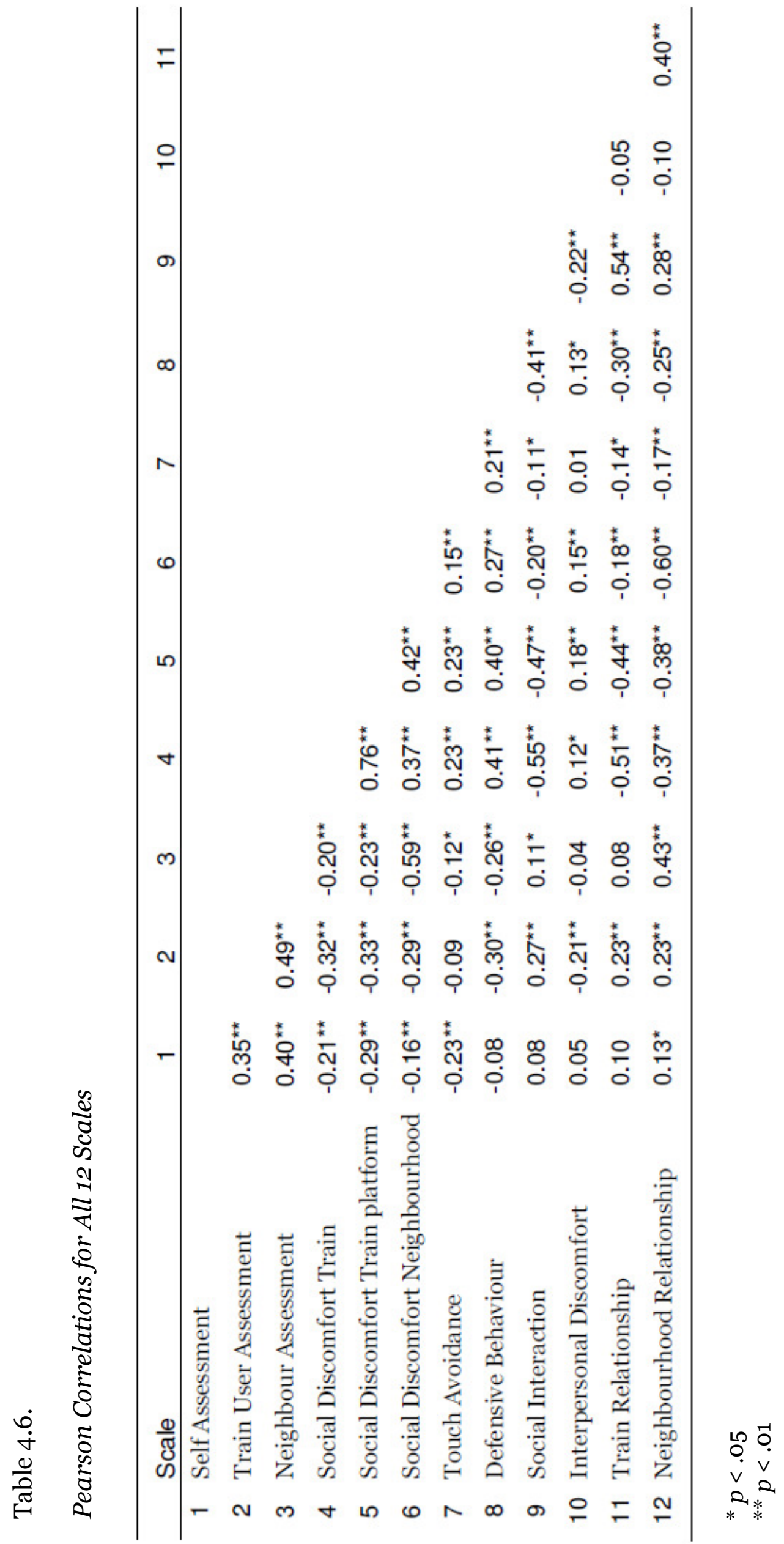


A varimax rotation revealed that items loaded well in relation to Social Interaction (Factor 1) and Interpersonal Distance Discomfort (Factor 2). Two items relating to politeness were discarded as they had factor loading scores below 0.3: "Passengers apologise if they accidentally touch me" and "Passengers place bags on the seats next to them to stop someone from sitting next to them." A further item relating to Social Interaction was removed to increase internal reliability: "I sit with other regular train passengers." Social Interaction (SI Cronbach's alpha $=0.71$ ) and Interpersonal Distance Discomfort (IPD Cronbach's alpha $=0.70$ ) both show good internal reliability.

Table 4.7 shows the final factor solution for the exploratory factor analysis. The item "I feel comfortable with the passenger that selects the seat beside me" loaded onto SI instead of IPD, but this may just indicate the necessity of social comfort with other passengers if social interaction is to occur.

\section{Politeness}

The items relating to politeness did not load on the SI or IPD factors, and did not form a separate factor. It appears that some passengers have very strong social rules that they apply to public settings, and when these are not obeyed by other users it can promote strong negative attitudes.

"I do get up regularly for elderly or female passengers and find it appalling that the overwhelming majority (basically everyone) rather keeps sitting instead of offering a seat." (Train participant number 349)

However, the overall opinion was that passengers were generally polite. For example, they were not perceived to be noisy and inconsiderate $(M=2.43, S D=$ 0.91), and they apologised if they accidently touched other passengers $(M=3.24$, $S D=1.16$ ). It may just be that people focus on other passengers' poor behaviour and ignore their own, indicating a self-enhancement bias.

When self-other measures of politeness were examined, there was some evidence of self-enhancement bias (or perhaps socially desirable responding) when it came to questions relating to self-assessment. Post hoc tests revealed a difference in participants' perception of others, such that others were perceived to be more likely to place a bag on the seat next to them to prevent train users from sitting 
there $(M=3.10, S D=1.18)$ when compared with themselves $(M=2.10, S D=0.85$; $t(346)=14.64, p<.001)$.

Table 4.7.

Factor Loadings, Means and Standard Deviations for the Two-Factor Solution

\begin{tabular}{|c|c|c|c|c|}
\hline Item & & & Factor1 & Factor2 \\
\hline $\begin{array}{l}\text { Passengers acknowledge me if I sit next to } \\
\text { them, by making eye contact or saying hello }\end{array}$ & 2.63 & $(1.10)$ & 0.73 & \\
\hline The passenger next to me will talk to me & 2.12 & $(1.25)$ & 0.70 & \\
\hline $\begin{array}{l}\text { I try to ignore the train passenger next to me } \\
\text { (R) }\end{array}$ & 2.83 & $(1.10)$ & 0.70 & \\
\hline $\begin{array}{l}\text { Other passengers smile at me if we make eye } \\
\text { contact }\end{array}$ & 3.23 & $(1.06)$ & 0.55 & \\
\hline $\begin{array}{l}\text { I feel comfortable with the passenger that } \\
\text { selects the seat beside me }\end{array}$ & 3.83 & $(0.78)$ & 0.53 & \\
\hline $\begin{array}{l}\text { Seated passengers avoid looking at me as I } \\
\text { board the train (R) }\end{array}$ & 3.00 & $(0.93)$ & 0.51 & \\
\hline The train is too crowded & 3.33 & $(1.18)$ & & 0.74 \\
\hline $\begin{array}{l}\text { The train feels stuffy because there are so } \\
\text { many people }\end{array}$ & 3.16 & $(1.12)$ & & 0.74 \\
\hline $\begin{array}{l}\text { The passenger sitting next to me takes up } \\
\text { more than their share of the room on the } \\
\text { seat }\end{array}$ & 2.76 & $(0.98)$ & & 0.64 \\
\hline $\begin{array}{l}\text { I am a comfortable distance to the nearest } \\
\text { passenger }(\mathrm{R})\end{array}$ & 2.72 & $(1.09)$ & & 0.61 \\
\hline $\begin{array}{l}\text { A passenger appears uncomfortable with the } \\
\text { person seated next to them }\end{array}$ & 2.76 & $(1.01)$ & & 0.53 \\
\hline I sit with no one directly next to me (R) & 3.92 & $(1.31)$ & & 0.51 \\
\hline Eigenvalue & & & 3.11 & 2.00 \\
\hline Explained variance & & & $25.94 \%$ & $16.58 \%$ \\
\hline Cronbach's Alpha & & & 0.71 & 0.70 \\
\hline
\end{tabular}

Note: $\mathrm{N}=328$. Explained variance (cumulative): 42.52\%; (R) = Reverse item; Factor loadings below 0.30 are not shown.

Standard Deviations are in parentheses.

\section{Self-Other Characteristic Assessment Analysis}

\section{Characteristic assessment scale counterbalancing issues}

Several participants failed to respond correctly to Olmstead and Durham's (1976) revised self-other personal assessment scale. These items were intentionally counterbalanced to check participants were responding to individual items correctly and so that their responses were not being influenced by the formatting 
of the item. For example, if they all had positive anchors on the right it may have biased some responses towards the right.

Some of the participants that expressed difficulty with these questions selfcorrected for the counterbalanced items by ticking or circling the word anchor to indicate that there scale response needed reversing (often with comments explaining what they had done).

Others that failed to respond correctly to the counterbalanced items were identified by examining the differences between the positively and negatively anchored items. First, the negatively coded items were reverse coded, so that someone who failed to respond to the counterbalancing would have quite different scores on the positive items compared with the negative. Second, mean scale scores were calculated for the four positively and four negatively anchored items and the difference between these scale scores was calculated. Third, the mean and standard deviation of the difference score was calculated. If the difference between positive and negative scale scores for an individual fell outside three standard deviations from the overall mean difference then they were identified as having made this error and their data for these items was removed from the dataset. This process was repeated across each assessment group with the following removals: Self, $\mathrm{n}=15$; Train user, $\mathrm{n}=17$; Neighbour, $\mathrm{n}=15$ (across 37 participants).

The analyst examined the individual cases identified by this process to ensure only cases with this type of error were removed. Examples of the error include those participants that responded that people are sincere and dangerous, wise and uneducated, and dirty and attractive. While these concepts were not necessarily exclusive, participants identified by this process were found to be making systemic errors rather than responding to the specific item content.

\section{Character assessment scale neutral response issues}

It was observed that many participants responded to the self items with scale variation and non-neutral replies (indicating understanding of the scale). They then consistently used neutral responses for all assessments of other people in train, train platform and neighbourhood settings. Neutral responses to items are 
fine, but when they occur repeatedly they may be a function of a systemic error, or even an indication of participant fatigue. Responses to other items and scales by the same individuals showed variation, indicating that this was not a fatigue response, suggesting there must be another explanation.

One explanation of this was that people were very diverse in their characteristics, such that a neutral response was the most accurate response in their opinion.

"Jonhsonville has a fairly diverse population, so it's pretty much impossible to judge character traits as anything other than halfway on any scale." (Train participant number 357)

Another explanation was that people did not like to make these judgements or stereotypes based on limited information.

"I question the relevance of identifying personal characteristics of other passengers since I have no idea of them." (Train participant number 271)

So individuals with neutral responses were identified by selecting individuals with with 75\% (or 6 out of 8) scale responses the same and a Mode of five. Neutral responses were removed from the analysis for the Self ( $n=1,0.3 \%$ ), Train User ( $n$ $=29,8.3 \%)$ and Neighbourhood User $(n=23,6.6 \%)$ characteristic assessments.

"What other people are like has no bearing at all on me when I use public transport - I use public transport because I need to...there are some people in my neighbourhood whom I would not want to sit next to!" (Train participant number 377)

\section{Character assessment analyses}

Character Assessment ratings were above five (neutral) indicating positive assessments of Self $(M=7.53, S D=1.00)$, Train users $(M=6.36, S D=0.97)$ and people from their Neighbourhood $(M=6.65, S D=1.20)$. Character Assessment scale scores were significantly different when assessment scores were compared within subjects for Self, Train users and Neighbours using a repeated measures ANOVA $(F(2,566)=158.41, p<.001)$. Post hoc tests revealed significant differences between all three groups, such that Self was rated more highly than Neighbourhood $(\mathrm{t}(307)=12.61, \mathrm{p}<.001)$ which in turn was rated more highly than Train $(\mathrm{t}(287)=-4.67, \mathrm{p}<.001)$. 
Measures of train and neighbourhood heterogeneity were also created by subtracting train assessment scores from self assessment scores (train heterogeneity) and neighbourhood assessment scores from self assessment scores (neighbourhood heterogeneity).

There was some commentary indicating that participants recognised and experienced some unease over stereotyping other passengers. It also suggests that participants may stereotype other passengers without explicitly processing what they are doing.

"Thought I was a happy smilie train traveller. After survey decided I stereotype train travellers too. Will try not too in the future: )" (Train participant number 358)

\section{Social Discomfort Analysis}

All discomfort ratings were below three (neutral) indicating a perception of comfort with the people from the train $(M=2.58, S D=0.50)$, the train platform $(M=2.62, S D=0.51)$ and their neighbourhood $(M=2.43, S D=0.57)$. A repeated measures analysis of variance (ANOVA) found significant differences in attitudes to Social Discomfort within subjects for the three applied settings $(F(2,527)=$ 25.48, $p$ <.001). 4 Post hoc tests found that comfort with people in the neighbourhood was significantly higher than comfort with people at the train platform $(t(347)=5.98, p<.001)$ or on the train $(t(347)=5.98, p<.001)$. There was no difference between train and train platform in relation to Social Discomfort $(t(347)=-1.72, p=.07, n s)$.

A stepwise linear regression was used to examine the covariates of train social discomfort (TSD). The following 33 key variables were placed into the regression

\footnotetext{
${ }^{4}$ A Greenhouse-Geisser test was used here as sphericity was not assumed.
} 
in this order: percent of other passengers perceived to be regulars; perception I am a train regular; experience with current train route (years); perceived future train use (years); self-assessment; train user assessment; neighbourhood assessment; touch avoidance; social interaction; train heterogeneity; neighbourhood heterogeneity; train relationships; neighbourhood relationships; relationship status; education; income; age; ethnicity (NZ European or other); gender; number of household vehicles; privacy on the train; personal preference for social interaction; perceived preference of other train users for social interaction; how full the train was when boarding; how full the train was when departing; distance required to travel to main activity $(\mathrm{km})$; duration of travel by train (mins); weekly train travel (days); housing density of neighbourhood; experience with current neighbourhood (years); neighbourhood social discomfort; defensive behaviour; IPD discomfort. 5 The stepwise criterion for entry into the model was a $p$ value of .05 and the criterion for exclusion from the model was a $p$ value of .10 .

Table 4.8.

Stepwise Linear Regression of TSD on Key Questionnaire Items

\begin{tabular}{lccccccc}
\hline & & & & & & \multicolumn{2}{c}{ Correlation } \\
\cline { 6 - 8 } & B & SE & Beta & $t$ & Sig. & Part & Partial \\
\hline $\begin{array}{l}\text { Neighbourhood } \\
\text { Discomfort }\end{array}$ & 0.18 & 0.04 & 0.21 & 4.40 & 0.001 & 0.26 & 0.19 \\
Defensive Behaviour & 0.16 & 0.05 & 0.15 & 3.04 & 0.003 & 0.19 & 0.13 \\
Touch Avoidance & 0.09 & 0.03 & 0.11 & 2.50 & 0.013 & 0.15 & 0.11 \\
Years current train route & -0.06 & 0.03 & -0.10 & -2.24 & 0.026 & -0.14 & -0.10 \\
Percent regulars & -0.10 & 0.03 & -0.15 & -3.52 & 0.001 & -0.21 & -0.15 \\
Education & -0.08 & 0.02 & -0.16 & -3.72 & 0.001 & -0.23 & -0.16 \\
Train Relationship & -0.13 & 0.03 & -0.25 & -4.88 & 0.001 & -0.29 & -0.21 \\
Social Interaction & -0.23 & 0.04 & -0.31 & -5.65 & 0.001 & -0.33 & -0.25 \\
(Constant) & 3.08 & 0.25 & & 12.34 & 0.001 & & \\
\hline
\end{tabular}

The independent variables in the model explained significant variation in the Train Social Discomfort scale $(F(8,259)=33.37, p<.001)$. The final model has a Multiple- $\mathrm{R}$ of 0.71 and an adjusted $\mathrm{R}^{2}$ of 0.49 indicating that $49 \%$ of the variance

\footnotetext{
${ }^{5}$ The Train Station Discomfort was not included in the linear regression as it correlated very highly with Train Discomfort (it was included in all later regression analyses).
} 
in Train Social Discomfort scale scores was explained by the model (see Table 4.8). These findings indicate that in the train setting Defensive Behaviour has a positive relationship with Social Discomfort, whereas Social Interaction and Train Relationships have a negative relationship with Social Discomfort.

\section{Social Atmosphere}

Table 4.9 shows some attitudes to conversation with other passengers $(1=$ Strongly disagree to $5=$ Strongly agree). Passengers reported that they were fairly neutral towards meeting new people on their regular train. However, there was evidence of a social norm not to talk to strangers on the train, with a strong perception that the passenger next to them would not converse back. It was unlikely that this social norm occurred because they found it difficult to talk to other passengers, as respondents did indicate a willingness to start a conversation with a stranger.

"The train is not really for socialising as in the mornings people either want to sleep or read the paper. The train home is a little more social at first but again everyone is tired." (Train participant number 66)

Table 4.9.

Attitudes to Conversation and Relationship Formation with Other Passengers

\begin{tabular}{lcc}
\hline Item & \multicolumn{2}{c}{$M$} \\
\hline The passenger next to me will talk to me & 2.12 & (1.25) \\
I find it difficult to talk to other passengers on my regular train & 2.64 & (0.91) \\
I would never start a conversation with a passenger I didn't know & 2.61 & (1.06) \\
I like meeting new people on my regular train & 3.03 & (0.90) \\
\hline
\end{tabular}

Note: Standard Deviations are in parentheses.

The baseline relationship network developed by train users in train and neighbourhood settings was examined in Table 4.10 (following measures similar to Festinger \& Kelley, 1951). Perceived likelihood of relationship formation and invitation to planned social occasions $(1=$ Strongly disagree to $5=$ Strongly agree), as well as reported frequency of people that were friends, known by name and spoken with, were measured in the train and neighbourhood setting (see Table 4.10). Within-subjects $t$-tests revealed that all relationship measures were higher in the neighbourhood setting, indicating less success of friendship formation in the 
train setting (see Table 4.10). It was perceived that other train passengers were not likely candidates for anything more than an acquaintance (with mean likelihood scores below three and very low frequencies of friends, see Table 4.10). It was unlikely that people met on the train were engaged socially outside of the train setting.

Table 4.10.

Mean Differences for Friendship Formation Measures in the Train and Neighbourhood Settings $(N=348)$.

\begin{tabular}{|c|c|c|c|c|c|}
\hline \multirow{2}{*}{$\begin{array}{l}\text { Item } \\
\text { How likely are you to make a good } \\
\text { friend in this setting? }\end{array}$} & \multicolumn{2}{|c|}{$\begin{array}{c}\text { Train } \\
M\end{array}$} & \multicolumn{2}{|c|}{$\begin{array}{l}\text { Neighbourhood } \\
M\end{array}$} & \multirow{2}{*}{$\frac{\mathrm{Sig}}{* * *}$} \\
\hline & 2.33 & $(1.16)$ & 3.29 & $(0.97)$ & \\
\hline $\begin{array}{l}\text { How likely are you to make an } \\
\text { acquaintance in this setting? }\end{array}$ & 3.19 & (1.11) & 3.84 & $(0.84)$ & $* * *$ \\
\hline $\begin{array}{l}\text { How likely are you to invite } \\
\text { someone you met in this setting to } \\
\text { your home? }\end{array}$ & 2.05 & (1.11) & $3 \cdot 51$ & (1.01) & $* * *$ \\
\hline $\begin{array}{l}\text { How likely are you to invite } \\
\text { someone you met in this setting to } \\
\text { a social event? (e.g. dinner or a } \\
\text { movie) }\end{array}$ & 2.12 & $(1.10)$ & 3.14 & $(1.06)$ & $* * *$ \\
\hline $\begin{array}{l}\text { How many people in this setting } \\
\text { would you call friends? }\end{array}$ & 2.26 & $\left(3.5^{2}\right)$ & 4.05 & $(6.54)$ & $* * *$ \\
\hline $\begin{array}{l}\text { How many people in this setting } \\
\text { do you know by name? }\end{array}$ & 3.24 & (4.69) & 8.56 & (10.91) & $* * *$ \\
\hline $\begin{array}{l}\text { How many people in this setting } \\
\text { have you spoken with? }\end{array}$ & 6.51 & (11.25) & 13.71 & (18.41) & $* * *$ \\
\hline
\end{tabular}

When participants were asked whether they wanted more privacy or more social interaction ( $\mathrm{o}=$ More privacy; $5=$ No Change $; 10=$ More social interaction), approximately $30 \%$ wanted more privacy, $44 \%$ wanted no change and $26 \%$ wanted more social interaction. ${ }^{6}$ When asked what other passengers wanted using the same scale, $48 \%$ of others were perceived to want more privacy, $36 \%$ wanted no change and only $16 \%$ were perceived to want more social interaction. Overall, both

\footnotetext{
${ }^{6}$ A cluster analysis confirms that participants do cluster themselves into groups that want more privacy, more social interaction, and a relatively neutral group. The privacy group has the highest IPD Discomfort, Defence and Train Social Discomfort; the social interaction group has the highest Social Interaction, moderate IPD Discomfort and the lowest Defence and Train Social Discomfort; and the neutral group has moderate Defence, Train Social Discomfort and Social Interaction, and the lowest IPD Discomfort.
} 
self $(M=4.89, S D=2.33)$ and other $(M=4.22, S D=1.93)$ ratings were on the privacy side of the scale. Post hoc tests revealed that others were perceived as wanting significantly more privacy $(t(345)=5.31, p<.001)$.

A stepwise linear regression was used to examine which variables were likely to influence ratings on the social interaction (SI) scale. The same independent variables were used as in the TSD regression, with TSD added as an independent variable and SI used as the dependent variable. The independent variables in the model explained significant variation in the SI scale $(F(5,262)=45.02, p<.001)$. Table 4.11 shows the variables in the final model that has a Multiple-R of 0.68 and an $\mathrm{R}^{2}$ of 0.45 indicating $45 \%$ of the variance in SI scale scores was explained by the model. Latent social interaction is lower amongst passengers that are socially uncomfortable with other passengers (as represented by higher TSD scores) and passengers that engage in defensive behaviours (high Defensive Behaviour scores).

Table 4.11.

Stepwise Linear Regression of SI on Key Questionnaire Items

\begin{tabular}{lccccccc}
\hline & & & & & & \multicolumn{2}{c}{ Correlation } \\
\cline { 7 - 9 } & B & SE & Beta & $t$ & Sig. & Part & Partial \\
\hline Train Relationships & 0.19 & 0.04 & 0.28 & 5.17 & 0.001 & 0.30 & 0.23 \\
$\begin{array}{l}\text { Duration of travel } \\
\text { (mins) }\end{array}$ & 0.06 & 0.02 & 0.18 & 3.76 & 0.001 & 0.23 & 0.17 \\
Privacy & 0.03 & 0.01 & 0.13 & 2.82 & 0.005 & 0.17 & 0.13 \\
Defensive Behaviour & -0.30 & 0.07 & -0.21 & -4.20 & 0.001 & -0.25 & -0.19 \\
Train Social & -0.41 & 0.07 & -0.31 & -5.51 & 0.001 & -0.32 & -0.25 \\
Discomfort (TSD) & & & & & & & \\
(Constant) & 3.96 & 0.28 & & 13.90 & 0.001 & 0.30 & 0.23 \\
\hline
\end{tabular}

Participant feedback identifies some additional areas related to social interaction that are not examined within the questionnaire items. For instance, the occurrence of an unusual or unscripted event, or if people are placed in a similar situation of frustration, it seems to increase social interaction. This is mostly likely due to the temporary creation of a common topic of conversation, and is minor evidence of a latent willingness to converse with other passengers.

"People usually get chatty when there's a train breakdown or delayed trains (talk on the platform)." (Train participant number 78) 
There are numerous comments both positive and negative that suggest that the conductors (ticket collectors) have a large influence on the social atmosphere.

"This survey could have included also the conductors as they are at occasions influencing the atmosphere on the train remarkably. Some staff are extremely cheerful and polite and this can start conversations between staff and passengers and between passengers." (Train participant number 308)

Commentary also examines the physical sterility of the train carriages, and how setting improvements may encourage passenger interaction.

"If I was trying to foster social connectedness interaction on the train I would decorate the train cabins with individual design/art/personality. I would love to see performing arts/busking/themes on the train." (Train participant number 95)

Participant comments revealed a desirability to appear friendly, and felt the need to point out that a lack of interaction was not synonymous with being anti-social.

"Interaction on the train is of no importance to me - not that I'm anti-social! But, getting up, preparing for work, getting there, tends to be done in a bit of an early morning stupor so to sit and read/relax is something to look forward to at the start." (Train participant number 354)

"People usually choose not to interact on the train but I don't necessarily see this as a sign of unfriendliness." (Train participant number 371)

This indicated the possibility of a social desirability bias, where participants wished to make their own responses look more favourable by responding to wanting more social interaction than was actually the case.

\section{Defensive Behaviour}

A stepwise regression was performed following the previous methodology (with 32 independent variables) to examine the factors influencing Defence scale scores. The independent variables in the model explained significant variation in the Defence scale $(F(8,259)=18.83, p<.001)$. The final model that has a Multiple-R of 0.61 and an adjusted $\mathrm{R}^{2}$ of 0.35 indicating $35 \%$ of the variance in the Defence scale scores was explained by the model (see Table 4.12). The model revealed that 
as the duration of travel increases, so do levels of defensive adaptation among respondents. Furthermore, the perception that participants belong to the train setting, as a train regular, lessens the need for defensive behaviours.

Table 4.12.

Stepwise Linear Regression of Defence on Key Questionnaire Items

\begin{tabular}{lccccccc}
\hline & & & & & & \multicolumn{2}{c}{ Correlation } \\
\cline { 7 - 8 } & $\mathrm{B}$ & $\mathrm{SE}$ & Beta & $t$ & Sig. & Partial & Part \\
\hline Train Discomfort & 0.18 & 0.06 & 0.18 & 3.03 & 0.003 & 0.18 & 0.15 \\
Duration of travel & 0.04 & 0.01 & 0.15 & 2.82 & 0.005 & 0.17 & 0.14 \\
Gender & 0.13 & 0.05 & 0.13 & 2.64 & 0.009 & 0.16 & 0.13 \\
Neighbourhood & & & & & & & \\
Heterogeneity & 0.05 & 0.02 & 0.13 & 2.59 & 0.010 & 0.16 & 0.13 \\
Income & 0.03 & 0.02 & 0.11 & 2.16 & 0.032 & 0.13 & 0.11 \\
Train regular & -0.19 & 0.05 & -0.20 & -3.85 & 0.001 & -0.23 & -0.19 \\
I want social & & & & & & & \\
interaction & -0.05 & 0.01 & -0.23 & -4.33 & 0.001 & -0.26 & -0.21 \\
Social Interaction & -0.18 & 0.04 & -0.25 & -3.97 & 0.001 & -0.24 & -0.20 \\
(Constant) & 2.74 & 0.28 & & 9.74 & 0.001 & & \\
\hline
\end{tabular}

\section{IPD Discomfort}

To examine the possible covariates of discomfort due to the close proximity of other train patrons a stepwise linear regression was used to determine which variables influenced ratings on the Interpersonal Distance (IPD) Discomfort scale. The stepwise regression was performed following the previous methodology (with 32 independent variables) to examine the factors influencing IPD Discomfort scale scores.

The independent variables in the model explained significant variation in the IPD Discomfort scale $(F(8,259)=12.62, p<.001)$. The final model that has a Multiple-R of 0.53 and an adjusted $\mathrm{R}^{2}$ of 0.26 indicating $26 \%$ of the variance in the IPD Discomfort scale scores was explained by the model (see Table 4.13). In addition to findings regarding passenger density, a higher perceived need for privacy increases discomfort from close IPD, whereas a desire for social interaction reduces discomfort from close IPDs.

Table 4.13. 
Stepwise Linear Regression of IPD Discomfort on Key Questionnaire Items

\begin{tabular}{lccccccc}
\hline & & & & & & \multicolumn{2}{c}{ Correlation } \\
\cline { 7 - 8 } & B & SE & Beta & $t$ & Sig. & Partial & Part \\
\hline $\begin{array}{l}\text { Train full when } \\
\text { board }\end{array}$ & 0.00 & 0.00 & 0.22 & 4.14 & 0.001 & 0.25 & 0.22 \\
$\begin{array}{l}\text { Train } \\
\text { heterogeneity }\end{array}$ & 0.12 & 0.03 & 0.19 & 3.58 & 0.001 & 0.22 & 0.19 \\
$\begin{array}{l}\text { Train full when } \\
\text { depart }\end{array}$ & 0.00 & 0.00 & 0.15 & 2.81 & 0.005 & 0.17 & 0.15 \\
$\begin{array}{l}\text { Neighbourhood } \\
\text { discomfort }\end{array}$ & 0.16 & 0.07 & 0.13 & 2.44 & 0.015 & 0.15 & 0.13 \\
$\begin{array}{l}\text { Weekly train travel } \\
\text { Education }\end{array}$ & 0.12 & 0.06 & 0.12 & 2.18 & 0.030 & 0.13 & 0.11 \\
$\begin{array}{l}\text { I want social } \\
\text { interaction }\end{array}$ & -0.08 & 0.04 & -0.11 & -2.07 & 0.040 & -0.13 & -0.11 \\
$\begin{array}{l}\text { Privacy } \\
\text { (Constant) }\end{array}$ & -0.05 & 0.02 & -0.15 & -2.78 & 0.006 & -0.17 & -0.15 \\
\hline
\end{tabular}

There was also some commentary to suggest that the trains are overcrowded, and that the seating conditions are too cramped.

"Sometimes the train is so full that the conductor has trouble clipping the tickets. It is a joke!" (Train participant number 330)

"Bus and train seats too close together, I do not fit and my knees get squashedsore!! Maybe an OSH issue? Need more leg room please!!! Very uncomfortable!!!" (Train participant number 303)

"The bain of the train is an obese person taking up all the room. I like to sit next to someone who is small, therefore more room for me." (Train participant number 95)

\section{Location Differences}

The Masterton location differed on several attributes from all of the other locations. Differences between locations show that the Masterton sample has the lowest housing density, longest trip durations, and lowest density of passengers (see Table 4.14). Masterton and Upper Hutt also have more train route experience than Lower Hutt.

ANOVAs were used to examine location differences between scale scores. Social discomfort was not significant across location for the Train setting $(F(3,344)=$ $.81, p>.05)$, the Station setting $(F(3,344)=.71, p>.05)$ and the Neighbourhood 
setting $(F(3,344)=1.464, p>.05)$. The Touch avoidance $(F(3,344)=2.26, p>$ $.05)$ and Neighbourhood relationships $(F(3,344)=2.28, p>.05)$ scales were not significantly different across location. None of the perceived heterogeneity or character assessment scales were significant except for Neighbourhood Characteristics $(F(3,313)=3.55, p<.05)$.

Table 4.14.

Characteristic Differences by Location

\begin{tabular}{|c|c|c|c|c|c|c|}
\hline \multirow{4}{*}{$\begin{array}{l}\text { Characteristic } \\
\text { Experience with train } \\
\text { route (years) }\end{array}$} & \multicolumn{6}{|c|}{ Location } \\
\hline & \multirow{2}{*}{$\begin{array}{c}\text { Lower Hutt } \\
\begin{array}{c}(n=78) \\
M\end{array} \\
\end{array}$} & \multirow{2}{*}{\multicolumn{2}{|c|}{$\begin{array}{c}\text { Johnsonville } \\
\left(\begin{array}{c}n=91) \\
M\end{array}\right. \\
\end{array}$}} & \multirow{2}{*}{\multicolumn{2}{|c|}{$\begin{array}{c}\text { Upper Hutt } \\
(n=103) \\
M\end{array}$}} & \multirow{2}{*}{$\begin{array}{c}\text { Masterton } \\
(n=76) \\
M\end{array}$} \\
\hline & & & & & & \\
\hline & $2.72 \quad(3.27)$ & 3.77 & $(5.76)$ & 5.19 & $(7.01)$ & $4.84 \quad(4.69)$ \\
\hline $\begin{array}{l}\text { Experience in } \\
\text { neighbourhood (years) }\end{array}$ & $3.81 \quad(4.32)$ & 5.26 & $(8.06)$ & 8.09 & $(9.51)$ & $7.63 \quad(10.50)$ \\
\hline $\begin{array}{l}\text { Housing density } \\
(\mathrm{o}=\text { Spread out; } 10= \\
\text { Dense) }\end{array}$ & $5.16 \quad(1.77)$ & 5.88 & $(1.72)$ & 4.69 & $(2.25)$ & $3.82 \quad(2.46)$ \\
\hline $\begin{array}{l}\text { Number of days } \\
\text { travelled } \\
\text { (each week) }\end{array}$ & $4.68 \quad(0.69)$ & 4.85 & (0.60) & 4.89 & $(0.48)$ & $4.62 \quad(0.88)$ \\
\hline $\begin{array}{l}\text { Duration of travel } \\
\text { (mins) }\end{array}$ & $22.09 \quad(5.96)$ & 25.28 & $(6.95)$ & 42.53 & $(9.26)$ & $95.34 \quad(25.67)$ \\
\hline $\begin{array}{l}\text { Train full when board } \\
\text { (\% full) }\end{array}$ & $63.54 \quad(35.57)$ & $47 \cdot 38$ & $(34.45)$ & 49.74 & (37.68) & $36.51 \quad(35.17)$ \\
\hline $\begin{array}{l}\text { Train full when depart } \\
\text { (\% full) }\end{array}$ & $73.01 \quad(34.78)$ & 70.13 & $(27.71)$ & 72.60 & $(35.57)$ & $62.39 \quad(37.84)$ \\
\hline
\end{tabular}

Note: Standard deviations are in parentheses

Defence $(F(3,344)=3.28, p<.05)$ and IPD Discomfort $(F(3,344)=13.14, p<$ .o01) scales did vary by location, as did the SI $(F(3,344)=9.20, p<.001)$ and Train relationships $(F(3,344)=6.60, p<.001)$ scales (see Figure 4.3$)$. Masterton has higher social interaction and higher positive attitudes to train relationship formation than any other location $(p<.05)$. Masterton has higher defence than Upper Hutt, and Masterton and Johnsonville have lower IPD Discomfort than Upper Hutt and Lower Hutt $(p<.05)$. 


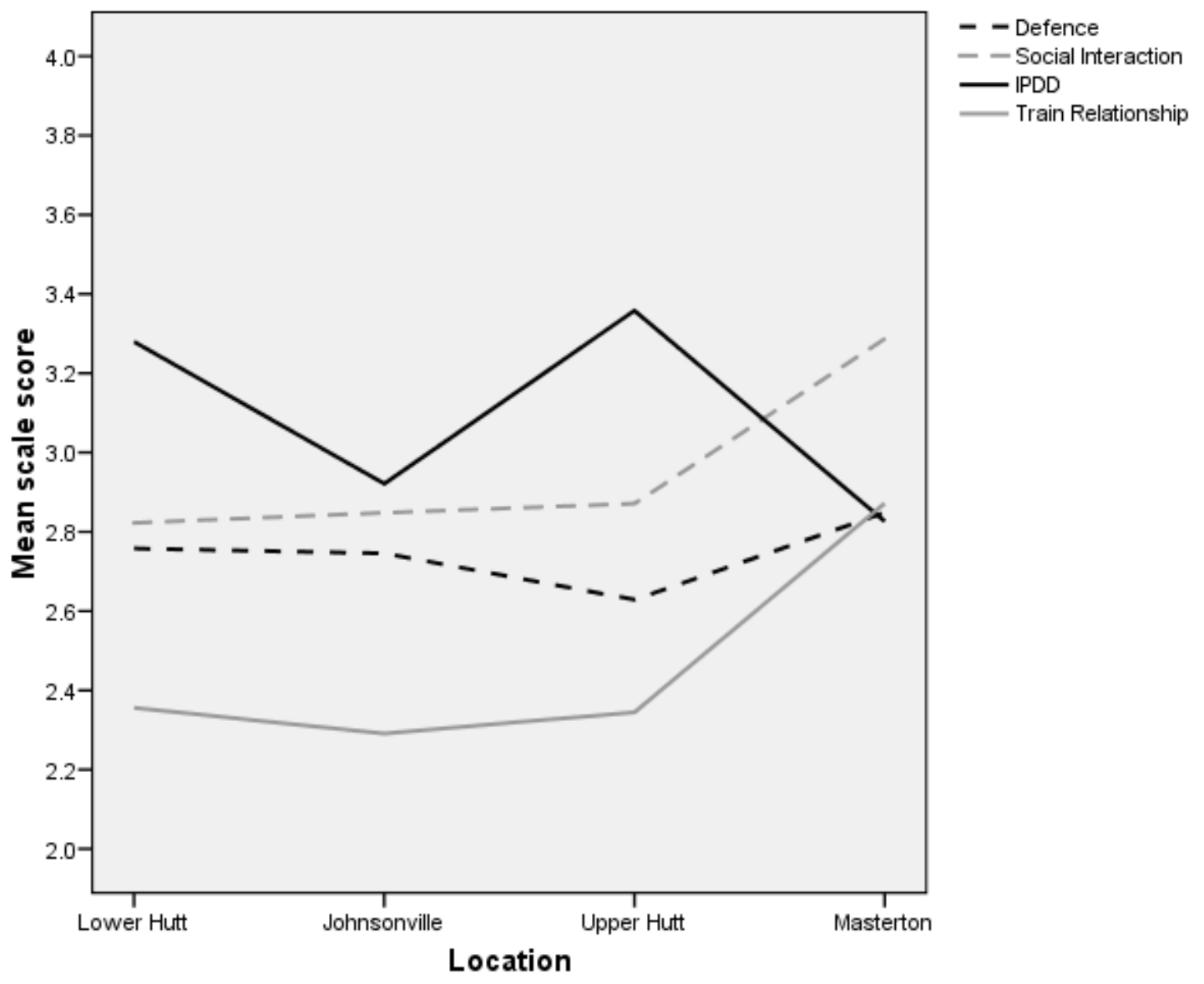

Figure 4.3. Mean Defence, Social Interaction, IPD Discomfort and Train Relationship scale scores for Lower Hutt $(n=78)$, Johnsonville $(n=91)$, Upper Hutt $(n=103)$ and Masterton $(n=76)$.

Commentary reinforces the improved social environment in the Masterton (also referred to as Wairarapa) train group.

"The Wairarapa train is a totally different experience. They are mainly friendly and it is like a community because we spend an hour and a half with each other usually in the same carriage everyday." (Train participant number 25)

There is even some evidence that there is an in-group effect, where there is a greater level of comparative trust in this group.

"I have answered questions from the point of view of travelling on the Wairarapa train, I would not feel as safe travelling on the Hutt train." (Train participant number 87)

The reported friendship levels and friendship formation measures from Table 4.10 showed significantly lower in the train setting when compared to the neighbourhood on every item $(p<.001)$. When these measures were repeated for 
the Masterton sample, some of these differences disappear (see Table 4.15). These findings add further support that Masterton has a more positive social environment.

Table 4.15 .

Mean Differences for Friendship Formation Measures in the Train and Neighbourhood Settings for Masterton $(n=76)$.

\begin{tabular}{|c|c|c|c|c|c|}
\hline \multirow{2}{*}{$\begin{array}{l}\text { Item } \\
\text { How likely are you to make a good } \\
\text { friend in this setting? }\end{array}$} & \multicolumn{2}{|c|}{$\begin{array}{c}\text { Train } \\
M\end{array}$} & \multicolumn{2}{|c|}{$\begin{array}{c}\text { Neighbourhood } \\
M\end{array}$} & \multirow{2}{*}{$\frac{\text { Sig }}{*}$} \\
\hline & 2.80 & $(1.22)$ & 3.11 & $(1.00)$ & \\
\hline $\begin{array}{l}\text { How likely are you to make an } \\
\text { acquaintance in this setting? }\end{array}$ & 3.68 & $(1.12)$ & 3.76 & $(0.86)$ & \\
\hline $\begin{array}{l}\text { How likely are you to invite } \\
\text { someone you met in this setting to } \\
\text { your home? }\end{array}$ & 2.51 & (1.34) & 3.66 & (1.03) & $* * *$ \\
\hline $\begin{array}{l}\text { How likely are you to invite } \\
\text { someone you met in this setting to } \\
\text { a social event? (e.g. dinner or a } \\
\text { movie) }\end{array}$ & 2.49 & (1.28) & 3.13 & (1.08) & $* * *$ \\
\hline $\begin{array}{l}\text { How many people in this setting } \\
\text { would you call friends? }\end{array}$ & 3.99 & (5.53) & 4.48 & $(10.32)$ & \\
\hline $\begin{array}{l}\text { How many people in this setting } \\
\text { do you know by name? }\end{array}$ & 6.77 & (7.43) & 8.36 & $(6.92)$ & \\
\hline $\begin{array}{l}\text { How many people in this setting } \\
\text { have you spoken with? }\end{array}$ & 12.60 & $(19.96)$ & 12.28 & (10.69) & \\
\hline
\end{tabular}

\section{Seat Selection Items}

The majority of passengers responded that they typically sat in the same carriage (83\% agreement) with other regular train users (60\% agreement). Feedback regarding the ability to pre-select a train seat was mixed. One participant responded that this would be an attractive option on longer trips. Other participants reported that seat selection would negatively impact on the train experience and may even encourage prejudice.

"I think it's a stupid idea to allocate preferred seating. Some Nzers already have a hard time accepting other fellow Nzers. Don't put in more ways to judge/discriminatelseparate people." (Train participant number 332)

"I would pay for seating allocated but then it takes the whole train experience away. Meet heaps of different people." (Train participant number 27) 


\section{Discussion}

Interactive adaptations are more successful than defensive adaptations when attempting to reduce social discomfort in the train setting, which supports Hall's (1966) proxemic theory. There is evidence to support passive contact theory (PCT; Festinger et al., 1950), as regular contacts relate to friendship formation, but there are impediments to the success of passive contacts in the train setting.

\section{Adaptations to Reduce Social Discomfort}

Adaptations in defensive behaviour, including situational withdrawal into an activity (e.g. reading or listening to music), defence of territory (e.g. placing a bag on or sitting in the aisle seat), and negative body language (e.g. avoiding eye contact with boarding passengers) did not succeed in reducing discomfort. The finding that defensive behaviours fail to reduce social discomfort supports previous research (such as Epstein et al., 1981), on stress and discomfort, where situational withdrawal into an activity had no influence on levels of physiological or perceived discomfort.

Conversely, defensive behaviour formed a positive association with discomfort, indicating that these behaviours are not an adaptation to reduce discomfort; rather they are a reaction to social discomfort. While defensive behaviours such as situational withdrawal may make the time pass more quickly, they fail to mask the underlying discomfort of the situation. Much like reading a magazine in a dentist's waiting room, they distract, but do not necessarily reduce discomfort.

Adaptations to reduce social discomfort through positive social interaction, including acknowledging other passengers with a greeting or body language, smiling at other passengers when eye contact is made and conversing with other passengers, are very effective. A positive social environment on the train and a positive perception towards friendship formation with other passengers has the greatest influence over social discomfort. Passengers that express these perceptions indicate a genuine, friendly and open attitude towards other train passengers. 
Furthermore, there is evidence that defensive behaviours can directly and indirectly cause social discomfort. In the Exploratory Study there was evidence of direct discomfort, where participants were less comfortable sitting beside other passengers that showed overt defensive behaviours (such as placing a bag on the seat beside them). Similarly, defensive behaviours, such as the use of activities (used by $25 \%$ of passengers in the Observation Study) can indirectly encourage discomfort by preventing "latent conversationalists" from engaging in social interactions that have been acknowledged as having the greatest ability to reduce social discomfort.

That social interaction amongst passengers can reduce social discomfort supports the basic tenet of Hall's (1966) proxemic framework, that people feel greater levels of comfort experiencing close interpersonal distances with people where they have formed relationships. Epstein et al. (1981) found that talking increased subjective feelings of control over the environment, whereas the defensive behaviour of reading a newspaper did not influence perceived control. If positive social interaction is the best means to reduce social discomfort, then it is reasonable to assume most passengers would interact, but this is not the case.

\section{Passive Contact Theory (PCT)}

There is evidence that PCT is disrupted in the train setting. Relative to the neighbourhood setting participants have fewer friendships, know fewer names and have spoken with fewer people in the train setting. There is a perception that there is less likelihood of building friendships on the train and train users are less likely to be invited back to someone's home or to a social event.

Arguably, train passengers have a similar opportunity for passive contacts as do neighbours. Participants are travelling between 44-190 minutes each day (depending on the service), during peak commuting times that provide large densities of passengers, implying a large frequency of passive contacts. Neighbours do not necessarily have this much opportunity, yet perceived likelihood of neighbourhood relationships and actual frequency of neighbourhood relationships are higher. It may be that the transience of the setting is a key factor as previous examples where PCT worked are based primarily on fixed residential settings (e.g. Segal, 1974; Festinger et al., 1950). 
There is evidence of habitual seating behaviours, such that regular train users choose to sit in the same section of seats with other regulars (60\% agreement) in the same carriage ( $83 \%$ agreement). Even though the setting is temporary and the adjacent person may change from trip to trip, there is an underlying regularity in seating behaviour that fosters passive contacts to cumulate. It is likely that regular passengers will be surrounded by "familiar strangers" (Milgram, 1977), therefore, it is more than the transience of the setting that interrupts PCT.

The perception of social comfort also improves with passive contacts. Experienced users (that have used the current train route for a greater number of years) have accumulated greater frequencies of passive contact over time, and are also more socially comfortable with the other users. People in familiar settings are more willing to accept closer interpersonal distances to others, as they feel more in control of their contact with other users of the space when in familiar territory (Altman, 1975). Passive contacts breed a sense of familiarity with the setting and patrons that Nash (1975) observes is an antecedent of social interaction. Therefore, social discomfort with the other passengers is not likely the reason why PCT is broken in the train setting, at least not between regular commuters.

A key barrier to the success of PCT is the pervasive perception of social sterility on public transport. There is a group of "latent conversationalists" that would like a greater level of social interaction on the train, but this is not being exploited because they will not break the norm by initiating conversation. Passengers indicate that they are open to talking to strangers, but they will not typically initiate conversation with strangers, as they perceive that other passengers are less amenable to conversation on the train.

Despite the fact that a quarter of passengers are observed to converse in the Observation study, there is still a social norm that conversing with "strangers," even if they are familiar, is not appropriate. A key premise of PCT is that "nodding acquaintances" can develop into verbal greetings, small talk, and more complex relationships (Festinger et al., 1950, p. 34), but conversation is inhibited in the train setting. A social norm of interaction avoidance is a commonly observed 
impediment to social interaction on public transport (e.g. Birenbaum, 1976; Fried and DeFazio, 1974; Milgram, 1977).

The perception of social sterility is likely to be magnified by the fact that defensive non-verbal signals are more salient and unequivocal than positive non-verbal signals. It is difficult to identify which other passengers want greater social interaction, other than going off positive body language, such as smiling or eye contact (Argyle, 1978). There is evidence from the Exploratory study that smiling induces positive affect but does not influence seating decisions, and gaze alone (without smiling) only had negative connotations.

Passengers that reported higher use of defensive behaviours discouraged social interaction. The finding of reduced interpersonal contact was supported in the Observational and Exploratory studies, where physical defence of territory was observed and reported to be successful in repelling unwanted intruders, and withdrawal into activity was observed and reported to successfully reduce unwanted social discourse. Self-other assessments of defensive behaviours show that participants reported that others were more likely to use defensive behaviours than themselves (i.e. placing a bag on the adjacent seat), which reinforces the perception of negative social behaviours in others. Baumeister (2001) found that bad impressions were more memorable and resistant to change than good impressions.

In crowded commuter conditions passive contact frequencies are higher, but the quality of contact is lower as a function of close IPDs. Opportunity for successful passive contact is disrupted as there is an increased perception of interpersonal passenger heterogeneity. This may be due to a dilution in the concentration of "familiar strangers" amongst the mass of strangers. The perception of a lower proportion of other regulars was found to increase social discomfort. There is also a perceived lack of privacy to talk to these passengers, and a limited opportunity to secure the seat next to them.

In the neighbourhood, the frequency of passive contacts may be lower but the opportunity for shifting from "nodding acquaintances" to friendships is not interrupted by social norms preventing conversation. Also the density of the 
neighbourhood is less likely to present dilution effects where strangers outnumber regulars. In fact, the lower density of the neighbourhood is likely to increase the predilection for conversation. If there are only two neighbours passing each other, anonymity is reduced and there is no social overload (see Milgram, 1970), so as a result greeting responses may be higher compared to crowded settings.

Passenger commentary provides further evidence of the group of "latent conversationalists" that just need the opportunity to engage in conversation. Commentary suggests that unusual or unscripted events, in this case the breakdown of the train, are likely to encourage conversation. This is supported by anecdotal observations elsewhere (Paulos and Goodman, 2004; Sommer, 1969, p. 37). The key elements of these events are that they break the social schema of the situation, create a shared experience unique to that group, and provide a common conversation topic in which there is a prior knowledge that the other person has a vested interest in the topic.

A barrier to social interaction may be a lack of natural conversation initiation techniques. Zurcher's (1979) observations of regular airplane users identified a number of conversation initiation techniques. These include helping other passengers getting settled, offering objects (such as chewing gum), or querying or providing another passenger with relevant travel information (Zurcher, 1979). Reciprocity, in which a positive action is taken with the expectation of a positive response, is a common technique used to engage with others. It has the particular advantage that conversation initiators are less likely to be given a curt response or other negative reaction when they attempt to interact with another passenger.

Participant commentary reveals desirability to appear friendly, which may be the reason participants rate themselves as more open to social interaction than other passengers. Participants in this study were informed that their responses would be entirely confidential to encourage honest, open answers. Perceived anonymity is the key strategy to reduce socially desirable responding (SDR), as there is no need to make yourself look good if your answers are not going to be traced back to you (Paulhus, 1991). Further, mail surveys are typically less susceptible to SDR as they are perceived to have greater anonymity (Paulhus, 1991). 
Even if the responses are biased, the important point here is that people do feel the need to reconcile the dissonance between their outwardly anti-social train behaviour and their social self-image (for more information on cognitive dissonance see Festinger, 1957). They rationalise the inconsistency with concepts like "I am too tired in the mornings" or "after a day of interacting with others I just want some time to myself". This base desirability to appear friendly indicates that people would be motivated to interact if it was perceived to be overtly unfriendly behaviour not to interact with others on the train. If passenger interaction was the norm, the need of these passengers to maintain their sociable public self-image would encourage them to talk and engage in social politeness with other passengers.

To summarise the PCT findings briefly, there is evidence that the habitual seat selection of regular users, the higher level of comfort with other regular users, the presence of "latent conversationalists" and the need to reconcile a sociable, friendly self-image should all facilitate PCT to work in the train setting. Unfortunately, the perception of socially sterility and norm-breaking required to engage in superfluous conversation, and the dilution of "familiar strangers" or even acquaintances in high density environments, mean that it requires atypical events to produce conversation that may occur very naturally in a neighbourhood setting.

The Masterton cohort provides a good example of where PCT is more likely to function in a train setting. The Masterton train had higher social interaction and more positive attitude to friendship formation compared with the other locations. Amongst the Masterton train commuters, friends were just as frequently neighbours as other train passengers. The key differences in the Masterton cohort were longer trip duration, high experience with train route and lower density of passengers. The Masterton finding also adds support to Nash's (1975) conclusions that conversation is fostered in public transport under conditions where there are lower densities of passengers, a longer duration trip and experienced passengers.

Nash's (1975) findings suggest that it is density that is interfering with PCT. Longer trip durations provides greater contact exposure with other passengers, and experience provides a greater frequency of contact with the other passengers. 
Density of passengers dilutes exposure to the familiar regulars and reduces the need for the social politeness that provides the basis of passive contacts evolving into friendships.

\section{Measuring Social Discomfort}

Personal character assessments, including measures of perceived heterogeneity, do not significantly influence social discomfort on the train. Even though other train users are perceived to be quite different, in that they have less sincerity, education, cleanliness, wisdom and are more dangerous, poor, unattractive and cold, this does not significantly alter social discomfort ratings. Neither does this support Siegfried et al.'s (1982) research that found that perceived passenger dissimilarity reduced reported liking of other passengers and reduced willingness to use public transport.

Social discomfort is not influenced by IPD discomfort. Participants in the sample travelled at peak times under crowded conditions, so IPD discomfort measures should have indicated some level of discomfort. IPD discomfort and defensive behaviours do increase with perceived heterogeneity, so these may be more sensitive measures of passenger discomfort. An increase in perceived neighbourhood heterogeneity increases defensive behaviour and an increase in perceived train heterogeneity increases IPD discomfort. Similarly, the Defence and IPD Discomfort scales picked up differences by location that the TSD scale did not.

A possible reason for the lack of sensitivity in the TSD scale is that the measure is compromised or masked by personality type. Items such as, "I like meeting new people on my regular train" naturally overlap with extraversion (the Exploratory study found a 0.74 correlation between Social Comfort and Extraversion). Extraverts may consistently show less discomfort than introverts in interpersonal situations, reducing the sensitivity of the measure within subjects. The Defence and IPD Discomfort scales both measure self-report of actual behaviour within the public transport setting, relying less on general personality and more on changes in the setting, indicating these are more contextually sensitive measures of discomfort. 
Overall ratings of social comfort on the train are positive, which suggests that social discomfort is not a barrier to train use. Greater scrutiny of this finding reveals that it is likely to be a biased positive response, as it is somewhat illogical to criticise a social group in which you are a member. Reticence to report discomfort reinforces the need for social research that uses relative discomfort measures or real adaptations to reveal the latent discomfort. The Exploratory study already identified that relative to other contexts the public transport setting was less comfortable. Similarly, this study has found that the train setting is less comfortable than the neighbourhood. Other measures of discomfort, including defensive behaviour and IPD discomfort successfully reveal differences in comfort between train locations.

The influence of social discomfort, social interaction, defensive behaviour and crowding on actual public transport patronage needs to be examined more definitively with comparison to a car commuter sample.

\section{Conclusion}

Defensive behaviour is not successful in reducing social discomfort on the train, and may even induce greater social discomfort by reducing the likelihood of a positive social environment. Of the measures examined in this study, social interaction is the most successful strategy to reduce social discomfort on the train. Under conditions conducive to conversation, such as those observed in the Masterton sample, where passengers are experienced, the duration of the trip is longer and privacy is more achievable, friendships are more likely to form. Perceived heterogeneity does not influence social discomfort or social interactions directly, but does increase defensive behaviour and discomfort in crowded conditions. It is unclear whether social discomfort or stereotypes of other users are a barrier to train use. 


\section{CHAPTER 5: IDENTIFYING SOCIAL BARRIERS TO TRAIN PATRONAGE}

The previous chapter revealed the different factors relating to a positive or negative public transport experience. Social interaction was a more successful adaptation than defensive behaviour in reducing social discomfort. The perception of interpersonal characteristic differences did not directly increase social discomfort, but did increase the need for defensive behaviour and discomfort with the close proximity of the nearest passengers. To examine whether social factors may act as barriers to public transport use, the attitudes and reported behaviour of car commuters were examined.

\section{Background}

"In the folklore passengers are packed in like sardines; the ride is slow and dirty and exhausting; the vehicles are places of crime and hooliganism" (Davis \& Levine, 1967, p.89).

Despite historical evidence that social factors influence public transport use (Hood, 1996; Davis, 1967), there is a shortage of contemporary, empirical research that establishes their level of influence (Stradling, Carreno, Rye \& Noble, 2007). The purpose of this chapter is to examine whether attitudinal and social factors, such as perceived heterogeneity (Siegfried, Tedeschi \& Cann, 1982), close interpersonal distances (Evans \& Wener, 2007), touch avoidance (see Exploratory chapter), and social discomfort are barriers to public transport use.

Research examining public transport patronage has typically focussed on instrumental factors including price, time of day and frequency of service (for example, Kyte, Stoners \& Cryer, 1988; Hensher, 2008). Moser and Bamberg (2008) provide evidence that studies that rely on "hard" interventions focussed on pricing or infrastructure initiatives are more successful in combination with "soft" 
initiatives, such as promotional campaigns to raise public awareness and acceptance. The central hypothesis recognises that unless the social factors associated with public transport are attended to, it is unlikely that public transport will compete successfully against the popularity of the private automobile.

The "ideal" bus journey is not simply based on cost and service provision; it encompasses social factors, such as perceived personal safety, self-image, unwanted physiological arousal due to crowding, and the inconsiderate behaviour of other passengers (Stradling et al., 2007). Stradling et al. (2007) examined 68 items (including cost, convenience and service) and found that the item most likely to discourage people from using the bus was the "drunk people" travelling at night ( $45 \%$ of participants discouraged), with the "behaviour of other passengers" (38\% of participants discouraged), coming in at fourth (Stradling et al., 2007). The bus running late (ranked second) and dislike of the need to produce the correct fare (ranked third) were also identified as issues.

Crowding is potentially an anomalous problem when placed in the context of promoting public transport use, as clearly patronage must be high if crowding is an issue. Nevertheless, crowding is a real issue that has been linked to increased physiological stress in the train setting (Evans \& Wener, 2007; Lundberg, 1976; Wener, Evans, Phillips \& Nadler, 2003). Long-term public transport commuters are being disadvantaged by having fewer resources (i.e. forced to stand rather than sit), a diminished service and greater levels of stress for the same price, and may feel encouraged to find alternative transport. Likewise, car commuters may hold off on their decision to switch to public transport if they have a negative perception of crowding.

Crowding reinforces the perception that train and bus users are packed into uncomfortable conditions where they are forced into a situation in which they have very limited control over their interpersonal space. Perceived control, level of behavioural constraint and level of arousal have both been posited to mediate the negative influences of crowding (Cox, Houdmont \& Griffiths, 2006). So a potential solution could be to take the focus away from the perception of crowding by getting passengers to re-focus on the behaviours that are under their direct control. For example, pointing out the leisurely nature of their trip, and their ability to enjoy 
social interaction, engage with their work, or relax listening to music or reading a good book.

At the extreme levels of crowding, conditions where touching other passengers is unavoidable are likely to lead to worse levels of stress (Nicosia, et al., 1979), particularly when the physical contact is with overtly heterogeneous passengers (Maines, 1977). In an examination of touch-avoidant behaviours on subways, Maines (1977) found that passengers were more likely to tuck their elbows in (moving their elbows from their sides to rest them in front of their body) if the nearest passenger was within close proximity (0-6 inches away) and of a different gender or ethnicity.

Differences in personality type may act as a barrier to public transport use, such that touch-avoidant people may avoid bus or train use. There is mixed support for this theory so far. There was evidence in the Exploratory study (with the student sample) that touch-avoidant people were more likely to use public transport, however, in the Train study (with a larger sample of train commuters) touchavoidance was found to relate positively to train discomfort. These mixed results need further examination.

Passive contact theory (PCT) or the idea that "familiarity breeds liking" suggests that regular train commuters are more familiar with the setting and the people, and are therefore more at ease with other passengers. This could be described as an exposure effect (see Bornstein, 1989) or a propinquity effect (see Festinger, Schacter \& Back, 1950). In the previous chapter on train users there was no distinguishable influence of social discomfort on IPD discomfort or defensive behaviour, but this discomfort may be more apparent in a group that do not regularly use the train, and are less familiar.

Anecdotal evidence suggests that there are currently negative attitudes towards public transport, for example, the perception that buses are "loser cruisers" and that "suits don't ride buses" (McIlheran, 2008). Individuals may also form unfounded assumptions or stereotypes about the type of people that use public transport. For example, "I have nothing in common with the person sitting next to me”, even though both parties are leaving from and going to a similar location 
using the same transport mode. Negative attitudes and subjective norms surrounding public transport are likely to reduce the use of public transport (Ajzen, 1985). Complaints about the physical factors associated with public transport such as travel time, frequency of service and cost may just be symptomatic of a poor social acceptability of public transport, as well as the strength of our acceptance of the private automobile.

Public transport users are likely to make initial judgements of other patrons based on limited visual information, such as ethnicity, gender, age, clothing, apparent level of hygiene or cleanliness, and physical attractiveness (for more on stereotyping see Burgoon, 1994). These appearance-based judgements influence seat selection decisions and level of comfort with nearby passengers. For example, differences in clothing style have been associated with greater discomfort and lower tolerance of closer interpersonal distances, as evidenced by faster "flight" behaviour (Barash, 1973). Similarly, military rank, designated by uniform, instantly displays status and determines appropriate interpersonal social rules. Dean, Willis and Hewitt (1975) observed interactions between 562 pairs of United States naval personnel and found that interpersonal distance increased with rank disparity when the subordinate initiated the interaction.

There is a paucity of research that has examined social factors in the context of public transport according to Stradling et al. (2007). Even less research has been done to measure the influence of social factors on actual behaviour in the form of public transport patronage. This research will assess the influence of social discomfort with other passengers, attitudes towards other passengers, touch avoidance, and discomfort with the close proximity to other passengers on train versus car commuting.

It is hypothesised that social discomfort and IPD discomfort will negatively influence train use, and that reported defensive behaviours (indicative of discomfort) will be higher amongst car commuters. Individual differences, such as touch avoidance, may also negatively influence train use. 


\section{Method}

The method used to obtain the train commuter sample was outlined in the previous chapter (see Train chapter for more details). The general sample of commuters from which the car commuter sample was derived came from the neighbours to the train sample and is outlined in more detail below.

\section{Participants: General Sample (Neighbours)}

Nine hundred questionnaire packs were mailed to people that came from the same neighbourhood as the train study sample (see Procedure for more details). Questionnaires were given to people from Johnsonville $(n=275)$, Lower Hutt ( $n=$ 310 ) and Upper Hutt ( $n=315$ ). It was expected that this sample would primarily include motor vehicle drivers, as a national survey of household travel shows that about $80 \%$ of travel is by personal motor vehicle (Ministry of Transport, 2008).

Forty four questionnaires were returned with incorrect addresses, a further questionnaire was returned as it was addressed to a business, and one was returned as the householder had already completed the train version of the questionnaire.

From the 854 questionnaires that reached correct addresses, 440 were returned giving a response rate of $50 \%$. Eleven of these questionnaires were returned blank, most of which came with notes, for example, "as I have impaired sight, I neither drive nor use public transport" or "we are retired and never travel on train or bus". This indicates that the filtering questions were working, encouraging participants to remove themselves from the sample if they never used public transport or never travelled by car. A further 21 questionnaires were returned incomplete, often with participants missing the middle pages of the questionnaire booklet, leaving a sample of 408.

Filter questions were used to ensure that the questionnaires were being filled in by people living in the correct suburb and people that had used buses or trains before. Two car commuters had never travelled by bus or train locally, in New Zealand or overseas, and were removed from the sample. One participant did not live in the suburb where the questionnaire was mailed. Four participants did not state the 
primary travel mode used to get to their main weekly activity and were removed.

The final sample was made up of 401 participants, $76 \%$ of whom commuted by motor vehicle (see Table 5.1).

Table 5.1.

Summary of Participant Characteristics

\begin{tabular}{llrr}
\hline Characteristic & & $n$ & \multicolumn{1}{c}{$\%$} \\
\hline Gender & Male & 160 & $41.3 \%$ \\
Travel mode & Female & 227 & $58.7 \%$ \\
& Car & 305 & $76.1 \%$ \\
& Bus & 33 & $8.2 \%$ \\
& Train & 47 & $11.7 \%$ \\
& Cycling & 6 & $1.5 \%$ \\
Education & Walking & 10 & $2.5 \%$ \\
& High school qualification & 116 & $30.0 \%$ \\
& Other post-school qualification & 127 & $32.8 \%$ \\
& Bachelor degree & 84 & $21.7 \%$ \\
Ethnicity & Higher degree & 60 & $15.5 \%$ \\
& New Zealand European & 326 & $81.3 \%$ \\
& Maori & 16 & $4.0 \%$ \\
& Asian & 17 & $4.2 \%$ \\
& Indian & 4 & $1.0 \%$ \\
& Pacific Islander & 9 & $2.2 \%$ \\
Location & Other & 29 & $7.2 \%$ \\
& Lower Hutt & 150 & $37.0 \%$ \\
Main weekly & Upper Hutt & 124 & $30.6 \%$ \\
activity & Johnsonville & 131 & $32.3 \%$ \\
& Work & 309 & $79.0 \%$ \\
& Education & 23 & $5.9 \%$ \\
& Shopping & 19 & $4.9 \%$ \\
& Social/Recreation & 35 & $9.0 \%$ \\
& Other & 5 & $1.3 \%$ \\
\hline & & &
\end{tabular}


Participants that commuted by walking or cycling (4\%) were not included in the analyses. The remaining 20\% were placed into bus and train user samples. The average household income for participants was $\$ 73,300$ ( $\mathrm{SD}=\$ 32,340$; New Zealand dollars), with an average participant age of 46.70 years ( $\mathrm{SD}=13.85$ years).

\section{Materials}

The questionnaire pack included a questionnaire, a personally signed cover letter (see Appendix C) ${ }^{1}$, a freepost return envelope, a prize draw card (to win $\$ 500$ worth of vouchers), and a $\$ 1$ Instant Kiwi lottery ticket. Each questionnaire was numbered with an ultraviolet pen so that they could be matched back to their meshblock details without cause for participants to worry about the confidentiality of their responses. Specific address information was removed from the address database at the time the questionnaires were mailed to ensure participant privacy and anonymity. Their responses were only matched to meshblock level census and travel survey data. Ethical approval was granted for this research.

The questionnaire was a shortened version of the train questionnaire from Study 1. Items regarding attitudes towards people at the train platform, items relating to friendship formation, and some further items relating specifically to train use were removed for this general questionnaire. Many items were reworded from "train" to "bus or train," to include general attitudes towards both public transport modes. The key scales included IPD Discomfort, Social Discomfort (in train and neighbourhood settings), Defensive Behaviours, Social Interaction, Characteristic Assessments (of self, train passengers and neighbours) and Touch Avoidance.

Two filter items were added to the beginning of the questionnaire to examine car and public transport use. If participants never travelled by car or never travelled by bus/train then they were told "you do not need to continue this questionnaire please pass this on to someone else in your household if appropriate”. An additional filter question checked that the participant currently lived in the suburb to which the questionnaire was sent.

1 The cover letter was printed on official Victoria University of Wellington letter head, and included the date and address. These aspects are missing from the example cover letter in the Appendices. 
Five transport facts were placed throughout the questionnaire. These were intended to demonstrate how transport research can provide members of the public with useful information. Appendix D contains the transport facts. Positive comments were received regarding the transport facts, for example, "loved the transport facts".

\section{Procedure}

A general sample of commuters was derived from the initial responses of participants from Study 1, where participants from the first questionnaire indicated the closest intersection to their house. The address locations for the Masterton part of the sample were not included, as this sample would be less likely to commute into Wellington city due to the longer distance necessary for people in this area to travel.

From the train sample, the closest road intersections to the homes of 180 participants were randomly selected. Five randomly assigned addresses from within one-two blocks of this intersection were sent the second questionnaire. It was expected that the secondary sample would include many car users, so car users could be used as a comparison group.

The five random addresses were selected via the following steps using Quickmap software. First, a random direction was generated from a random number ranging from one-four to represent north, east, south and west. If the actual road layout did not match to the random direction, the next road going in the clockwise direction was assigned. For example, if the random direction was west and the road options were north, south or east, then the direction would be north. Second, the distance from the intersection was decided by randomly visually assigning the road into deciles and randomly assigning a number from one-ten. Third, any intersection met while "travelling" in the assigned direction for the assigned distance was given the equal opportunity (with random numbers) for a change of direction or continuation. 
The 76 train participants from Masterton were removed from the train sample and the 47 train commuters from the general sample were added to the train sample for all comparative analyses. This gave a sample of 319 train commuters and 305 car commuters for the final comparative analysis. A tentative analysis of the bus versus car samples revealed some differences in mode choice. ${ }^{2}$

\section{Results}

\section{Scale Reliability}

Table 5.2 shows a summary of the scale scores, including the sample size, number of items in the scale, the internal reliability of the scale (Cronbach's alpha), the scale range, mean and standard deviation. All scale scores were formed by taking the mean score of its component items. The mean was selected instead of aggregating the item scores to increase the number of respondents, and also allowed for non-statistical comparisons of group means for scales measured on the same metric. A mean score was calculated for any participant that filled in at least $50 \%$ of the items.

The scales were normally distributed, with no signs of skew (skew values were all under one), and only minor indications of central clustering (with positive kurtosis values for Train Social Discomfort and Neighbour Assessment). The Cronbach's Alpha scores for the Social Interaction (SI), Interpersonal Distance (IPD) Discomfort and Touch Avoidance scales do not show high reliability (0.70 or higher is recommended; Christmann \& Van Aelst, 2006).

${ }^{2}$ The sample numbers were too low, especially after allowing for missing data, but an exploratory binary logistic regression between car $(n=205)$ and bus $(n=18)$ commuters was used to see if different factors influenced bus use (when compared with train). Several different factors were apparent that increased bus use, such as lower levels of Touch Avoidance, a lower number of household vehicles, and a desire for less social interaction on public transport. Bus use was also associated with more positive bus commuter characteristic assessments and higher neighbourhood social discomfort. Overall, the regression model explained $38 \%$ of the variation between car and bus users. These differences substantiated the need for a closer examination of bus commuters, which will be examined further in the next chapter. 
Table 5.2.

Car Commuter Scale Reliability Tables

\begin{tabular}{|c|c|c|c|c|c|c|}
\hline Scale & $N$ & $\begin{array}{l}\text { Number } \\
\text { of items } \\
\text { in scale }\end{array}$ & Alpha & $\begin{array}{l}\text { Scale } \\
\text { range }\end{array}$ & $M$ & $S D$ \\
\hline Social Interaction & 299 & 6 & 0.68 & $1-5$ & 2.89 & 0.60 \\
\hline Interpersonal Discomfort & 298 & 6 & 0.69 & $1-5$ & 3.25 & 0.66 \\
\hline Self Assessment & 297 & 8 & 0.72 & $0-10$ & $7 \cdot 52$ & 0.99 \\
\hline Train User Assessment & 252 & 8 & 0.80 & $0-10$ & $5 \cdot 77$ & 0.88 \\
\hline Neighbour Assessment & 280 & 8 & 0.87 & $0-10$ & 6.75 & 1.29 \\
\hline Social Discomfort (Train) & 305 & 7 & 0.73 & $1-5$ & 2.55 & 0.47 \\
\hline Social Discomfort (Neighbourhood) & 305 & 7 & 0.83 & $1-5$ & 2.23 & 0.52 \\
\hline Defensive Behaviour & 305 & 13 & 0.81 & $1-5$ & 2.85 & 0.48 \\
\hline Touch Avoidance & 304 & 4 & 0.65 & $1-5$ & 2.41 & 0.59 \\
\hline
\end{tabular}

\section{Car and Train Commuter Sample Characteristics}

Differences between car and train commuter samples were examined using independent sample $t$-tests and Chi-square analyses (see Table 5.3). Train commuters were more ethnically diverse, whereas car commuters were more likely to be New Zealand Europeans (odds ratio $=1.5,95 \%$ confidence interval $[\mathrm{CI}]=$ 1.02 to $2.24, p<.05)$. Car commuters were over five times more likely to own their house (odds ratio $=5.3,95 \% \mathrm{CI}=3.06$ to $9.09, p<.001$ ), and train commuters were over five times more likely to be travelling for work purposes when travelling to their main weekly activity (odds ratio $=5.6,95 \% \mathrm{CI}=3.03$ to $10.20, p<.001$ ) 3 . 
Table 5.3.

Demographic and Household Characteristics for the Car and Train Samples

\begin{tabular}{|c|c|c|c|c|}
\hline Demographics & $\begin{array}{c}\text { Car } \\
(n=305) \\
M\end{array}$ & $(n=$ & $\begin{array}{l}\text { rain } \\
=319) \\
M\end{array}$ & Sig \\
\hline Gender $(1=$ male; $2=$ female $)$ & 1.59 (0.49) & 1.53 & $(0.50)$ & \\
\hline $\begin{array}{l}\text { Ethnicity ( } 1=\text { NZ European; } 2 \text { = } \\
\text { other) }\end{array}$ & $1.18 \quad(0.38)$ & 1.25 & $(0.43)$ & * \\
\hline $\begin{array}{l}\text { Education ( } 1=\text { secondary school } \\
\text { qualification; } 4 \text { = post-graduate } \\
\text { degree) }\end{array}$ & $2.17 \quad(1.00)$ & 2.48 & $(1.05)$ & $* * *$ \\
\hline Age (years) & $47.60 \quad(13.62)$ & 39.40 & $(12.04)$ & $* * *$ \\
\hline Household income ( $\$ \mathrm{NZ}$ ) & $73,400 \quad(32,480)$ & 79,800 & $(29,740)$ & * \\
\hline $\begin{array}{l}\text { Relationship status ( } 1=\text { single; } 4= \\
\text { married) }\end{array}$ & $3.36 \quad(1.17)$ & 3.16 & $(1.25)$ & * \\
\hline $\begin{array}{l}\text { Own versus rent home }(1=\text { own; } 2 \\
=\text { rent })\end{array}$ & $1.06 \quad(0.24)$ & 1.25 & $(0.44)$ & $* * *$ \\
\hline $\begin{array}{l}\text { Housing density ( }(0=\text { very spread } \\
\text { out; } 10=\text { very dense) }\end{array}$ & $5.15 \quad(1.82)$ & 5.28 & (2.03) & \\
\hline $\begin{array}{l}\text { Number of household motor } \\
\text { vehicles }\end{array}$ & $1.93 \quad(0.74)$ & 1.77 & $(0.91)$ & * \\
\hline Trip duration (mins) & $19.30 \quad(12.23)$ & 30.10 & (11.80) & $* * *$ \\
\hline $\begin{array}{l}\text { Travel activity ( } 1=\text { work; } 2= \\
\text { other) }\end{array}$ & $1.21 \quad(0.40)$ & 1.04 & $(0.21)$ & $* * *$ \\
\hline
\end{tabular}

Note: Standard deviations are in parentheses; ${ }^{*} p<.05,{ }^{* *} p<.01,{ }^{* * *} p<.001$.

\section{Car Versus Train Binary Logistic Regression}

A forward conditional binary logistic regression was used to examine the factors that influenced train use compared with car use. The 24 variables in the equation included: self assessment; train characteristic assessment; neighbourhood characteristic assessment; touch avoidance; train social discomfort; neighbourhood social discomfort; defence; social interaction; interpersonal discomfort; perceived heterogeneity of other train users; perceived heterogeneity of neighbours; duration of travel by train (mins); personal preference for social interaction; perceived preference of other train users for social interaction; number of household motor vehicles; relationship status; education; income; age; ethnicity (NZ European or other); gender; housing density of neighbourhood; privacy; and experience with current neighbourhood (years). 
Income heterogeneity was also examined both in terms of the difference between a participant's household and the neighbouring households (from their meshblock), as well as the difference between a participant's neighbourhood and other neighbourhoods sampled in their location. Neither of these income heterogeneity measures was significant in the model, and due to missing data they were not included in the final analysis.

The sample examined was comprised of 306 car commuters and 319 train commuters $(N=625)$. Due to missing data across the 24 independent variables this was lowered to 205 car commuters and 220 train commuters $(N=425)^{4}$. Steps were taken to improve the accuracy of the model by removing outliers and influential cases, and to validate the model with holdout samples (following the steps outlined by Schwab, 2007).

The accuracy rate of the initial model was 76.5\%, and classification accuracy measures confirm that the model predicts better than chance (see Hair et al., 1995, for more on classification accuracy measures). The proportional chance criterion was $50 \%$, the maximum chance criterion was $52 \%$, and the classification accuracy was significantly better than chance (Press's $\mathrm{Q}(N=625)=141.75, \mathrm{p}<.001)$. For the model to be practically useful, Hair et al. (1995, p.204) recommend that classification accuracy should be at least $25 \%$ greater than that achieved by chance. In this case $125 \%$ of the $50 \%$ proportional chance criterion was $62.5 \%$, and even considering uneven group sizes and using $125 \%$ of the $52 \%$ maximum chance criterion, the threshold of predictive accuracy would be $65.0 \%$. At $76.5 \%$ the model exceeds the most conservative predictive accuracy threshold by more than $10 \%$.

To examine the influence of outliers and influential cases, standardised residuals and Cook's distance values were saved from this regression. Cook's distance values over 1 indicate influential cases (Hosmer \& Lemeshow, 1989, p.180), and standardised residuals greater than 3.00 or less than -3.00 indicate outliers. Five cases were removed because of outliers and the regression was re-run, producing a predictive accuracy rate of $79.0 \%$. As this was more than a $2 \%$ increase in accuracy

4 The binary logistic was re-run entering only the six predictor variables in Table 5.4 to check that the model findings held when the cases lost from missing data were reduced $(N=505)$. All six predictor variables were still significant and the model explained $55 \%$ of the variance between car and train users. 
rate from the baseline model, the new model with outliers removed was adopted. With 420 valid cases, the ratio of valid cases to independent variables in the model was 70:1 (a ratio of at least 10:1 is acceptable and 20:1 is preferred; Schwab, 2007).

There was a significant relationship between the independent and dependent variables $\left(X^{2}(6, N=420)=219.36, p<.001\right)$. Table 5.4 shows the final model that significantly explains approximately $54 \%$ of the variance between car and train users (NagelKerke $R^{2}=0.54$ ). The Hosmer and Lemeshow test shows that the model adequately fits the data $\left(X^{2}(6, N=420)=13.07, p=.11, n s\right)$. The stepwise criterion for entry into the model was a $p$ value of .01 and the criterion for exclusion from the model was a $p$ value of .05.

The variables in Table 5.4 are ordered as they were entered into the regression model, with trip duration predicting the most variance and Interpersonal Discomfort predicting the least. The standard error (SE) values for the independent variables are all less than two, showing no indication of multicollinearity (strong interrelationships between independent variables can complicate the interpretation of the model; Schwab, 2007).

Table 5.4.

Model Summary for the Binary Logistic Regression of Train Use

\begin{tabular}{lccccccc}
\hline \multirow{2}{*}{ Variable } & & & & \multicolumn{3}{c}{ Correlation } \\
\hline Trip duration & S.E. & Wald & Sig & Exp(B) & Partial & Part \\
Neighbourhood experience & -0.15 & 0.13 & 75.01 & 0.001 & 3.16 & 0.48 & 0.42 \\
Train user characteristics & 0.11 & 14.63 & 0.001 & 0.67 & -0.19 & -0.15 \\
Age & 0.91 & 0.15 & 35.46 & 0.001 & 2.49 & 0.29 & 0.23 \\
Neighbourhood discomfort & -0.41 & 0.12 & 10.92 & 0.001 & 0.67 & -0.19 & -0.15 \\
Interpersonal discomfort & -0.58 & 0.27 & 9.36 & 0.002 & 2.26 & 0.14 & 0.10 \\
Constant & -6.34 & 1.55 & 16.69 & 0.001 & 0.00 & & \\
\hline
\end{tabular}

Log-likelihood $=361.935$

A split-sample validation with a 75-25 split was used to cross-validate the model (a 75-25 split is commonly used for validation purposes; Hair et al., 1995). The 75\% analysis sample was used to derive a model and the $25 \%$ holdout sample was used to validate the model. Random numbers were generated to split the samples. The 
split was repeated five times to ensure the model did not alter by chance. Four of the five randomly assigned analysis samples produced the same model.

In the fifth sample, IPD Discomfort and Neighbourhood Discomfort were removed from the model and Privacy was added. The perception that participants had privacy from other passengers relates negatively with IPD Discomfort $(r(666)=-$ $0.33, p<.001$ ), meaning that as privacy increases, the perception of crowding is reduced and vice versa. This indicates that for one random sampling the model had replaced the perception of crowding with a related concept, perception of privacy. The minimum accuracy rate requirement for all five holdout samples was met, with all accuracy rates for the holdout samples within $10 \%$ of the accuracy rates for the analysis samples (Schwab, 2007).

The social factors that influence train use over car use are more positive train user characteristic assessments, lower IPD Discomfort scores, and higher neighbourhood discomfort scores. These social influences were represented in many of the comments, where safety from "undesirable" train users and the crowded conditions were raised as issues:

"I believe Buses and Trains are no longer safe at nights and are over crowded during the day." (Participant number 335)

The other factors that influence preference for train use are longer trip durations, a lower level of establishment or experience in the neighbourhood (as measured by fewer years lived there), and younger age.

\section{Trip duration}

Trip duration had the largest influence on train use, with longer duration trips typically being taken by train. Distance to main activity was not measured in the general questionnaire, so difference in trip duration could be due to several reasons. The duration difference could be partly explained by a location difference between samples, such that train users lived further from their main travel activity destination. However, the nature of the matched sample meant that geographical differences were controlled. Further evidence of this was that household location 
did not significantly alter between car and train commuter groups $\left(X^{2}(2, N=624)\right.$ $=1.58, p>.45, n s)$.

The difference in Trip duration may also have been due to variation in primary destination; for example, train commuters were more likely to have Wellington $\mathrm{CBD}$ as their final destination, compared with car commuters that may have been travelling to a closer destination.

Another explanation would be that train journeys simply take longer than car journeys. Several comments suggested that the longer trip time associated with public transport, particularly when individuals had to take multiple transport modes to reach their final destination, was a barrier to use:

"My problem with using public transport to go to my main activity is the amount of time it would take to walk to the bus stop wait for the bus, ride the bus (making all stops) and then walk to work site. Its not the cost or people or anything else just the time." (Participant number 426)

\section{Age}

Age shows a small negative relationship with number of vehicles $(r(616)=-0.08$, $p<.05$ ), so it is unlikely that older participants took a motor vehicle simply because they had better access. A general preference or positive attitude towards the train in younger passengers, however, does not explain why younger participants were more likely to catch the train. When presented with a hypothetical scenario where cost, convenience and travel time were equal for train and car, perceived preference for train over car was not influenced by age ( $r$ (597) $=0.05, p=.17, n s)$.

Lifestyle may be part of the reason for car use, such that increased travel requirements occur at stages where there are greater demands on resources, as with parents of children. Family status was not measured within the questionnaire but several comments suggested that having children made using public transport difficult: 
"With children it is difficult to use public transport and still be available for them." (Participant number 129)

\section{Neighbourhood}

Neighbourhood experience, as measured by years lived in the neighbourhood, showed a negative relationship with neighbourhood discomfort $(r(622)=-0.12, p$ $<$.01). This relationship provides evidence for the propinquity effect in the fixed neighbourhood setting, as more passive contacts would be likely over a longer duration. Similarly, those that owned their house, suggesting a higher level of establishment in the neighbourhood, had lower levels of neighbourhood discomfort $(r(592)=0.19, p<.001)$. Train commuters were less likely to own their house $(r(592)=-0.27, p<.001)$ and had shorter neighbourhood experience $(r(622)=-0.29, p<.001)$, which may explain their lower levels of discomfort with neighbours $(r(624)=-0.14, p<.001)$.

When asked whether passengers would feel more comfortable if all of the other passengers came from their neighbourhood, there was mostly disagreement (on the 1-5 scale item, responses were below the neutral midpoint of 3 ). Train commuters revealed higher levels of disagreement $(M=2.34, S D=0.86)$ than car commuters $(M=2.69, S D=0.88 ; t(613)=5.02, p<.001)$.

Car commuters may not associate their neighbours with regular public transport use because they themselves are not frequent users. For example, some negative comments made by car commuters were directed at people from other neighbourhoods:

"Am tired of alleyways up our street. They seem to attract undesirables from other neighbourhoods thru ours. They are on their way to catch buses etc. There is a need to get buses etc. to their neighbourhoods." (Participant number 570) 


\section{Interpersonal Distance (IPD) Discomfort}

IPD Discomfort scores were above neutral for both car $(M=3.21, S D=0.66)$ and train commuters $(M=3.18, S D=0.68)$, indicating that discomfort with close interpersonal distances was an issue for both groups. Discomfort from overcrowding at peak commuting times was recognised as problematic, where all seats were full and passengers were forced to stand:

"The trains get very overcrowded during peak times - there should be more carriages put on to encourage people to use trains. Sometimes it is so packed the conductor can't move through the carriage to check tickets. This is uncomfortable for people who aren't touch avoidant!" (Participant number 26)

Commentary suggests that discomfort also occurs in less crowded situations. In conditions where the carriage was more than half full, passengers would have to sit immediately adjacent to other passengers, where the limited seat space forces them to touch:

"One problem on public transport - buses is that the seats are too small to fit two people comfortably, only two children can fit in side by side. This leads to people being squashed!! (old buses) It can be very embarrassing." (Participant number 673)

There was even the suggestion that when all the empty seats were taken, passengers would maximise the space available to them by actively selecting a small passenger to sit beside:

"Seat selection - always look for the most room so skinny people I'll sit beside." (Participant number 556)

A closer investigation of the covariates of IPD discomfort was undertaken for the car commuter sample using a stepwise linear regression. 5 The following 23 key variables were placed into the regression: all eight scales; personal preference for

\footnotetext{
5 The same regression analysis already revealed the eight key influences on IPD DISCOMFORT for Train commuters were: Train full when board, Train Heterogeneity, Train full when depart, Neighbourhood Discomfort, Weekly train travel (number of days), Privacy, personal preference for social interaction, and Education (see Train chapter).
} 
social interaction; perceived preference of other train users for social interaction; experience with current neighbourhood (years); duration of travel by train (mins); privacy on the train; train heterogeneity; neighbourhood heterogeneity; housing density of neighbourhood; number of household vehicles; relationship status; ethnicity (NZ European or other); gender; income; age; and education.

Table 5.5 shows the independent variables in the model that explained significant variation in the IPD Discomfort scale $(F(5,233)=16.98, p<.001)$. The final model has a multiple-R of 0.52 and an adjusted $R^{2}$ of 0.25 indicating that $25 \%$ of the variance in IPD Discomfort scale scores was explained by the model. The Beta weights show that a car commuter's perception of Privacy and Social Interaction are the largest influences on IPD Discomfort scale scores for car commuters, and that these variables form negative relationships with IPD Discomfort.

Table 5.5.

Stepwise Linear Regression of IPD Discomfort on Key Questionnaire Variables for the Car Commuter Group

\begin{tabular}{lccccccc}
\hline & & & & & & \multicolumn{2}{c}{ Correlation } \\
\cline { 7 - 8 } & B & SE & Beta & $t$ & Sig & Partial & Part \\
\hline Duration of trip & 0.08 & 0.03 & 0.15 & 2.65 & 0.009 & 0.17 & 0.15 \\
Housing density & 0.04 & 0.02 & 0.12 & 2.03 & 0.043 & 0.13 & 0.11 \\
Age & -0.06 & 0.03 & -0.12 & -2.08 & 0.038 & -0.14 & -0.12 \\
Privacy & -0.06 & 0.02 & -0.21 & -3.64 & 0.001 & -0.23 & -0.20 \\
Social Interaction & -0.35 & 0.06 & -0.32 & -5.48 & 0.001 & -0.34 & -0.31 \\
(Constant) & 4.24 & 0.25 & & 16.65 & 0.001 & & \\
\hline
\end{tabular}

Social interaction and the underlying feeling of friendliness among users was reduced under crowded conditions, which was reflected in some participant commentary:

"Some of your questions regarding crowd density are difficult to answer as the Upper Hutt to Wellington trains suddenly fill up at Waterloo. So the Upper Hutt people are a relaxed bunch and then it all becomes more stressful and less friendly." (Participant number 556) 
There is some suggestion by participants that maintaining privacy reduces even the minor social interactions based on body language, such as making eye contact:

"Whilst I do enjoy the quiet and time to "switch off" public transport allows - I do also believe in being polite and acknowledging people/strangers when in eye contact. I think many people today can't be bothered acknowledging people and prefer their own space and not bothering about social graces - this is evident on public transport..." (Participant number 502)

Level of attraction and level of acquaintance were also suggested as influential on tolerance of closer IPDs:

"I don't like people I don't know coming into my 'personal space'. Unless it's a pretty girl, I don't want anybody sitting next to me that I don't know. I don't like crowds and avoid them whenever possible." (Participant number 463)

\section{Train User Characteristics}

The mean scores for the eight items that made up the Train User Characteristic scale were all positive (above 5 on the o-10 scale), for both train and car commuter groups. Independent samples t-tests revealed significant differences between the commuting groups for all eight items $(\mathrm{p}<.05)$, such that train commuters rated other train users as more sincere, wise, warm, safe, clean, attractive, rich and educated.

There was some evidence that different users had different expectations about appropriate behaviour, and may have wanted a different train experience. For some passengers this even went to the point where they believed they would have a better train experience if the other users were similar, by moving the "undesirable", different groups to other carriages:

"I don't mind people talking quietly or listening to music quietly but often - esp young people/school kids are too noisy/play music way too 
loud. "I'm not a grumpy old man" but often noise from earphones will be very loud even if person is at other end of section of carriage ( 6 seats away). These people are very inconsiderate. I would have liked to see you ask some questions about if people would be prepared to pay more to sit in quiet or about views on recent WRC initiative (might have stopped) about having student free carriages." (Participant number 564)

Situations exist (such as job requirements) where passengers who typically have a good level of cleanliness will become "dirty" during the course of their day:

"When I started building and caught the train home (we had a set start/finish point so I could) people always left the seat next to me vacant as I probably smelt sweaty and had 'dirty' clothes on. This didn't happen in the morning though as my clothes were clean then!" (Participant number 423)

The example above demonstrates a normal situation that causes some awkwardness, and may reinforce a negative stereotype of other passengers being "dirty" or "smelly".

A closer investigation of the covariates of Train User Characteristics was undertaken for all commuters using a stepwise linear regression with the same key variables used in the IPD Discomfort regression above, except for Train Homogeneity which was not included as it was derived from the Train User Characteristic scale. Table 5.6 shows the independent variables in the model that explained significant variation in the Train User Characteristic scale $(F(6,418)=$ $49.86, p<.001)$. The final model has a multiple-R of 0.65 and an adjusted $R^{2}$ of 0.41 indicating that $41 \%$ of the variance in Train User Characteristic scale scores was explained by the model. ${ }^{6}$

\footnotetext{
${ }^{6}$ Initial analysis produced a more complex model with ten independent variables and an adjusted $R^{2}$ of 0.43 . By changing the $F$ criteria (the criteria determining stepwise entry into the model) from .05 to .01 this reduced the number of independent variables in the model to six without substantially altering the explanatory value of the model (the adjusted $R^{2}$ was only reduced to 0.41 ). The four additional variables in the original model were: Household density, Privacy, Trip Duration, and Neighbourhood Experience (years).
} 
The Beta weights in Table 5.6 show that Neighbourhood Characteristics had the largest positive influence on Train User Characteristics followed by Self Characteristics. Defensive Behaviour had the strongest negative influence on the assessment of other train users. When Train User Characteristic ratings were not controlled, Defensive Behaviour was higher in car commuters $(t(622)=3.44, p<$ .01). Higher education, a perception that other passengers want social interaction, and social comfort with other train users all improve the characteristic ratings of other train users.

Table 5.6.

Stepwise Linear Regression of Train User Characteristics on Key Questionnaire Variables

\begin{tabular}{lccccccc}
\hline & & & & & \multicolumn{3}{c}{ Correlation } \\
& B & SE & Beta & $t$ & Sig & Partial & Part \\
\hline $\begin{array}{l}\text { Neighbourhood } \\
\text { Characteristics }\end{array}$ & 0.32 & 0.03 & 0.40 & 9.72 & 0.001 & 0.43 & 0.36 \\
Self Characteristics & 0.20 & 0.04 & 0.19 & 4.57 & 0.001 & 0.22 & 0.17 \\
Education & 0.11 & 0.04 & 0.12 & 3.14 & 0.002 & 0.15 & 0.12 \\
$\begin{array}{l}\text { Others want social } \\
\text { interaction }\end{array}$ & 0.06 & 0.02 & 0.12 & 3.08 & 0.002 & 0.15 & 0.11 \\
Train Discomfort & -0.26 & 0.09 & -0.13 & -2.96 & 0.003 & -0.14 & -0.11 \\
Defence & -0.35 & 0.09 & -0.17 & -3.89 & 0.001 & -0.19 & -0.15 \\
(Constant) & 3.59 & 0.46 & & 7.87 & 0.001 & & \\
\hline
\end{tabular}

Figure 5.1 shows that characteristic assessments of self and neighbours did not differ between car and train commuters. It also shows that characteristic assessments reduce from self to neighbour to train user for both car and train commuter groups. 


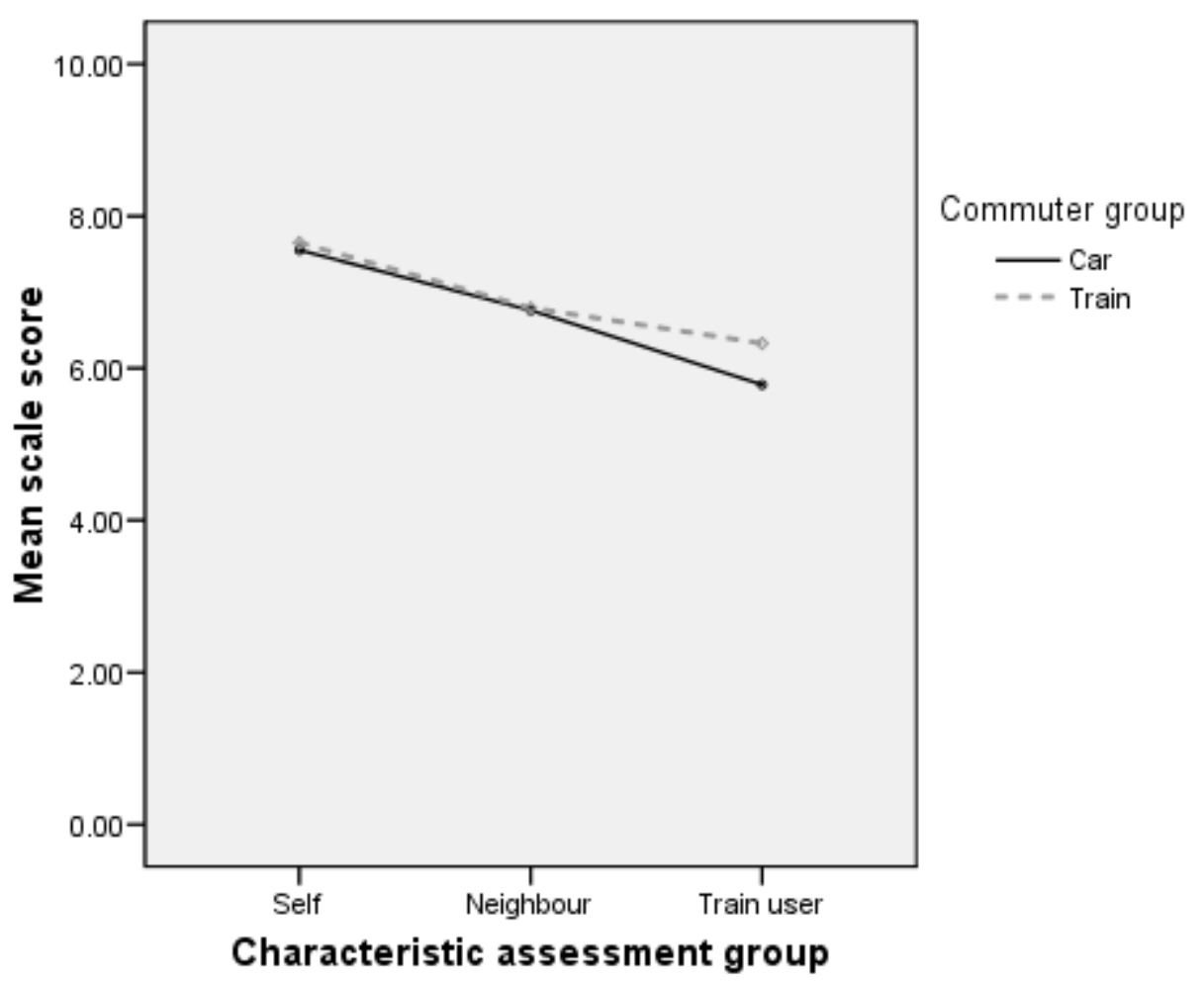

Figure 5.1. Mean self, neighbour and train user characteristic assessments for car $(n=241)$ and train commuters $(n=258)$.

\section{Discussion}

The direct measures of train discomfort and touch avoidance did not reveal any differences between car and train commuter groups. It was expected that touch avoidant passengers would be more likely to avoid crowded trains where they would be forced into touch distance with other passengers, but this was not the case. Similarly, it was expected that car commuters would be less open to interaction with other public transport users, due to a lower familiarity with the setting and its users. There is no evidence that car commuter are less open to interaction, they are just as socially comfortable with other passengers.

Discomfort or fear of interaction with other train users is not a barrier to train use. However, regular train commuters do have more positive attitudes towards other train passengers, and are more tolerant of the close interpersonal distances that occur on the train when compared with car commuters. These findings provide evidence that social influences on public transport use require attention alongside 
the more tangible and directly measurable influences such as price, reliability and convenience.

The other social factors that are significant in predicting train use relate to the neighbourhood. Neighbourhood discomfort is higher in train commuters, which is counter-intuitive. It is reasonable to expect that people that are socially uncomfortable with their neighbours would prefer a mode that is more solitary, such as the car, over a more social mode, such as the train. Especially when some of the same neighbours will be taking the train and your likelihood of passive contact is higher using this mode. This finding of discomfort is likely to be accounted for by the fact that car commuters have a greater level of establishment in their neighbourhoods. Car commuters are more likely to own their homes (as opposed to renting) and have dwelled in their neighbourhood for a longer period. The reduction in neighbourhood discomfort is evidence of passive contact theory (PCT) at work in the neighbourhood setting.

The higher level of neighbourhood establishment could be related to the fact that car commuters are older than train commuters. This age effect could be attributed to income; with older commuters better placed to afford the higher costs typically associated with private car use. Previous research suggests that income and number of household vehicles form a positive relationship with car use (see Mitchelson, 1982 or Parolin, 1992). However, this is not the case here, as car commuters were found to have a lower income and the number of vehicles per household decreased with age. Basic preference for train over car does not relate to age either. Based on this, vehicle access does not appear to contribute to the age effect, neither does preference for train over car, so factors external to the scope of this research may provide greater insight.

The age finding is corroborated in the national survey of transport mode selection, where younger age groups were found to be more likely to use public transport (in particular the 15-24 year age group) when compared with older age groups who were more likely to use motor vehicles (Ministry of Transport, 2008). New Zealanders in the 35-64 age range spend the most time travelling (Ministry of Transport, 2008), so the additional travel requirements of this age group combined with the convenience of the typically faster trips made by car may be one 
reason for the age difference. Furthermore, there is an increasing trend in the proportion of parents dropping their children to secondary school by car (Ministry of Transport, 2008) 7, which may help to explain the more intensive car use amongst higher age groups.

Trip duration is the most influential factor on train use. The extra duration for trips for train users could be interpreted as a greater distance travelled by train commuters or it could be that public transport simply takes longer to get to the destination compared with cars. Distance was not measured in the general sample, so it cannot be ruled out, however evidence suggests that the distance travelled is not likely to differ due to the matched nature of the samples that controlled for geographical differences.

Duration is a significant factor, so the added travel time of public transport is arguably a real barrier to patronage. This finding is reflected in much of the literature relating to the convenience of the car (e.g. Eriksson et al., 2008). Compared with the car, public transport usually requires trip chaining through multiple modes and wait times (prior to boarding the service and for passenger stops preceding the final destination). In a satisfaction survey of public transport in the Greater Wellington Region, only $27 \%$ of residents reported that journeys on public transport were faster than journeys by car (Greater Wellington Regional Council, 2008b).

Discomfort caused by close Interpersonal Distance (IPD) is a barrier to train use. Both train and car commuters were uncomfortable with the close conditions, however, car commuters are less tolerant of the close distances of other passengers. With a growing population and in a climate of increasing petrol prices, demand for public transport is increasing, and crowding is a growing problem. At present, demand outstrips supply at peak commuting times in the larger New Zealand cities (e.g. Auckland Regional Transport Authority, 2008). There are health and safety issues with the large numbers of standing passengers forcing riders to stand in locations where there are signs instructing them to avoid standing in the space. At the extreme end of the scale, the media has reported 
cases of injury and passenger complaints about the "cattle class" conditions due to crowding (Close Up, 2008).

The concept of crowding is not just a physical lack of space or a high density of people (e.g. Freedman, 1975). Crowding is a psychological state that relies heavily on individual expectation and perception, and is context specific (Freedman, 1975). For example, a high density of people in close proximity is desirable in situations such as at a party or when a spectator at a sports event, with the concept of a "good crowd". In the context of the train, it is perhaps not surprising that discomfort from crowding occurs at peak times where passengers are forced to stand due to limitations in seating. Less obvious is the fact that there are negative effects that occur when two strangers sit side-by-side in the seats designated for them.

Lundberg (1976) found that physiological stress (as measured by catecholamine excretion) does increase under crowded conditions on a train commute. Stress levels are likely to be exacerbated at peak commuting times when crowding causes interpersonal distances that force unavoidable bodily contact (Nicosia, et al., 1979). Although touch avoidance did not influence train use or interpersonal discomfort in this study, this may have been due to the fact that the scale was a shortened version of the original and three of the four items referred to touching friends instead of strangers. Items asking about touching strangers were deemed too evocative for this study, (as it was, several comments suggested discomfort answering the items as they were) so a different wording may have found that touch avoidant people also avoided public transport, but this study found no evidence that this is the case.

Even under conditions where a train is not full, close interpersonal distance increases stress levels of passengers (Evans and Wener, 2007). Passengers sitting in designated seats are stressed by the extremely close distance to the nearest seated passengers. Evans and Wener (2007) examined interpersonal distance and density on the train and found that close interpersonal distance (as measured by the proportion of full seats in the same row) increased physiological stress levels (as measured by salivary cortisol levels), reduced mood (feeling more burdened and frustrated) and reduced motivation (task performance at proofreading). 
Density of passengers in the overall carriage, while related to IPD, did not significantly influence any of these measures. Thus, in the train setting, the IPD measure was sensitive to the negative influences of crowding, whereas the less refined measure of carriage density was not (Evans \& Wener, 2007).

A closer examination of the covariates of IPD discomfort for car commuters reveals that the variables that increase the tolerance for close interpersonal distances with other passengers include positive perceptions of the latent social atmosphere, a perception that privacy can be maintained, and higher age. The variables that reduce tolerance for close interpersonal distances include trip duration and household density.

People who live in high density situations (such as apartments) have a lower tolerance of other passengers being in close proximity. This provides evidence that people do not habituate to crowded conditions, and that the reverse is true, that people become less tolerant if other facets of their life are crowded. This reflects the need for balance in the privacy-social interaction dynamic, such that people must achieve a certain level of privacy in some part of their day.

There is more to trip duration than the convenience of a quicker trip to the destination. There are social influences on trip duration, such that on longer trips car commuters become less comfortable with the close interpersonal distances. Discomfort from close interpersonal distances is exacerbated by greater exposure to crowded conditions. Duration is not a factor in train user IPD discomfort (see Train chapter), suggesting that train users are better at dealing with longer exposure to stressful conditions.

There are contrary findings in the literature relating to trip duration and stress. Lundberg (1976) found that social factors were more influential on stress than trip duration or length. However, other studies found that a reduction in train trip duration has been found to reduce stress (Wener et al., 2003; Evans \& Wener, 2006). The difference in findings could be due to variable levels of crowding and an increase in perceived control in the long duration group in Lundberg's (1976) study. In Evans and Wener's (2006) research they found that the conditions of the train carriage including density, having one's own seat, and being able to select 
seat location, were unrelated to commuting time. Commuting time increased stress under crowded passenger conditions.

Lundberg's (1976) key finding was that the longer duration group (who were less stressed) had greater control over their surroundings when they boarded the train which produced a different social context. For example, passengers had greater control over the seat selection decision, the ability to sit next to an acquaintance or friend, and more space to arrange their belongings, which also suggested lower levels of crowding. The short duration group that boarded the same train at a later stage had greater constraints on their immediate environment, more crowded conditions, and consequently greater levels of stress. The benefit of an increase in perceived control of the space on its users is substantial, as it will significantly reduce stress.

Passengers are more comfortable with close interpersonal distances when there is a positive latent social atmosphere. Johnson (1989) examined the factors associated with adult friendship amongst friends, acquaintances and strangers and found that being perceived as polite and friendly were strong predictors of friendship. The more intimate the levels of acquaintance or friendship, the more accepting people are of close interpersonal distances (e.g. Burgess, 1983), which is the basis of Hall's (1966) theory of proxemics. However, Nash (1975) suggests that crowded conditions are one of the key factors that reduce social interaction. This reduction in social interaction may be inhibited by the perceived social surveillance of other passengers, which has been shown to induce verbal withdrawal in laboratory conditions (Greenberg \& Firestone, 1977). Therefore, social interaction does reduce discomfort from crowding, but crowded conditions may naturally impede social interaction from occurring, particularly between strangers.

People are sensitive to the need for privacy in other contexts, for example, Li and $\mathrm{Li}$ (2007) found that people provided greater IPDs when queuing to use automatic teller machines (most private information, e.g. pins and personal savings informaiton), when compared with add value machines (some private information attached) or ticket vending machines (least private information attached). On the train, people are sensitive to the need for privacy as well, whether motivated by their own need or respect for other passenger's space. People will not sit next to 
strangers until they have to; with a preference for paired seats that are empty (see Observation Chapter). The difficulty occurs when people recognise the need for a passenger's privacy but are forced to sit next immediately next to them. Not only has an invasion of space occurred to the seated passenger, but the invader recognises that they are entering someone's intimate space, causing a level of awkwardness or discomfort to both people.

The findings show that older passengers are more tolerant of close IPDs. Previous research examining observations of age and interpersonal distance is not conclusive and often only examines age groups based on elderly or child samples, where age is not the primary focus of the experimental design, merely a demographic finding (for example Webb \& Weber, 2003). Where there is a trend, it shows that IPD increases with age (for example, Ozdemir, 2008). However, other studies do not find this linear relationship. Remland, Jones and Brinkman (1995) observed naturalistic interactions in public settings and found that their 4059 age group couples were observed with greater IPDs than either the 20-39 or the 60 or more age group couples. Heshka and Nelson (1972) also found a curvilinear relationship between age and IPD, where younger and older dyads maintained closer interpersonal distances.

The finding of a negative relationship between IPD and age may be because it is a self-report measure, as opposed to objectively observed IPDs. Age was not measured in the observational study (see Observational chapter), as gender formed a clearer relationship in the literature, and due to the eye-witness observation technique (with no surveillance equipment for verification) was deemed easier and quicker to identify. Whether this finding is robust or not, avoidance of the train by car commuters is not likely to be caused by a perception of crowding.

Discomfort with other neighbours increases IPD Discomfort for train commuters, but not for the car commuters. This suggests that car commuters have the potential to be more comfortable in close proximity to other train passengers, as they are older and more comfortable with their neighbours. It also reflects a general capability to handle social situations that improves with age and experience. 
Train commuters are more positive in their assessment of other train users. Setting familiarity and acquaintance with the other regular users may induce these positive attitudes. Bornstein (1989) performed a meta-analysis on 134 studies examining the relationship between affect and exposure, and found that mere exposure to a stimulus does promote positive attitudes towards that stimulus, as per the concept of "familiarity breeds liking". This explains a fundamental aspect of why PCT should work, but most of the exposure studies were based on simple stimuli, and only very few examined the complexity of social interactions.

If exposure effects do hold for social interactions, then regular train users are more likely to form positive associations with other train users based on frequency of use, which is one plausible explanation for the difference in train user characteristic ratings between car and train commuters. Saegert, Swap and Zajonc (1973) had participants taste either pleasant or noxious liquids when they met people, and found that even with aversive stimuli there was still a positive exposure effect, with higher attractiveness ratings after a greater number of contacts. Therefore, even under "poor" conditions, such as a crowded train carriage full of complete strangers, exposure and familiarity are still likely to promote better attitudes towards other users.

General attitudes towards public transport users are all positive, suggesting that some of the old stereotypes showing that public transport users are "poor" or "dirty" are not upheld, even by car users. The cause of the positive attitudes may reflect an improved perception of public transport users, with the train or bus as a safe, cost-effective, environmentally friendly alternative to the private car. The finding may also be influenced by a social desirability bias, as it is not publicly correct to stereotype people. The important finding here is that there is a difference in attitudes towards train passengers that may act as a barrier to train use.

As suggested above, a reasonable explanation of the more positive ratings of train users could be due to an exposure effect, and the natural extension of this, a propinquity effect with more passive contacts and more friendship formation over time. From a car user perspective, lower personal characteristic ratings are natural for a group with which someone does not form strong associations. This is a form 
of self-enhancement, where the groups someone identifies with are rated more highly than other groups. If this is the case, then car users may avoid train use because of the type of people that take the train. There is some evidence in the defensive behaviour of car commuters and their lower level of education that may lead to negative perceptions of train users.

That education relates to more positive character assessments of train users suggests that improved information may be effective in reducing poor stereotypes of train users and improve tolerance for the different users of trains. The car commuters in this study are less educated than train users and may consequently be more likely to hold unfounded negative perceptions of train users. Siegfried et al. (1982) found that willingness to take public transport increased if people perceived that the "typical" user was similar to them. The authors suggested an intervention focussed on promoting similarities to break down negative stereotypes (Siegfried et al., 1982).

People that adopt defensive behaviour when taking the train are not viewed positively. Most likely, they come across as unfriendly and in some instances rude. For example, defending space by placing objects on the adjacent seat could be viewed as unfriendly or inconsiderate behaviour by a passenger looking for a seat. In contrast, the perception that other passengers want more social interaction indicates a belief that other train passengers are friendly and sociable, with consequent positive characteristic ratings. Car users are more likely to adopt defensive behaviours and consequently may receive less positive feedback from other passengers, which is likely to promote a poor perception of train users as unfriendly.

\section{Limitations}

Because participants in the car commuter sample were asked about public transport (rather than solely about trains) for some items, any differences between the sample groups may be attributed to a difference in attitude towards buses and trains versus solely trains. Also, there is a social desirability to appear clean and green and reduce household vehicle emissions and congestion, meaning that there is some bias towards using public transport. For example, a large number of the 
comments from the car commuters included an explanation of why they did not travel by public transport more regularly. These explanations suggest cognitive dissonance between their relatively poor emissions behaviour and their pro-social attitudes or desire for a pro-social image. This also signifies understanding that the overall goal of the research is to promote public transport patronage.

\section{Conclusions}

The social factors associated with public transport are more difficult to measure and verbalise complaints about, but this does not make them less important. In some ways the less tangible factors are more important, as they are the elements that have been neglected. Social discomfort and touch avoidance were not barriers to train use, but close interpersonal distances and attitudes towards train users are potential social barriers that need to be better understood and overcome.

Evidence presented above suggests that solutions focussed on increasing a passenger's perception of control over the environment will be beneficial to reducing social discomfort due to close interpersonal distances. Another solution is to demarcate the seat spacing more appropriately. Often there is a bench seat that allows room for two passengers, but there is no visual or tactile indication of the seat's midpoint. Evans and Wener (2007) suggest the use of "territorial props" such as armrests or small tables.

Positive characteristic ratings of train users are reduced by defensive behaviours and increased by social interactions. Promoting social interaction or even social politeness, reducing ineffective defensive behaviours, and improving perception of passenger control are all likely to promote the train as a popular alternative to the car by reducing social discomfort (see Train Chapter) and enhancing the perception of the other users. 


\section{CHAPTER 6: SOCIAL DISCOMFORT ON THE BUS}

The previous chapters draw out the apparent differences between train and bus travel, and the necessity to more closely examine bus user attitudes and behaviours. This chapter attempts to form a better picture of the differences between bus and train travel, with a focus on how bus travel may have different barriers to uptake by car users in the context of the interpersonal situation. The sample of car and train commuters is extended to a bus sample by using the same questionnaire and tailoring it for bus commuters.

\section{Background}

There are fundamental differences between bus and train travel that are likely to influence social discomfort and the adaptations passengers use to reduce that discomfort. For example, the Observational study found that the physical parameters surrounding buses and trains, with smaller seats, less leg room and narrower aisles on buses, are likely to increase interpersonal discomfort.

Hensher (2008) reviewed demand for public transport in a meta-analysis using over 319 studies, and found that one of the key factors influencing elasticities of use was specificity of mode. That is, the particular splitting of bus and train modes, as opposed to the generic class of public transport. There is further evidence for the split, for example, increased fuel prices are more likely to see car users shifting to train, whereas shifts to bus travel may not be as sensitive to fuel price (Currie \& Phung, 2008). Although trip duration differences are not as much of a modal barrier as they once were, with the adoption of bus rapid transit and dedicated bus lanes (e.g. Currie, 2005).

Ory and Mokhtarian (2005) found greater liking for the train, with an even split of participants liking (30\%) and disliking (30\%) the train, when compared with the majority of participants that disliked the bus (63\%), which outnumbered bus liking (8\%) greatly. In the Greater Wellington region of New Zealand overall bus performance (68\% of participants view the bus as excellent or very good) is rated better than train performance (62\% of participants view the train as excellent or 
very good; Greater Wellington Regional Council, 2008b). In transport planning there is a preference for train travel, but the train is often not an option due to prohibitive infrastructure costs (Currie, 2005; Currie \& Phung, 2008). Any concomitant social benefits, such as less stress or a more pleasant trip, are typically not factored into cost-benefit considerations, as the relative importance of social factors is more difficult to measure.

In an Australian study (arguably a population with some similar characteristics to New Zealand), Parolin (1992) examined household travel survey data and found unique differences between bus and train users. Bus use related positively with social heterogeneity (a composite measure created from differences such as ethnicity, income and housing type) and residential density, whereas train use related positively with car ownership. A household travel survey examining bus use in the US found a positive relationship between bus commuting, service quality (frequency and coverage of service in an area) and household density and a negative relationship between bus commuting and car ownership, social heterogeneity and income (Mitchelson, 1982).

Several key differences in the findings from the Observational and Car studies support the need for a closer examination of the factors influencing bus and train use, although this was not clearly supported in the Exploratory Chapter, where there were mixed findings. When shown photographs of the bus and train settings under different conditions, ratings of comfort of sitting in an empty paired seat, comfort sitting beside another passenger, or ratings of whether the passenger looked comfortable sitting in that setting did not vary by travel mode (see Exploratory Chapter). Sitting beside a stranger on a bus was perceived as more uncomfortable than sitting beside a stranger on a train, but both situations were categorised as high discomfort when compared with other contexts. Overall, the Exploratory Chapter suggests that both settings are perceived as uncomfortable, with some evidence of less discomfort in the train setting.

The Observational Chapter provided evidence of several differences between bus and train travel, such that: the train is less full, has lower passenger totals, lower capacity for passengers, longer trip durations, greater frequency of activities (e.g. reading or listening to music), a later time of day, and larger interpersonal 
distances between passengers. These factors suggest lower levels of crowding, a consequence of which may be greater perceived social comfort on the train.

Finally, the small sample of bus commuters $(n=33)$ in the general sample of the public from the Car study showed some different characteristics when placed into a binary logistic regression with car commuters. These included lower touch avoidance than car commuters, a lower number of household vehicles, and a lower need for social interaction on public transport. These influences were not observed in the car-train regression analyses and so point to the importance of a closer inspection of bus user characteristics, including potentially different barriers to uptake.

The purpose of this chapter is to examine differences between bus and train commuting and identify the possible barriers to bus use for car commuters. It is expected that train commuting will be perceived as more preferable to bus commuting, as observed across a range of measures including interpersonal and social discomfort.

\section{Hypotheses}

1. Car commuters self-reported ratings of travel mode preference will be higher for the train when compared with the bus.

2. Social discomfort is higher in the bus commuter group when compared with car and train commuters, as represented by higher public transport social discomfort scores, higher interpersonal discomfort scores, a higher willingness to pre-pay for a seat, higher defensive behaviour scores, a lower perception of privacy, and lower social interaction.

\section{Method}

\section{Participants}

Three hundred questionnaire packs were personally handed out to people standing at two bus stops in the Wellington CBD, of which 202 (a $67 \%$ response rate) were returned. Ten of these had incomplete data, leaving a sample of 192 people that used the bus. 
Most participants ( $n=157,82 \%$ ) reported the bus as their primary travel mode, with the remaining 35 (18\%) indicating that they did travel by bus occasionally. Closer examination of the remaining 35 participants found that 24 of these travelled by bus at three days a week, so these were recoded as bus users for the purposes of all of the following analyses (the same criteria was used in the previous chapters). The final sample of bus users was 183, with the additional participants travelling by car $(n=6)$, cycle $(n=1)$, or walking $(n=2)$. The additional participants were not used in any of the following analyses.

The 33 participants from the general population that happened to travel by bus (see the Car study) were also added to this sample to give a total of 216 bus commuters. The average age of bus commuters was 41.9years ( $\mathrm{SD}=10.24$ years), and the average household income of bus commuters was $\$ 79,800$ ( $\mathrm{SD}=\$ 33$, 160). Table 6.1 provides a summary of other bus sample characteristics.

Table 6.1.

Summary of Bus Sample Characteristics

\begin{tabular}{llrr}
\hline Characteristic & & $n$ & $\%$ \\
\hline Gender & Male & 76 & $42.0 \%$ \\
& Female & 105 & $58.0 \%$ \\
Activity & Work & 172 & $94.0 \%$ \\
& Education & 9 & $4.9 \%$ \\
& Other & 2 & $1.1 \%$ \\
Education & High school qualification & 36 & $20.3 \%$ \\
& Other post-school & 45 & $25.4 \%$ \\
& qualification & 51 & $28.8 \%$ \\
& Bachelor degree & 45 & $25.4 \%$ \\
& Higher degree & 123 & $68.0 \%$ \\
& New Zealand European & 14 & $7.7 \%$ \\
& Maori & 13 & $7.2 \%$ \\
& Asian & 8 & $4.4 \%$ \\
& Indian & 8 & $4.4 \%$ \\
& Pacific Islander & 15 & $8.3 \%$ \\
\hline
\end{tabular}




\section{Materials}

The questionnaire pack was very similar to the pack handed to participants in the train study (see Train Chapter). The differences were that the questionnaire pack included a personally signed cover letter, the prize draw was of a lower value (\$250 to reflect the smaller sample being examined), and a slightly shorter questionnaire (with 129 items as opposed to 137). Many items were reworded from "bus" to "train". One new item was added that asked "What is the name or number of your regular bus?”

Key measures included IPD Discomfort, Social Discomfort (in train and neighbourhood settings), Defensive Behaviours, Social Interaction, Characteristic Assessments (of self, train passengers and neighbours) and Touch Avoidance. Five transport facts were placed throughout the questionnaire. These were intended to demonstrate how transport research can provide members of the public with useful information. Appendix E contains the bus transport facts. Three participants responded with positive comments about the transport facts.

\section{Procedure}

Questionnaires were handed out to members of the public waiting at two bus stops in the Wellington central business district over a period of two days. Both stops were selected based on the high concentration of people waiting to catch the bus. Potential participants were approached by an experimenter, given a brief verbal description of the research, and asked if they were taking the bus. If they gave confirmation that they were catching the bus they were asked if they wished to volunteer and given a questionnaire pack. Ethical approval was gained for this study.

There was a bus driver strike the day before the survey began, with limited buses running between $9 \mathrm{am}-3 \mathrm{pm}$. The cause of the strike was a pay dispute. Some of the participants initially thought that was what the questionnaire was about. The strike may have coloured participant responses. Just from talking to the passengers in waiting, there were people who were sympathetic to the bus drivers and those that were not, so this may have influenced questionnaire responses in positive or negative directions. None of the items ask specifically about the driver. 
The sample was not matched by neighbourhood (the train and general car sample were, see the Car study for more details for the matched samples procedure), so it was expected that the bus sample would have a different demographic makeup.

\section{Results}

\section{Travel Mode Preference}

When car commuters were asked which mode of public transport they preferred (on an 11-point continuous scale; $\mathrm{O}=$ Bus; $5=$ No preference; $10=$ Train), the overall preference was towards the train $(M=6.78, S D=3.15)$. Participant commentary also tended to agree with this finding:

"I prefer the train to the bus because the train journey is more interesting and has a sense of being on an adventure; with views into backyards and through bush." (General participant number 669)

Car commuters were also asked the ease (on a five-point Likert scale from $1=$ Very easy to $5=$ Very difficult) with which they could travel to their main activity given two scenarios. First, a train scenario, where there is a major traffic jam and they could instead drive to a park and ride facility to catch the train. Second, a bus scenario, where the car is suddenly unavailable as it is under repair, and the bus is taken instead. Both were rated above the theoretical scale midpoint, and the difficulty of the train scenario was higher $(M=3.48, S D=1.43)$ than the bus scenario $(M=3.15, S D=1.31 ; t(303)=4.09, p<.001)$. The car sample had the same spatial factors relating to their place of residence, such as distance to station, as the train commuters (due to the matched neighbourhood sample), yet they viewed this mode as more difficult, even though there was a slight preference for the train.

Finally, when asked about preferred travel mode in a scenario where cost, convenience and travel time were equal, there was a significant difference between travel mode preference $\left(\chi^{2}(4, N=817)=194.19, p<.001\right)$. Each group reported 
their own travel mode as their preferred mode when cost and service provision measures were equal. However, car commuters were only 3.62 times as likely to choose the car over the train, whereas they were 4.19 times as likely to choose the car over the bus, indicating a slight preference towards the train.

\section{Car, Train and Bus Commuter Sample Characteristics}

Demographic, household and trip characteristic differences between car $(n=305)$, train $(n=319)$ and bus $(n=216)$ commuters were examined using one-way ANOVAs (Analysis of Variance) and Kruskal-Wallis tests (for the non-parametric variables; see Table 6.2). The only variable with no significant difference between groups was gender, where females had slightly higher representation across all of the groups.

\section{Demographic differences}

Bus commuters were more likely to be ethnically diverse (non-New Zealand European $=31.5 \%$ ) when compared with car commuters (non-New Zealand European $=17.8 \%)$. In the Wellington region of New Zealand there was an average of $70 \%$ of people that identify themselves as New Zealand European, with a further 13\% Maori, 8\% Pacific Islander, and 8\% Asian (Statistics New Zealand, 2008c). This suggests that car commuters were less representative of the general community.

Car commuters were more likely to have a long-term relationship than bus commuters, have a lower income than train commuters, and a lower level of education and a higher age than train or bus commuters. Train commuters also had a higher level of education than bus commuters. 
Table 6.2.

Demographic, Household and Trip Characteristics for the Car, Train and Bus Commuter Groups

\begin{tabular}{|c|c|c|c|c|c|c|c|}
\hline \multirow{2}{*}{$\begin{array}{l}\text { Characteristic } \\
\text { Gender }(1=\text { male; } 2 \\
=\text { female })\end{array}$} & \multicolumn{2}{|c|}{$\begin{array}{c}\text { Car } \\
M\end{array}$} & \multicolumn{2}{|c|}{$\begin{array}{l}\text { Train } \\
M\end{array}$} & \multicolumn{2}{|c|}{$\begin{array}{c}\text { Bus } \\
M\end{array}$} & \multirow[t]{2}{*}{ Sig } \\
\hline & 1.59 & $(0.49)$ & 1.53 & $(0.50)$ & 1.58 & $(0.49)$ & \\
\hline $\begin{array}{l}\text { Ethnicity }(1=\mathrm{NZ} \\
\text { European; } 2= \\
\text { other) }\end{array}$ & 1.18 & $(0.38)$ & 1.25 & $(0.43)$ & 1.31 & $(0.47)$ & $* *$ \\
\hline $\begin{array}{l}\text { Education }(1= \\
\text { secondary school } \\
\text { qualification; } 4= \\
\text { post-graduate } \\
\text { degree) }\end{array}$ & 2.17 & $(1.00)$ & 2.48 & (1.05) & 2.55 & (1.08) & $* * *$ \\
\hline Age (years) & 47.60 & $(13.62)$ & 39.40 & $(12.04)$ & 41.90 & $(10.24)$ & $* * *$ \\
\hline $\begin{array}{l}\text { Relationship status } \\
(1=\text { single; } 4= \\
\text { married })\end{array}$ & $3 \cdot 36$ & $(1.17)$ & 3.16 & $(1.25)$ & 3.09 & $(1.26)$ & $* *$ \\
\hline $\begin{array}{l}\text { Household income } \\
(\$ N Z)\end{array}$ & 73,400 & $(32,480)$ & 79,800 & $(29,740)$ & 79,800 & $(33,160)$ & * \\
\hline $\begin{array}{l}\text { Own versus rent } \\
\text { home }(1=\text { own; } 2= \\
\text { rent) }\end{array}$ & 1.06 & $(0.24)$ & 1.25 & $(0.44)$ & 1.32 & $(0.47)$ & $* * *$ \\
\hline $\begin{array}{l}\text { Neighbourhood } \\
\text { experience (years) }\end{array}$ & 12.54 & $(11.59)$ & 6.40 & $(8.20)$ & 9.21 & $(10.56)$ & $* * *$ \\
\hline $\begin{array}{l}\text { Housing density (o } \\
\text { = very spread out; } \\
10 \text { = very dense) }\end{array}$ & 5.15 & $(1.82)$ & 5.28 & (2.03) & $5 \cdot 70$ & (1.89) & $* *$ \\
\hline $\begin{array}{l}\text { Number of } \\
\text { household motor } \\
\text { vehicles }\end{array}$ & 1.93 & $(0.74)$ & 1.77 & $(0.91)$ & 1.48 & $(0.82)$ & $* * *$ \\
\hline $\begin{array}{l}\text { Trip duration } \\
\text { (mins) }\end{array}$ & 19.30 & $(12.23)$ & 30.10 & $(11.80)$ & 24.70 & (9.99) & *** \\
\hline Distance $(\mathrm{km})$ & NA & NA & 19.20 & $(9.7)$ & 10.35 & (6.35) & $* * *$ \\
\hline $\begin{array}{l}\text { Travel activity }(1= \\
\text { work; } 2=\text { other })\end{array}$ & 1.21 & $(0.40)$ & 1.04 & $(0.21)$ & 1.10 & $(0.30)$ & $* * *$ \\
\hline
\end{tabular}

\section{Household differences}

Household characteristics revealed that car commuters were more likely to own their home, have a higher number of household vehicles, and have lived in their local community for a longer period of time than either bus or train commuters (see Table 6.2). Bus commuters lived in an area with a higher housing density than 
car or train commuters, and had longer neighbourhood experience and a lower number of household vehicles than train commuters.

\section{Trip differences}

Car trip durations were shortest, followed by bus, then train. Bus trips were shorter than train trips and trip duration was relative to travel distance (see Table 6.2). When travel distance was controlled, the difference between trip duration for bus and train travel was no longer significant $(F(1,441)=3.06, p=.08$, n.s. $)$, indicating that perceived travel speed between bus and train did not differ significantly. The primary purpose for travel was typically work, with train commuters travelling the most for work (95.6\%) followed by bus (90.3\%), and lastly car (79.5\%).

\section{Key Scales}

\section{Reliability}

The Social Interaction and Self Assessment scales show low internal reliability, with scores well below the criteria of 0.70 (Christmann \& Van Aelst, 2006). The Interpersonal Discomfort scale also shows low internal reliability, just below the 0.70 criteria. The remaining scales all show adequate internal reliability (see Table $6.3)$.

\section{Issues with personal assessment scales for bus commuters}

Seven individuals that responded to the personal characteristic scales with consistently neutral responses (identified by the method in the Train Chapter; 75\% identical responses and a mode of 5$)$ included some Bus User $(n=4)$ and some Neighbour $(n=3)$, but no Self characteristic scales. A further five participants failed to respond correctly to the counterbalanced items in the characteristic scale (see Train Chapter for more on counterbalancing issues), so data was also removed for Self $(n=3)$, Bus User $(n=1)$ and Neighbour $(n=2)$ scales. 
Table 6.3.

Scale Reliabilities by Car, Train and Bus Commuter Groups

\begin{tabular}{lccccc}
\hline & $\begin{array}{c}\text { Number of } \\
\text { items in } \\
\text { scale }\end{array}$ & $\begin{array}{c}\text { Scale } \\
\text { range }\end{array}$ & $\begin{array}{c}\text { Car } \\
\text { Alpha }\end{array}$ & $\begin{array}{c}\text { Train } \\
\text { Alpha }\end{array}$ & $\begin{array}{c}\text { Bus } \\
\text { Alpha }\end{array}$ \\
\hline Scale & 6 & $1-5$ & 0.68 & 0.69 & 0.63 \\
Interpersonal Discomfort & 6 & $1-5$ & 0.69 & 0.71 & 0.68 \\
Self Assessment & 8 & $0-10$ & 0.72 & 0.73 & 0.61 \\
Bus User Assessment & 8 & $0-10$ & 0.80 & 0.84 & 0.79 \\
Neighbour Assessment & 8 & $0-10$ & 0.87 & 0.88 & 0.83 \\
$\begin{array}{l}\text { Social Discomfort (public } \\
\text { transport) }\end{array}$ & 7 & $1-5$ & 0.73 & 0.69 & 0.70 \\
Social Discomfort (CBD bus & & & & & \\
stop) & 7 & $1-5$ & NA & 0.77 & 0.82 \\
Social Discomfort & & & & & \\
(Neighbourhood) & 7 & $1-5$ & 0.83 & 0.89 & 0.85 \\
Defensive Behaviour & 13 & $1-5$ & 0.81 & 0.77 & 0.74 \\
Touch Avoidance & 4 & $1-5$ & 0.65 & 0.69 & 0.72 \\
Bus Relationship & 4 & $1-5$ & NA & 0.87 & 0.85 \\
Neighbourhood Relationship & 4 & $1-5$ & NA & 0.84 & 0.84 \\
\hline
\end{tabular}

\section{Between-group differences for scales}

Differences between car, train and bus commuter groups were examined using one-way ANOVAs. The means, standard deviations and levels of significance for these groups were presented in Table 6.4.

Post-hoc tests explored the specific inter-group differences. Interpersonal discomfort was higher for bus commuters when compared with train commuters $(t$ $(525)=2.80, p<.01)$ or car commuters $(t(512)=2.46, p<.05)$. Ratings of public transport users were significantly more positive for train commuters compared with bus $(t(469)=2.37, p<.01)$ or car commuters $(t(514)=6.59, p<.001)$, and bus commuter ratings were significantly higher than car commuters $(t(439)=$ $3.76, p<$.001). Neighbourhood social discomfort was significantly lower for car commuters compared with train $(t(608)=-3.54, p<.001)$ or bus commuters $(t$ $(504)=-3.73, p<$.001). Defensive behaviour was significantly higher for car commuters compared with train $(t(613)=3.54, p<.001)$ or bus commuters $(t$ $(504)=2.91, p<.01)$, indicating greater IPD discomfort. 
Table 6.4.

Scale Means, Standard Deviations and Significant Differences between Car ( $n=$ 305), Train $(n=319)$ and Bus $(n=216)$ Commuter Groups

\begin{tabular}{|c|c|c|c|c|c|c|c|}
\hline \multirow{2}{*}{$\begin{array}{l}\text { Scale } \\
\text { Social Interaction }\end{array}$} & \multicolumn{2}{|c|}{$\begin{array}{c}\text { Car } \\
M\end{array}$} & \multicolumn{2}{|c|}{$\begin{array}{l}\text { Train } \\
M\end{array}$} & \multicolumn{2}{|l|}{$\begin{array}{r}\text { Bus } \\
M\end{array}$} & \multirow[t]{2}{*}{ Sig } \\
\hline & 2.89 & $(0.60)$ & 2.83 & (0.64) & 2.83 & $(0.62)$ & \\
\hline $\begin{array}{l}\text { Interpersonal } \\
\text { Discomfort }\end{array}$ & $3.25 b$ & $(0.66)$ & $3.21 \mathrm{~b}$ & $(0.70)$ & $3.40_{a}$ & (0.69) & * \\
\hline Self Characteristics & $7 \cdot 52$ & $(0.99)$ & $7 \cdot 56$ & $(1.01)$ & $7 \cdot 47$ & $(0.87)$ & \\
\hline $\begin{array}{l}\text { Public Transport User } \\
\text { Characteristics }\end{array}$ & $5 \cdot 77 \mathrm{c}$ & $(0.88)$ & $6.30_{a}$ & (1.04) & $6.06_{b}$ & $(0.99)$ & $* * *$ \\
\hline $\begin{array}{l}\text { Neighbour } \\
\text { Characteristics }\end{array}$ & 6.75 & $(1.29)$ & 6.75 & $(1.28)$ & 6.60 & $(1.14)$ & \\
\hline $\begin{array}{l}\text { Social Discomfort } \\
\text { (public transport) }\end{array}$ & 2.55 & $(0.47)$ & 2.57 & $(0.47)$ & 2.63 & $(0.47)$ & \\
\hline $\begin{array}{l}\text { Social Discomfort (bus } \\
\text { stop/train station) }\end{array}$ & NA & NA & 2.63 & $(0.48)$ & 2.65 & $(0.51)$ & \\
\hline $\begin{array}{l}\text { Social Discomfort } \\
\text { (Neighbourhood) }\end{array}$ & $2.23 \mathrm{~b}$ & $(0.52)$ & $2.4 \mathrm{O}_{\mathrm{a}}$ & (o.61) & $2.4 \mathrm{O}_{\mathrm{a}}$ & $(0.52)$ & $* * *$ \\
\hline Defensive Behaviour & $2.85 \mathrm{a}$ & $(0.48)$ & $2.71_{b}$ & $(0.48)$ & $2.73 b$ & $(0.43)$ & $* *$ \\
\hline Touch Avoidance & 2.41 & $(0.59)$ & 2.46 & $(0.65)$ & 2.40 & (0.64) & \\
\hline Bus Relationship & NA & NA & 2.33 & (o.89) & 2.22 & $(0.81)$ & \\
\hline $\begin{array}{l}\text { Neighbourhood } \\
\text { Relationship }\end{array}$ & NA & NA & 3.45 & $(0.79)$ & 3.46 & $(0.77)$ & \\
\hline
\end{tabular}

Note: Means in the same row that do not share subscript letters differ at p < .05; Standard deviations are in parentheses; ${ }^{*} p<.05,{ }^{* *} p<.01,{ }^{* * *} p<.001$.

\section{Discriminant Analysis}

Discriminant analysis was used to determine which variables accurately differentiate between car $(n=305)$, train $(n=319)$ and bus $(n=216)$ use. It provides a method to distinguish the relative contributory power of each variable. A stepwise method, with a Mahalanobis $D^{2}$ measure was used for estimating the discriminant function (Hair et al., 1995 suggest that Mahalanobis $D^{2}$ and Rao's V are the most appropriate measures when using a stepwise method). The same key 24 variables identified for use in the binary logistic regression in the Car Study were used as predictors. 


\section{Model assumptions}

The variables used were normally distributed (with the exception of Ethnicity, that had a positive skew of 1.25), and outliers and influential cases $(n=9)$ were removed from the sample. The sample was further reduced to $N=705$ due to missing data $(n=126)$ across the range of variables. Even with the reduced sample, the ratio of cases to the seven predictor variables in the final model was acceptable at 100:1 (above the ratio of 20:1 recommended by Hair et al., 1995, p.195).

The test of homogeneity of variance-covariance matrices was significant (Box's M $=105.70 ; F(56,893253)=1.86, p<.001)$, indicating a violation in the assumption of homoscedasticity. However, the Box's M test is a notoriously sensitive test of homogeneity of variance-covariance matrices, particularly with large samples (see Hair et al., 1995). The Mahalanobis procedure attempts to correct for this by adjusting for unequal variances.

\section{Predictive ability of the model}

Two significant discriminant functions were produced, the first explained 81.3\% $\left(\chi^{2}(12, N=625)=264.52, p<.001\right)$ and the second explained $18.7 \%\left(\chi^{2}(5, N=\right.$ $625)=54.99, p<.001)$ of the between-groups variance, indicating that the first variable explains most of the variation. The stepwise criterion for entry into the model was a $p$ value of .005 and the criterion for exclusion from the model was a $p$ value of .02.

The model correctly classified $61.6 \%$ of participants into their correct group (see Table 6.6). Classification accuracy measures show that the model predicts better than chance (for more on classification accuracy measures see Hair et al., 1995). The proportional chance criterion was $34 \%$ (this would have been $33 \%$ if all three groups had equal sample size), and the maximum chance criterion was $38 \%$ (the percent correct obtained if all cases were assigned to the group with the highest probability of occurrence, in this case the train commuter group). Finally, the classification accuracy was significantly better than chance (Press's $\mathrm{Q}(N=702)=$ $252.77, p<.001)$. 
Hair et al. (1995) recommend that classification accuracy should be at least 25\% greater than that achieved by chance to be practically useful. In this case $125 \%$ of the $34 \%$ proportional chance is $42.5 \%$. Even taking into account the uneven group size and using $125 \%$ of the $38 \%$ maximum chance, the threshold of predictive accuracy would be $47.5 \%$. Either way the model was well above the recommended criterion for predictive accuracy at $61.6 \%$. Table 6.6 shows that the correct classification rate (shown in parentheses) was higher for the Car and Train groups, but lower for the Bus commuter group. However, the lower rate for bus commuters (54\%) was still more than required for predictive accuracy. It also shows that both car and train commuters are more likely to be miss-classified as bus users, indicating they are more like bus than each other.

Table 6.5.

Group Classification Results for Car, Train and Bus Commuters

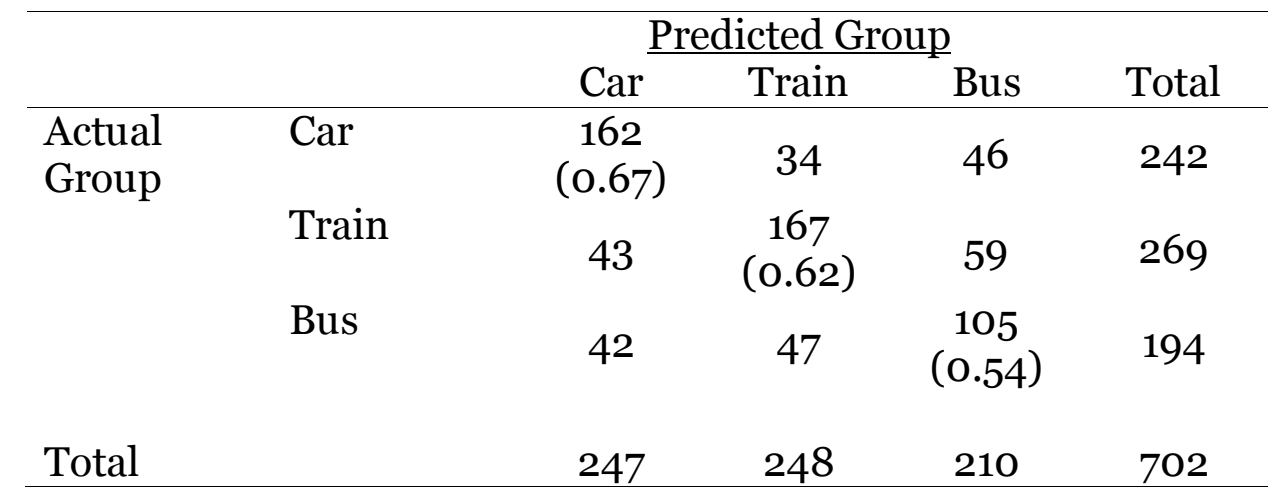

\section{Relative contribution of variables in the model}

The variables in Table 6.7 are ordered by the absolute size of the discriminant loadings, which shows the strength of correlation with each function (the number in bold indicates which function they correlate to most highly). The discriminant loadings, partial $F$ values and potency values can all be used to assess the relative contribution of each independent variable to the discriminant function (see Hair et al., 1995). A higher value represents a greater influence of the variable on the function. Potency values were derived by multiplying the squared value of the discriminant loading for a variable by the eigenvalue of the discriminant function (Function 1 eigenvalue $=0.48$; Function 2 eigenvalue $=0.11$ ) 
The social factors (public transport user characteristics, neighbourhood discomfort and interpersonal discomfort) in the model contribute less to the discriminant functions than the demographic and household factors (see Table 6.7). Trip duration was the most important variable for Function 1 and number of household vehicles was the most important variable for Function 2.

Table 6.6.

Summary of Interpretive Measures for Discriminant Analysis

\begin{tabular}{|c|c|c|c|c|c|c|}
\hline \multirow[b]{2}{*}{$\begin{array}{l}\text { Independent } \\
\text { Variables }\end{array}$} & \multicolumn{2}{|c|}{ Discriminant Loading } & \multirow{2}{*}{$\begin{array}{l}\text { Univariate } \\
\text { F Ratio }\end{array}$} & \multicolumn{2}{|c|}{ Potency Value } & \multirow{2}{*}{$\begin{array}{l}\text { Potency } \\
\text { Index }\end{array}$} \\
\hline & $\begin{array}{c}\text { Function } \\
1\end{array}$ & $\begin{array}{c}\text { Function } \\
2\end{array}$ & & $\begin{array}{c}\text { Function } \\
1\end{array}$ & $\begin{array}{c}\text { Function } \\
2\end{array}$ & \\
\hline Trip Duration & 0.63 & 0.28 & 57.72 & 0.19 & 0.04 & 0.23 \\
\hline $\begin{array}{l}\text { Neighbourhood } \\
\text { experience }\end{array}$ & $-\mathbf{0 . 3 7}$ & -0.11 & 20.12 & 0.07 & 0.01 & 0.08 \\
\hline Age & $-\mathbf{0 . 3 7}$ & -0.01 & 19.24 & 0.07 & 0.00 & 0.07 \\
\hline $\begin{array}{l}\text { Public Transport User } \\
\text { Characteristics }\end{array}$ & 0.35 & -0.02 & 17.37 & 0.06 & 0.00 & 0.06 \\
\hline $\begin{array}{l}\text { Neighbourhood } \\
\text { Discomfort }\end{array}$ & 0.22 & -0.17 & $7 \cdot 79$ & 0.02 & 0.01 & 0.03 \\
\hline $\begin{array}{l}\text { Number of household } \\
\text { motor vehicles }\end{array}$ & -0.22 & 0.77 & 24.96 & 0.02 & 0.28 & 0.30 \\
\hline $\begin{array}{l}\text { Interpersonal } \\
\text { Discomfort }\end{array}$ & 0.03 & -0.44 & 6.07 & 0.00 & 0.09 & 0.09 \\
\hline
\end{tabular}

\section{Cross-validation of model}

A series of five split-sample validations were performed to ensure the model did not alter by chance (for more information on cross validation see Hair et al, 1995). A 75-25 split was used, where 75\% of cases were randomly assigned to the analysis sample to derive a model, and the remaining $25 \%$ were used as a holdout sample. All five hold-out samples had accuracy rates within $10 \%$ of the accuracy rate of the analysis sample, meeting the minimum accuracy rate requirement.

Four of the five analysis samples replicated the model. The fifth sample removed Neighbourhood Discomfort and replaced it with Train Discomfort, but was identical across the remaining six variables. These concepts were fairly closely related $(r(831)=0.46, p<.001)$ and replacement only occurred once, so the model was deemed robust via cross-validation. 


\section{Description of the discriminant functions}

Figure 6.1 shows that the first discriminant function separates car commuters from public transport commuters, and the second discriminant function separates bus commuters from car or train commuters. The social factors relating to Function 1 (indicating public transport use, particularly the train) include more positive ratings of other passengers on public transport, and greater discomfort with neighbours. Negative attitudes towards passengers could be a barrier to public transport use by car commuters. Bus users appear to have a more negative impression of other passengers than train users, and consequently may be more likely to shift to another mode given the opportunity.

The primary barrier to public transport use (particularly the train) by car users may be the longer trip length. Other factors related to public transport use were lower age and less neighbourhood experience. The lower level of neighbourhood experience may account for some of the increase in neighbourhood discomfort (see the Car study for more discussion on this).

The variables that predict positions on Function 2 (Train and car use, or low bus use) were a higher number of vehicles, and low interpersonal discomfort. The train users in the sample were gained from park and rides and mostly drove to the station, so household access to motor vehicles was close to that of car drivers. Given the opportunity (availability of an automobile), many bus users may switch to using the car or even switch to using a park-and-ride and catching the train. A key reason to change mode is high IPD experienced on the bus. ${ }^{1}$

\footnotetext{
${ }^{1}$ Hair et al. (1995, p. 237) suggest caution when interpreting the results of a second function, as additional functions typically explain less of the variance, but the potency values were still high for the second function (see Table 6.8) so these interpretations are reasonable.
} 


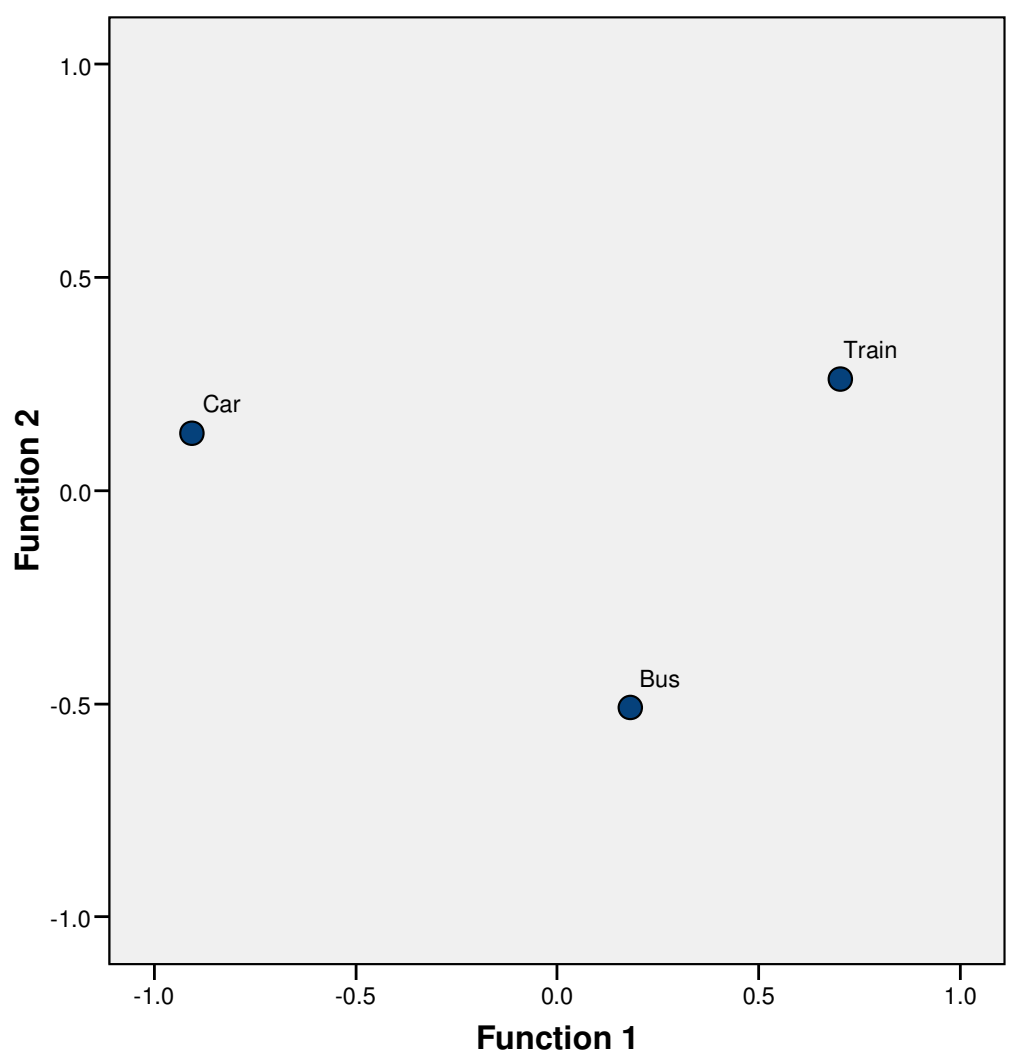

Figure 6.1. Group centroids (means) for car, train and bus commuter groups.

\section{Interpersonal Distance (IPD) Discomfort}

Passenger commentary suggested that the design of buses did not meet their needs, especially in terms of space. There was some suggestion that bus seats and aisles appeared to be getting smaller, while passengers were getting larger:

"I think [the reason] people do not particularly like to share seats is partially due to the size and leg room available. Seats appear to be getting progressively smaller with each new bus style and even the central aisle seems to be getting narrower as well. Design of buses do not allow for baggage (even handbags) or sufficient hand grips for standing passengers - a health and safety issue if ever there was one!" (Bus participant number 167)

Several comments were made regarding the increasing problem of passenger obesity and the need for larger seats. The discomfort caused by this goes beyond 
physical, as it causes embarrassment and the social discomfort from being forced to come into physical contact when seated beside another passenger.

"I would like to see bigger seats on buses. It is very difficult perching yourself on a seat next to a big person and very uncomfortable and embarrassing for a larger person." (Bus participant number 108)

"I loathe casual touching on buses. I find with growing obesity rates I get regularly squashed in a corner next to someone large. Either seats need to be wider or people need to be smaller!" (Bus participant number 179)

Passengers attempt to accommodate the disparity between small seats and large passengers by selecting their seat based on body type and clear seat space:

"Size of a person and how much seat is left usually determines whether or not I sit beside them." (Bus participant number 123)

"It makes a huge difference whether I get a big fat bloke or an attractive woman sitting next to me. I really do not want his buttock squashed up against mine, even with two lot of trousers and undies in between. I don't get that problem with a slim woman." (Bus participant number 158)

The level of crowding and discomfort with other passengers (at least in the form of safety concerns) may have a u-shaped relationship, with low passenger levels leading to reduced feelings of personal safety due to low social surveillance, and high passenger levels leading to greater anonymity in the crowd and the opportunity to use the circumstance to behave inappropriately:

"I can be very comfortable on the bus, but the occasional person might raise a "safety" issue for me as a female passenger usually travelling on my own, particularly at night. Such as the male passenger who chooses to sit next to me on an empty bus, or on another occasion who quite deliberately had inappropriate contact (unwanted) with me on a 
crowded bus - where passengers were standing. I think crowding creates additional tensions, and raises these issues for passengers." (Bus participant number 188)

There was also some indication of physical defence of space even after the immediately adjacent seat had been occupied by another passenger. Typically a passenger would at least recognise the presence of the "invader" of the space by making small adjustments to reduce the mass of their body to avoid touching the other passenger, including placing their arms in front of them, narrowing the gap between their legs and turning the body away. Ignoring the other passenger by a lack of adjustment could be deemed a form of physical defence of space and also be deemed rude.

"One of the major upsets about riding the bus for me are people who do not move, when you sit down next to them!!" (Bus participant number 35)

Passenger commentary also suggested that close interpersonal distances reduced activity use (lower levels of activity were observed under more crowded conditions in the Observational study). This may have related to less physical space to engage in an activity (especially if forced to stand), a reduced ability to concentrate with so many other passengers making noise, or perhaps the increased anonymity meant that passengers could just sit quietly and observe other passengers.

"Buses are packed especially on the trip home very uncomfortable \& with poor lighting on the bus you cannot read." (Bus participant number 25)

"Noise inside the bus (atmosphere) - cell phone, music, talking, laughing, etc. I find it so distracting when people are so inconsiderate when they talk or laugh so loud while others are quietly reading or just sitting quietly." (Bus participant number 5o)

Crowded conditions do enter into considerations to stop using the bus: 
"The buses are getting busier which has made me contemplate driving to work again. At this stage, I still prefer the convenience of the bus. (Bus participant number 69)

\section{IPD Discomfort regression}

Bus users were found to be particularly sensitive to IPD discomfort in the discriminant analysis so further analysis of this variable was deemed appropriate. A stepwise linear regression was used to determine which variables influenced ratings on the IPD Discomfort scale for bus commuters. The same key 24 variables used previously for the car-bus regression were entered into the regression in the same order (with IPD Discomfort as the dependent variable and the remaining 23 as independent variables). The stepwise criterion for entry into the model was a $p$ value of .05 and the criterion for exclusion from the model was a $p$ value of .10.

The independent variables in the model explained significant variation in the IPD Discomfort scale $(F(4,186)=13.26, p<.001)$, with a Multiple-R of 0.47 and an adjusted $\mathrm{R}^{2}$ of 0.21 indicating $21 \%$ of the variance in the IPD Discomfort scale scores was explained by the model (see Table 6.8). The final regression model shows that for bus commuters IPD Discomfort increased with perceived bus heterogeneity (bus heterogeneity was calculated by subtracting the characteristic assessment scale scores of bus users from self-assessment scale scores), and reduced with perceived privacy and the perception that the typical passenger desires more social interaction. These factors were more closely examined in the following sections.

Table 6.7.

IPD Discomfort Regression for Bus Commuters

\begin{tabular}{lccccccc}
\hline & & & & & & \multicolumn{2}{c}{ Correlation } \\
\cline { 7 - 8 } & B & SE & Beta & $t$ & Sig. & Partial & Part \\
\hline Trip duration & 0.13 & 0.05 & 0.19 & 2.91 & 0.004 & 0.21 & 0.19 \\
Bus heterogeneity & 0.12 & 0.04 & 0.19 & 2.88 & 0.004 & 0.21 & 0.19 \\
Privacy & -0.06 & 0.02 & -0.22 & -3.33 & 0.001 & -0.24 & -0.22 \\
$\begin{array}{l}\text { Others want social } \\
\text { interaction }\end{array}$ & -0.09 & 0.02 & -0.25 & -3.75 & 0.001 & -0.26 & -0.24 \\
(Constant) & 3.40 & 0.20 & & 16.85 & 0.001 & & \\
\hline
\end{tabular}




\section{Trip duration}

The regression model in Table 6.8 indicates that bus commuters are more tolerant of IPD discomfort on shorter trips, where they will escape the discomfort of the situation after a brief wait. This closely parallels the situation of taking a very short duration trip on a busy elevator, where IPD discomfort was expected prior to boarding, and tolerated due to the brief period of time.

\section{Social interaction and privacy}

Participants that were amongst the most uncomfortable with the intimate proximity to other passengers were also more likely to desire privacy (and not social interaction) and believe that other passengers also desired privacy. Another way to view these findings was that people that held the perception that other passengers desired greater social interaction and were less concerned with maintaining privacy also felt less discomfort from the close proximity of other passengers.

Desire for social interaction over privacy was measured on an 11-point semantically anchored continuous scales, with $\mathrm{o}=$ More privacy, $5=$ No change, and $10=$ More social interaction. ANOVAs revealed no significant differences between commuter groups in terms of either their personal preference for more social interaction versus more privacy $(F(2,834)=1.42, p=.24$, n.s. $)$ or their perception of whether the "average" passenger wants more social interaction versus more privacy $(F(2,833)=0.77, p=.47$, n.s. $)$.

Within-subjects analysis revealed that participants actually wanted greater social interaction $(M=4.78, S D=2.27)$ when compared with their perception of the “average" passenger $(M=3.98, S D=2.02 ; t(834)=9.78, p<.001)$. This finding suggests that the normative perception was for lower social interaction and more privacy, whereas actual users were neutral in their response (with a mean of 4.78, just below five). There was some suggestion that the non-social norm was changing:

"The bus has got friendlier in the past few years" (Bus participant number 34) 
Positive interaction with the bus driver also improved passengers' positive attitudes towards the ride, especially the social politeness of thanking the bus driver.

"I love how people say thanks to drivers in Wellington on buses. Its so respectful." (Bus participant number 2)

Perception of privacy differed between commuting groups $(F(2,831)=4.77, p<$ .01). Perceived privacy was measured on an 11-point continuous scale from $0=$ No privacy through to $10=$ Very private. Car commuters perceived a lower level of privacy on public transport $(M=2.97, S D=2.19)$ when compared with train $(M=$ $3.51, S D=2.59 ; t(611)=-2.81, p<.01)$ or bus commuters $(M=3.51, S D=2.43 ; t$ $(431)=-2.55, p<.05)$. All group ratings suggested a perception of low privacy, with means below five (the mid-point on the scale).

\section{Bus user characteristic assessments}

Bus heterogeneity, calculated from the gap between self-characteristic assessment and bus user characteristic assessment, positively influences IPD Discomfort (see Table 6.8), suggesting that close interpersonal distances were more tolerable if the participant viewed other bus passengers as having similar characteristics as themselves.

Perception of appropriate bus behaviour was also related to characteristic assessments, with behaviours viewed as impolite increasing negative assessments of bus users, for example:

"3 things that do annoy me on the bus are: 1) Passengers who fart (seriously)! Very inconsiderate 2) Standing passengers who wear backpacks that constantly hit your head if you are sitting down 3) Parents travelling with college-age children who do not ask their kids to stand up for adults. Very rude." (Bus participant number 69) 
Occasional or rare cases of people viewed as having negative characteristic assessments were probably more salient, and consequently more likely to negatively colour perceptions of the typical bus user, for example:

"I've only occasionally been uncomfortable (mentally) on a bus trip. That usually happens when someone intoxicated or drugged gets on the bus and starts haranging the other passengers sometimes dirty people also detract from the enjoyment of the journey." (Bus participant number 138)

\section{Willingness to pay for a pre-selected seat}

To further examine the relative importance of seat selection, the willingness to pay for a seat selection system where you could pre-select your seat (similar to those used by airlines) was examined. This would ensure that a participant would not have to stand, and also allow for some choice over the location in which they sat (meaning there could be more control over sitting with friends or acquaintances). To ensure participants were anchoring their willingness on the overall travel cost, participants were first asked the approximate cost of a one-way ticket to their main activity. Train trips $(M=\$ 4.80, S D=\$ 1.92)$ were more costly than bus trips $(M=$ $\$ 3.37, S D=\$ 0.99 ; t(414)=10.31, p<.001)$.

Within-subjects analysis revealed that participants were willing to pay an increased ticket cost for the service of a seat selection system, with a mean increase of $\$ 0.34(S D=\$ 0.60 ; t(436)=12.00, p<.001)$. However, the majority (6o.6\%) of participants did not wish to pay anything extra for this service. The proportional increase in fare did not differ between train and bus commuters $(t(316)=-0.64, p$ $=.52, n s$ ), indicating that the importance of a seat was no different between modes. Of course this null finding may reflect a dislike of paying extra or even the dislike of a seat selection system, and certainly does not apply to everyone:

"I do check out where the best seat for me is (feel comfortable) or most room. If I sit in a seat and then find for some reason ie: it smells - don't like person (sitting behind me) I will move to the other end of the bus normally to the front." (Bus participant number 159) 


\section{Discussion}

Car commuters prefer the train over the bus, and if the instrumental factors of cost, convenience and travel time are equal across modes, the train is still the preferred alternative to the car. When asked about the ease of getting to their main activity, car commuters found the bus easier, even though they came from the same neighbourhoods as the train commuters, so distance to the station would be similar. Overall, these measures show support for hypothesis one, that car commuters do prefer the train over the bus.

The literature typically supports the train preference from an instrumental standpoint, especially in relation to faster travel times in the congested traffic conditions typically associated with commuting (e.g. Balcombe et al., 2004). However, even when controlling for these factors, the train comes out as preferred, indicating that there is a positive affective relationship when it comes to the train. Romantic notions attached to recreational trips as tourists are typically associated with the train (Shrady, 1993). As opposed to negative stereotypes which typically form in relation to the bus, for example the concept of buses as "loser cruisers."

In addition to being the less-preferred alternative to the car, it was expected that social discomfort would be higher in the bus commuter group. Of the six measures of social discomfort used to test this hypothesis only one measure provides support. The only evidence for greater social discomfort in the bus commuter group was higher interpersonal discomfort scores when compared with either the car or train commuters. Public transport social discomfort scores, willingness to pre-pay for a seat, and social interaction scores did not differ between any of the commuter groups. The final two measures of perceived privacy and defensive behaviour only provided evidence that car commuters are less comfortable in the public transport setting. Therefore, social discomfort is not found to be higher in the bus commuter group and hypothesis two is not supported.

Similarly, there is no difference between commuter groups when examining selfother preference for more social interaction versus more privacy when travelling on public transport. About a quarter of passengers were found to socially interact on public transport in the Observational study, but there is a perception that other passengers want more privacy and less social interaction, even though they 
actually favour no change in the current conditions. This gap suggests that there is a normative pressure not to socially interact that is most likely based on the fact that the majority (75\%) of users do not interact, rather than an actual need for privacy. Under the correct conditions this norm could be reversed (see the Train Chapter for more detail on the covariates of social interaction).

Social discomfort is more evident in car commuters than bus commuters. Car commuters perceived there was less privacy on public transport and reported a higher level of intentionally defensive behaviour when using public transport compared with the other commuter groups. However, these differences were not significant in the discriminant analysis.

Younger age, longer trip duration, higher neighbourhood discomfort and positive public transport user assessments are associated with both train and bus use (when compared with car use), suggesting some consistency across the variables. The variables that are introduced by the discriminant analysis (i.e. those that were not present in the car-train regression) are housing density and the number of household motor vehicles.

Bus use increases as housing density increases and the number of available motor vehicles per household decreases. Housing density has previously been linked to higher bus use (Mitchelson, 1982; Parolin, 1992), and this relationship does not typically extend to train use (Parolin, 1992), which would explain why this variable was not present in the car-train regression. Mitchelson (1982) also found a negative relationship between bus use and level of car ownership, but Parolin (1992) found no relationship between bus use and car ownership, instead he found a positive relationship between train use and car ownership.

Discriminant analysis reveals that the most important factors differentiating between car and public transport commuting are variables relating to instrumental need, the household and demographics. This supports previous research focussed on instrumental factors (e.g. see Paulley, Balcombe, Mackett et al, 2006). However, social factors still showed a significant association with commuter mode, and consequently should be given a greater level of attention. 
The overall body of research examining public transport use disproportionately favours instrumental factors, particularly cost, regularity of trip, and trip duration. There is a relative paucity of research on social influences, and where these exist they are typically holistic studies (such as focus group analyses) that capture all factors without being able to methodologically distinguish the importance of each variable. The discriminant analysis used here provides a method to distinguish which variables contribute significantly to the predictive accuracy of the model, in addition to the relative contributory power of each variable.

The five variables that separate out car commuters (identified in Function 1 of the discriminant analysis) are also identified in the car-train binary logistic regression in the Car study. The factors associated with public transport commuting in order of importance are 1) longer trip durations (a key measure of convenience), 2) less experience (years) living in their neighbourhood, 3) lower age groups, 4) more positive characteristic assessments of passengers, and 5) greater social discomfort with neighbours.

The rationale for why these five factors differentiate between car and public transport use has already been discussed in the Car study, so further discussion here is redundant. Instead the focus of this discussion is the two variables that differentiate between bus commuters and the other groups, namely, 1) a lower number of household vehicles and 2) a higher level of interpersonal passenger discomfort.

Discomfort from close proximity with others is particularly problematic in the bus setting. Stradling et al (2007) also found that 'unwanted arousal' increased disliking of and discouraged use of the bus. The concept of 'unwanted arousal' included core aspects of discomfort from close proximity, such as the seats being too cramped, the bus being too crowded, and other people taking up too much space, as well as indirect influences on interpersonal discomfort, such as too much noise and discomfort from extreme weather (e.g. too hot; Stradling et al, 2007).

Interpersonal discomfort differences between bus and train commuters could be attributed to several different factors, including bus commuters' more negative attitudes towards other passengers. The physical differences from the Observation 
study are also likely to explain at least some of the variation, as there is typically more available space on trains, with larger seat sizes, leg spacing, and aisle gap. The smaller seating of buses raises basic anthropometric concerns in passengers, which are presented in the many comments regarding the need for larger seating to accommodate the increasing proportion of larger passengers. In addition to the physical differences between modes, the Observational study also revealed that there a greater use of adaptive behaviour, and less crowded conditions (in terms of the proportion of passengers to seats) in the train setting.

The strongest factor that differentiates bus commuters from train and car commuters is a lack of household vehicles. Several differences between train and car travel help explain the lack of motor vehicles for bus commuters. Commuters typically used park-and-ride facilities in the Train study, necessitating the car as part of their overall journey. While the number of household vehicles is lower for train when compared with car, household access to at least one motor vehicle is still very high for train commuters. Also, bus commuter trip distances are shorter than those of train commuters. At closer distances the convenience factors associated with the bus (such as no need to park a motor vehicle) become more apparent, and the need for a private motor vehicle is lessened. Living in higherdensity areas closer to the cities central business district also implies that the bus services are more frequent due to the higher latent demand.

The discriminant analysis establishes that there are key differences between the groups, such that bus and train commuters have distinct experiences and different issues. Their needs should be addressed according to these different criteria. Therefore, even very similar settings such as the train and bus cause different behavioural adaptations in the passengers and differing levels of discomfort.

\section{Limitations}

A key limitation was that the car and train samples were matched by neighbourhood, whereas only a small portion of the bus sample was matched in this way. To some extent, differences based on varying neighbourhoods were controlled for by the measured demographic and household variables, but the variation between bus and train commuters could in part be due to variation in sample collection methodology. The bus, train and car comparative analyses are 
essentially correlational, and though the implied direction of causality seems logical, this remains to be empirically tested. This could be examined further through a programme of longitudinal research.

\section{Conclusion}

The train is the preferred alternative mode of transport for car commuters, even though the bus is perceived as being easier to use. Train and bus commuters prefer the car as an alternative mode of transport, and for bus commuters this is particularly important, as a lack of access to motor vehicles is a primary influence on their use of the bus.

Instrumental factors are more important than social factors in the use of public transport, but social factors still contribute significantly. There is a relative paucity of research on social influences and virtually no use of social indicators to monitor public transport performance. This needs to be addressed in the future. Of particular importance is the formation of positive attitudes towards the other users of public transport, and the need to address discomfort from interpersonal distances with strangers. 


\section{CHAPTER 7: GENERAL DISCUSSION}

\section{Outline}

This research is a synthesis of observations of passenger behaviour, an exploratory examination of the consequences of these behaviours, and an examination of possible individual, interpersonal and situational antecedents of interpersonal discomfort in bus and train settings. This research aimed to examine the social environment of public transport and determine which aspects (if any) were barriers to patronage.

The discussion that follows will begin by re-capping the key discomfort findings, including the interruption of Festinger et al.'s (1950) passive contact theory (PCT) in the bus and train settings. Subsequently, the specific facets of public transport that are likely causes for this interruption will be discussed, from the socially crippling seat layout, to the socially and physically sterile environment. A number of possible social (such as marketing or informational campaigns to shift passenger attitudes or behaviours) and design-based solutions (such as seat layouts that facilitate social interaction and more stimulating physical environments) are discussed. Finally, some practical recommendations for passengers and public transport providers are outlined.

\section{Key Findings}

\section{Discomfort in the Bus and Train Settings}

There is evidence of psychological or social discomfort when riding on buses and trains. An exploratory factor analysis of public settings in the Exploratory study found that sitting beside a stranger on a bus or train is ranked alongside crowded elevators as the worst public environments in terms of social discomfort. Observations of passenger behaviour show that $60 \%$ of passengers adapt to their environment, most of which are defensive adaptations (such as situational withdrawal into an activity, typically reading or listening to music). Closer examination of the motivations of these behaviours revealed that they are at least 
in part, for defensive purposes. For example, $50 \%$ of the students in the Exploratory study agree that they perform activities to avoid verbal interaction with other passengers.

\section{Passenger Interaction Reduces Social Discomfort}

Social interaction and friendship formation reduce social discomfort, whereas defensive behaviour is indicative of social discomfort, as shown in the Train study. Similarly, desire for social interaction reduces discomfort with close proximities in the Bus comparison study, which supports Hall's (1966) proxemic theory, that social closeness promotes an expectation of physical closeness. Observations of passenger behaviour also support Hall's (1966) proxemic theory, as couples (passengers that arrived together and sat adjacent) were more likely to be observed in conversation and less likely to perform defensive behaviours, when compared with passengers that were paired together with no apparent prior relationship.

\section{Barriers to Public Transport}

Instrumental factors, in particular shorter trip durations and a higher number of household vehicles, are identified as the most important barriers to public transport, but social factors still contribute significantly. The two key social factors that are likely to reduce public transport use and cause interpersonal discomfort are low passenger affect and high IPD discomfort. This evidential proof supports earlier qualitative work that suggests that a perception of "undesirable" passengers and concerns for personal space invasion are neglected issues in the public transport context (e.g. Gardner \& Abraham, 2007; Guiver, 2007; Stradling et al., 2007).

\section{PCT Applied to Public Transport}

"The bus is a great way to meet people in your street. Twice, just recently, the bus has been late/delayed and I have been able to meet neighbours and have an excuse to chat to them. Now we always say hello when we see each other." (Bus participant number 194) 
There is evidence that Festinger et al.'s (1950) passive contact theory (PCT) is interrupted in the train setting. PCT posits that the frequency of unplanned contact with others, due to regular close proximity, will develop into friendships providing the "psychological factors" are right (Festinger et al., 1950, p. 34). Support for this notion that "familiarity breeds liking" is typically reported in residential environments with homogenous groups (e.g. Abu-Ghazzeh, 1999; Festinger et al., 1950; Segal, 1974). The neighbourhood environment arguably provides less opportunity for chance meetings than the public transport setting, where the concentration of passengers provides higher frequencies of passive contact and an average exposure to other passengers of about 55 minutes each day (probably more time than someone would spend walking around their neighbourhood).

Friendship levels, perception of friendship formation and the likelihood of additional social engagements were all significantly lower with public transport passengers when compared with neighbours. This failure of passive contacts to translate into friendships was not found to relate directly to the homogeneity of users, as passengers were observed to look for similarities (such as the same gender) when they selected their seat. Homogenous seating patterns were also found in previous research, where subway users were found to be more likely to sit with the same gender and ethnicity (Maines, 1979). There was no indication that the transience of the setting prevented passive contacts from evolving into friendships, as there is evidence that regular patrons have habitual seating patterns, such that they sat in the same part of the vehicle each day with the same "familiar strangers."

The Masterton cohort of the train commuters provides evidence that PCT does work in the public transport setting under the correct conditions. Within the Masterton train commuter group, friends are just as frequently neighbours as other train commuters. These commuters also have the longest exposure to other passengers (longer trip durations), a higher frequency of contact (longer time spent travelling on the same train route) and a lower density of passengers. These findings are supported by Nash's (1975) observations of bus passengers, where high trip durations, more experienced passengers and moderate passenger densities all increased social interaction. 
Frequency of contact (Festinger et al., 1950) and exposure time (Bornstein, 1989) are common elements of PCT, such that the concept that high passenger density increases (implying a greater number of passive contacts). However, the findings show that higher passenger densities reduced friendship formation, which is inconsistent with the theory as it stands. It is suggested that the relationship between passive contacts and friendship formation is mediated by social density, such that relatively low or high social densities impede friendships. A low density of passengers provides a lower frequency of passive contacts. Also, given the IPD maximising behaviour observed by public transport users, strangers will not sit together unless they have no choice.

That a high density of passengers reduces friendship formation could be due to social overload. Milgram's (1970) theory of social overload suggests that people necessarily minimise their interpersonal interactions in overloaded social environments. The consequence is that reciprocity, altruistic behaviour, and basic social courtesies, including greetings, are likely to reduce as passenger density increases. Similarly, discomfort with the close proximity of other passengers is also likely to reduce pro-social behaviours (e.g. DeBeer-Keston et al., 1986). Further, high passenger densities could cause a dilution of exposure to familiar regulars amongst the mass of strangers, which would interfere with the functionality of PCT.

Non-verbal or verbal greetings are a necessary element of PCT. Frequent passive contacts provide the opportunity to develop into what Festinger et al. (1950, p. 34) describes as "nodding acquaintances," which then develop into friendships. Without greetings, passive contacts never evolve into conversations and consequently friendships. Therefore, the finding that higher passenger densities reduce friendships is likely to be a function of reduced social politeness. This finding explains why the "community" feel of public transport is often in evidence only in lower density communities, such as rural communities (e.g. Guiver, 2007). There is a need to bring social politeness back in the public transport setting. These findings have implications for friendship formation in high-density environments, such as cities. 


\section{Perception of Social Sterility}

There is a normative perception across car, bus and train commuters that other public transport users want more privacy and less social interaction on public transport. This lends some support to previous findings, particularly subway studies, that identified superfluous verbal behaviour as something to be avoided (e.g. Birenbaum, 1976; Fried \& DeFazio, 1974). Davis and Levine (1967) describes the public transport setting as one which even inhibits interaction among friends.

Observations of passengers reveal that a quarter of bus and train passengers converse. Even when accounting for passengers that arrived together and sat beside each other on public transport (indicating a stronger level of interpersonal relationship), $15 \%$ of the other passengers are observed to converse. Passenger interaction may not be the norm, but the environment is not socially stagnant. It may be that passengers are so engrossed with ignoring one another, with the use of situational withdrawal into an activity or gaze-avoidance, that they do not notice that interactions are actually a common occurrence. Even conversing dyads may use conversation to mentally withdraw from the other passengers, and so may not notice that their behaviour is not unique.

Non-verbal cues also perpetuate the myth of a social vacuum in public transport. It is difficult to establish which other passengers are open to conversation just from body language, whereas defensive behaviours send very clear messages not to attempt to interact. Participant ratings of photographs of common bus and train user behaviours found that positive body language (making eye contact and smiling) makes a person look more at ease, increases the level of comfort when talking to this person and improves the likelihood of getting on with a person's friends, but does not increase the likelihood that a person will chose a seat beside them. To complicate this further, the appropriateness of the non-verbal behaviours depends on the context and the duration, particularly for eye contact. Appropriate durations of eye contact are likely to have positive effects (Scherer, 1974), whereas longer durations that could be interpreted as staring are viewed negatively (e.g. Ellsworth, Carlsmith \& Henson, 1972).

Negative body language, particularly the use of defensive behaviours such as defending territory by placing a bag on the adjacent seat, sends an unmistakable 
message that reduces social interaction. Even activities such as reading or listening to music signal that these individuals are busy and do not wish to be disturbed. The combined effectiveness of negative body language (such as gaze avoidance), situational withdrawal into activities, and the physical defence of space (placing a bag on the adjacent seat) send strong messages not to interact, regardless of the intention of the passenger engaged in this behaviour.

A better understanding surrounding the level of formality of the public transport setting may demystify some of this non-verbal behaviour. The perceived formality of a setting has been established as a factor that relates to the appropriateness of different behaviours and provides insight into how behaviours may be interpreted (e.g. Freedman, 1975). For example, a birthday party may have a very low level of formality whereas a work presentation to clients may have a very high level of formality.

It is not clear where the train and bus settings fit along this sliding scale, but a shift in perception will intuitively alter behaviour. A shift in perceptions to make the setting less formal is likely to encourage conversation and pro-social behaviour. The extreme example of this is Nash's (1975) number two express bus, where there was a community atmosphere to the bus, such that the passengers bought each other coffee and celebrated the driver's birthday.

\section{Latent Conversationalists in Public Transport}

While there is a normative perception that others want more privacy, closer examination reveals that there is a group of passengers that would prefer a social situation similar to Nash's (1975) number two express bus. These "latent conversationalists" are positive to social interaction, but are impeded by their perception of a norm of social sterility.

"When I changed jobs and began taking the bus to work, I was very aware of trying to fit in with the "normal" social interactions of the other people using the bus - ie there aren't any! And I think it's a shame, but I guess no-one wants to be the first to start. Two people I already know take the same bus as me, and it always makes a nice start to my 
day to chat to them on the bus in the morning. I guess potentially that could happen much more often if social interaction increased on the bus." (Bus participant number 132)

There are definite missed opportunities for social interaction on public transport. Passengers want to be viewed as friendly and sociable. This is evident in the need for passengers to provide additional commentary to explain the dissonance between their desire for a friendly or sociable self-image, and their non-social behaviour when travelling on the train or bus (for more on dissonance see Festinger et al., 1957). If passenger interaction was more normal, this same need is likely to drive them to converse and engage in social politeness with other passengers.

Participant commentary in the Train study suggests that people usually get "chatty" when there is a breakdown, and anecdotal observations of public transport users in previous research (Paulos \& Goodman, 2004; Sommer, 1969) consistently identify salient or atypical events as an opportunity for participants to converse. This is further evidence of a group of "latent conversationalists" that are just waiting for the opportunity to interact. Sommer (1969, p. 37) used the example of emergency situations such as a lost child, an injury or a breakdown as events which promoted social interaction. Describing a group who "dislike the lonely alienated condition of subway travel and look forward to emergency situations in which people become real" (Sommer, 1969, p. 37).

Atypical events that cause shared user experiences can provide the opportunity to begin conversations in a non-threatening way. The key element is that these events cause a common point of interest for conversation in which there is a priori knowledge that the other person also has a vested interest. For example, particularly bad weather and delays to the public transport affect most public transport users. Travelling for non-work situations, such as going to the same sports event wearing your team's colours, also provides the grounds for a perception of commonality between passengers that can foster greater interpersonal communication. 


\section{Promotion of Social Interaction as a Solution}

There are definite benefits to socially interacting with the other regulars on the bus or train, including benefits at both the individual and community level. The concept of social capital (an Organisation for Economic Co-operation and Development [OECD] indicator) describes the latent benefits of establishing social participation, establishing public environments that have a "community" feel, although there is little evidence of this occurring in the public transport setting (Currie \& Stanley, 2008). This thesis provides empirical evidence for key factors that influence social capital in a public transport setting, including a successful case study within the Masterton sample where there is greater trust, reciprocity, social politeness, and friendships are more common with other passengers than with neighbours.

In addition to the benefit of building trust and feeling more comfortable with the other passengers, sociable people are viewed more positively and have higher life satisfaction scores (Emmons \& Diener, 1986). Selecting who will be open to conversation may be difficult, but the findings of the Exploratory study show that there are several cues to look for, including positive body language. When selecting a seat look for someone who is not occupied with an activity or engaged in defensive behaviour, as this is likely to preclude conversation. Also, try and sit in the same seat or section of seats and sit near other regulars that you recognise. Looking for similarities such as similar age and perceived similarity of clothing style is a good option, as there may be other lifestyle similarities that provide common conversation topics.

There are many techniques travellers can use to facilitate conversation. Asking simple questions such as "do you have the time?" or offering comments about the weather may engage someone (see Zurcher, 1979, for some other examples). Observe the other passengers response, including their body language, and if it is positive attempt to continue the conversation. Another good tactic is to take advantage of unusual events, such as vehicle breakdowns, as these provide opportunities where talking is more acceptable (Paulos \& Goodman, 2004). Positive body language and smiling helps, but it is important to remember that people are very good at discerning whether your smile and intentions are genuine. 


\section{Bringing Social Politeness Back}

Positive social interaction is not limited to conversation. The concept also taps into the perceived latent friendliness of other passengers, for example, the perception that another passenger would offer assistance if required. When passengers are not verbally interactive, body language and behaviour that indicates a latent friendliness, or at the bare minimum a basic level of politeness amongst passengers, is required. Social politeness is identified as a key prerequisite for PCT to function.

A key impediment to the success of PCT in public transport is that social politeness does not have as strong a presence in this setting. In the Exploratory study a lack of politeness was identified, particularly surrounding the seat selection process. An intruding passenger is unlikely to acknowledge the person they chose to sit beside, and the defending passenger is unlikely to adjust their seat position to accommodate for the space requirements of the intruder. In another context, such as a busy restaurant, people would be likely to ask permission or at very least acknowledge another patron before they sat beside a stranger.

One reason why interpersonal politeness appears absent from the public transport setting is because strangers are being forced to sit more closely than is appropriate, which indicates disrespect. Distance is used as a sign of respect (e.g. Dean, Willis \& Hewitt, 1975). Even recognising that it is a necessity to engage in a close proximity due to the confined nature of the seating arrangement, a feeling of disrespect may still occur on a subconscious level. There may be subsequent negative consequences, such as less favourable attitudes towards that person.

A lack of social politeness and conversation is likely to reinforce negative stereotypes of other passengers. It promotes the view that passengers do not know correct social behaviour. The extreme example of this is people with personality disorders, such as schizophrenia, that have trouble maintaining appropriate interpersonal distances (Altman, 1975). People need to recognise that they are in a social setting where environmental influences, in particular the uncomfortably close interpersonal distances, interfere with typical social schemas (Pennington, 2000), such as greeting or acknowledging the person they sit beside. 
The lack of social politeness may also be self-perpetuating, as it follows the pattern of social loafing (see Geen, 1991). If individuals do not expect other passengers to make the effort to greet or acknowledge each other, social loafing suggests they will decrease their level of effort to match the norm and achieve equity (e.g. Geen, 1991). One positive point is that the level of effort to greet someone is relatively minimal, so the behaviour is relatively easy to change. For example, in the Observational study, anecdotal observation shows that if the first passenger to leave the bus thanks the driver, the passengers immediately following them are also likely to thank the driver. The benefit back to the passenger in observing prosocial behaviour is that they are likely to be viewed with greater affect by other passengers (Emmons \& Diener, 1986).

People do not need to engage in a long conversation with another passenger to improve the social atmosphere. There are simple things they can do to enhance the atmosphere, such as using social courtesies they would apply in other settings. Saying hello or acknowledging the passenger they sit beside is a basic courtesy that requires little effort. If a passenger is in a good mood they should show it by smiling. If they have had a hard day, and just need some quiet time, they should avoid displaying negative behaviours to other passengers, and perhaps engage in situational withdrawal into an activity.

\section{Defensive Strategy Avoidance}

"The hospital administrator who does not arrange his wards to facilitate interaction will find the wards arranging the patients to minimize it." (Sommer, 1969, p. 83).

Defensive behaviours have been found to be symptomatic of interpersonal discomfort rather than a solution to reduce discomfort. Epstein et al. (1981) attempted to examine strategies to reduce discomfort in a simulation of a crowded public transport setting, and found that reading was better than no activity in reducing feelings of crowding, but reading did not reduce physiological stress levels. Reading a magazine in a dentist's waiting room is distracting, but does not necessarily reduce the discomfort of the situation. This also supports Proshansky 
et al.'s (1976) suggestion that acceptance of, or adaptation to, a crowded situation is not commensurate with an absence of discomfort.

Participants that report higher use of defensive behaviour in the public transport setting are also more socially uncomfortable, suggesting that there may even be a rebound effect (for more on rebound effects see Macrae, Bodenhausen, Milne \& Jetten, 1994). Actively trying to suppress thoughts about the inappropriate nearness of the adjacent passenger by withdrawing into an activity may in fact have a rebound effect, where the very passenger they are trying to ignore becomes the focus.

Continuing with a defensive strategy is likely to be self-perpetuating in that it encourages others to respond to this behaviour with their own defensive behaviour, which may breed a norm. It is axiomatic that defensive behaviours impede interactive behaviours, so if defensive adaptation is the norm, it will create a social vacuum, where it is rude to initiate a conversation with another passenger. The extreme case is crowded subways in USA, where interaction avoidance is the norm, to the point where you break a social rule simply by initiating a conversation (Birenbaum, 1976).

There are varying degrees of defensive behaviour, such that situational withdrawal into an activity may not be viewed as overtly defensive. If a passenger is not interested in conversation, for example, if they have had a hard day and just want some time to themselves, then they can engage in an activity such as reading or listening to music (at a volume that won't annoy other passengers). This is not seen as overtly negative behaviour, but will discourage social interaction. Physically occupying a space by sitting in the aisle seat or placing objects or limbs on the adjacent seat is viewed negatively, at least by the people commuting for work purposes (as the vehicles are likely to be full).

\section{Promotion of Positive Attitudes and Norms}

"Privacy can be achieved by altering the physical environment or by learning to relate to other common users of the space." (Prohansky, Ittelson \& Rivlin, 1976, p.180) 
Most bus and train users will have an example of a person that behaves strangely or breaks what they believe is a social rule on a train trip. One-off, salient incidents of negative passenger or driver behaviour cloud the underlying friendliness of most passengers (e.g. Gardner \& Abraham, 2007). Positive events, such as someone giving a pregnant woman a seat or thanking the driver, are given less consideration by witnesses, are less memorable and less newsworthy when compared with negative events of other bus or train users displaying "odd" or "anti-social" behaviour (Baumeister et al., 2001).

Unfortunately humans focus on and process negative events more thoroughly than positive events (Baumeister et al., 2001). Similarly, negative impressions and stereotypes form more quickly and show greater resistance to change (Baumeister et al., 2001). It is important to note that the very fact that these negative events are salient proves that this is actually odd behaviour that does not typically occur, and that most of the other passengers also felt uncomfortable.

Intentional lack of exclusivity may also have negative repercussions on passenger affect. Transport policy in New Zealand is focused on the social inclusion of vulnerable or transport-disadvantaged groups that require access to public transport to "participate in society" (Ministry of Transport, 2008, p.14). This predominantly refers to groups such as children, elderly, disabled, but also includes socio-economic groups where affordability of transport is a key issue (Ministry of Transport, 2008). Combining this perception of disadvantaged public transport users with vestigial attitudes from times when there were closer links to poverty and public transport is likely to cause lower affect for public transport. Self-image is raised as an issue when taking public transport (e.g. Stradling et al., 2007), and there is still a perception that public transport users are "second class citizens" (Guiver, 2007).

The language issues surrounding public transport can be likened to those of gender bias in language, in that they are pervasive and indicative of underlying stereotypes (e.g. Billings, Halone, \& Denham, 2002). Even the fact that public transport is referred to as an "alternative" mode of transport reinforces the concept that it is non-normative behaviour. Billings et al. (2002) examined sports broadcast 
commentaries using content analysis and found that the language surrounding male athletes was primarily focussed on athleticism and physicality, whereas the language surrounding female athletes was focussed on factors such as personality and appearance. Language surrounding public transport reinforces a similar dominance (e.g. Guiver, 2007). The car represents convenience factors that are strongly associated with transport mode use, whereas alternate modes are more commonly linked with less important predictors of use, such as environmental attitudes (e.g. Gardner \& Abraham, 2008).

There is generally a great deal of commonality among passengers, but this is impeded by a social setting that artificially enhances negative attitudes towards other users. At peak times, the crowded conditions encourage passengers to think of other users more as competition to limited resources such as seats, or impediments to a hasty departure (Davis \& Levine, 1967), rather than real people that deserve friendly or, at the least, polite behaviour. Consistently high numbers of passengers are necessary for the successful operation of a public transport service, and are particularly important in securing improvements to the service, including greater trip frequency and more modern facilities.

The only times public transport is crowded and proximity to other users is a direct issue is at peak commuter times. Commuters travelling at these times are likely to hold down regular working hours at a job, and are likely to have similar lifestyles and responsibilities if they are travelling from the same neighbourhoods. The regular users of public transport also have a social responsibility to follow social rules on board the train and avoid conflict with other passengers. They have to use the train the next day as well and are not likely to behave strangely.

Social marketing campaigns to improve the perception of public transport can help break down stereotypes and improve affective links to public transport (e.g. McKenzie-Mohr, 2000; Winett, Cleaveland, Tate, et al., 1997). Pointing out that passengers share the train and bus with their neighbours and workmates may form positive associations by pointing out the commonalities between users. Similarly, advertising focussed on success stories of positive social contact on buses and trains could help break the myth of the socially defunct atmosphere on public transport. Finally, status based campaigns that show "suits" and celebrities riding 
buses and trains may have some impact on negative perceptions of other passengers.

McKenzie-Mohr (2000) points out that simply identifying barriers to pro-social behaviour is not enough, as there is a need to integrate the research within the broader strategies of local marketing program planners. Recent marketing schemes in Wellington include the "go the train" campaign, which highlights instrumental factors such as convenience, as well as a positive social experience (Greater Wellington Regional Council, 2008a).

The effectiveness of social marketing campaigns also highlights the need for staff participation. For example, the effectiveness of a "sun-safe" campaign targeted at swimming pools was significantly improved when lifeguards participated in the campaign by displaying skin protective behaviours (Winett et al., 1997).

Behaviours such as wearing a shirt, hat or sunglasses, and the use of shard went from about $31 \%$ to $52 \%$ when the lifeguards also adopted these behaviours.

Therefore, any campaign aimed at improving social behaviour on public transport will be enhanced by bus and train staff engaging in pro-social behaviours, such as greetings.

\section{Bus Driver or Conductor Interaction}

Passenger commentary suggests that ticket collectors (or conductors) and bus drivers have the ability to remarkably alter the social atmosphere such that cheerful and polite behaviour in the staff is reflected in passenger behaviour. Positive interactions with staff have been shown to increase positive associations with the service (Edwards \& Johnston, 1977) and improve the feeling of community in public transport (Guiver, 2007). However, during the course of this study an automated electronic ticketing system called "Snapper" has been introduced to Wellington city buses, which is likely to reduce driver interaction.

Snapper has the potential to reduce both positive interactions (including greetings, farewells and thanking responses) as well as negative interactions (such as passengers being reprimanded for not having the correct change). In saying that, 
Snapper also provides the unique opportunity to free up the driver from their stressful workload to give warm greetings to passengers (for more on bus driver stress see Raggatt \& Morrissey, 1997). The concomitant benefits back to polite drivers (and conductors on trains) should be happier passengers that are more likely to see them as real people and less likely to complain about any service delays.

\section{Design Solutions}

In addition to social solutions, such as shifting attitudes toward a socially active environment where there are positive perceptions of other passengers, environmental design solutions are also necessary. Cox et al. (2006) call for design innovations focussed on reducing perceived crowding and increasing perceived personal safety, with particular regard for improving passenger control over space and seat selection choices.

\section{Socially Crippling Seat Layouts}

For most public transport users, the on-board atmosphere is socially wanting. However, design interventions can improve social interaction (e.g. Evans, Lepore \& Schroeder, 1996; Holahan \& Saegert, 1973; Sommer, 1969). The intimate seating design of public transport is arguably derived from economic necessity, to the point where even physical comfort levels are being tested. There is limited leg room for taller passengers and inadequate seat width for less slender passengers. Where limited space is not an issue, some concern for physical comfort has been given, such that the seats are designed to be forward facing where possible, which is likely to reduce nausea and receives strong passenger preference (Han et al., 1998).

No real concern has been given to social considerations in the layout of the seating, possibly because social needs have never been identified as a requirement, or perhaps they rank well below economic and anthropometric concerns. The paired seats do not afford social interaction. The immediately adjacent seat is too close for comfortable conversation unless the relationship is that of a partner or spouse, and even then making eye contact and facing towards them (normal behaviours when 
communicating) causes physical discomfort due to the cramped conditions. Sommer (1969) found that elderly members of a medical ward had difficulty conversing when the seats were adjacent.

Passengers are more likely to choose seating that is either facing, L-shaped or even choose opposing aisle seats to talk across the aisle so there is a reasonable gap between them when conversing. Maines (1979) examined passenger behaviour on subways and also found that L-shaped paired seating afforded conversation and fostered less defensive behaviour when compared with adjacent seating. Ideally conversations occur when passengers are seated either opposite or at right angles to each other, rather than immediately adjacent (Sommer, 1969). Perhaps one of the key findings here is that a quarter of train and bus passengers find a way to communicate despite socially crippling seating conditions.

\section{Poor Design Solutions to Avoid}

"An overcrowded chicken farm produces fewer eggs." (Chinese proverb)

At a practical level, health and safety issues will be attended out of necessity; however, this is likely to mean immediate physical solutions. Physical interventions should be focussed away from short-term solutions. For example, simply pulling out seats to make more standing room to fit a greater number of passengers is no panacea. Long term encouragement of public transport should focus on proactively making the ride comfortable (physically and socially) rather than reactively catering to the necessity of packing more people into already crowded carriages and buses.

The obvious solution is to increase the number and spacing of seats on public transport and provide more services to target the demand at busy commuting times. Unfortunately there are constraints and limitations to what can be attained in a context where short-term economic need is placed above that of long-term social need out of practicality. 


\section{Actual Environmental Control}

The aeroplane is an example of a social context where there are similar limitations as those placed on train and bus commuters, sitting beside a stranger for a fixed duration, yet the Exploratory study found less social discomfort in this setting. Perceived control is likely to be higher (with the ability to pre-select seats, a set of controls within the passengers reach, and the presence of an attendant), the aeroplane is more exclusive in terms of cost, and there are status-based differences (such as first class or business class). This raises the concepts of exclusivity and adds environmental controls.

There are associations between air or even limousine travel and success, for example celebrities travel by airplane but not public transport, and conversely lower socio-economic groups are probably less likely to travel by air but may be regulars on land-based public transport. Introducing a seating class system, where passengers pay a slight premium for a number of additional features aimed at increasing their enjoyment of the trip, would also elevate feelings of status within these passengers (public transport use has been linked negatively with impression formation, e.g. Stradling et al., 2007; Guiver, 2007). However, any increase in status should be made with concern for transport disadvantaged groups, as it is important not to increase social exclusion (see Ministry of Transport, 2008).

Features could include adjustable armrests and small tables that would naturally demarcate space. Also features that help control the immediate environment of the individual passenger, such as temperature controls, reading lights, folding tray tables, foot rests and adjustable seats.

\section{Demarcation of Space}

Altman (1975) suggests that a sign of poor design in public spaces is that there are insufficient boundary-control mechanisms. Baxter (1970) found that individuals have different spatial arrangement goals based on age, gender and ethnicity, and that anxiety is induced when expectation of appropriate spacing are in conflict. Therefore, demarcation of space is likely to mediate these expectation differences, as it will guide appropriate interpersonal spacing behaviour based on fixed environmental cues. 
Goffman (1971, p.34) talks about the practical use of clearly bounded spaces to which people can lay temporary claim, suggesting that the key elements of these spaces is that they provide "external, easily visible, defendable boundaries for a spatial claim." In the office setting there is a preference for privacy with the use of partitions when it becomes more crowded (Tripathi, 2002). Greater architectural depth in residences, that is, the number of spaces one must pass through to shift from room to room, reduces psychological distress and likelihood of social withdrawal (Evans, Lepore \& Schroeder, 1996). Evans and Wener (2007) also suggest the use of "territorial props" such as armrests or small tables as a solution to the discomfort caused by the close proximity of passengers. In many ways these solutions are still limited by the space currently allowed for each passenger.

\section{Less Sterile Environments}

"If I was trying to foster social connectedness interaction on the train I would decorate the train cabins with individual design/art/personality. I would love to see performing arts/busking/themes on the train."(Train participant number 95)

The features identified as important, and likely to increase patronage when refurbishing or introducing new public transport vehicles include appearance, ride quality, ventilation, seating comfort, seating layout and noise levels (Wardman \& Whelan, 2001). A positive appearance is important as it refers to a high level of cleanliness and a lack of vandalism, which implies a level of care and pride in the service, and should encourage users to show respect for the environment and other patrons (Wardman \& Whelan, 2001). Appearance also relates to the level of drabness of the environment and the improvement of décor that goes beyond seating (Wardman \& Whelan, 2001). Exposure to public settings with pleasant environments has been shown to have concomitant benefits, such as altruistic behaviour (Sherrod et al., 1977).

More complex stimuli would reduce the sterility of the environment, provide conversation pieces, and if done correctly have other concomitant benefits. Sommer (1969) points out that choices regarding environmental layouts and 
stimulus are often not selected based on actual user preference, but may be a function of other considerations, such as ease of cleanliness or maintenance. "Clutter" avoidance strategies breed a sterile environment that may be in conflict with other needs from the space, including the need for social interaction (Sommer, 1969).

Visual stimulus could include items that breed a sense of belonging or attachment to the place. Personalisation is a concept used in other settings, such as the workplace, where a person marks their territory with pictures of close friends and family or other objects that have personal meaning to them (see Bechtel, 1997, p. 193). Personalisation at the individual level is not currently an option on public transport, but this does not prevent personalisation at the community level. Examples of personalisation at a community level could include the use of posters of upcoming local events or the use of prints from local artists.

Likewise, positive associations with the train and bus could be nurtured with positive advertising about public transport, the presentation of public transport facts and information about upcoming improvements to the service. Audio stimulus in the form of music could also cultivate a more positive atmosphere, and encourage greater personal attachment by promoting local musicians (perhaps even with live acoustic performances).

\section{Designing for Homogeneity}

Increasing perceived homogeneity in the train setting is likely to reduce perceptions of crowding. However, it is important that any change to promote homogeneity does not limit an individual's choice, and therefore limit their perceived control. So the preference should be for minor environmental modifications rather than rule-based changes that precipitate segregation by some arbitrary group membership. For example, altering some train carriages to naturally afford quiet or private activities such as reading or reflecting on ones thoughts, and altering other carriages to make them more sociable.

Tailoring the design is likely to allow a better match between an individual's requirements of the space, and the additional carriage selection choice increases 
perceived control. The individual may even form a greater level of attachment with that carriage; much like a regular may prefer a certain table or booth at their local bar. Siegfried et al. (1982) suggests that stressing the similarities between car users and public transport users would promote patronage, even going so far as to offer up themes for the different bus routes to highlight their point, such as "the broker's bus" or "the executive express." West (2006) examined "Aussie" themed pubs in London and shows how themes provide symbolic contexts that may induce greater commonality of users as well as common interests for conversation.

The problem with designing for a heterogeneous group is that no design is correct for them, which is perhaps why the train and bus environments are so neutral and sterile. Design lessons taken from successful social establishments, such as restaurants or bars, may naturally foster social interaction or at the very least shift the normative perception towards greater acceptability to engage in small-talk with strangers (e.g Sommer, 1969; West, 2006). Similarly, creative solutions taken from successful libraries may create a more private or tranquil environment for quiet activities such as reading or even work, where it would be reasonable to expect a lower level of disturbance from other passengers without the stigma from being overtly anti-social.

Sommer (1969) identifies several factors related to the facilitation of social interaction that are borrowed from public drinking environments, including low levels of lighting and low levels of noise. Hall (1969) suggests that settings with high noise level and low illumination foster intimate relationships, which are similar conditions to those of night-clubs. He bases this on the fact that sight often distorts at intimate distances so lower levels of illumination will mitigate the issue of distorted facial features, and louder environmental noise require closer distances to converse without shouting. It is perhaps not surprising that designs for private activities, such as studying or quiet reading, benefit from high illumination and low levels of noise (Sommer, 1969). These findings highlight the fact that social and private requirements may have conflicting design elements.

Advanced knowledge surrounding the motivations of other users and their expected behaviour is likely to reduce stress. Compensatory defensive reactions to personal space intrusion were higher in a reading room of a university library than 
a dentist's waiting room (Ajdukovic, 1988). The author explained this finding in relation to expectation, suggesting that intrusion was less expected in the library reading room, and therefore elicited greater stress and behavioural adaptation (Ajdukovic, 1988). In the public transport setting, physiological and perceived stress is higher amongst commuters with lower levels of perceived predictability over commute times (Evans, Wener \& Phillips, 2002). While it is expected that peak commuting times will be crowded, and there will be an immediately adjacent passenger, it may be unexpected and stressful if that passenger attempts to start a conversation. Designing carriages so that they naturally afford either quiet or social activities would assist passenger expectation and likely reduce stress.

The privacy-social interaction dynamic is only one dimension of the complicated behaviour engaged in by individuals, but observed behavioural adaptations prove that this dimension is important in these public transport settings, and attitudes towards other users and interpersonal distance discomfort are posited as barriers to public transport use. Behavioural adaptations indirectly signal passenger preferences, and as such, could be utilised as a tool for designers in the public transport setting. The success of any design could be measured by behavioural change, such as changes in defensive behaviour, social interaction, and for trains, how quickly the improved carriages are filled.

\section{A Social Focus in Design}

Evidence here asserts that new designs should attempt to attend to the neglected social requirements of public transport users, as this will reduce passenger discomfort. The opposing argument is that many public transport patrons gain pleasure from the trip by remaining inactive, unwinding after their day, and taking some time to themselves where they do not wish to be disturbed by other passengers (e.g. Stradling, 2007). Evidence from passenger observations and attitudes shows that the public transport setting is socially uncomfortable, and that a passenger's ability to mentally withdraw from the setting is limited, implying that relaxing by remaining inactive on public transport seems unlikely to succeed. Stradling (2007) does acknowledge that there is another group that gains pleasure and a sense of community from social interaction, a finding that is replicated in similar studies (e.g. Guiver, 2007). 
Success and failure in other public environments, such as neighbourhoods, also suggests that designs should facilitate social interaction. Freedman (1975, p.122) speculates that the crucial element in residential building design is the facilitation of close social interaction. Abu-Ghazzeh (1999) found that the most successful residential building design to foster social interaction between immediate neighbours was a condensed, block arrangement of housing units (as opposed to a row of houses) with a central, shared courtyard. This design promoted more positive attitudes towards the building and had the greatest affiliation between neighbours with a strong feeling of community. Neighbours were more likely to know everyone's name, and were more likely to turn to neighbours for material support (such as borrowing a cup of sugar or a book) or for social support in an emergency (such as an illness or electrical problems).

Yancey (1971) found that a lack of semi-public space built into the design of a highrise building led to the atomization of social networks with negative consequences, such as lower levels of altruistic behaviour and higher levels of anti-social behaviour. Without informal social networks, the sense of community responsibility that provided an informal level of social control also dissipated, such that minor conflicts that may have been easily resolved between neighbours ended up requiring external groups, such as the police (Yancey, 1971). The designers here attempted to minimise "wasted" space by ensuring that all space was either occupied with dwelling units or necessary access to these dwellings. This design has been used as an example poor design (Yancey, 1971), yet closely parallels the design of commuter trains and buses in that there is also a principle of no "wasted" space.

Some of the same concerns identified by Yancey (1971) regarding anti-social behaviour have also been identified by Guiver (2007) in the public transport setting. Guiver (2007) found that many bus patrons had observed anti-social behaviours, such as swearing, verbal abuse, spitting and being sick. There was even a suggestion to bring on a bus conductor to control these behaviours and reduce passenger vulnerability. Positive social interactions and friendship formations can foster a better sense of community (Nash, 1975; Yancey, 1971). With a sense of community comes informal social controls for dealing with inappropriate 
behaviour (Yancey, 1971), and a feeling that other users will "back you up," alleviating the need for a bus conductor.

Creating semi-public spaces specifically designed for social interaction or group activities is difficult in the situation of commuter trains and buses, where there is no allowance for this "wasted space." There is some allowance for this concept in trains designed for longer trips, where passengers can move to a dining carriage for a more social atmosphere. The argument has already been put forward in this discussion to provide a train coach specially designed to facilitate social interaction.

Simply improving design to encourage social interaction is not a solution in itself, but it is a step in the right direction. The important fact to note here is that there is a user need for social interaction, and this should be given the appropriate attention alongside other important passenger considerations, such as the need for better seat demarcation or air conditioning, and most likely ahead of such considerations as more physically comfortable seating. Chan (1999) concludes that architectural designs that meet user needs or expectations will reduce crowding in situations where space is constrained.

Social factors are more difficult to attend to, as there are less obvious pathways to implementing change. It is hoped that some of the practical options outlined by this discussion, in terms of suggestions regarding design, individual behaviour shifts, and shifts in normative attitudes, are examined more closely by users and providers. In addition to practical findings, there are several key findings that support psychological theory, as well as the use of methods that may be transferable to other public settings.

\section{Measurement Tools}

A number of tools were developed during the course of this research that have the potential to be applicable to measure discomfort in other social settings. 


\section{Interpersonal Distance Measurement}

The novel interpersonal distance (IPD) measurement methodology developed during the course of this research is simple to use, unobtrusive, and can be adapted to fit other shared social spaces (see the method section of the Observational Chapter for more specific detail). Evans and Wener (2007) call for more finely tuned proxemic tools, suggesting that simple density measurements are not effective when it comes to measuring stress in crowded social spaces. The IPD method can be used to investigate stress in a public location or as an index to measure intervention effectiveness.

Research focussed on infrastructural ergonomics would benefit from utilising IPD data in the design of inner city outdoor spaces, offices, residences, cafeterias, restaurants, bars, and of course buses, trains, ferries and planes. This is especially the case if the goal of the design is to encourage or discourage interpersonal interaction, or where there is evidence of interpersonal discomfort among the users of the space (i.e. evidence of defensive behaviours). However, the precise measurement of distance in a setting and the complexity of settings may be deterrents, as IPD measurement does not appear to have found a foot-hold in contemporary research methodology.

The method uses functional distance units to measure the seat distance to the nearest passenger, following a similar concept to Festinger et al. (1950), who measured residence distance using residence units. One point of IPD is added for each seat gap to the nearest passenger, i.e. one for each row, each seat across, and one for the aisle, and a score of zero if there is an immediately adjacent passenger. This method allows for easy measurement by observers without sophisticated surveillance equipment, which means that even if the primary interest of the research isn't proxemics, it can be measured as an additional factor with little effort or cost.

The method could also be adapted for standing environments, but relies to some extent on the nature of the environment, working best in relatively symmetrical environments where users are interacting with the physical elements of their surroundings. Consequently, it is probably not appropriate for fluid environments such as footpaths unless there is some component of the environment that is static. 


\section{Monitoring Success in Social Environments}

This research also contributes tools to examine the needs of users in different social environments. Common mechanisms for naturalistically observing the success of public environments include the frequency of users and the duration of their use of the space. However, these measures do not provide information regarding the users' spatial preferences or insight into improvements of the space. Due to the nature of different social settings and their different uses, refining observational and attitudinal tools with environmental specificity can create sensitive measures of interpersonal space requirements, social discomfort, and environmental success.

Observation of the range and nature of current user behaviours is important. The range and frequency of activities when coupled with attitudinal information provides a good picture of the use of the space. Similarly, the nature of behaviours reveals user discomfort, with defensive behaviours indicating social discomfort and interactive behaviours indicating social comfort. Specific adaptive behaviours should be looked for, such as the use of activities, conversation frequency (or even conversation level if you used auditory equipment), the use of body posture, and the use of props (such as jackets, bags, or even items picked up in the environment).

\section{General Strengths and Limitations}

Some of the relative strengths and weaknesses of these studies relate to the methods used to attain the samples and the measures used to examine observed and self-reported behaviours. Ideally, all of the samples would have been matched, such that observed behaviours could have been directly compared with attitudinal and self-report measures, and physiological measures of stress (arousal) would have been taken. 


\section{Sample Characteristic Strengths and Weaknesses}

The sample of convenience of students used in the Exploratory Chapter was relatively small $(N=105)$, and the questionnaire was given to them in a classroom setting. Sears (1986) points out the weakness of relying on narrow samples, suggesting that among other factors, students have less crystallised attitudes and more unstable peer group relationships than older adults, and that these differences are likely to be exaggerated when in a non-natural setting. While students are younger, and as such are a key group of public transport users, they are still a narrow grouping of the overall users, and as perceived heterogeneity was determined to be an important facet of interpersonal spacing and public transport use, this group was less than ideal.

Relative to the Exploratory sample, the car $(n=305)$ train $(n=319)$ and bus $(n=$ 216) commuter samples were larger and targeted towards the appropriate users without the systemic biases inherent in narrower samples (see Sears, 1986). For the train and bus commuters, questionnaire packs were handed to them immediately prior to their trip (with a pen), so they could fill the questionnaire in while travelling in the natural setting. The larger samples allowed more complicated multi-variable analysis, missing data was less problematic, and there was the ability to perform validity testing with hold-out samples that would likely have had lower adequacy in smaller samples.

Response rates were acceptable for the car sample (50\%) and exceeded acceptable levels for the train $(65 \%)$ and bus $(67 \%)$ samples (overall response rate $=59 \%$ ). Baruch (1999) in their review of 175 studies, published in journals identified as leading in their fields, over three decades found that the average response rate was $55.6 \%$ ( $\mathrm{SD}=19.7 \%$ ), but that response rates were dropping over time, and recommended a minimum level of $40 \%$ response rate for academic studies in the behavioural sciences. A higher response rate is beneficial, as it suggests a broader range of car, train and bus commuters are examined, rather than a narrower group of users whose responses may be skewed by people with atypically strong views (positive or negative) of public transport. With higher response rates it is less likely that there are systemic biases such that the respondents differ substantially from the non-respondents. 
Techniques used here to increase response rates included the use of colour paper for the questionnaires and local university logos on the envelopes to distinguish the questionnaires packs from other mail, incentives (lottery tickets and prize draws), the inclusion of free pens, and personally signed cover letters on university letterhead (e.g. Fox, Crask \& Kim, 1988; Yammarino, Skinner \& Childers, 1991). When handing out questionnaires to the public at bus stops and train stations researchers used positive body language, were very enthusiastic and well-informed to answer any queries. It is worth a mention that whatever techniques go into the efforts to increase response rates, the underlying features that participants seem to detect are enthusiasm and care for the research, which they can interpret from interactions with the researchers or observe indirectly through the level of effort and consideration taken in putting together the questionnaire pack.

Sample limitations also included the typical issue of extrapolation. The results may not be transferable to public transport settings outside of the Wellington region of New Zealand. More specifically, most of the findings are limited to highly educated commuters travelling at peak travel times for work purposes. This is particularly problematic given the apparent contextual sensitivity of social discomfort measures. For example, education was found to have a negative relationship with IPD Discomfort in the train sample. In saying that, there are consistencies between bus and train users, such that similar carriage and bus layouts do afford certain sets of behaviours in people due to their amalgam with human physiology, regardless of cultural or interpersonal differences in the users.

Differences in attitudes to public transport between cities have been observed across Auckland, Wellington and Christchurch (New Zealand's three largest cities), such that Wellington has lower prejudice towards public transport than the other cities (Walton, Murray \& Thomas, under review). This suggests that poor attitudes to passengers may be an even greater barrier to use in other New Zealand cities.

\section{Actual Behaviour}

Measuring the differences in attitudes and self-reported behaviours of actual car, train and bus commuters also had benefits. An alternative would have been to measure willingness to use public transport in a sample of car users. While there 
are strong links between intention and future behaviour, this method does increase error, particularly in the context of shifting behaviour from car use. Private motor vehicle use has been identified as a habitual behaviour (Gardner \& Abraham, 2008), and as such would take a good deal of effort to alter. Effort moderates the relationship between self-reported willingness to perform a behaviour and actual behaviour, such that the gap is larger for high effort behaviours. For example, someone with positive environmental attitudes is more likely to make contributions to an environmental organisation (low effort), but is no more likely to use alternative modes of transport to the car (high effort; Walton, Thomas \& Dravitzki, 2003).

\section{Observational Study}

Researchers tend to rely on questionnaires to measure user attitudes towards specific elements of a space, but supplementing these responses with observed behaviour provided a better overall picture (see Hall, 1950, p.10). The benefit of the observational method is that behaviour can be visually measured by an observer with great ease, the observer can identify and focus on important movements, and the observer is unobtrusive and subsequently less likely to interfere with naturalistic behaviour. An alternative to this method would have been using video surveillance.

The use of video footage would have required greater effort in terms of the technology setup, the permissions required, and the time coding the footage. However, this would have been balanced against other benefits. Video would have allowed for more precise measurement of distance and the possibility of measuring subtle non-verbal cues, such as smiling or body orientation. Also, the attentional capacity of observers is limited, such that they may miss behaviours that would be picked up by video. Overall, there are pros and cons to each method; the important element was that behaviours were observed.

\section{Sensitivity of Scales}

Interpersonal distance discomfort and social discomfort measures are so contextually sensitive that replicability of findings may be difficult to achieve. 
Passengers may be sitting next to a good friend one day or an obese stranger who is taking up more than their share of the seat, or even forced to stand the next day. Difficulty in replicating even simple findings, such as the relationship between interpersonal discomfort and gender, is testament to this (e.g. see Hayduk's review, 1983). Cross-validation techniques were used to limit this issue.

In hindsight, a shortened version of the Social Anxiety scale (adapted from Liebowitz, 1987) from the Exploratory Chapter should have been used in place of the Social Discomfort scale (adapted from Lawrence et al., 2006). The Social Anxiety scale may have been more sensitive to differences in setting discomfort between commuter groups. The Social Anxiety scale used contextually sensitive examples, and in doing so primed the participant to think about location specific events that allowed for deeper consideration of underlying anxiety levels. The Social Discomfort scale was chosen at the time because it was conceptually similar and positively correlated with Social Anxiety, and because it was easier to adapt for the questionnaires that followed. The Social Discomfort items were more easily transferable into different settings and the scale had fewer items, whereas many of the Social Anxiety items were context specific in nature and the scale would have required shortening.

\section{Lack of Physiological Measures}

Physiological measures (such as salivary cortisol, see Evans \& Wener, 2007) could have examined individuals across the reported and actual use of defensive strategies and interactive strategies. This would have provided definitive evidence over the success of different strategies. The use of physiological measures could also have examined the relative influences of reported IPD discomfort, social discomfort, and the perceived heterogeneity of other passengers, on commuter stress.

\section{Future Research}

While there is a strong body of research linking instrumental factors to public transport patronage (e.g. Balcombe et al., 2004; Currie \& Wallis, 2008; Eriksson, Friman \& Gärling, 2008; Holmgren, 2007) there is a relative paucity of empirical 
evidence that identifies the importance of social factors (e.g. Richards, 1978; Stradling et al., 2007) and even fewer studies that provide robust support for specific social factors (e.g. Gardner \& Abraham, 2008). This research gap needs to be addressed.

There is a particular need for experimental research that determines the strength of the relationship relative to other known contributors, such as the instrumental variables of trip cost and duration. Performance monitoring and modelling of public transport demand would also benefit from the inclusion of social factors. In addition to these gaps in knowledge and performance monitoring, there are specific studies that would naturally follow from this research, such as a physiological stress study and a train carriage study.

\section{Train Carriage Interaction Study}

The train setting provides an excellent audience for field testing passenger preference, as it provides passengers with the opportunity to choose. For example, refurbishing one train carriage for interaction and one train carriage for privacy would be an excellent test of passenger preference. Measures of success could include frequency counts of passengers in the train carriage, the sequential order in which passengers select carriages and seats within the carriages (indicating preference), and defensive and interactive behavioural adaptations.

Methodologically, the other carriages could be used as controls, or even better, measures could be taken before and after any intervention.

\section{Physiological Stress Study}

Social discomfort has a negative relationship with defensive behaviour and a positive relationship with social interaction. A physiological examination of defensive and interactive strategies could confirm this finding. The conditions of interpersonal distance would have to be controlled, most likely be ensuring the vehicle was fairly full, such that participants were required to have someone sitting directly beside them (or interpersonal distance could be used as an independent measure). 
Passengers observed maintaining defensive behaviour, verbal interactive behaviour, and no observable behaviour (control group) could be approached while on public transport after an acceptable time period, such as 1omins (but duration could be simply be measured as an independent variable). Volunteers would then be measured for physiological levels (a simple measure would be required, such as a salivary cortisol measure which could be quickly administered) and asked some simple questions, such as the level of relationship to the adjacent passenger, their affective assessment of their travel mode, and their current level of perceived stress.

\section{Monitoring Public Transport Performance}

Monitoring public transport should include social influences, particularly some measure of passenger affect, interaction with other passengers, and some measure of interpersonal distance discomfort. Unless these factors are measured consistently over time they will not be highlighted as pertinent issues to improving the service. These factors may be difficult to measure and even more difficult to alter, but are still important.

Annual monitoring of public transport services in the Wellington region of New Zealand already incorporates perception of safety, and has identified other social factors, such as staff friendliness, as important features of the service (Greater Wellington Regional Council, 2008b). Extending these types of questionnaires is important. Possible social measures to include could be interpersonal distance discomfort, privacy, likelihood of observing polite behaviours/anti-social behaviours, and passenger friendliness or atmosphere. Coupling these annual perceptions with an annual observation study of a random selection of vehicles would also be useful. Observational measures could include frequency counts of specific defensive behaviours, passenger interactions (or take noise measurements and partial out non-verbal noise), graffiti, litter, driver greetings, and thanking the driver. 


\section{Practical Recommendations}

Fact sheets have been created to extract the key points in a useable way for passengers and public transport agencies, including the actual providers and groups interested in transport policy direction. The passenger facts are intended to let passengers know how their behaviours are likely to be interpreted, and how to go about promoting a positive self-image (if that is what they desire). The public transport agency facts are primarily focussed on design and marketing interventions. These groups are necessary to facilitate any change in the social situation (e.g. Ajzen, 1985; McKenzie-Mohr, 2000; Winett, et al., 1997).

\section{Passenger Facts Sheet}

1. Public transport is a socially active travel mode, with at least a quarter of passengers talking.

2. Smiling and making eye contact make you appear friendlier to other passengers.

3. Always greet and thank the bus driver or ticket collector, as this encourages other polite behaviour.

4. If you want to avoid conversation with other passengers but maintain a friendly appearance, engage in activities. Non-visually engaging activities are best, such as listening to music (as this still allows you to acknowledge other passengers).

5. If you want to avoid people sitting directly beside you, placing a bag on the adjacent seat, sitting in the aisle seat or taking up more than your share of the seat will work, but be aware that you may be viewed as rude or unfriendly, especially when the vehicle begins to fill.

6. If you want to be social and promote interaction with other passengers there are several small adjustments you can make and trial for yourself to see what is most successful:

- Maintain positive body language, such as eye contact or smiling (but do not openly stare)

- Leave enough space beside you on the adjacent seat, or even make an active show of moving over as passengers approach looking for a seat

- Acknowledge the person with a brief positive gesture or short verbal greeting 
- Attempt to sit beside people you recognise as other regulars, particularly if they have positive body language

- Avoid people that are engaged in an activity or taking up more than their half of the seat

- Conversation initiation techniques are perhaps the most difficult choice, as you do not want to come across as weird. You could try asking for the time, offering a stick of gum, or even a light-hearted comment about the weather.

7. Remember that you need the other passengers if you are to have a successful, efficient, enjoyable transit service.

\section{Public Transport Agency Facts Sheet}

1. The seating situation in public transport causes social discomfort comparable to a crowded elevator.

2. Anything done to increase the perceived control of passengers on trains and buses will reduce social discomfort down to a more tolerable level (similar to that of aeroplane travel). For example:

- Clearly partitioned seats

- Additional controls (such as over localised temperature or a call button for attention)

- Providing staff with the resources to improve passenger comfort

3. Staff friendliness impacts strongly on the enjoyment, perceived quality and perceived ride quality of the trip. Encouraging simple things like greetings and farewells have concomitant benefits such as:

- Friendlier passengers, that are likely to respect and be polite to the driver/ticket collector

- More tolerant passengers (i.e. they won't be as upset with journey delays)

4. Consideration of targeted refurbishments with specific user needs in mind, especially seat layout.

5. Good public transport providers already monitor the performance of their service on instrumental factors. Consideration should be given to include social influences, for example measures of:

- Attitudes towards the other regular passengers

- Interaction with other passengers and staff (frequency count or even verbal noise level measurements) 
- Interpersonal distance discomfort or privacy measures

- Use of defensive behaviours

6. Marketing campaigns could be targeted to improve the perception of other public transport users by pointing out the similarities amongst passengers.

- The removal of negative stereotypes of public transport as "second class" travel should be targeted. For example, the use of celebrity endorsement.

- Advertising focussed on success stories of positive social contact on buses and trains could reduce the barriers to social interaction and increase the feeling of community.

- Use of positive public transport advertising at bus and train facilities where there are captive audiences.

- Improving affective links to public transport and making the service seem more personalised will likely benefit use. For example, the advertising of local community events on board trains and buses.

7. Alternative seating layouts would benefit from:

- Seat demarcation through the use of props such as adjustable arm rests and small tables, or even markings or indentations on the seats indicating appropriate spacing

- A greater use of social seating layouts, with seats facing each other (probably across the aisle) or L-shaped seating (even just if in one carriage)

8. More stimuli in the environment, such as posters or local art, particularly if it helps form personal associations (such as the use of advertising of local events, as mentioned above).

\section{General Conclusions}

Public transport cannot successfully compete with car travel until the associated social and instrumental factors of bus and train travel are competitive. The relative paucity of empirical social research means that social factors, such as IPD discomfort and negative passenger affect are neglected. Even research regarding social elements, such as attitudes to public transport, concern for personal safety and crowding is typically qualitative, and therefore difficult to contrast against instrumental factors such as pricing schemes (e.g. Guiver, 2007). Consequently, customer surveys to monitor public transport performance and evaluate targeted 
improvements to the service do not typically include social factors. A myopic focus on instrumental factors should be substituted for a more holistic approach.

It is essential that the basic desire for personal space is given careful attention in the public transport setting. The close yet impersonal environment is not conducive to the needs of individuals that desire greater social interaction, and impedes the needs of other individuals that desire a greater level of privacy. There is no simple solution to these issues, as a delicate balance is required in meeting these quite polar needs.

Negative stereotypes surrounding public transport need to be broken. Even the fact that public transport is thought of as an 'alternative' mode of transport reinforces entrenchment with private motor vehicles as the norm. The people taking public transport are the same people that live in our neighbourhoods and work with us, yet the relative quality of the character of the people that take public transport is rated as less positive.

Evidence here suggests that the most successful strategy in reducing social discomfort is to adopt a positive attitude toward other passengers, be open to greater levels of social interaction and even instigate verbal behaviour with other passengers. Defensive behaviours and a fixation on an unachievable level of privacy are less effective, acting more as symptoms of discomfort rather than solutions. Interactive strategies are supported by Hall's (1969) proxemic theory that establishes that perception of crowding or discomfort from close interpersonal distance is mitigated by the formation of closer relationships with other users of a shared space. Unfortunately only a quarter of passengers adopt interaction strategies.

Many reasons are identified for why a social strategy is not adopted by more patrons. The high density of passengers causing social overload and a dilution of the regular passengers, a physically sterile environment, a socially crippling seating layout, a perception that it is more acceptable not to interact, and the fact that defensive behaviours require less effort than social behaviours all contributes. Several design-based solutions are offered to improve the social environment, particularly a different seat layout. 
The primary solution is to promote pro-social behaviours, such as smiling, acknowledging other passengers and greeting other passengers, particularly the immediately adjacent passenger. Non-verbal and verbal greetings restore the ability of passive contacts to develop into friendships. A failure to acknowledge other passengers (probably due to social overload and social loafing) interrupts Festinger et al.'s (1950) passive contact theory (PCT; except in the Masterton cohort). An increase in these low-effort behaviours is likely to be achieved through the enthusiasm of public transport staff in promoting these behaviours (see Winett et al., 1997) and the willingness of passengers to be open to basic interaction. 


\section{REFERENCES}

Abu-Ghazzeh, T.M. (1999). Housing layout, social interaction, and the place of contact in Abu-Nusier, Jordan. Journal of Environmental Psychology, 19, 41-73.

Aiello, J.R. (1987). Human Spatial Behavior. In D. Stokols \& I. Altman (Eds.), Handbook of Environmental Psychology (pp. 389-504). New York: John Wiley \& Sons.

Aiello, J.R., Thompson, D.E., \& Brodzinsky, D.M. (1983). How Funny is Crowding Anyway? Effects of Room Size, Group Size, and the Introduction of Humor. Basic and Applied Social Psychology, 4 (2), 193-207.

Ajdukovic, D. (1988). A contribution of the methodology of personal space research. Psychologische Beitrage, 30 (1-2), 198-208.

Ajzen, I. (1985). From intentions to actions: A theory of planned behaviour. In J. Kuhl \& J. Beckmann (Eds.) Action Control: From Cognition to Behavior. Berlin: Springer.

Alben, L. (1997). At the heart of interaction design. Design Management Journal, 8 (9), 9-26.

Altman, I. (1975). The Environment and Social Behavior. Brooks/Cole Publishing Company: California.

Altman, I., \& Vinsel, A.M. (1977). Personal space: An analysis of E.T. Hall's proxemics framework. In I. Altman \& J.P. Wohlwill (Eds.), Human Behavior and Environment: Advances in Theory and Research, Volume 2. Plenum Press: New York.

Andersen, P.A., \& Liebowitz, K. (1978). Development and nature of the construct touch avoidance, Environmental Psychology and Nonverbal Behavior, 3, 89-106. 
Argyle, M. (1978). The Psychology of Interpersonal Behavior. New York: Penguin Books Ltd.

Argyle, M., \& Dean, J. (1965). Eye-contact, distance and affiliation. Sociometry, 28, 289-304.

Auckland Regional Transport Authority (2008, August 20). Annual patronage figures show shift to public transport. Auckland: ARTA. Retrieved February 12, 2009, from: http://www.arta.co.nz/media-releasearchive.html?releaseid $=d d 675001-f 206-b 719-3 d 33-$ dgdc5f5eb46a\&prev $=1$

Balcombe, R., Mackett, R., Paulley, N., Preston, J., Shires, J., Titheridge, H., Wardman, M., \& White, P. (2004). The Demand for Public Transport: A Practical Guide. Wokingham: Transport Research Laboratory. Retrieved October 20, 2008, from: http://www.demandforpublictransport.co.uk/

Bamberg, S. (2000). The promotion of new behavior by forming an implementation intention: Results of a field experiment in the domain of travel mode choice. Journal of Applied Social Psychology, 30 (9), 19031922.

Barash, D.P. (1973). Human ethology: Personal space reiterated. Environment and Behavior, 5 (1), 67-73.

Baron, R.M., Mandel, D.R., Adams, C.A., \& Griffen, L.M. (1976). Effects of social density in university residential environments. Journal of Personality and Social Psychology, 34 (3), 434-446.

Baum, A., Riess, M., \& O'Hara, J. (1974). Architectural variants of reaction to spatial invasion. Environment and Behavior, 6 (1), 91-100. 
Baumeister, R. F., Bratslavsky, E., Finkenauer, C., \& Vohs, K. D. (2001). Bad is stronger than good. Review of General Psychology, 5, 323-370.

Baumeister, R.F., \& Leary, M.R. (1995). The need to belong: Desire for interpersonal attachments as a fundamental human motivation. Psychological Bulletin, 117 (3), 497-529.

Baxter, J.C. (1970). Interpersonal spacing in natural settings. Sociometry, 33 (4), 444-456.

Bechtel, R.B. (1997). Environment \& Behavior: An Introduction. London: Sage Publications.

Bevan, T., Fellner, E., Park, N. (Producers), \& Wright, E. (Director). (2004). Shaun of the Dead [Motion picture]. United Kingdom: Universal Studios.

Billings, A.C., Halone, K.K., \& Denham, B.E. (2002). "Man, that was a pretty shot": An analysis of gendered broadcast commentary surrounding the 2000 men's and women's NCAA final four basketball championships. Mass Communication \& Society, 5 (3), 295-315.

Birenbaum, A. (1976). Norms and Human Behavior. New York: Praeger Publishers.

Bornstein, R.F. (1989). Exposure and affect: Overview and meta-analysis of research, 1968-1987. Psychological Bulletin, 106 (2), 265-289.

Brewster, H. (1977). The River Gods of Greece: Myths and Mountain Waters in the Hellenic World. London: I.B. Tauris Publishers.

Brooks, M. (2003). The Zombie Survival Guide: Complete Protection from the Living Dead. California: Three Rivers Press. 
Burgess, J.W. (1983). Interpersonal spacing behavior between surrounding nearest neighbors reflects both familiarity and environmental density. Ethology and Sociobiology, 4, 11-17.

Burgoon, J.K. (1994). Nonverbal Signals. In M.L. Knapp \& G.R. Miller (Eds.) Handbook of Interpersonal Communication (2nd Ed.), p. 229-285. California: Sage Publications Incorporated.

Byrne, D. (1961). Interpersonal attraction and attitude similarity. Journal of Abnormal and Social Psychology, 62, 713-5.

Caplan, M., \& Goldman, M. (1981). Personal space violations as a function of height. Journal of Social Psychology, 114, 167-177.

Cattell, R.B. (1966). The scree test for the number of factors. Multivariate Behavioral Research, 1, 245-276.

Chan, Y. (1999). Density, crowding, and factors intervening in their relationship: Evidence from a hyper-dense metropolis. Social Indicators Research, 48 (1), 103-124.

Christmann, A., \& Van Aelst, S. (2006). Robust estimation of Cronbach's alpha. Journal of Multivariate Analysis, 97, 1660-1674.

Close Up (2008). Trains, world class or cattle class? Close Up, TV One, 7pm, 7th August 2008. Retrieved October 18, 2008, from: http://tunzondemand.co.nz/content/close up 2008 o8 26/ondemand video skin

Cox, T., Houdmont, J., \& Griffiths, A. (2006). Rail passenger crowding, stress, health and safety in Britain. Transportation Research Part A, 4O, 244258. 
Cox, V.C., Paulus, P.B., \& McCain, G. (1984). Prison crowding research: The relevance for prison housing standards and a general approach regarding crowding phenomena. American Psychologist, 39 (10), 1148-116o.

Crane, D.R., \& Griffin, W. (1983). Personal space: An objective measure of marital quality. Journal of Marital \& Family Therapy, 9 (3), 325-327.

Currie, G. (2005). The demand performance of bus rapid transport. Journal of Public Transportation, 8 (1), 41-55.

Currie, G., \& Phung, J. (2008). Understanding links between transit ridership and gasoline prices evidence from the United States and Australia. Transportation Research Record, 2063, 133-142.

Currie, G., \& Stanley, J. (2008). Investigating links between social capital and public transport. Transport Reviews, 28 (4), 529-547.

Currie, G., \& Wallis, I. (2008). Effective ways to grow urban bus markets - a synthesis of evidence. Journal of Transport Geography, 16, 419-429.

Davis, M., \& Levine, S. (1967). Toward a sociology of public transit. Social Problems, 15 (1), 84-91.

Dean, L.M., Willis, F.N., \& Hewitt, J. (1975). Initial interaction distance among individuals equal and unequal in military rank. Journal of Personality and Social Psychology, 32 (2), 294-299.

DeBeer-Keston, K., Mellon, L., \& Solomon, L.Z. (1986). Helping behavior as a function of personal space invasion. The Journal of Social Psychology, 126 (3), 407-409.

Department for Transport (2003). Understanding Customer Needs. London: Department for Transport. Retrieved October 20, 2008, from: http://www.dft.gov.uk/pgr/regional/buses/bpf/coll understandingcust omerneeds/rstandingcustomerneedsfu3684.doc 
Dumas, J.S., \& Dobson, R. (1979). Linking consumer attitude to bus and carpool usage. Transportation Research, 13A, 417-423.

Edney, J.J. (1972a). Place and space: The effects of experience with a physical locale. Journal of Experimental Psychology, 8, 125-135.

Edney, J.J. (1972b). Property, possession and permanence: A field study in human territoriality. Journal of Applied Social Psychology, 3 (3), 275-282.

Edwards, K.A., \& Johnston, R. (1977). Increasing greeting and farewell responses. Education and Treatment of Children, 1 (1), 9-18.

Ekman, P., Friesen, W.V., \& Ellsworth, P. (1972). Emotions in the Human Face. New York: Pergamon.

Ellayway, A., Macintyre, S., Hiscock, R., \& Kearns, A. (2003). In the driving seat: Psychosocial benefits from private motor vehicle transport compared to public transport. Transportation Research Part F, 6, 217-231.

Ellison, B. (1967, January 15). If the movie is comic, sex is ok, in suburbia. Chicago Sun Times, p.4.

Ellsworth, P.C., Carlsmith, J.M., \& Henson, A. (1972). The stare as a stimulus to flight in human subjects: A series of field experiments. Journal of Personality and Social Psychology, 21, 302-311.

Emmons, R.A., \& Diener, Ed (1986). Influence of Impulsivity and Sociability on Subjective Well-Being. Journal or Personality and Social Psychology, 50 (6), 1211-1215.

Epstein, Y.M., Teitelbaum, R., Karlin, R.A., Katz, S., \& Aiello, J.R. (1981). An assessment of the effectiveness of two tactics to reduce arousal in crowded 
mass transit settings. Journal of Applied Social Psychology, 11 (3), 259267.

Eriksson, L., Friman, M., \& Gärling, T. (2008). Stated reasons for reducing work-commute by car. Transportation Research Part F, 11, 427-433.

Eroglu, S.A., Machleit, K.A., \& Chebat, J. (2005). The interaction of retail density and music tempo: Effects on shopper responses. Psychology and Marketing, 22 (7), 577-589.

Evans, G.W. (1973). Personal space. Psychological Bulletin, 80 (4), 334-344.

Evans, G.W., \& Lepore, S.J. (1992). Conceptual and analytic issues in crowding research. Journal of Environmental Psychology, 12, 163-173.

Evans, G.W., Lepore, S.J., \& Schroeder, A. (1996). The role of interior design elements in human responses to crowding. Journal of Personality and Social Psychology, 70 (1), 41-46.

Evans, G.W., \& Wener, R.E. (2006). Rail commuting duration and passenger stress. Health Psychology, 25 (3), 408-412.

Evans, G.W., \& Wener, R.E. (2007). Crowding and personal space invasion on the train: Please don't make me sit in the middle. Journal of Environmental Psychology 27, 90-94.

Evans, G.W., Wener, R.E., \& Phillips, D. (2007). The morning rush hour: Predictability and commuter stress. Environment and Behavior, 34 (4), 521-530.

Festinger, L. (1957). A Theory of Cognitive Dissonance. Stanford: Stanford: University Press. 
Festinger, L. \& Kelly, H.H. (1951). Changing Attitudes Through Social Contact: An Experimental Study of a Housing Project. Ann Arbor: University of Michigan.

Festinger, L., Schachter, S. \& Back, K. (1950). Social Pressures in Informal Groups: A Study of Human Factors in Housing. Stanford, California: Stanford University Press.

Fife-Schaw, C. (2008). How do I test the normality of a variable's distribution? University of Surrey. Retrieved May 25, 2008, from: http://www.psy.surrey.ac.uk/cfs/p8.htm

Finighan, W. (1980). Some empirical observations on the role of privacy in the residential environment. Man Environment Systems, 10, 153-159.

Fleming, R., Baum, A., \& Singer, J.E. (1985). Social support and the physical environment. In S. Cohen \& S.L. Syme (Eds.), Social Support and Health. Orlando: Academic Press.

Fox, R.J., Crask, M.R., \& Kim, J. (1988). Mail survey response rate: A metaanalysis of selected techniques for inducing response. Public Opinion Quarterly, 52, 467-491.

Frank, M.G., Ekman, P., \& Friesen, W.V. (1993). Behavioral markers and recognizability of the smile of enjoyment. Journal of Personality and Social Psychology, 64 (1), 83-93.

Freedman, J.L. (1975). Crowding and Behavior: The Psychology of High Density Living. New York: The Viking Press.

Fried, M.L., \& DeFazio, V.J. (1974). Territoriality and boundary conflicts in the subway. Psychiatry, 37, 47-59. 
Fry, G., Grogan, S., Gough, B., \& Conner, C. (2008). Smoking in the lived world: How young people make sense of the social role cigarettes play in their lives. British Journal of Social Psychology, 47, 763-780.

Fujii, S., Gärling, T., \& Kitamura, R. (2001). Changes in drivers' perceptions and use of public transport during a freeway closure: Effects of temporary structural change on cooperation in a real-life social dilemma. Environment and Behavior, 33, 796

Gardner, B., \& Abraham, C. (2008). Psychological correlates of car use: A metaanalysis. Transportation Research Part F, 11, 300-311.

Garfinkel, H. (1964). Studies of the routine grounds of everyday activities. Social Problems, 11 (3), 225-250.

Geen, R.G. (1991). Social motivation. Annual Review of Psychology, 42, 377-99.

Gibson, J. J. (1979). The Ecological Approach to Visual Perception. New Jersey: Lawrence Erlbaum Associates, Incorporated.

Gifford, R. (1982). Projected interpersonal distance and orientation choices: personality, sex, and social situation. Social Psychology Quarterly, 45 (3), $145^{-152 .}$

Gifford, R., Hine, D.W., Muller-Clemm, W., Reynolds, D.J., \& Shaw, K.T. (2000). Decoding modern architecture: A lens model approach for understanding the aesthetic differences of architects and laypersons. Environment and Behavior, 32 (2), 163-187.

Glaser, U. (1985). The tavern as psychosocial encounter setting: Approaches and results of an empirical study. Gruppen Dynamic, 16, 351-359.

Goffman, E. (1961). Encounters: Two studies in the sociology of interaction. The Bobbs-Merrill Company Inc.: New York. 
Goffman, I. (1971). Relations in Public: Microstudies of the Public Order. London: Allen Lane the Penguin Press.

Goldberg, L.R. (1999). A broad-bandwidth, public domain, personality inventory measuring the lower-level facets of several five-factor models. In I. Mervielde, I. Deary, F. De Fruyt \& F. Ostendorf (Eds.), Personality Psychology in Europe Vol. 7, pp. 7-28. Tilburg, Netherlands: Tilburg University Press.

Goldsmith, E., \& Hill, R. (1986). Family development theory and space utilization: A review and synthesis. Journal of Social Behavior and Personality, 1, 223-232.

Gray, G.E. (1992). Perceptions of Public Transportation. In G.E. Gray \& L.A. Hoel (Eds.), Public Transportation ( ${ }^{\text {nd }} E d$.) New Jersey: Prentice Hall.

Greater Wellington Regional Council (2008a). Go the Train. Retrieved October 18, 2008, from: http://www.gw.govt.nz

Greater Wellington Regional Council (2008b). Greater Wellington Regional Council Annual Public Transport Satisfaction Monitor 2008. Retrieved October 18, 2008, from: http://www.gw.govt.nz/story images/5399 PTSurvey s10880.pdf

Greenberg, C.I., \& Firestone, I.J. (1977). Compensatory responses to crowding: Effects of personal space intrusion and privacy reduction. Journal of Personality and Social Psychology, 35 (9), 637-644.

Griffitt, W., \& Veitch, R. (1971). Hot and crowded: Influences of population density and temperature on interpersonal affective behavior. Journal of Personality and Social Psychology, 17, 92-98.

Griffitt, W., \& Veitch, R. (1974). Ten days in a fall-out shelter. Sociometry, 37, 163-173. 
Guiver, J.W. (2007). Modal talk: Discourse analysis of how people talk about bus and car travel. Transportation Research Part A, 41, 233-248.

Hai, D.M., Khairullah, Z.Y., Coulmas, N. (1982). Sex and the single armrest: Use of personal space during air travel. Psychological Reports, 51 (3), 743-749.

Hair, J.F., Anderson, R.E., Tatham, R.L., \& Black, W.C. (1995). Multivariate Data Analysis: With Readings ( $4^{\text {th }}$ Ed.). New Jersey: Prentice Hall.

Hall, E. (1966). The Hidden Dimension. New York: Doubleday.

Han, S.H., Jung, E.S., Jung, M., Kwahk, J., \& Park, S. (1998). Psychophysical methods and passenger preferences of interior designs. Applied Ergonomics, 29 (6), 499-506.

Hayduk, L.A. (1978). Personal space: An evaluative and orienting overview. Psychological Bulletin, 85, 117-134.

Hayduk, L.A. (1983). Personal space: Where we now stand. Psychological Bulletin, 94 (2), 293-335.

Hediger, H. (1955). Studies of the Psychology and Behavior of Captive Animals in Zoos and Circuses. Newton, MA: Butterworth's Scientific.

Hendrickson, C. (1986). A note on trends in transit commuting in the United States relating to employment in the central business district. Transportation Research Part A, 20 (1), 33-37.

Hensher, D.A. (2008). Assessing systematic sources of variation in public transport elasticities: Some comparative warnings. Transportation Research Part A, 42, 1031-1042.

Hern, W. (1991). Proxemics: The application of theory to conflict arising from antiabortion demonstrators. Population and Environment: A Journal of Interdisciplinary Studies, 12, 379-388. 
Heshka, S., \& Nelson, Y. (1972). Interpersonal speaking distance as a function of age, sex, and relationship. Sociometry, 35 (4), 491-498.

Holahan, C.J., \& Saegert, S. (1973). Behavioral and attitudinal effects of largescale variation in the physical environment of psychiatric wards. Journal of Abnormal Psychology, 82 (3), 454-462.

Holmgren, J. (2007). Meta-analysis of public transport demand. Transportation Research Part A, 41, 1021-1035.

Hood, C. (1996). Changing perceptions of public spaces on the New York rapid transit system. Journal of Urban History, 22 (3), 308-331.

Hosmer, D.W., \& Lemeshow, S. (1989). Applied Logistic Regression. New York: Wiley.

Ittelson, W.H., Proshansky, H.M., Rivlin, L.G., \& Winkel, G.H. (1974). An Introduction of Environmental Psychology. New York: Holt, Rinehard and Winston, Inc.

Johnson, M.A. (1989). Variables associated with friendship in an adult population. The Journal of Social Psychology, 129 (3), 379-390.

Jung, E.S., Han, S.H., Jung, M., \& Choe, J. (1998). Coach design for the Korean high-speed train: A systematic approach to passenger seat design and layout. Applied Ergonomics, 29, 507-519.

Karlin, R.A., Katz, S., Epstein, Y.M., \& Woolfolk, R.L. (1979). Clinical interventions to reduce the effects of crowding-induced stress. Environmental Psychology and Non-verbal Behavior, 3 (4), 219-227.

Kashdan, T.B., \& Wenzel, A. (2005). A transactional approach to social anxiety and the genesis of interpersonal closeness: Self, partner, and social context. Behavior Therapy, 36, 335-346. 
Katsikitis, M., \& Brebner, J. (1980). Individual differences in the effects of personal space invasion: A test of the brebner-cooper model of extraversion. Personality and Individual Differences, 2, 5-10.

Kenner, A.N., \& Katsimaglis, G. (1993). Gender differences in proxemics: Taxiseat choice. Psychological Reports, 72, 625-626.

Kirmeyer, S.L. (1978). Urban density and pathology: A review of research. Environment and Behavior, 10 (2), 247-269

Kunzendorff, R. and Denney, J. (1982). Definitions of personal space: Smokers versus nonsmokers. Psychological Reports, 5o, 818.

Krizek, K.J., \& El-Geneidy, A. (2007). Segmenting preferences and habits of transit users and non-users. Journal of Public Transportation, 10 (3), 7194 .

Kyte, M., Stoners, J., \& Cryer, J. (1988). A time-series analysis of public transit ridership in Portland, Oregon, 1971-1982. Transportation Research Part A, 22 (5), 34-359.

Langer, E.J. and Saegert, S. (1977). Crowding and cognitive control. Journal of Personality and Social Psychology, 35 (3), 175-182.

Latane, B., \& Nida, S. (1981). Ten years of research on group size and helping behaviour. Psychological Bulletin, 89, 308-334.

Lawrence, J.W., Fauerbach, J.A., Heinberg, L.J., Doctor, M., \& Thombs, B.D. (2006). The reliability and validity of the Perceived Stigmatization Questionnaire (PSQ) and the Social Comfort Questionnaire (SCQ) among an adult burn survivor sample. Psychological Assessment, 18 (1), 106-111.

Ley, D., \& Cybriwsky, R. (1974). The spatial ecology of stripped cars. Environment and Behavior, 6 (1), 53-68. 
Li, S., \& Li, Y. (2007). How far is far enough? A measure of information privacy in terms of interpersonal distance. Environment and Behavior, 39 (3), 317-331.

Liebowitz, M.R. (1987). Social Phobia. Modern Problems of Pharmacopsychiatry, 22, 141-173.

Lill, M.M., \& Willkinson, T.J. (2005). Judging a book by its cover: Descriptive survey of patients' preferences for doctors' appearance and mode of address. British Medical Journal, 331 (7531), 1524-1527.

Lombard, M., Snyder-Duch, J., \& Bracken, C.C. (2008). Practical Resources for Assessing and Reporting Intercoder Reliability in Content Analysis Research Projects. Philadelphia: Temple University. Retrieved, January 16, 2009, from: http://astro.temple.edu/ lombard/reliability/

Long, G.T., Calhoun, L.G., \& Selby, J.W. (1977). Personality characteristics related to cross-situational consistency of interpersonal distance. Journal of Personality Assessment, 41 (3), 274-278.

Long, G.T. (1984). Psychological tension and closeness to others: Stress and interpersonal distance preference. Journal of Psychology: Interdisciplinary and Applied, 117 (1), 143-146.

Lundberg, U. (1976). Urban commuting: Crowdedness and catecholamine excretion. Journal of Human Stress, 2 (3), 26-32.

Macrae, C.N., Bodenhausen, G.V., Milne, A.B., \& Jetten, J. (1994). Out of mind but back in sight: Stereotypes on the rebound. Journal of Personality and Social Psychology, 67 (5), 808-817.

Maines, D.R. (1977). Tactile relationships in the subway as affected by racial, sexual, and crowded seating situations. Environmental Psychology and Nonverbal Behavior, 2 (2), 100-108. 
Maines, D.R. (1979). Ecological and negotiation processes in New York subways. The Journal of Social Psychology, 108, 29-36.

Maslow, A., \& Mintz, N. (1956). Effects of aesthetic surroundings. Journal of Psychology, XLI, 247-254.

McCarthy, D., \& Saegert, S. (1978). Residential density, social overload, and social withdrawal. Human Ecology, 6 (3), 253-272.

McClelland, L., \& Auslander, N. (1978). Perceptions of crowding and pleasantness in public settings. Environment and Behavior, 10, 535-553.

McIlheran, P. (2008, July 18). Commute of the Future? The Bus. The New York Sun. Retrieved January 21, 2009, from: http://www.nysun.com/opinion/commute-of-the-future-the-bus/82185/

McKenzie-Mohr, D. (2000). Promoting sustainable behavior: An introduction to community-based social marketing. Journal of Social Issues, 56 (3), $543-554$.

Merry, B. (2004). Encyclopaedia of Modern Greek Literature. London: Greenwood Publishing Group.

Middlemist, R.D., Knowles, E.S., \& Matter, C.F. (1976). Personal space invasions in the lavatory: Suggestive evidence of arousal. Journal of Personality and Social Psychology, 33 (5), 541-546.

Miles, L., \& Johnston, L. (2007). Detecting happiness: Perceiver sensitivity to enjoyment and non-enjoyment smiles. Journal of Non-verbal Behavior, $31,259-275$.

Milgram, S. (1970). The experience of living in cities. Science, 167 (3924), 14611468. 
Milgram, S. (1977). The Individual in a Social World: Essays and Experiments. Reading, Massachusetts: Addison-Wesley Publishing Company.

Miller, S. (1981). Coping with crowding in an elevator: Staring at the floor numbers is not enough. Environmental Design Research Association, 12 235-240.

Ministry of Transport (2008a). Comparing travel modes. Retrieved October 18, 2008, from:

http://www.transport.govt.nz/assets/NewPDFs/Comparing-travelmodesv1.4.pdf

Ministry of Transport (August 2008b). Government Policy Statement on Land Transport Funding 2009/1O - 2018/19. Wellington: Ministry of Transport. Retrieved October 18, 2008, from:

http://www.transport.govt.nz/assets/Images/NewFolder-2/GPS-final5-August-2008-2.pdf

Mishcel, W. (1969). Continuity and change in personality. American Psychologist, 24, 1012-1018.

Mitchelson, R.L. (1982). The effect of social heterogeneity within urban travel corridors on the travel behavior of residents. Professional Geographer, 34, 185-196.

Moos, R.H., \& Insel, P.M. (1974). Issues in Social Ecology: Human Milieus. California: National Press Books.

Möser, G., \& Bamberg, S. (2008). The effectiveness of soft transport policy measures: A critical assessment and meta-analysis of empirical evidence. Journal of Environmental Psychology, 28, 10-26.

Nash, J.E. (1975). Bus riding: Community of wheels. Urban Life, 4 (1), 99-124. 
Ng, C.F. (2003). Satisfying shoppers' psychological needs: From public market to cyber-mall. Journal of Environmental Psychology, 23, 439-455.

Nicosia, G.J., Hyman, D., Karlin, R.A., Epstein, Y.M., \& Aiello, J.R. (1979). Effects of bodily contact on reactions to crowding. Journal of Applied Social Psychology, 9 (6), 508-523.

Olmstead, D.W., \& Durham, K. (1976). Stability of Mental Health Attitudes: A Semantic Differential Study. Journal of Health and Social Behaviour, 17, $35-44$.

Ory, D.T., \& Mokhtarian, P.L. (2005). When is getting there half the fun? Modeling the liking for travel. Transportation Research Part A, 39, 97123.

Ozdemir, A. (2008). Shopping malls: Measuring interpersonal distance under changing conditions and across cultures. Field Methods, $2 O$ (3), 226-248.

Parolin, B. (1992). The effects of social heterogeneity on travel patterns: A replication study. Socio-Econ. Plann. Sci., 4, 231-239.

Patterson, M.L., Mullens, S., \& Romano, J. (1971). Compensatory reactions to spatial intrusion. Sociometry, 34, 114-121.

Patterson, M.L., \& Sechrest, L.B. (1970). Interpersonal distance and impression formation. Journal of Personality, 38 (2), 161-166.

Paulhus, D.L. (1991). Measurement and control of response bias. In J.P. Robinson, P.R. Shaver, \& L.S. Wrightman (Eds.) Measures of Personality and Social Psychological Attitudes.

Paulley, N., Balcombe, R., Mackett, R., Titheridge, H., Preston, J., Wardman, M., et al. (2006). The demand for public transport: The effects of fares, quality of service, income and car ownership. Transport Policy, 13, 295306. 
Paulos, E., \& Goodman, E. (2004). The Familiar Stranger: Anxiety, Comfort and Play in Public Places. Berkley, California: Intel Research. Retrieved July 25, 2008, from:

http://www.paulos.net/papers/2004/Familiar\%20Stranger\%2O(CHI\%2 o2004).pdf

Pennington, D.C. (2000). Social cognition. New York: Psychology Press.

Proshansky, H.M., Ittelson, W.H., \& Rivlin, L.G. (1976). Environmental psychology: People and their physical settings ( $\left.2^{\text {nd }} E d\right)$. Oxford, England: Holt.

Raggatt, P.T.F., \& Morrissey, S.A. (1997). A field study of stress and fatigue in long-distance bus drivers. Behavioral Medicine, 23 (3), 122-127.

Remland, M.S., Jones, T.S., \& Brinkman, H. (1995). Interpersonal distance, body orientation, and touch: Effects of culture, gender, and age. The Journal of Social Psychology, 135 (3), 281-297.

Richards, L.G., Jacobson, I.D., \& Kuhlthau, A.R. (1978). What the passenger contributes to passenger comfort. Applied Ergonomics, 9 (3), 137-142.

Rodin, J., Solomon, S., \& Metacif, J. (1978). Role of control in mediating perceptions of density. Journal of Personality and Social Psychology, 36 (9), 988-999.

Saegart, S. (1976). Stress-inducing and Reducing Qualities of Environments. In H.M. Proshansky, W.H. Ittelson \& L.G. Rivlin (Eds.), Environmental Psychology: People and their Physical Settings. New York: Hold, Rinehard and Winston.

Saegert, S., Swap, W., \& Zajonc, R.B. (1973). Exposure, context, and interpersonal attraction. Journal of Personality and Social Psychology, 25 (2), 234-242. 
Segal, M.W. (1974). Alphabet and attraction: An unobtrusive measure of the effect of propinquity in a field setting. Journal of Personality and Social Psychology, 30, 654-657.

Schwab, A.J. (2007). Logistic Regression: Complete Problems. Austin: University of Texas. Retrieved July 25, 2008, from: www.utexas.edu/courses/schwab/sw388r7/SolvingProblems/LogisticRe gression CompleteProblems.ppt

Schwartz, S.H. (1992). Universals in the content and structure of values theoretical advances and empirical tests in 20 countries. Advances in Experimental Social Psychology, 25, 1-65.

Sherer, S.E. (1974). Influence of proximity and eye contact on impression formation. Perceptual and Motor Skills, 38, 538-538.

Sherrod, D.R., Armstrong, D., Hewitt, J., Madonia, B., Speno, S., \& Teruya, D. (1977). Environmental attention, affect, and altruism. Journal of Applied Social Psychology, 7 (4), 359-371.

Shrady, T. (1993). The romance of the past: An image worth keeping. Passenger Train Journal, 24 (5), 40-41.

Siegfried, W.D., Tedeschi, R.G., \& Cann, A. (1982). How current users of public transit determine its attractiveness to others. Psychological Reports, 50, 1173-1174.

Singer, J.E., Lundberg, U., \& Frankenhaeuser, M. (1978). Stress on the train: A study of urban commuting. In A. Baum, J.E. Singer \& S. Valins (Eds), Advances in Environmental Psychology, Volume 1: The Urban Envrionment (pp. 41-56). New Jersey: Lawrence Erlbaum Associates.

Sommer, R. (1969). Personal Space: The Behavioral Basis of Design. Englewood Cliffs, NJ: Prentice Hall. 
Smith, R., \& Knowles, E. (1978). Attributional consequences of personal space invasions. Personality \& Social Psychology Bulletin, 4, 429-433.

Smith, R.J., \& Knowles, E.S. (1979). Affective and cognitive mediators of reactions to spatial invasions. Journal of Experimental Social Psychology, $15,437-452$.

Smith, T.E. (1997). Adolescent gender differences in time alone and time devoted to conversation. Adolescence, 32 (126), 483-496.

Statistics New Zealand (2008a). Household Economic Survey. Retrieved October 18, 2008, from: http://www.stats.govt.nz/products-andservices/hot-off-the-press/household-economic-survey/householdeconomic-survey-income-juno8year-hotp.htm?page=paraoo2Master

Statistics New Zealand (2008b). Glossary term meshblock. Retrieved February 23, 2008, from:

http://www2.stats.govt.nz/domino/external/omni/omni.nsf/wwwglsry/ Meshblock

Statistics New Zealand (2008c). Quickstats National Highlights. Retrieved February 23, 2008, from http://www.stats.govt.nz/census/2006-censusdata/national-highlights/2006-census-quickstats-national-highlightsrevised.htm?page=paraoo4Master

Stradling, S., Carreno, M., Rye, T., \& Noble, A. (2007). Passenger perceptions and the ideal urban bus journey experience. Transport Policy, 14, 283-292.

Strube, M. \& Werner, C. (1983). Interpersonal distance and personal space: A conceptual methodological note. Journal of Nonverbal Behavior, 6, 163170. 
Strube, M. \& Werner, C. (1983). Personal space claims a function of interpersonal threat: The mediating role of need for control. Journal of Nonverbal Behavior, 8, 195-209.

Sundstrom, E. (1975). An experimental study of crowding, effects of room size, intrusion and goal blocking on nonverbal behavior, self-disclosure and self-reported stress. Journal of Personality and Social Psychology, 32, $645-655$.

Thompson, D., Aiello, J. \& Epstein, Y. (1979). Interpersonal distance preferences. Journal of Nonverbal Behavior, 4, 113-118.

Tripathi, N. (2002). Seating preference and seat placement as indicators of privacy preference. Psychological Studies, 47 (1-3), 129-138.

Walton, D., Dravitzki, V and Donn, M. (2007). The relative influence of wind, sun and temperature on comfort in outdoor urban settings. Building and Environment, 42 (9), 3166-3175.

Walton, D., Murray, S.J., \& Thomas, J.A. (Under review). Attitudes towards public transport in New Zealand. Transportation.

Walton, D., Thomas, J. \& Dravitzki, V. (2003). Commuters concern for the environment and knowledge of the effects of vehicle emissions.

Transportation Research Part D. Transport and the Environment, 9, 335340 .

Wardman, M., \& Whelan, G. (2001). Valuation of improved railway rolling stock: A review of the literature and new evidence. Transport Reviews 21 (4), 415-447.

Webb, J.D., \& Weber, M.J. (2003). Influence of sensory abilities on the interpersonal distance of the elderly. Environment and Behavior, 35 (5), 695-711. 
Wener, R.W., Evans, G.W., \& Boately, P. (2005). Commuting stress:

Psychophysiological effects of a trip and spillover into the workplace. Transportation Research Record, 1924, 112-117.

Wener, R.E., Evans, G.W., Phillips, D., \& Nadler, N. (2003). Running for the 7:45: The effects of public transit improvements on commuter stress. Transportation 30, 203-220.

Willis, F.N. (1966). Initial speaking distance as a function of the speakers' relationship. Psychonomic Science, 5 (6), 221-222.

Wilson, M.S., \& Bryson, K. (2004). A 20-year follow-up of a 20-year follow-up: Changes in attitudes to mental illness since the 1960s. Annual conference of the New Zealand Psychological Society, August 2004. Wellington, New Zealand.

Winett, R.A., Cleaveland, B.L., Tate, D.F., Lombard, D.N., Lombard, T.N., Russ, C.R., \& Galper, D. (1997). The Effects of the Safe-sun Program on Patrons' and Lifeguards' Skin CancerRisk-reduction Behaviors at Swimming Pools. Journal of Health Psychology, 2, 85-95.

Witten, K., McCreanor, T., \& Rose, E. (2006). Travel Behaviour, Experience and Choices of Aucklanders: A Qualitative Investigation. Auckland, New Zealand: Shore.

Yammarino, F.J., Skinner, S.J., \& Childers, T.L. (1991). Understanding mail survey response behavior: A meta-analysis. Public Opinion Quarterly, 55 (4), 613-639.

Yancey, W.L. (1971). Architecture, interaction and social control: The case of a large-scale public housing project. Environment and Behavior, 3, 3-18.

Zubeidat, I., Salinas, J.M., \& Sierra, J.C. (2008). Exploration of the psychometric characteristics of the Liebowitz social anxiety scale in a Spanish adolescent sample. Depression and Anxiety, 25, 977-987.

Zurcher, L. (1979). The airplane passenger. Qualitative Sociology, 1 (3), 77-99. 


\section{APPENDICES}




\section{Appendix A: Exploratory Questionnaire}

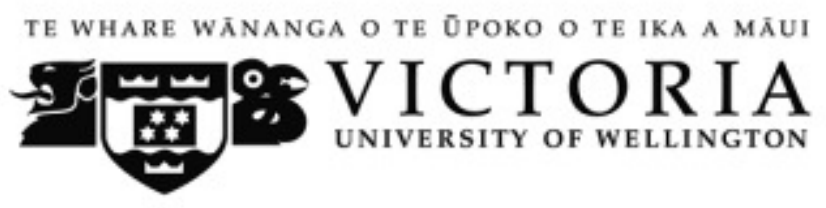

\section{Public Transport Questionnaire}

The purpose of this research is to examine your attitudes and behaviour conceming buses and trains. We are interested in your opinion even if you only very rarely take public transport.

1. What is your main weekly activity that would require you to travel [You can think of your main activity as the one that takes up the greatest amount of your time away from home each week. Please tick only one box to indicate your main activity]

\begin{tabular}{l|l|l|l|l}
$\square$ Work & $\square$ Education & $\square$ shopping & $\square$ Social/ Recreation & $\square$ Other...
\end{tabular}

2. What do you primarily use to travel to your main weekly activity? [If you regularly use several types of travel to get to your main activity then select the one that covers the larger part of the distance. Please tick only one box to indicate your main travel type]

\begin{tabular}{|c|c|c|c|c|c|}
\hline$\square$ Motor vehicle & $\square$ Bus & $\square$ Train & $\square$ cycling & $\square$ walking & $\square$ other.. \\
\hline
\end{tabular}

3. Please estimate the distance (in $\mathrm{km}$ ) from your house to your main weekly activity [We realise this may be difficult to estimate, your best guess is fine]

\begin{tabular}{l|l|l|l|l|l|l|l}
$\square 0-1 \mathrm{~km}$ & $\square 1-5 \mathrm{~km}$ & $\square 5-10 \mathrm{~km}$ & $\square 10-15 \mathrm{~km}$ & $\square 15-20 \mathrm{~km}$ & $\square 20-25 \mathrm{~km}$ & $\square 25-30 \mathrm{~km}$ & $\square 30 \mathrm{~km}+$ \\
\hline
\end{tabular}

4. Please estimate the time it takes you to travel from your house to your main weekly activity [We realise this may be difficult to estimate, your best guess is fine]

\begin{tabular}{|c|c|c|c|c|c|c|c|}
\hline$\square 0-5$ mins & $\begin{array}{c}\square \text { 5-10 } \\
\text { mins }\end{array}$ & $\begin{array}{c}\square \text { mins } \\
\text { mins }\end{array}$ & $\begin{array}{c}\square \text { mins } \\
\text { mins }\end{array}$ & $\begin{array}{c}\square \text { mins } \\
\text { min-30 }\end{array}$ & $\begin{array}{c}\square \text { mins } \\
\text { mins }\end{array}$ & $\begin{array}{c}\square \text { mins } \\
\text { mins }\end{array}$ & $\square$ 60mins+ \\
\hline
\end{tabular}

\begin{tabular}{|l|c|c|c|c|c|}
\hline $\begin{array}{l}\text { Crowded public places } \\
\text { [please tick the box that best describes your level of } \\
\text { agreement] }\end{array}$ & $\begin{array}{l}\text { Strongly } \\
\text { disagree }\end{array}$ & Disagree & $\begin{array}{c}\text { Not sure/ } \\
\text { Neutral }\end{array}$ & Agree & $\begin{array}{c}\text { Strongly } \\
\text { agree }\end{array}$ \\
\hline $\begin{array}{l}\text { 5. When I visit the beach I would prefer to walk an extra 5 } \\
\text { minutes to find a spot away from other people }\end{array}$ & $\square$ & $\square$ & $\square$ & $\square$ & $\square$ \\
\hline $\begin{array}{l}\text { 6. I would rather share a small park bench with a stranger } \\
\text { than sit on the grass }\end{array}$ & $\square$ & $\square$ & $\square$ & $\square$ & $\square$ \\
\hline 7. I would rather take a crowded elevator than use the stairs & $\square$ & $\square$ & $\square$ & $\square$ & $\square$ \\
\hline 8. I prefer to go shopping at "off-peak" times to avoid crowds & $\square$ & $\square$ & $\square$ & $\square$ & $\square$ \\
\hline $\begin{array}{l}\text { 9. I would rather sit pushed up next to another passenger so } \\
\text { that they were touching me than stand when taking the bus } \\
\text { or train }\end{array}$ & $\square$ & $\square$ & $\square$ & $\square$ & $\square$ \\
\hline $\begin{array}{l}\text { 10. I would rather use a crowded bus shelter than stand out in } \\
\text { the cold wind }\end{array}$ & $\square$ & $\square$ & $\square$ & $\square$ & $\square$ \\
\hline \begin{tabular}{l} 
11. I Iike having lots of people around when I am out and about \\
\hline
\end{tabular} & $\square$ & $\square$ & $\square$ & $\square$ & $\square$ \\
\hline
\end{tabular}




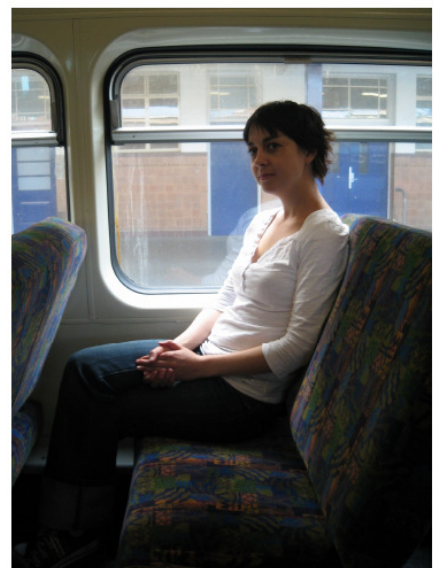

Figure 1.

Please examine the person and seating location in Figure 1 (above left) when responding to the following items:

12. The person in Figure $\mathbf{1}$ looks comfortable

13. I would feel comfortable sitting in the seat beside the person in Figure 1

14. I would feel comfortable talking to the person in Figure 1

15. Just from first appearances, I believe the person in Figure 1 would get on well with my friends

16. Do you know the person in Figure 1 above?

Please examine the person and seating location in Figure 2 (above right) when responding to the following items:

\section{The person in Figure 2 looks comfortable}

18. I would feel comfortable sitting in the seat beside the person in Figure 2

19. I would feel comfortable talking to the person in Figure 2

20. Just from first appearances, I believe the person in Figure 2 would get on well with my friends

21. Do you know the person in Figure 2 above?

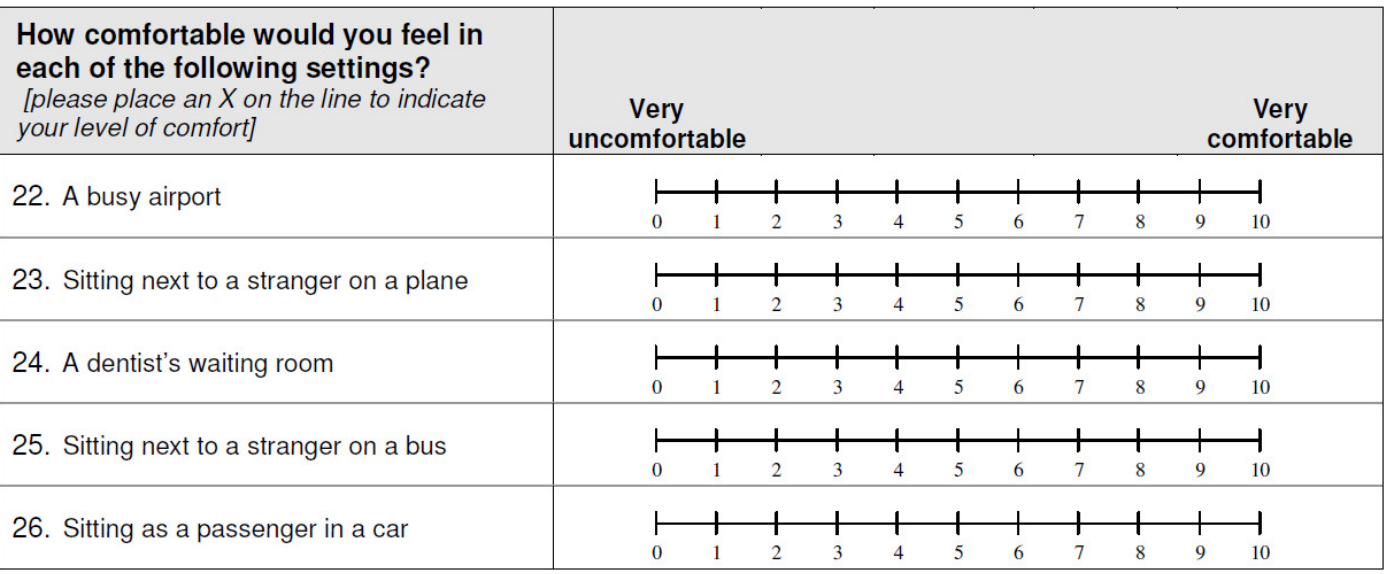




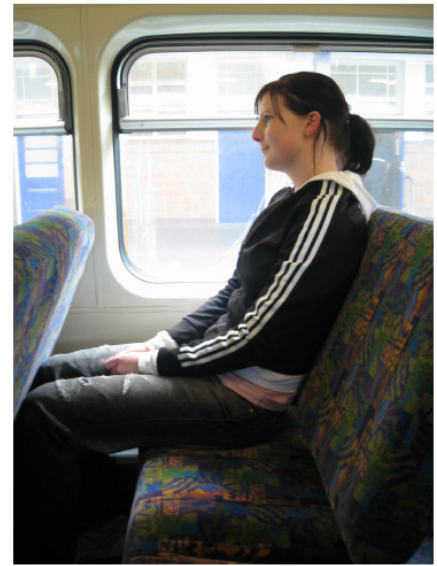

Figure 3.

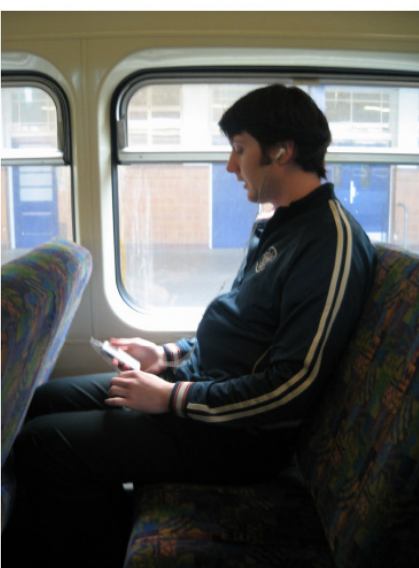

Figure 4.

Please examine the person and seating location in Figure 3 (above left) when responding to the following items:

27. The person in Figure 3 looks comfortable

28. I would feel comfortable sitting in the seat beside the person in Figure 3

29. I would feel comfortable talking to the person in Figure 3

30. Just from first appearances, I believe the person in Figure 3 would get on well with my friends

31. Do you know the person in Figure 3 above?

Please examine the person and seating location in Figure 4 (above right) when responding to the following items:

32. The person in Figure 4 looks comfortable

33. I would feel comfortable sitting in the seat beside the person in Figure 4

34. I would feel comfortable talking to the person in Figure 4

35. Just from first appearances, I believe the person in Figure 4 would get on well with my friends

36. Do you know the person in Figure 4 above?

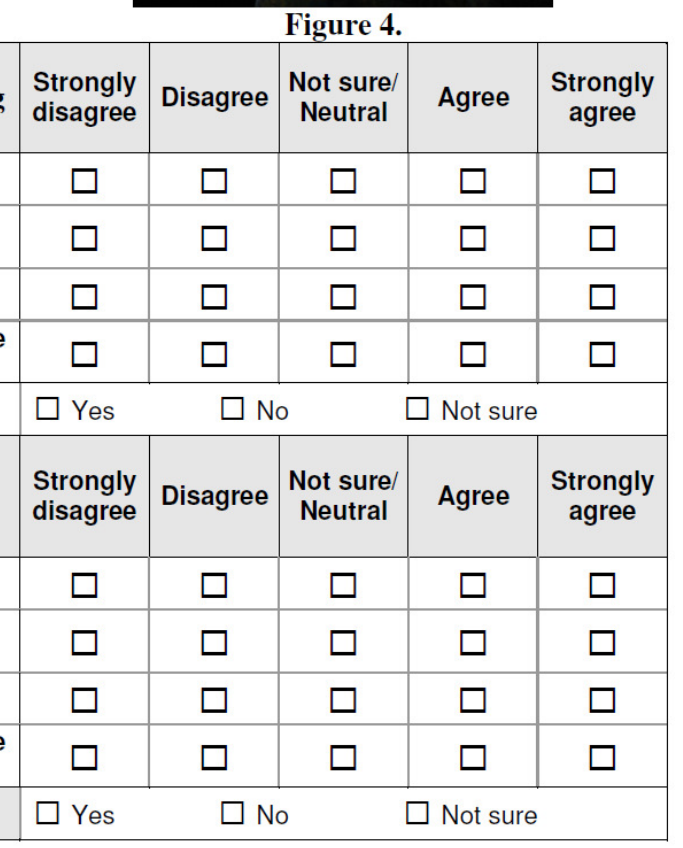

\begin{tabular}{|c|c|c|c|c|c|c|c|c|c|}
\hline $\begin{array}{l}\text { Please think about the likelihood of } \\
\text { the following activities happening on } \\
\text { public transport } \\
\text { [place an X on the line to indicate the } \\
\text { likelihood] }\end{array}$ & Very unlikely & & & & & & & & Very likely \\
\hline \multirow{2}{*}{$\begin{array}{l}\text { 37. Passengers thanking the bus driver as } \\
\text { they leave the bus }\end{array}$} & & & & & & & & & + \\
\hline & 1 & 2 & 3 & 4 & 5 & 6 & 7 & 8 & 10 \\
\hline \multirow{2}{*}{$\begin{array}{l}\text { 38. A passenger offering their seat to an } \\
\text { elderly person or someone that may have } \\
\text { trouble standing }\end{array}$} & & & & & & & & & \\
\hline & 1 & 2 & 3 & 4 & 5 & 6 & 7 & 8 & 10 \\
\hline \multirow{2}{*}{$\begin{array}{l}\text { 39. Passengers acknowledging the person } \\
\text { they sit next to by making eye contact or } \\
\text { saying hello }\end{array}$} & & & & & & & & & \\
\hline & 1 & 2 & 3 & 4 & 5 & 6 & 7 & 8 & 10 \\
\hline \multirow{2}{*}{$\begin{array}{l}\text { 40. Passengers taking up more space than } \\
\text { they need }\end{array}$} & & & & & & + & & & + \\
\hline & 1 & 2 & 3 & 4 & 5 & 6 & 7 & 8 & 10 \\
\hline \multirow{2}{*}{$\begin{array}{l}\text { 41. Passengers apologising when they } \\
\text { accidentally touch a stranger }\end{array}$} & & & & & & & & & \\
\hline & & 2 & 3 & 4 & 5 & 6 & 7 & 8 & 10 \\
\hline
\end{tabular}




\begin{tabular}{|l|c|c|c|c|c|}
\hline $\begin{array}{l}\text { Please think about where you choose to sit when } \\
\text { you use buses or trains and there are plenty of } \\
\text { available seats } \\
\text { [please tick the box that best describes your level of } \\
\text { agreement] }\end{array}$ & $\begin{array}{c}\text { Strongly } \\
\text { disagree }\end{array}$ & Disagree & $\begin{array}{c}\text { Not sure/ } \\
\text { Neutral }\end{array}$ & Agree & $\begin{array}{c}\text { Strongly } \\
\text { agree }\end{array}$ \\
\hline 42. I like to sit beside other passengers & $\square$ & $\square$ & $\square$ & $\square$ & $\square$ \\
\hline 43. I prefer a window seat & $\square$ & $\square$ & $\square$ & $\square$ & $\square$ \\
\hline 44. I always choose a seat with a good view & $\square$ & $\square$ & $\square$ & $\square$ & $\square$ \\
\hline 45. I like seats that face other passengers & $\square$ & $\square$ & $\square$ & $\square$ & $\square$ \\
\hline $\begin{array}{l}\text { 46. I choose the seat that will give me the most space to } \\
\text { spread out my gear and give me enough leg space }\end{array}$ & $\square$ & $\square$ & $\square$ & $\square$ & $\square$ \\
\hline 47. I really don't care where I sit & $\square$ & $\square$ & $\square$ & $\square$ & $\square$ \\
\hline $\begin{array}{l}\text { 48. I select a seat as far away from other passengers as } \\
\text { possible }\end{array}$ & $\square$ & $\square$ & $\square$ & $\square$ & $\square$ \\
\hline 49. I like to sit by the door for a quick exit & $\square$ & $\square$ & $\square$ & $\square$ & $\square$ \\
\hline
\end{tabular}

\begin{tabular}{|c|c|c|c|c|c|}
\hline $\begin{array}{l}\text { Please think about where whom you choose to sit } \\
\text { beside when you use buses or trains that are } \\
\text { crowded and you have to sit next to another person } \\
\text { [please tick the box that best describes your level of } \\
\text { agreement] }\end{array}$ & $\begin{array}{l}\text { Strongly } \\
\text { disagree }\end{array}$ & Disagree & $\begin{array}{c}\text { Not sure/ } \\
\text { Neutral }\end{array}$ & Agree & $\begin{array}{c}\text { Strongly } \\
\text { agree }\end{array}$ \\
\hline $\begin{array}{l}\text { 50. If I have to sit next to another passenger, I sit next to } \\
\text { someone of the same gender }\end{array}$ & $\square$ & $\square$ & $\square$ & $\square$ & $\square$ \\
\hline $\begin{array}{l}\text { 51. The person I sit next to has no influence on my decision to } \\
\text { sit there }\end{array}$ & $\square$ & $\square$ & $\square$ & $\square$ & $\square$ \\
\hline $\begin{array}{l}\text { 52. I like sitting next to someone l've never met before on } \\
\text { public transport }\end{array}$ & $\square$ & $\square$ & $\square$ & $\square$ & $\square$ \\
\hline 53. I prefer to sit next to someone about the same age as me & $\square$ & $\square$ & $\square$ & $\square$ & $\square$ \\
\hline 54. I dislike sitting next to school kids and teenagers & $\square$ & $\square$ & $\square$ & $\square$ & $\square$ \\
\hline $\begin{array}{l}\text { 55. I sit next to people that are already busy with an activity, } \\
\text { such as reading or listening to music }\end{array}$ & $\square$ & $\square$ & $\square$ & $\square$ & $\square$ \\
\hline
\end{tabular}

\begin{tabular}{|l|c|c|c|c|c|}
\hline $\begin{array}{l}\text { Once seated on public transport } \\
\text { [please tick the box that best describes your level of } \\
\text { agreement] }\end{array}$ & $\begin{array}{c}\text { Strongly } \\
\text { disagree }\end{array}$ & Disagree & $\begin{array}{c}\text { Not sure/ } \\
\text { Neutral }\end{array}$ & Agree $\begin{array}{c}\text { Strongly } \\
\text { agree }\end{array}$ \\
\hline 56. I like to spread out so no one will sit next to me & $\square$ & $\square$ & $\square$ & $\square$ & $\square$ \\
\hline $\begin{array}{l}\text { 57. I like to perform activities such as read and listen to music } \\
\text { so other passengers wont talk to me }\end{array}$ & $\square$ & $\square$ & $\square$ & $\square$ & $\square$ \\
\hline \begin{tabular}{l} 
58. I like it when another passenger chooses to sit beside me \\
\hline $\begin{array}{l}\text { 59. I avoid the eye contact of boarding passengers in the hope } \\
\text { that they wont sit next to me }\end{array}$
\end{tabular}$\quad \square$ & $\square$ & $\square$ & $\square$ & $\square$ \\
\hline $\begin{array}{l}\text { 60. I leave the window seat open and sit in the aisle seat to } \\
\text { avoid sitting beside other passengers }\end{array}$ & $\square$ & $\square$ & $\square$ & $\square$ & $\square$ \\
\hline \begin{tabular}{l} 
61. I always leave room for other passengers to sit next to me \\
\hline
\end{tabular} & $\square$ & $\square$ & $\square$ & $\square$ & $\square$ \\
\hline
\end{tabular}




\begin{tabular}{|l|c|c|c|c|c|}
\hline $\begin{array}{l}\text { Now we would like to know how often you feel } \\
\text { or think in certain ways. Rate how often you } \\
\text { feel or think the statements below. } \\
\text { [please tick the box that best describes your level of } \\
\text { agreement] }\end{array}$ & Never & $\begin{array}{c}\text { Almost } \\
\text { never }\end{array}$ & Sometimes & Often & Always \\
\hline 62. I feel like I fit in with most groups & $\square$ & $\square$ & $\square$ & $\square$ & $\square$ \\
\hline 63. No one can understand me & $\square$ & $\square$ & $\square$ & $\square$ & $\square$ \\
\hline 64. I would rather be by myself than with other people & $\square$ & $\square$ & $\square$ & $\square$ & $\square$ \\
\hline 65. I like meeting new people & $\square$ & $\square$ & $\square$ & $\square$ & $\square$ \\
\hline 66. It is easy for me to talk to other people my age & $\square$ & $\square$ & $\square$ & $\square$ & $\square$ \\
\hline 67. I feel comfortable in a crowd & $\square$ & $\square$ & $\square$ & $\square$ & $\square$ \\
\hline 68. I feel like I don't fit in with other people & $\square$ & $\square$ & $\square$ & $\square$ & $\square$ \\
\hline 69. It is easy for me to blend in with other people & $\square$ & $\square$ & $\square$ & $\square$ & $\square$ \\
\hline
\end{tabular}

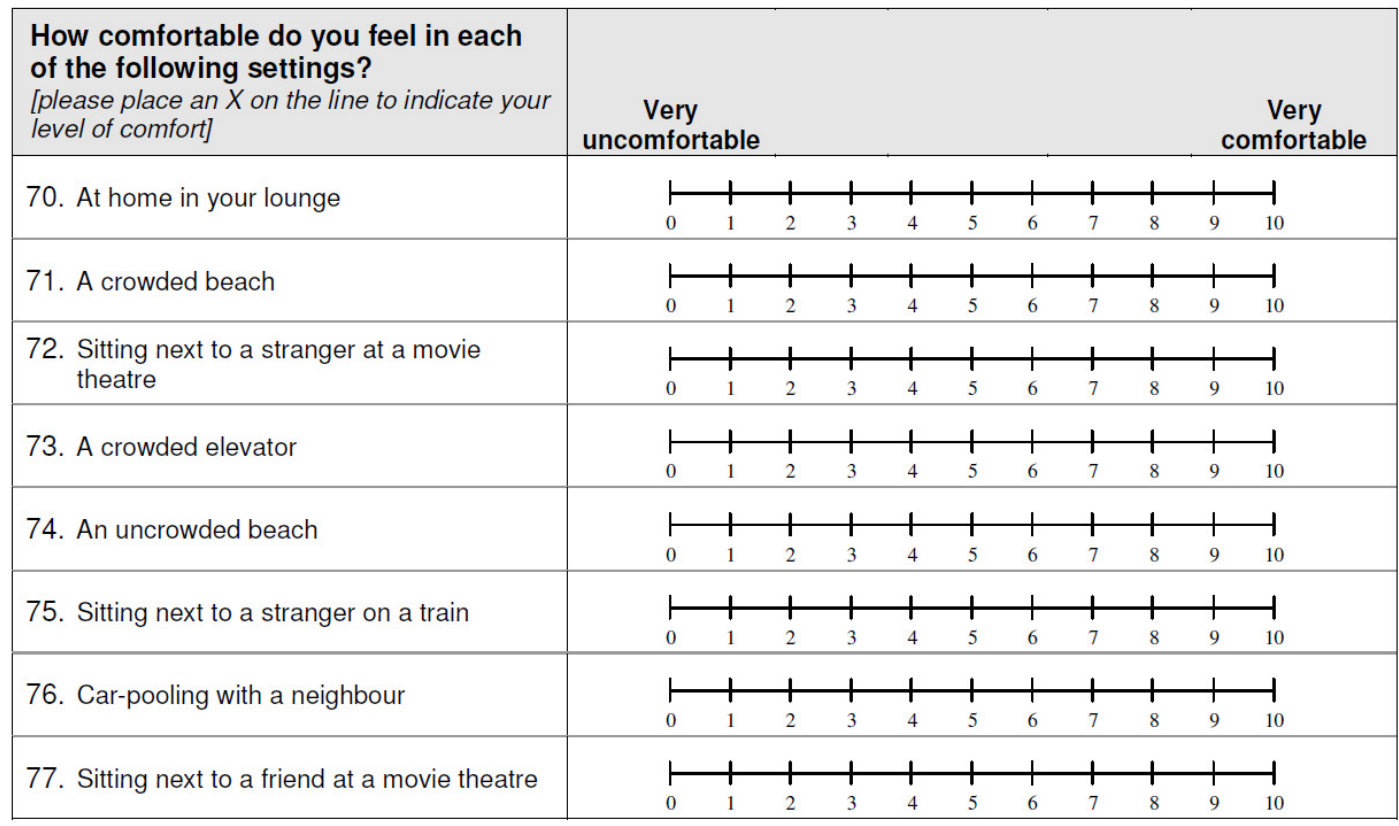

Listed below are many situations in which people may become nervous or tense about interacting with others, especially when they are around people they do not know well. Some people avoid such situations because they know they will get nervous.

\begin{tabular}{|l|c|c|c|c|}
\hline $\begin{array}{l}\text { Please indicate how much each of these situations would usually } \\
\text { make you nervous or embarrassed or how much you try to avoid } \\
\text { such situations. }\end{array}$ & $\begin{array}{c}\text { Not at } \\
\text { all }\end{array}$ & $\begin{array}{c}\text { Just a } \\
\text { little }\end{array}$ & $\begin{array}{c}\text { Pretty } \\
\text { much }\end{array}$ & $\begin{array}{c}\text { Very } \\
\text { much }\end{array}$ \\
\hline $\begin{array}{l}78 . \quad \text { I do not like answering the telephone when I don't know who is } \\
\text { calling. }\end{array}$ & $\square$ & $\square$ & $\square$ & $\square$ \\
\hline $79 . \quad$ I do not like participating in small group activities. & $\square$ & $\square$ & $\square$ & $\square$ \\
\hline $80 . \quad$ I do not like eating in restaurants with a lot of strangers present. & $\square$ & $\square$ & $\square$ & $\square$ \\
\hline $81 . \quad \begin{array}{l}\text { Ido not like drinking in restaurants or bars with a lot of strangers } \\
\text { present. }\end{array}$ & $\square$ & $\square$ & $\square$ & $\square$ \\
\hline
\end{tabular}




\begin{tabular}{|c|c|c|c|c|}
\hline $\begin{array}{l}\text { Please indicate how much each of these situations would usually } \\
\text { make you nervous or embarrassed or how much you try to avoid } \\
\text { such situations. }\end{array}$ & $\begin{array}{l}\text { Not at } \\
\text { all }\end{array}$ & $\begin{array}{l}\text { Just a } \\
\text { little }\end{array}$ & $\begin{array}{l}\text { Pretty } \\
\text { much }\end{array}$ & $\begin{array}{l}\text { Very } \\
\text { much }\end{array}$ \\
\hline $\begin{array}{l}\text { 82. I do not like talking to police, doctors, or other members of authority } \\
\text { that I don't know well. }\end{array}$ & $\square$ & $\square$ & $\square$ & $\square$ \\
\hline 83. I am uncomfortable standing up in front of others to talk & $\square$ & $\square$ & $\square$ & $\square$ \\
\hline 84. I do not like to go to a party where I won't know everyone. & $\square$ & $\square$ & $\square$ & $\square$ \\
\hline 85. I do not like to work while others are watching. & $\square$ & $\square$ & $\square$ & $\square$ \\
\hline 86. I do not like to write while others are watching. & $\square$ & $\square$ & $\square$ & $\square$ \\
\hline 87. I do not like to call someone I don't know very well. & $\square$ & $\square$ & $\square$ & $\square$ \\
\hline 88. I do not like to talk with someone I don't know very well. & $\square$ & $\square$ & $\square$ & $\square$ \\
\hline 89. I am uncomfortable meeting strangers. & $\square$ & $\square$ & $\square$ & $\square$ \\
\hline 90. I am uncomfortable meeting strangers my own age. & $\square$ & $\square$ & $\square$ & $\square$ \\
\hline 91. I do not like to use a public bathroom when others are present. & $\square$ & $\square$ & $\square$ & $\square$ \\
\hline $\begin{array}{l}\text { 92. I am uncomfortable entering a room when others are seated and will } \\
\text { notice me. }\end{array}$ & $\square$ & $\square$ & $\square$ & $\square$ \\
\hline 93. I do not like to be the centre of attention in a group in public. & $\square$ & $\square$ & $\square$ & $\square$ \\
\hline 94. I do not like to speak up when in a group meeting. & $\square$ & $\square$ & $\square$ & $\square$ \\
\hline 95. I am uncomfortable taking a test or being evaluated for performance. & $\square$ & $\square$ & $\square$ & $\square$ \\
\hline $\begin{array}{l}\text { 96. I do not like to express a disagreement to someone I don't know very } \\
\text { well. }\end{array}$ & $\square$ & $\square$ & $\square$ & $\square$ \\
\hline $\begin{array}{l}\text { 97. I am uncomfortable looking at people I don't know very well in the } \\
\text { eyes. }\end{array}$ & $\square$ & $\square$ & $\square$ & $\square$ \\
\hline 98. I do not like to present a report or give a speech. & $\square$ & $\square$ & $\square$ & $\square$ \\
\hline $\begin{array}{l}\text { 99. I am uncomfortable approaching someone I don't know to make new } \\
\text { friends. }\end{array}$ & $\square$ & $\square$ & $\square$ & $\square$ \\
\hline 100. I am uncomfortable talking to someone attractive of the opposite sex. & $\square$ & $\square$ & $\square$ & $\square$ \\
\hline $\begin{array}{l}\text { 101. I am uncomfortable returning something I have borrowed or bought } \\
\text { (e.g. overdue library books or returning goods to stores) }\end{array}$ & $\square$ & $\square$ & $\square$ & $\square$ \\
\hline $\begin{array}{l}\text { 102. I do not like to throw a party (including organizing and inviting } \\
\text { others). }\end{array}$ & $\square$ & $\square$ & $\square$ & $\square$ \\
\hline $\begin{array}{l}\text { 103. I am uncomfortable resisting pressure and saying no when someone } \\
\text { is urging me to do something. }\end{array}$ & $\square$ & $\square$ & $\square$ & $\square$ \\
\hline
\end{tabular}

\begin{tabular}{|c|c|c|c|c|c|}
\hline $\begin{array}{l}\text { Touch scale: Please indicate how you feel about } \\
\text { touching other people and being touched. } \\
\text { [tick the box that best describes your level of agreement] }\end{array}$ & $\begin{array}{l}\text { Strongly } \\
\text { disagree }\end{array}$ & Disagree & $\begin{array}{c}\text { Not sure/ } \\
\text { Neutral }\end{array}$ & Agree & $\begin{array}{l}\text { Strongly } \\
\text { agree }\end{array}$ \\
\hline 104. A hug from a same-sex friend is a true sign of friendship & $\square$ & $\square$ & $\square$ & $\square$ & $\square$ \\
\hline 105. Opposite-sex friends enjoy it when I touch them & $\square$ & $\square$ & $\square$ & $\square$ & $\square$ \\
\hline 106. I often put my arm around friends of the same sex & $\square$ & $\square$ & $\square$ & $\square$ & $\square$ \\
\hline $\begin{array}{l}\text { 107. When I see two friends of the same sex hugging, it } \\
\text { revolts me }\end{array}$ & $\square$ & $\square$ & $\square$ & $\square$ & $\square$ \\
\hline 108. I like it when members of the opposite sex touch me & $\square$ & $\square$ & $\square$ & $\square$ & $\square$ \\
\hline $\begin{array}{l}\text { 109. People shouldn't be so uptight about touching persons of } \\
\text { the same sex }\end{array}$ & $\square$ & $\square$ & $\square$ & $\square$ & $\square$ \\
\hline $\begin{array}{l}\text { 110. I think it is vulgar when members of the opposite sex } \\
\text { touch me }\end{array}$ & $\square$ & $\square$ & $\square$ & $\square$ & $\square$ \\
\hline
\end{tabular}




\begin{tabular}{|l|c|c|c|c|c|}
\hline $\begin{array}{l}\text { Touch scale: Please indicate how you feel about } \\
\text { touching other people and being touched. } \\
\text { [tick the box that best describes your level of agreement] }\end{array}$ & $\begin{array}{l}\text { Strongly } \\
\text { disagree }\end{array}$ & Disagree & $\begin{array}{c}\text { Not sure/ } \\
\text { Neutral }\end{array}$ & Agree & $\begin{array}{c}\text { Strongly } \\
\text { agree }\end{array}$ \\
\hline $\begin{array}{l}\text { 111. When a member of the opposite sex touches me, I find it } \\
\text { unpleasant }\end{array}$ & $\square$ & $\square$ & $\square$ & $\square$ & $\square$ \\
\hline $\begin{array}{l}\text { 112. I wish I were free to show emotions by touching } \\
\text { members of same sex }\end{array}$ & $\square$ & $\square$ & $\square$ & $\square$ & $\square$ \\
\hline 113. I'd enjoy giving a massage to an opposite-sex friend & $\square$ & $\square$ & $\square$ & $\square$ & $\square$ \\
\hline 114. I enjoy kissing a person of the same sex & $\square$ & $\square$ & $\square$ & $\square$ & $\square$ \\
\hline 115. I like to touch friends that are the same sex as I am & $\square$ & $\square$ & $\square$ & $\square$ & $\square$ \\
\hline $\begin{array}{l}\text { 116. Touching a friend of the same sex does not make me } \\
\text { uncomfortable }\end{array}$ & $\square$ & $\square$ & $\square$ & $\square$ & $\square$ \\
\hline 117. I find it enjoyable when my date and I embrace & $\square$ & $\square$ & $\square$ & $\square$ & $\square$ \\
\hline $\begin{array}{l}\text { 118. I enjoy getting a back rub from a member of the opposite } \\
\text { sex }\end{array}$ & $\square$ & $\square$ & $\square$ & $\square$ & $\square$ \\
\hline 119. I dislike kissing relatives of the same sex & $\square$ & $\square$ & $\square$ & $\square$ & $\square$ \\
\hline $\begin{array}{l}\text { 120. Intimate touching with members of the opposite sex is } \\
\text { pleasurable }\end{array}$ & $\square$ & $\square$ & $\square$ & $\square$ & $\square$ \\
\hline $\begin{array}{l}\text { 121. I find it difficult to be touched by a member of my own } \\
\text { sex }\end{array}$ & $\square$ & $\square$ & $\square$ & $\square$ & $\square$ \\
\hline
\end{tabular}

\section{Personality}

The following phrases describe people's behaviours. Please rate how accurately each statement describes you. Describe yourself as you generally are now, not as you wish to be in the future. Describe yourself as you honestly see yourself, in relation to other people you know of the same gender as you are, and roughly your same age. So that you can describe yourself in an honest manner, your responses will be kept in absolute confidence. Please read each statement carefully, and then circle the number that best describes the accuracy of each statement.

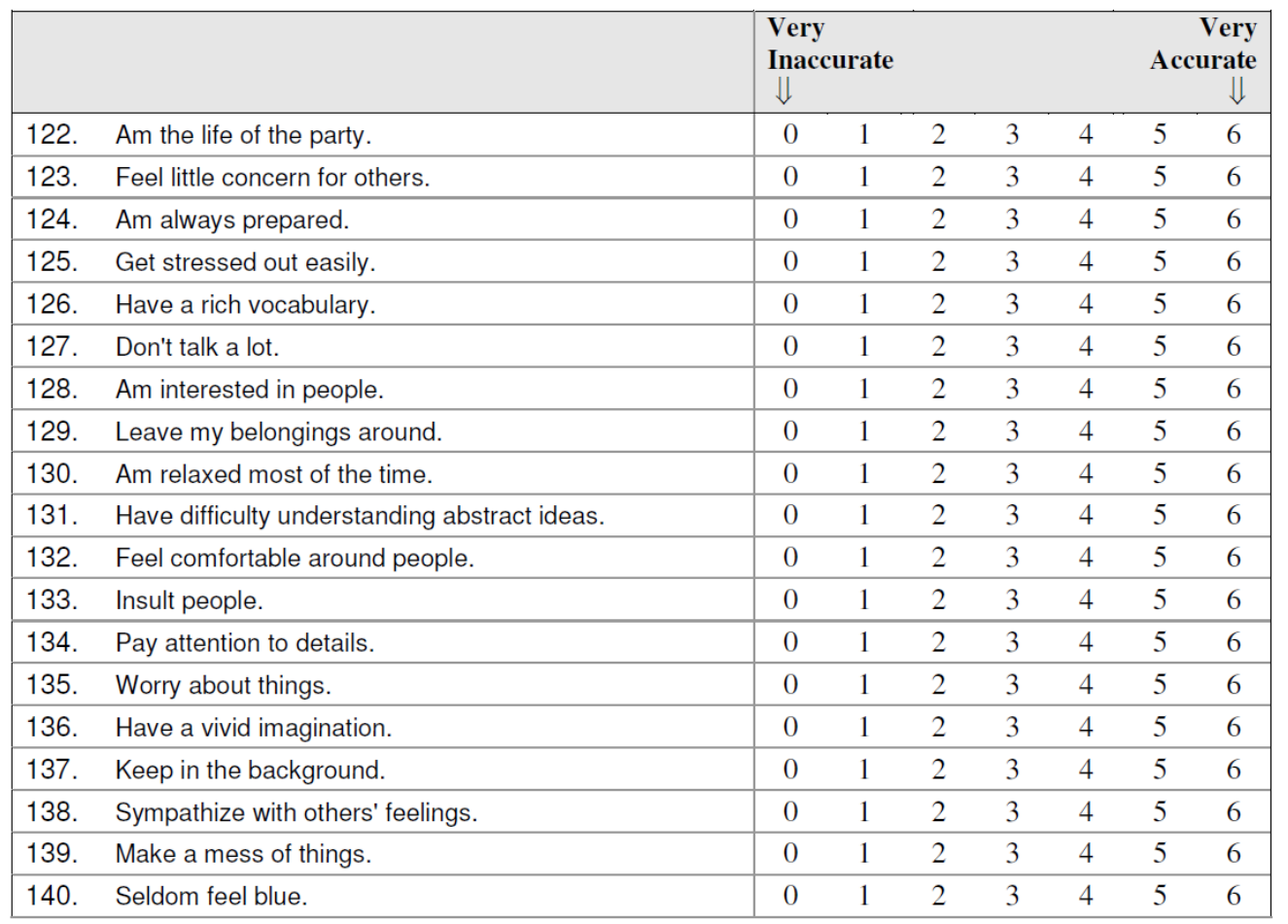




\begin{tabular}{|c|c|c|c|c|c|c|c|c|}
\hline \multirow[b]{2}{*}{141.} & \multirow[b]{2}{*}{ Am not interested in abstract ideas. } & \multicolumn{5}{|c|}{$\begin{array}{l}\text { Very } \\
\text { Inaccurate } \\
\Downarrow\end{array}$} & \multicolumn{2}{|c|}{$\begin{array}{r}\text { Very } \\
\text { Accurate } \\
\Downarrow\end{array}$} \\
\hline & & 0 & 1 & 2 & 3 & 4 & 5 & 6 \\
\hline 142. & Start conversations. & 0 & 1 & 2 & 3 & 4 & 5 & 6 \\
\hline 143. & Am not interested in other people's problems. & 0 & 1 & 2 & 3 & 4 & 5 & 6 \\
\hline 144. & Get chores done right away. & 0 & 1 & 2 & 3 & 4 & 5 & 6 \\
\hline 145. & Am easily disturbed. & 0 & 1 & 2 & 3 & 4 & 5 & 6 \\
\hline 146. & Have excellent ideas. & 0 & 1 & 2 & 3 & 4 & 5 & 6 \\
\hline 147. & Have little to say. & 0 & 1 & 2 & 3 & 4 & 5 & 6 \\
\hline 148. & Have a soft heart. & 0 & 1 & 2 & 3 & 4 & 5 & 6 \\
\hline 149. & Often forget to put things back in their proper place. & 0 & 1 & 2 & 3 & 4 & 5 & 6 \\
\hline 150. & Get upset easily. & 0 & 1 & 2 & 3 & 4 & 5 & 6 \\
\hline 151. & Do not have a good imagination. & 0 & 1 & 2 & 3 & 4 & 5 & 6 \\
\hline 152. & Talk to a lot of different people at parties. & 0 & 1 & 2 & 3 & 4 & 5 & 6 \\
\hline 153. & Am not really interested in others. & 0 & 1 & 2 & 3 & 4 & 5 & 6 \\
\hline 154. & Like order. & 0 & 1 & 2 & 3 & 4 & 5 & 6 \\
\hline 155. & Change my mood a lot. & 0 & 1 & 2 & 3 & 4 & 5 & 6 \\
\hline 156. & Am quick to understand things. & 0 & 1 & 2 & 3 & 4 & 5 & 6 \\
\hline 157. & Don't like to draw attention to myself. & 0 & 1 & 2 & 3 & 4 & 5 & 6 \\
\hline 158. & Take time out for others. & 0 & 1 & 2 & 3 & 4 & 5 & 6 \\
\hline 159. & Shirk my duties. & 0 & 1 & 2 & 3 & 4 & 5 & 6 \\
\hline 160. & Have frequent mood swings. & 0 & 1 & 2 & 3 & 4 & 5 & 6 \\
\hline 161. & Use difficult words. & 0 & 1 & 2 & 3 & 4 & 5 & 6 \\
\hline 162. & Don't mind being the centre of attention. & 0 & 1 & 2 & 3 & 4 & 5 & 6 \\
\hline 163. & Feel others' emotions. & 0 & 1 & 2 & 3 & 4 & 5 & 6 \\
\hline 164. & Follow a schedule. & 0 & 1 & 2 & 3 & 4 & 5 & 6 \\
\hline 165. & Get irritated easily. & 0 & 1 & 2 & 3 & 4 & 5 & 6 \\
\hline 166. & Spend time reflecting on things. & 0 & 1 & 2 & 3 & 4 & 5 & 6 \\
\hline 167. & Am quiet around strangers. & 0 & 1 & 2 & 3 & 4 & 5 & 6 \\
\hline 168. & Make people feel at ease. & 0 & 1 & 2 & 3 & 4 & 5 & 6 \\
\hline 169. & Am exacting in my work. & 0 & 1 & 2 & 3 & 4 & 5 & 6 \\
\hline 170. & Often feel blue. & 0 & 1 & 2 & 3 & 4 & 5 & 6 \\
\hline 171. & Am full of ideas. & 0 & 1 & 2 & 3 & 4 & 5 & 6 \\
\hline
\end{tabular}

\begin{tabular}{|c|c|c|c|c|c|c|}
\hline 172. & $\begin{array}{l}\text { What is your highest } \\
\text { educational qualification? }\end{array}$ & $\begin{array}{l}\text { 173. Please } \\
\text { indicate your } \\
\text { personal income }\end{array}$ & 174. & $\begin{array}{l}\text { Please } \\
\text { indicate } \\
\text { your age } \\
\text { group }\end{array}$ & 175. & $\begin{array}{l}\text { Please indicate } \\
\text { your ethnicity }\end{array}$ \\
\hline$\square F$ & th Form Qualification & $\square \$ 15,000$ or less & & $\square 17-24$ & $\square$ & New Zealand European \\
\hline$\square S$ & xth Form Qualification & $\square \$ 15-001-\$ 30,000$ & & $\square 25-34$ & $\square$ & Maori \\
\hline$\square \mathrm{r}$ & gher School Qualification & $\square \$ 30,001-\$ 50,000$ & & (35-44 & $\square$ & Samoan \\
\hline$\square \mathrm{B}$ & chelor degree & $\square \$ 50,001-\$ 70,000$ & & $\square 45-54$ & $\square$ & Cook Island Maori \\
\hline$\square h$ & gher degree & $\square \$ 70,001-\$ 100,000$ & & $\square 55-64$ & $\square$ & Tongan \\
\hline$\square C$ & her post-school qualification & $\square \$ 100,001$ or more & & $\square 65-74$ & $\square$ & Niluean \\
\hline$\square \mathrm{N}$ & ne of the above & & & $\square 75+$ & $\square$ & Chinese \\
\hline \multirow{2}{*}{\multicolumn{2}{|c|}{$\square$ Other }} & & & & $\square$ & Indian \\
\hline & & & & & $\square$ & $\begin{array}{l}\text { Other (such as Dutch, } \\
\text { Japanese. Tokelauan) }\end{array}$ \\
\hline
\end{tabular}

176. Please indicate your gender $\square$ Male $\quad \square$ Female




\section{Appendix B: Train Questionnaire}

\begin{tabular}{l}
\hline \\
The purpose of this research is to examine your train using behaviour, your attitudes towards the \\
atmosphere on the train service you take, and your perception of the other passengers. Similar questions will \\
examine your attitudes towards your neighbourhood for the purposes of comparison. \\
This research will help to inform public transport providers and policy makers of passenger needs that go \\
beyond factors such as cost and trip frequency. \\
Please take the time to complete the survey, fill out as much as you can and return it in the freepost \\
envelope provided. To show my appreciation for your time I will place you in a prize draw to win vouchers for \\
public transport, petrol, or books to the value of $\$ 500$. \\
With kind regards \\
Jared Thomas \\
If you have any queries, please feel free to contact me. Email: Jared. Thomas@vuw.ac.nz
\end{tabular}

\begin{tabular}{|l|}
\hline IMPORTANT POINTS \\
1. I value your opinion \\
2. If a question doesn't make sense then let me know, but try to answer by choosing the most \\
appropriate response \\
3. Your answers are entirely confidential, so please answer honestly and openly \\
4. You may withdraw your participation at any point and still enter the prize draw \\
5. A brief summary of the findings will be made available on this web page www.transportco2.org.nz \\
This survey should take about 20-30 minutes
\end{tabular}

1. How many days would you travel by train in a typical week? [Please tick the appropriate box]

\begin{tabular}{|l|l|l|l|l|l|l|l|c|}
\hline$\square 1$ & $\square 2$ & $\square 3$ & $\square 4$ & $\square 5$ & $\square 6$ & $\square 7$ & $\begin{array}{c}\square \text { I very rarely } \\
\text { take the train }\end{array}$ & $\begin{array}{c}\square \text { I never take the train } \\
\text { [you do not need to continue this questionnaire] }\end{array}$ \\
\hline
\end{tabular}

2. What is the main weekly activity that would require you to travel? [Your main activity is the one that takes up the greatest amount of your time away from home each week. Please tick only one box]

\begin{tabular}{|c|c|c|c|c|}
\hline$\square$ Work & $\square$ Education & $\square$ Shopping & $\square$ Social/ Recreation & $\square$ Other.................... \\
\hline
\end{tabular}

3. What do you primarily use to travel to your main weekly activity? [If you use more than one type of travel then select the one that covers the larger part of the distance. It does not matter if the train is not your main travel type. Please tick only one box]

\begin{tabular}{|c|c|c|c|c|c|}
\hline$\square$ Motor vehicle & $\square$ Bus & $\square$ Train & $\square$ cycling & $\square$ Walking & 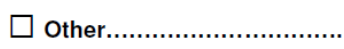 \\
\hline
\end{tabular}

4. Please estimate the distance (in $\mathrm{km}$ ) from your house to your main weekly activity [We realise this may be difficult to estimate, your best guess is fine]

\begin{tabular}{|l|c|c|c|c|c|c|c|}
\hline$\square 0-1 \mathrm{~km}$ & $\square 1-5 \mathrm{~km}$ & $\square 5-10 \mathrm{~km}$ & $\square 10-15 \mathrm{~km}$ & $\square 15-20 \mathrm{~km}$ & $\square 20-25 \mathrm{~km}$ & $\square 25-30 \mathrm{~km}$ & $\square 30 \mathrm{~km}+$ \\
\hline
\end{tabular}


5. How long are you on board the train when you travel by train to your main weekly activity?

\begin{tabular}{c|c|c|c|c|c|c|c|}
$\begin{array}{c}\square 0-10 \\
\text { mins }\end{array}$ & $\begin{array}{c}\square \text { mins } \\
\text { min-20 }\end{array}$ & $\begin{array}{c}\square 20-30 \\
\text { mins }\end{array}$ & $\begin{array}{c}\square 30-40 \\
\text { mins }\end{array}$ & $\begin{array}{c}\square 40-50 \\
\text { mins }\end{array}$ & $\begin{array}{c}\square 50-60 \\
\text { mins }\end{array}$ & $\begin{array}{c}\square 60-90 \\
\text { mins }\end{array}$ & $\square 90$ mins+ \\
\hline
\end{tabular}

6. If cost, convenience and travel time were equal, which of these would you prefer to travel by?

\begin{tabular}{|l|l|l|}
\hline Motor vehicle & $\square$ Bus & $\square$ Train \\
\hline
\end{tabular}

7. What is the name of the station where you catch the train to go to your main activity?

8. What suburb are you travelling to? (i.e. suburb of main weekly activity)

9. What time do you typically catch the train to your main activity?

10. What time do you typically catch the train to return home?

For the following questions please place an $X$ on the line to indicate the percentage. Your best guess is fine.

11. On your most recent train trip how full were the seats on the train when you boarded?

12. On your most recent train trip how full were the seats on the train when you departed?

13. What percentage of the passengers are likely to be regular train users?

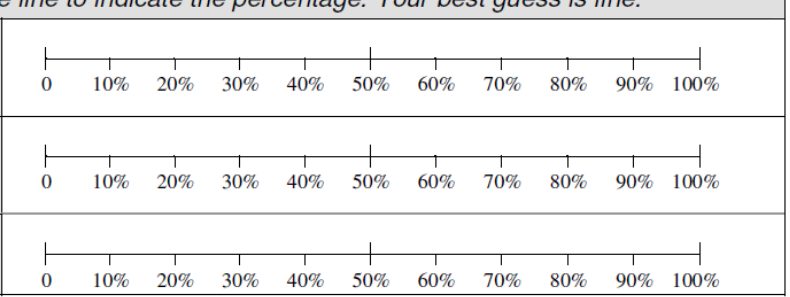

\begin{tabular}{|l|c|c|c|c|c|}
\hline $\begin{array}{l}\text { How likely is it that the following things happen the next } \\
\text { time you take your reqular train? } \\
\text { [please tick the box that best describes the likelihood] }\end{array}$ & $\begin{array}{c}\text { Very } \\
\text { unlikely }\end{array}$ & Unlikely & $\begin{array}{c}\text { Not sure/ } \\
\text { Neutral }\end{array}$ & Likely & $\begin{array}{c}\text { Very } \\
\text { likely }\end{array}$ \\
\hline 14. I sit with no one directly next to me & $\square$ & $\square$ & $\square$ & $\square$ & $\square$ \\
\hline 15. The passenger next to me will talk to me & $\square$ & $\square$ & $\square$ & $\square$ & $\square$ \\
\hline 16. The train is too crowded & $\square$ & $\square$ & $\square$ & $\square$ & $\square$ \\
\hline 17. Passengers apologise if they accidentally touch me & $\square$ & $\square$ & $\square$ & $\square$ & $\square$ \\
\hline 18. I try to ignore the train passenger next to me & $\square$ & $\square$ & $\square$ & $\square$ & $\square$ \\
\hline $\begin{array}{l}\text { 19. I am a comfortable distance to the nearest passenger } \\
\text { 20. A passenger appears uncomfortable with the person } \\
\text { seated next to them }\end{array}$ & $\square$ & $\square$ & $\square$ & $\square$ & $\square$ \\
\hline 21. Other passengers smile at me if we make eye contact & $\square$ & $\square$ & $\square$ & $\square$ & $\square$ \\
\hline $\begin{array}{l}\text { 22. Passengers place bags on the seats next to them to stop } \\
\text { someone from sitting next to them }\end{array}$ & $\square$ & $\square$ & $\square$ & $\square$ & $\square$ \\
\hline
\end{tabular}

23. Would YOU rather have more privacy or more social interaction with other passengers when travelling on the train?

\begin{tabular}{|c|c|c|}
\hline More privacy & No change change & $\begin{array}{c}\text { More social } \\
\text { interaction }\end{array}$ \\
More privacy & interaction
\end{tabular}




\begin{tabular}{|l|c|c|c|c|c|}
\hline $\begin{array}{l}\text { How likely is it that the following things happen the next } \\
\text { time you take your regular train } \\
\text { [please tick the box that best describes the likelihood] }\end{array}$ & $\begin{array}{c}\text { Very } \\
\text { unlikely }\end{array}$ & Unlikely & $\begin{array}{c}\text { Not sure/ } \\
\text { Neutral }\end{array}$ & Likely & $\begin{array}{c}\text { Very } \\
\text { likely }\end{array}$ \\
\hline 25. I sit in the same carriage I usually sit in & $\square$ & $\square$ & $\square$ & $\square$ & $\square$ \\
\hline $\begin{array}{l}\text { 26. I feel comfortable with the passenger that selects the seat } \\
\text { beside me }\end{array}$ & $\square$ & $\square$ & $\square$ & $\square$ & $\square$ \\
\hline $\begin{array}{l}\text { 27. Seated passengers avoid looking at me as I board the train } \\
\text { 28. Passengers acknowledge me if I sit next to them, by } \\
\text { making eye contact or saying hello }\end{array}$ & $\square$ & $\square$ & $\square$ & $\square$ & $\square$ \\
\hline $\begin{array}{l}\text { 29. The train feels stuffy because there are so many people } \\
\text { 30. I sit with other regular train passengers }\end{array}$ & $\square$ & $\square$ & $\square$ & $\square$ & $\square$ \\
\hline $\begin{array}{l}\text { 31. The passenger sitting next to me takes up more than their } \\
\text { share of the room on the seat }\end{array}$ & $\square$ & $\square$ & $\square$ & $\square$ & $\square$ \\
\hline
\end{tabular}

32. Please indicate how much of a regular train user you believe you are

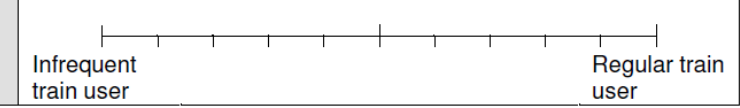

Please rate YOURSELF on the following personal characteristics.

[Please place an $X$ on the line to indicate how you think of yourself]

\begin{tabular}{|c|c|c|c|c|c|c|c|c|c|c|c|c|c|}
\hline \multirow{2}{*}{33.} & \multirow[b]{2}{*}{ Insincere } & \multicolumn{11}{|c|}{ 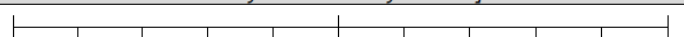 } & \multirow[b]{2}{*}{ Sincere } \\
\hline & & 0 & 1 & 2 & 3 & 4 & 5 & 6 & 7 & 8 & 9 & 10 & \\
\hline 34. & Wise & $\mapsto$ & 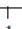 & 1 & 1 & 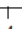 & $\therefore$ & 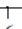 & 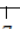 & 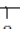 & 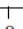 & 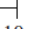 & \multirow{2}{*}{ Foolish } \\
\hline & & & & & & & & & & & & & \\
\hline \multirow{2}{*}{35.} & \multirow{2}{*}{ Cold } & $\vdash$ & $T$ & 1 & 1 & $T$ & † & 1 & $T$ & $T$ & T & 1 & \multirow[b]{2}{*}{ Warm } \\
\hline & & 0 & 1 & 2 & 3 & 4 & 5 & 6 & 7 & 8 & 9 & 10 & \\
\hline \multirow{2}{*}{36.} & \multirow{2}{*}{ Safe } & $\vdash$ & 1 & 1 & 1 & T & 1 & 1 & 1 & 1 & T & $\exists$ & \multirow{2}{*}{ Dangerous } \\
\hline & & 0 & 1 & 2 & 3 & 4 & 5 & 6 & 7 & 8 & 9 & 10 & \\
\hline \multirow{2}{*}{37.} & \multirow{2}{*}{ Dirty } & $\mapsto$ & 1 & $T$ & 1 & T & 1 & 1 & $T$ & 1 & 1 & $\neg$ & \multirow{2}{*}{ Clean } \\
\hline & & 0 & 1 & 2 & 3 & 4 & 5 & 6 & 7 & 8 & 9 & 10 & \\
\hline \multirow[b]{2}{*}{38.} & \multirow{2}{*}{ Attractive } & $\vdash$ & 1 & & & 1 & 4 & 1 & 1 & & & & \multirow{2}{*}{ Unattractive } \\
\hline & & 0 & 1 & 2 & 3 & 4 & 5 & 6 & 7 & 8 & 9 & 10 & \\
\hline 39. & Poor & $\vdash$ & i & 1 & 1 & 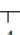 & 5 & 1 & 7 & & 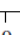 & , & \multirow{2}{*}{ Rich } \\
\hline & & & & & & & & & & & & & \\
\hline \multirow{2}{*}{40.} & \multirow{2}{*}{ Educated } & $\vdash$ & $T$ & $T$ & $T$ & T & † & 1 & T & $T$ & & & \multirow{2}{*}{ Uneducated } \\
\hline & & 0 & 1 & 2 & 3 & 4 & 5 & 6 & 7 & 8 & 9 & 10 & \\
\hline
\end{tabular}

41. How many of the passengers on your regular train route would you call friends (approximately)?

42. How many of the passengers on your regular train route do you know by name (approximately)?

43. How many of the passengers on your regular train route have you spoken with (approximately)?

\begin{tabular}{|l|c|c|c|c|}
\hline $\begin{array}{l}\text { On my regular train } \\
\text { [please tick the box that best describes your level of } \\
\text { agreement] }\end{array}$ & $\begin{array}{c}\text { Strongly } \\
\text { disagree }\end{array}$ & Disagree & $\begin{array}{c}\text { Not sure/ } \\
\text { Neutral }\end{array}$ & $\begin{array}{c}\text { Agree } \\
\text { agree }\end{array}$ \\
\hline $\begin{array}{l}\text { 44. I feel like I fit in with most of the different types of people } \\
\text { on my regular train }\end{array}$ & $\square$ & $\square$ & $\square$ & $\square$ \\
\hline $\begin{array}{l}\text { 45. When taking my regular train I would rather sit by myself } \\
\text { W6. I would feel uncomfortable travelling on my regular train at } \\
\text { night }\end{array}$ & $\square$ & $\square$ & $\square$ & $\square$ \\
\hline $\begin{array}{l}\text { 47. I like meeting new people on my regular train } \\
\text { 4ikn }\end{array}$ & $\square$ & $\square$ & $\square$ \\
\hline
\end{tabular}




\begin{tabular}{|l|c|c|c|c|c|}
\hline $\begin{array}{l}\text { On my regular train } \\
\text { [please tick the box that best describes your level of } \\
\text { agreement] }\end{array}$ & $\begin{array}{c}\text { Strongly } \\
\text { disagree }\end{array}$ & Disagree & $\begin{array}{c}\text { Not sure/ } \\
\text { Neutral }\end{array}$ & Agree & $\begin{array}{c}\text { Strongly } \\
\text { agree }\end{array}$ \\
\hline $\begin{array}{l}\text { 48. I do not relate to the other train passengers on my regular } \\
\text { train }\end{array}$ & $\square$ & $\square$ & $\square$ & $\square$ & $\square$ \\
\hline 49. The other passengers are often noisy and inconsiderate & $\square$ & $\square$ & $\square$ & $\square$ & $\square$ \\
\hline 50. I feel comfortable when my regular train is crowded & $\square$ & $\square$ & $\square$ & $\square$ & $\square$ \\
\hline 51. I feel like I don't fit in with the other train passengers & $\square$ & $\square$ & $\square$ & $\square$ & $\square$ \\
\hline $\begin{array}{l}\text { 52. I find it difficult to talk to other passengers on my regular } \\
\text { train }\end{array}$ & $\square$ & $\square$ & $\square$ & $\square$ & $\square$ \\
\hline $\begin{array}{l}\text { 53. I have a lot in common with the other passengers on my } \\
\text { train }\end{array}$ & $\square$ & $\square$ & $\square$ & $\square$ & $\square$ \\
\hline $\begin{array}{l}\text { 54. I would feel more comfortable if all of the other passengers } \\
\text { came from my neighbourhood }\end{array}$ & $\square$ & $\square$ & $\square$ & $\square$ & $\square$ \\
\hline $\begin{array}{l}\text { 55. It is easy for me to blend in with other people on my train } \\
\text { 56. I would never start a conversation with a passenger I didn't } \\
\text { know }\end{array}$ & $\square$ & $\square$ & $\square$ & $\square$ & $\square$ \\
\hline
\end{tabular}

57. How long have you been using your current train route?

58. How many years do you believe you will continue to use the train?

\begin{tabular}{|c|c|c|c|c|c|c|c|c|c|c|c|c|c|}
\hline \multicolumn{14}{|c|}{$\begin{array}{l}\text { Please think about the people that you have encountered on the train. Now imagine the typical } \\
\text { train passenger and rate them on the following personal characteristics. } \\
\text { [Please place an } X \text { on the line to indicate how you think of other train passengers] }\end{array}$} \\
\hline 59. & Insincere & 0 & 1 & 2 & $\begin{array}{l}1 \\
3\end{array}$ & 4 & 5 & 6 & 7 & 8 & 9 & 10 & Sincere \\
\hline 60. & Wise & 0 & 1 & 2 & 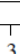 & 4 & 5 & 6 & 7 & 8 & 0 & 10 & Foolish \\
\hline 61. & Cold & 0 & 1 & 2 & $\begin{array}{l}1 \\
3\end{array}$ & 4 & 5 & 6 & 7 & 8 & 9 & 10 & Warm \\
\hline 62. & Safe & $\begin{array}{l}7 \\
0\end{array}$ & 1 & $\frac{1}{2}$ & $\begin{array}{l}1 \\
3\end{array}$ & 4 & 5 & 6 & 7 & 8 & 9 & 10 & Dangerous \\
\hline 63. & Dirty & $\begin{array}{l}7 \\
0\end{array}$ & 1 & 2 & 3 & 4 & 5 & 6 & 7 & 8 & 9 & 10 & Clean \\
\hline 64. & Attractive & 0 & 1 & 2 & $\begin{array}{l}1 \\
3\end{array}$ & 4 & 5 & 6 & 7 & 8 & 9 & 10 & Unattractive \\
\hline 65. & Poor & $\begin{array}{l}7 \\
0\end{array}$ & 1 & 2 & $\begin{array}{l}1 \\
3\end{array}$ & 4 & 5 & 6 & 7 & 8 & 9 & 10 & Rich \\
\hline 66. & Educated & 0 & $\begin{array}{l}T \\
1\end{array}$ & $\begin{array}{l}1 \\
2\end{array}$ & $\begin{array}{l}1 \\
3\end{array}$ & 4 & 5 & 6 & 7 & 8 & 9 & 10 & Uneducated \\
\hline
\end{tabular}

\begin{tabular}{|l|c|c|c|c|c|}
\hline $\begin{array}{l}\text { Where do you choose to sit when you use the train } \\
\text { and there are plenty of available seats? } \\
\text { [tick the box that best describes your level of agreement] }\end{array}$ & $\begin{array}{c}\text { Strongly } \\
\text { disagree }\end{array}$ & Disagree & $\begin{array}{c}\text { Not sure/ } \\
\text { Neutral }\end{array}$ & Agree & $\begin{array}{c}\text { Strongly } \\
\text { agree }\end{array}$ \\
\hline 67. I like to sit beside other passengers & $\square$ & $\square$ & $\square$ & $\square$ & $\square$ \\
\hline $\begin{array}{l}\text { 68. I choose the seat that will give me the most space to } \\
\text { spread out my gear and give me enough leg space }\end{array}$ & $\square$ & $\square$ & $\square$ & $\square$ & $\square$ \\
\hline \begin{tabular}{l} 
69. I really don't care where I sit \\
\hline $\begin{array}{l}\text { 70. I select a seat as far away from other passengers as } \\
\text { possible }\end{array}$
\end{tabular}$\quad \square$ & $\square$ & $\square$ & $\square$ & $\square$ \\
\hline
\end{tabular}




\begin{tabular}{|l|c|c|c|c|c|}
\hline $\begin{array}{l}\text { Which passengers do you choose to sit beside } \\
\text { when the train is crowded and you have to sit next } \\
\text { to another person? } \\
\text { [tick the box that best describes your level of agreement] }\end{array}$ & $\begin{array}{c}\text { Strongly } \\
\text { disagree }\end{array}$ & Disagree & $\begin{array}{c}\text { Not sure/ } \\
\text { Neutral }\end{array}$ & Agree & $\begin{array}{c}\text { Strongly } \\
\text { agree }\end{array}$ \\
\hline $\begin{array}{l}\text { 71. If I have to sit next to another passenger, I sit next to } \\
\text { someone of the same gender }\end{array}$ & $\square$ & $\square$ & $\square$ & $\square$ & $\square$ \\
\hline $\begin{array}{l}\text { 72. The person I sit next to has no influence on my decision to } \\
\text { sit there }\end{array}$ & $\square$ & $\square$ & $\square$ & $\square$ & $\square$ \\
\hline $\begin{array}{l}\text { 73. I like to sit next to people that are already busy with an } \\
\text { activity, such as reading or listening to music }\end{array}$ & $\square$ & $\square$ & $\square$ & $\square$ & $\square$ \\
\hline
\end{tabular}

\begin{tabular}{|c|c|c|c|c|c|}
\hline $\begin{array}{l}\text { Once seated on the train } \\
\text { [tick the box that best describes your level of agreement] }\end{array}$ & $\begin{array}{l}\text { Strongly } \\
\text { disagree }\end{array}$ & Disagree & $\begin{array}{c}\text { Not sure/ } \\
\text { Neutral }\end{array}$ & Agree & $\begin{array}{l}\text { Strongly } \\
\text { agree }\end{array}$ \\
\hline 74. I like to spread out so no one will sit next to me & $\square$ & $\square$ & $\square$ & $\square$ & $\square$ \\
\hline $\begin{array}{l}\text { 75. I like to perform activities such as read and listen to music } \\
\text { so other passengers wont talk to me }\end{array}$ & $\square$ & $\square$ & $\square$ & $\square$ & $\square$ \\
\hline 76. I like it when another passenger chooses to sit beside me & $\square$ & $\square$ & $\square$ & $\square$ & $\square$ \\
\hline $\begin{array}{l}\text { 77. I avoid the eye contact of boarding passengers in the hope } \\
\text { that they wont sit next to me }\end{array}$ & $\square$ & $\square$ & $\square$ & $\square$ & $\square$ \\
\hline $\begin{array}{l}\text { 78. I leave the window seat open and sit in the aisle seat to } \\
\text { avoid sitting beside other passengers }\end{array}$ & $\square$ & $\square$ & $\square$ & $\square$ & $\square$ \\
\hline 79. I always leave room for other passengers to sit next to me & $\square$ & $\square$ & $\square$ & $\square$ & $\square$ \\
\hline
\end{tabular}

80. How much privacy do you have from other passengers on the train?

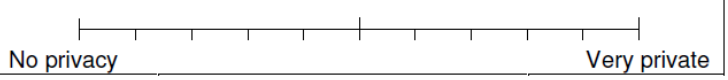

81. How much is the cost of a one-way train ticket to get to your main activity? [if you are not sure because you use a day pass or other regular pass then your best guess is fine]

82. How much would you be willing to pay per trip to be able to use a seat selection system (similar to those used with airlines) to pre-select your train seat?

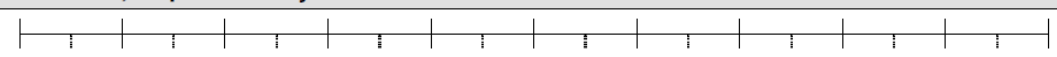

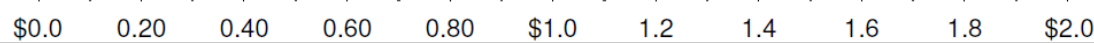

\begin{tabular}{|l|c|c|c|c|}
\hline $\begin{array}{l}\text { Train relationships } \\
\text { [tick the box that best describes the likelihood of the } \\
\text { following] }\end{array}$ & $\begin{array}{c}\text { Very } \\
\text { unlikely }\end{array}$ & Unlikely & $\begin{array}{c}\text { Not sure/ } \\
\text { Neutral }\end{array}$ & $\begin{array}{c}\text { Likely } \\
\text { likely }\end{array}$ \\
\hline 83. How likely are you to make a good friend on the train? & $\square$ & $\square$ & $\square$ & $\square$ \\
\hline 84. How likely are you to make an acquaintance on the train? & $\square$ & $\square$ & $\square$ & $\square$ \\
\hline $\begin{array}{l}\text { 85. How likely are you to invite someone you met on the train } \\
\text { to your home? }\end{array}$ \\
\hline $\begin{array}{l}\text { 86. How likely are you to invite someone you met on the train } \\
\text { to a social event? (e.g. dinner or a movie) }\end{array}$ \\
\hline
\end{tabular}

87. Please estimate the distance (in $\mathrm{km}$ ) from your house to your local station/platform where you catch the train [We realise this may be difficult to estimate, your best guess is fine]

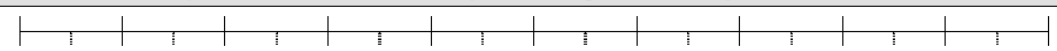

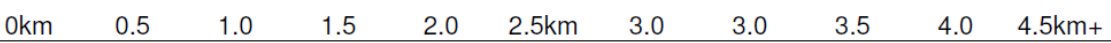


88. How do you typically travel to your local train station?

\begin{tabular}{|l|l|l|l|}
\hline$\square$ Motor vehicle & $\square$ Walk & $\square$ Cycle & $\square$ Bus \\
\hline
\end{tabular}

\begin{tabular}{|c|c|c|c|c|c|}
\hline $\begin{array}{l}\text { At my local train station } \\
\text { [tick the box that best describes your level of agreement] }\end{array}$ & $\begin{array}{l}\text { Strongly } \\
\text { disagree }\end{array}$ & Disagree & $\begin{array}{l}\text { Not sure/ } \\
\text { Neutral }\end{array}$ & Agree & $\begin{array}{l}\text { Strongly } \\
\text { agree }\end{array}$ \\
\hline $\begin{array}{l}\text { 89. I feel like I fit in with most of the different types of people } \\
\text { waiting at my local train station }\end{array}$ & $\square$ & $\square$ & $\square$ & $\square$ & $\square$ \\
\hline $\begin{array}{l}\text { 90. When waiting at my local train platform I would rather } \\
\text { stand away from the other people }\end{array}$ & $\square$ & $\square$ & $\square$ & $\square$ & $\square$ \\
\hline 91. I have a lot in common with the people at my train station & $\square$ & $\square$ & $\square$ & $\square$ & $\square$ \\
\hline $\begin{array}{l}\text { 92. I find it difficult to talk to other people on the local train } \\
\text { platform }\end{array}$ & $\square$ & $\square$ & $\square$ & $\square$ & $\square$ \\
\hline 93. I do not relate to the other people waiting at my station & $\square$ & $\square$ & $\square$ & $\square$ & $\square$ \\
\hline $\begin{array}{l}\text { 94. I like meeting new people when waiting on the local train } \\
\text { platform }\end{array}$ & $\square$ & $\square$ & $\square$ & $\square$ & $\square$ \\
\hline $\begin{array}{l}\text { 95. I feel like I don't fit in with the other people at my train } \\
\text { station }\end{array}$ & $\square$ & $\square$ & $\square$ & $\square$ & $\square$ \\
\hline $\begin{array}{l}\text { 96. I feel comfortable waiting on the local train platform when it } \\
\text { is crowded }\end{array}$ & $\square$ & $\square$ & $\square$ & $\square$ & $\square$ \\
\hline $\begin{array}{l}\text { 97. I would feel uncomfortable walking home from my local } \\
\text { station at night }\end{array}$ & $\square$ & $\square$ & $\square$ & $\square$ & $\square$ \\
\hline $\begin{array}{l}\text { 98. It is easy for me to blend in with the other people at my } \\
\text { train station }\end{array}$ & $\square$ & $\square$ & $\square$ & $\square$ & $\square$ \\
\hline
\end{tabular}

The following section will ask questions about the place you live, and the people in your neighbourhood.

99. Where do you live?

City ......

Suburb

100. How long have you lived in your current neighbourhood?

101. Please state the closest intersection to where you live...e.g. Browns Rd/Russell Rd

Please think about the people that you have encountered in your neighbourhood. Now imagine your typical neighbour and rate them on the following personal characteristics. [Please place an $X$ on the line to indicate how you think of your neighbours]

\begin{tabular}{|c|c|c|c|c|c|c|c|c|c|c|c|c|c|}
\hline & & ⺊ & $T$ & & & & t & & & & & & \multirow[b]{2}{*}{ Sincere } \\
\hline 102. & Insincere & 0 & 1 & 2 & 3 & 4 & 5 & 6 & 7 & 8 & 9 & 10 & \\
\hline 103. & Wise & 0 & 1 & 1 & 3 & , & 5 & 1 & 1 & $\begin{array}{l}1 \\
8\end{array}$ & 1 & 0 & Foolish \\
\hline \multirow{2}{*}{104.} & \multirow{2}{*}{ Cold } & - & T & & & & $t$ & T & & & & & \multirow{2}{*}{ Warm } \\
\hline & & 0 & 1 & 2 & 3 & 4 & 5 & 6 & 7 & 8 & 9 & 10 & \\
\hline 105. & \multirow{2}{*}{ Safe } & $r$ & T & 1 & 1 & 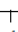 & + & T & 1 & 1 & 1 & 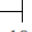 & \multirow{2}{*}{ Dangerous } \\
\hline & & & & & & & & & & & & & \\
\hline 106. & Dirty & H & T & 1 & . & T & t & 1 & 1 & 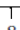 & 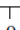 & 0 & Clean \\
\hline \multirow[b]{2}{*}{107.} & \multirow[b]{2}{*}{ Attractive } & - & & & & & $t$ & & & & & & \multirow[b]{2}{*}{ Unattractive } \\
\hline & & 0 & 1 & 2 & 3 & $\frac{1}{4}$ & 5 & $\frac{1}{6}$ & 7 & 8 & 9 & 10 & \\
\hline \multirow{2}{*}{108.} & \multirow{2}{*}{ Poor } & 1 & 1 & 1 & 1 & 1 & 1 & 1 & 1 & $T$ & 1 & 1 & \multirow{2}{*}{ Rich } \\
\hline & & 0 & 1 & 2 & 3 & 4 & 5 & 6 & 7 & 8 & 9 & 10 & \\
\hline 109. & Educated & 1 & 1 & 1 & . & 1 & 1 & 1 & 1 & 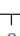 & 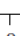 & 1 & Uneducated \\
\hline
\end{tabular}




\begin{tabular}{|c|c|c|c|c|c|}
\hline $\begin{array}{l}\text { In my neighbourhood } \\
\text { [tick the box that best describes your level of agreement] }\end{array}$ & $\begin{array}{l}\text { Strongly } \\
\text { disagree }\end{array}$ & Disagree & $\begin{array}{c}\text { Not sure/ } \\
\text { Neutral }\end{array}$ & Agree & $\begin{array}{l}\text { Strongly } \\
\text { agree }\end{array}$ \\
\hline $\begin{array}{l}\text { 110. I feel like I fit in with most of the different types of people } \\
\text { in my neighbourhood }\end{array}$ & $\square$ & $\square$ & $\square$ & $\square$ & $\square$ \\
\hline $\begin{array}{l}\text { 111. I would feel uncomfortable walking around my } \\
\text { neighbourhood at night }\end{array}$ & $\square$ & $\square$ & $\square$ & $\square$ & $\square$ \\
\hline 112. I like meeting new people from my neighbourhood & $\square$ & $\square$ & $\square$ & $\square$ & $\square$ \\
\hline 113. I do not relate to the other people in my neighbourhood & $\square$ & $\square$ & $\square$ & $\square$ & $\square$ \\
\hline $\begin{array}{l}\text { 114. I find it difficult to talk to other people from my } \\
\text { neighbourhood }\end{array}$ & $\square$ & $\square$ & $\square$ & $\square$ & $\square$ \\
\hline $\begin{array}{l}\text { 115. It is easy for me to blend in with other people from my } \\
\text { neighbourhood }\end{array}$ & $\square$ & $\square$ & $\square$ & $\square$ & $\square$ \\
\hline $\begin{array}{l}\text { 116. I have a lot in common with the people from my } \\
\text { neighbourhood }\end{array}$ & $\square$ & $\square$ & $\square$ & $\square$ & $\square$ \\
\hline $\begin{array}{l}\text { 117. I feel like I don't fit in with the other people from my } \\
\text { neighbourhood }\end{array}$ & $\square$ & $\square$ & $\square$ & $\square$ & $\square$ \\
\hline
\end{tabular}

118. How would you describe the housing density of the neighbourhood in which you live?

\begin{tabular}{|l|r|r|}
$\begin{array}{l}\text { Houses are } \\
\text { very spread } \\
\text { out (e.g. rural) }\end{array}$ & & $\begin{array}{r}\text { Houses are very } \\
\text { dense (e.g. city } \\
\text { apartments) }\end{array}$ \\
\hline
\end{tabular}

\begin{tabular}{|l|c|c|c|c|}
\hline $\begin{array}{l}\text { Building relationships in your neighbourhood } \\
\text { [tick the box that best describes the likelihood of the } \\
\text { following] }\end{array}$ & $\begin{array}{c}\text { Very } \\
\text { unlikely }\end{array}$ & Unlikely & $\begin{array}{c}\text { Not sure/ } \\
\text { Neutral }\end{array}$ & $\begin{array}{c}\text { Likely } \\
\text { likely }\end{array}$ \\
\hline $\begin{array}{l}\text { 119. How likely are you to make a good friend from your } \\
\text { neighbourhood? }\end{array}$ & $\square$ & $\square$ & $\square$ \\
\hline $\begin{array}{l}\text { 120. How likely are you to make an acquaintance from your } \\
\text { neighbourhood? }\end{array}$ & $\square$ & $\square$ & $\square$ & $\square$ \\
\hline $\begin{array}{l}\text { 121. How likely are you to invite someone you met from your } \\
\text { neighbourhood to your home? }\end{array}$ & $\square$ & $\square$ & $\square$ & $\square$ \\
\hline $\begin{array}{l}\text { 122. How likely are you to invite someone you met from your } \\
\text { neighbourhood to a social event? (e.g. dinner or a movie) }\end{array}$ & $\square$ & $\square$ & $\square$ & $\square$ \\
\hline
\end{tabular}

123. How many of the people in your neighbourhood would you call friends (approximately)?

124. How many of the people in your neighbourhood do you know by name (approximately)?

125. How many of the people in your neighbourhood have you spoken with (approximately)?

\begin{tabular}{|l|c|c|c|c|c|}
\hline $\begin{array}{l}\text { Touch avoidance } \\
\text { [tick the box that best describes your level of agreement] }\end{array}$ & $\begin{array}{c}\text { Strongly } \\
\text { disagree }\end{array}$ & Disagree & $\begin{array}{c}\text { Not sure/ } \\
\text { Neutral }\end{array}$ & $\begin{array}{c}\text { Agree } \\
\text { Strongly } \\
\text { agree }\end{array}$ \\
\hline 126. $\quad$ People shouldn't be so uptight about touching people & $\square$ & $\square$ & $\square$ & $\square$ \\
\hline 127. I don't like to touch my friends $\quad \square$ & $\square$ & $\square$ & $\square$ & $\square$ \\
\hline 128. A hug from a person is a true sign of friendship & $\square$ & $\square$ & $\square$ & $\square$ \\
\hline 129. Touching a friend makes me uncomfortable $\quad \square$ & $\square$ & $\square$ & $\square$ & $\square$ \\
\hline
\end{tabular}


130. Do you own or rent the place where you live?

\begin{tabular}{|l|l|l|}
$\square$ Own & $\square$ Rent & $\square$ Other ............................. \\
\hline
\end{tabular}

\begin{tabular}{l}
$\begin{array}{l}\text { 131. How many motor vehicles do you have in } \\
\text { your household? }\end{array}$ \\
\hline
\end{tabular}

\begin{tabular}{|l|l|l|l|l} 
132. What is your current relationship status? & $\square$ Single & $\begin{array}{l}\square \text { Short-term } \\
\text { relationship }\end{array}$ & $\begin{array}{l}\square \text { Long term } \\
\text { relationship }\end{array}$ & $\begin{array}{r}\square \text { Married/ } \\
\text { De-facto }\end{array}$
\end{tabular}

\begin{tabular}{|l|c|c|l|}
\hline $\begin{array}{c}\text { 133. What is your highest } \\
\text { educational qualification? }\end{array}$ & $\begin{array}{c}\text { 134. Please indicate } \\
\text { your annual } \\
\text { household income }\end{array}$ & $\begin{array}{c}\text { 135. Please indicate } \\
\text { your age group }\end{array}$ & $\begin{array}{c}\text { 136. Please indicate your } \\
\text { ethnicity }\end{array}$ \\
\hline$\square$ High School Qualification & $\square \$ 15,000$ or less & $\square 17-24$ & $\square$ New Zealand European \\
\hline$\square$ Other post-school qualification & $\square \$ 15-001-\$ 30,000$ & $\square 25-34$ & $\square$ Maori \\
\hline$\square$ Bachelor degree & $\square \$ 30,001-\$ 50,000$ & $\square 35-44$ & $\square$ Asian \\
\hline$\square$ Higher degree & $\square \$ 50,001-\$ 70,000$ & $\square 45-54$ & $\square$ Indian \\
\hline$\square$ Other & $\square \$ 70,001-\$ 100,000$ & $\square 55-64$ & $\square$ Pacific Islander \\
\hline & $\square \$ 100,001-\$ 130,000$ & $\square 65-74$ & (such as Samoan, Tongan) \\
\hline & $\square \$ 130,000$ or more & $\square 75+$ & $\square$ Other \\
\hline
\end{tabular}

\begin{tabular}{|l|l|} 
137. Please indicate your gender & $\square$ Male $\square$ Female \\
\hline
\end{tabular}

Comments (I welcome your comments regarding any aspect of this survey)

I REALLY APPRECIATE THE TIME YOU TOOK TO FILL IN THIS SURVEY. PLEASE REMEMBER TO FILL IN THE PRIZE DRAW CARD TO GO INTO THE DRAW TO WIN \$500 WORTH OF VOUCHERS. 


\section{Appendix C: Example Cover Letter}

Dear Householder

\section{TRANSPORT ATTITUDES RESEARCH 2008}

I am undertaking research to examine attitudes towards the social atmosphere and behaviour of passengers on buses and trains in the Greater Wellington area.

This research will help to inform public transport providers and policy makers of passenger needs that go beyond factors such as cost and trip frequency. You will also be helping me with my PhD research at Victoria University of Wellington.

I am very interested in your impressions, even if you almost never use public transport.

A similar questionnaire has already been filled in by a member of your neighbourhood that regularly uses public transport. For my research to work I need to examine the attitudes of someone from your area that uses or has access to a motor vehicle. You and a few of your neighbours have been randomly selected from your neighbourhood. Your address details were removed from our files at the time this survey was posted to ensure anonymity and to protect your privacy.

If you have already filled in a transport questionnaire for me, I thank you very much for your time and ask that you pass this on to another member of your household.

I've included the 'Instant Kiwi' to say thanks for taking the time to open this letter. Additionally, the person who completes the survey will be entered into a prize draw to win $\$ 500$ worth of vouchers of their choosing.

Please take the time to complete the survey, fill out as much as you can and return the survey and prize draw card in the freepost envelope provided.

With kind regards

Jared Thomas

If you have any queries, please feel free to contact me directly.

Email: Jared.Thomas@vuw.ac.nz

Note: If you are under 18, or do not want the 'Instant Kiwi' ticket included, please return the unscratched ticket to me in the same envelope as the completed survey and prize draw card, including a return address, and I will send you a $\$ 5$ gift voucher. 


\section{Appendix D: General Questionnaire Transport Facts}

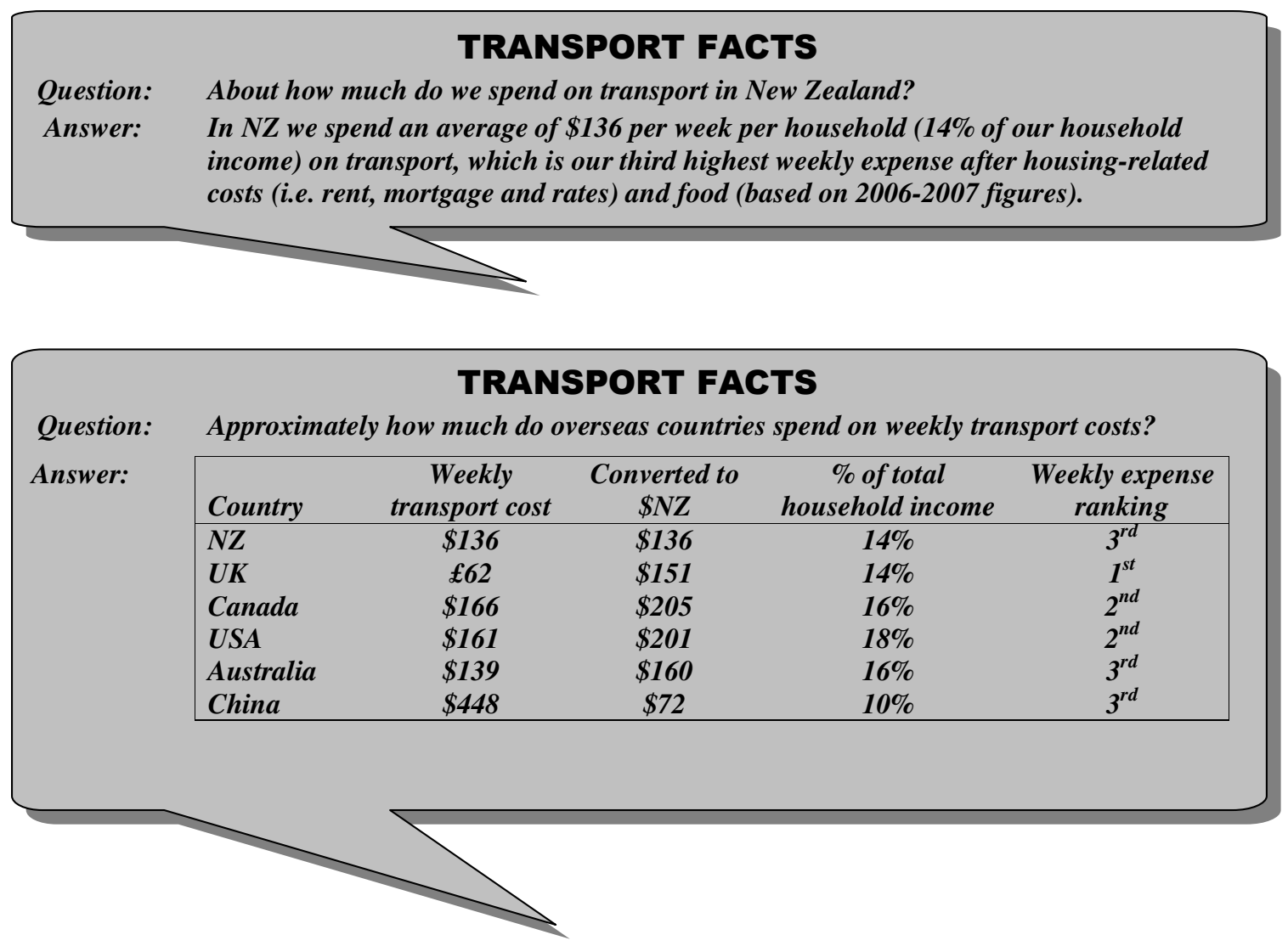

\section{TRANSPORT FACTS}

Question: $\quad H o w$ long do New Zealand commuters take to travel to work by motor vehicle? Answer: On average, approximately 15 mins.

\section{TRANSPORT FACTS}

Question: Does commuting time by motor vehicle differ much depending on where you live?

Answer: $\quad Y e s$. The average motor vehicle commuter in the Auckland region takes about 20mins, whereas a Wellington commuter takes about 16mins, and a Canterbury commuter takes about 15mins to travel to work.

\section{TRANSPORT FACTS}

Question: Did you know how long people from your city took to travel to their main activity before you looked at these travel facts?

Answer: $\quad$ Probably not. Most people believe they travel more quickly than other people. Groups of Auckland, Wellington and Christchurch commuters overestimated the travel time of other people by about $30 \%$. 


\section{Appendix E: Bus Questionnaire Transport Facts}

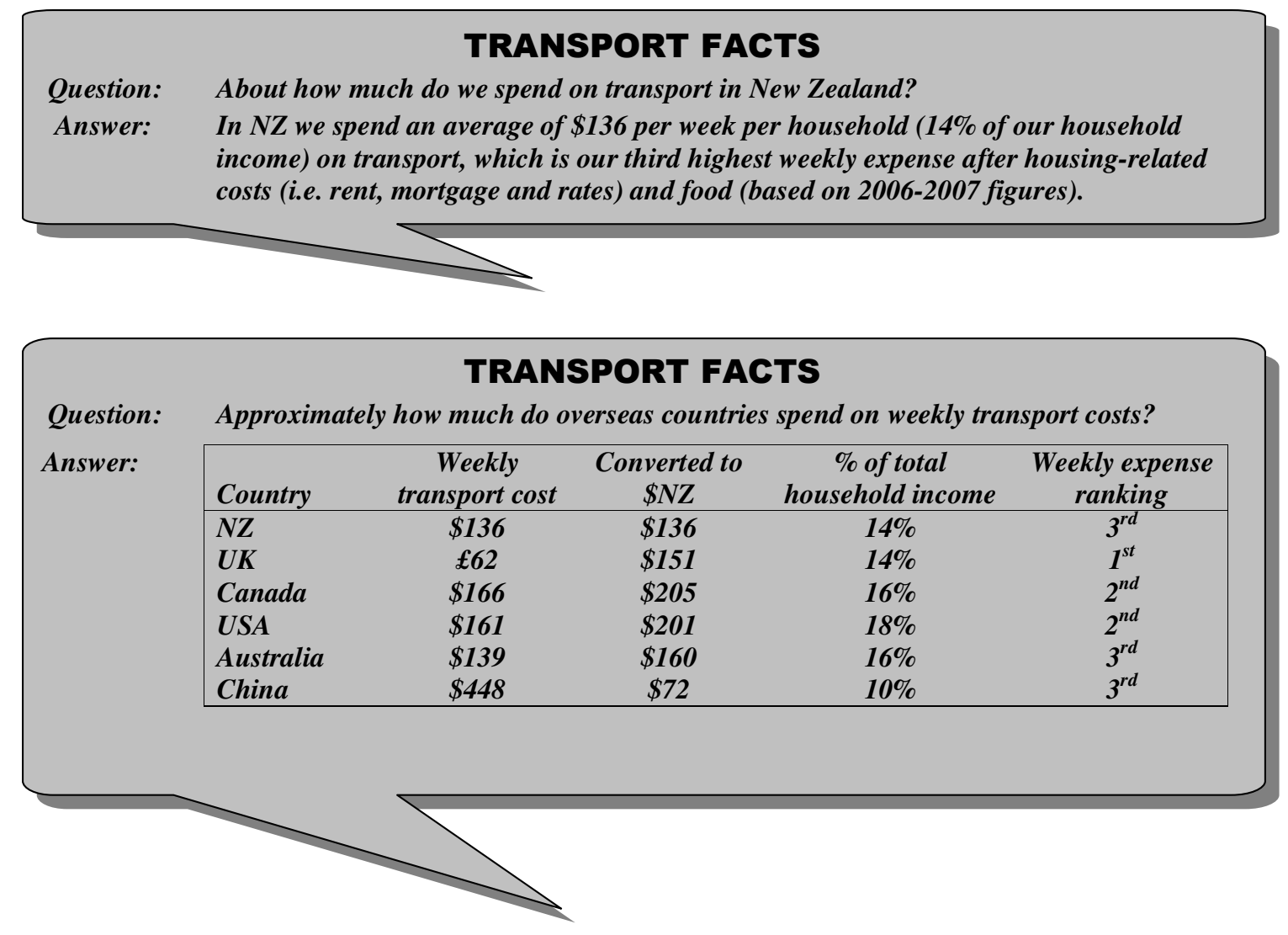

\section{TRANSPORT FACTS}

Question: How many trips are made by bus each year in Wellington?

Answer: $\quad 22,964,384$ bus trips were made in 2007-2008 (an increase of 0.7\% from 2006-2007)

\section{TRANSPORT FACTS}

Question: What proportion of people use buses in Wellington?

Answer: $\quad 53 \%$ percent of residents in the Wellington region said they had used the bus services in the last three months (June 2008).

\section{TRANSPORT FACTS}

Question: How easy is it to access public transport in the Wellington area?

Answer: $\quad$ Very easy. Around 90\% of Wellington residents live within 400 metres (approximately 5 minutes walk) of a bus stop or train station. In the greater Wellington area there are 103 bus routes, with around 2,800 bus stops. 